\title{
FACTORES EXPLICATIVOS DE COMPETITIVIDAD EMPRESARIAL
}

Amado Olivares Leal

Martha Lucía Moya Pardo

Josefina Ochoa Ruiz

Francisco Espinoza Morales

(Coordinadores)

Qartuppi.

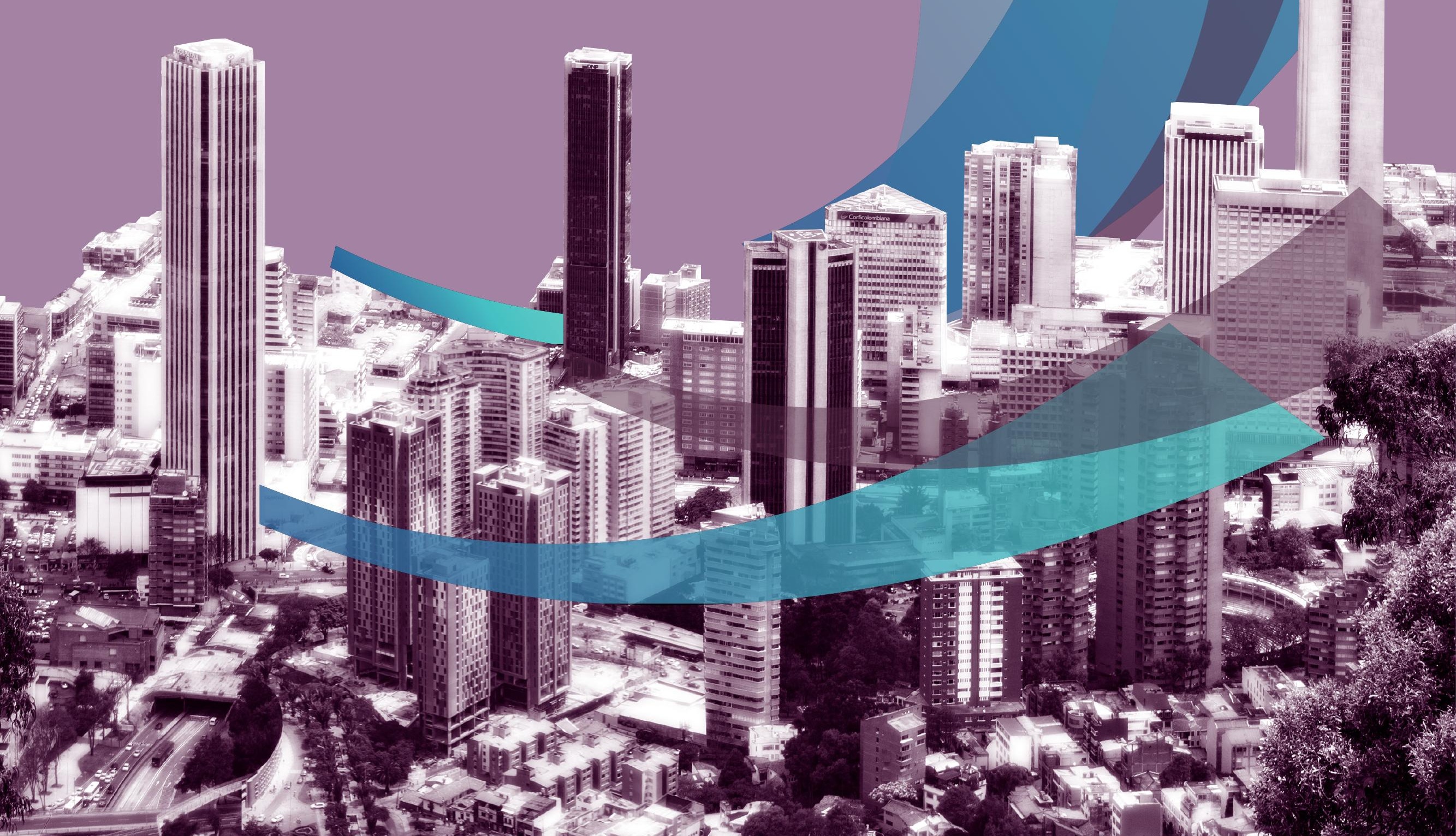




\section{(c) $\underset{\mathrm{BY}}{\mathrm{N}} \mathrm{\textrm {NC }}$}

Esta obra está bajo una Licencia Creative Commons Atribución-NoComercial 4.0 Internacional.

https://creativecommons.org/licenses/by-nc/4.0/deed.es 


\section{FACTORES EXPLICATIVOS DE COMPETITIVIDAD EMPRESARIAL}

Amado Olivares Leal

Martha Lucía Moya Pardo

Josefina Ochoa Ruiz

Francisco Espinoza Morales

(Coordinadores)

Qartuppi 
Factores explicativos de competitividad empresarial

1era. edición, noviembre 2016.

ISBN 978-607-97326-1-5

DOI 10.29410/QTP.16.07

D.R. (c) Qartuppi, S. de R.L. de C.V. Calle Real 63, Col.Villa Satélite

Hermosillo, Son. 83200 México http://www.qartuppi.com

Edición: Qartuppi, S. de R.L. de C.V.

Diseño de Portada: León Felipe Irigoyen Morales 


\section{Contenido}

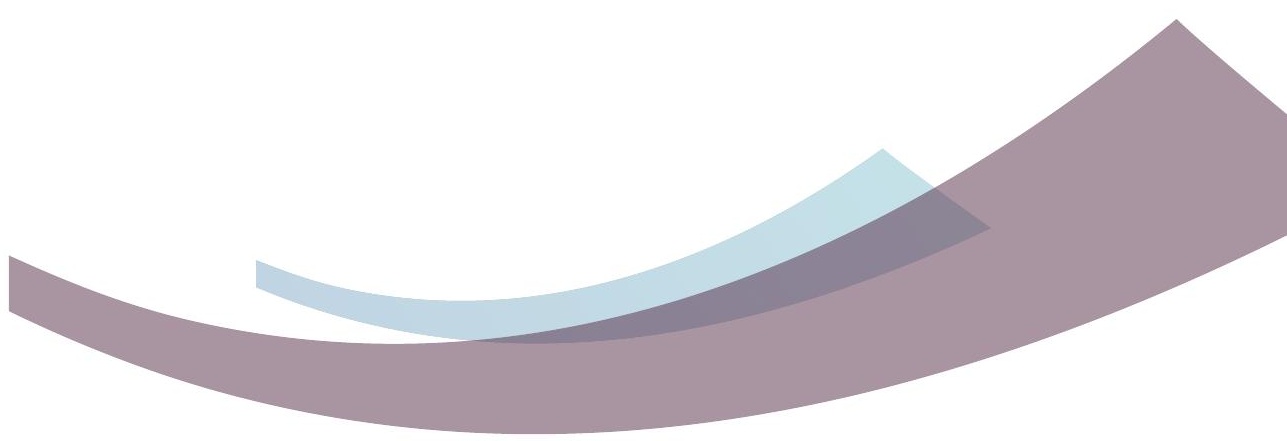

\section{Capítulo 1}

Los factores competitivos que aportan las tecnologías de la información y comunicaciones para las MIPyMES Miguel Ángel Palomo González y Jorge Alberto Islas Pineda

21 Capítulo 2

La Filosofía Lean y la Competitividad en la Ganadería Bovina en Yucatán

Antonio Emmanuel Pérez Brito y Martha Isabel Bojórquez Zapata

$35 \quad$ Capítulo 3

Factores Endógenos de competitividad de empresas sociales Leonardo Vázquez Rueda, Blanca Isela Ramírez y Concepción Suástegui Barrera

$49 \quad$ Capítulo 4

Subcontratación (outsourcing) integral en una empresa minera como factor explicativo de competitividad empresarial Amado Olivares Leal, Josefina Ochoa Ruiz, Elda Patricia Castro Cota, Pabla Peralta Miranda y Francisco Espinoza Morales

\section{Capítulo 5}

Fórmula para determinar la conveniencia del endeudamiento a largo plazo en una empresa José María Güereña de la Llata 
Análisis económico de las PyMES mexicanas y la aplicación de modelos estadísticos de optimización para el incremento de la productividad. Caso: Empresa Comercializadora de Abarrotes Metropolitana, S. A. Guillermo Velázquez Valadez y Jesus Ivan Huerta Licona

$97 \quad$ Capítulo 7

Estrés laboral en centro de atención telefónica de empresa distribuidora y comercializadora de energía eléctrica en el noroeste de México María Elena Saavedra Cota y José Ángel Coronado Quintana

115 Capítulo 8

Competitividad en PyMES de confección textil.

Una perspectiva desde las habilidades humanas de sus directivos Jesús Enrique García Guiliany, Ronald Antonio Prieto Pulido y Ernesto Rafael García Cali

$131 \quad$ Capítulo 9

Modelos de madurez de la gestión del talento humano para el desarrollo del capital intelectual como ventaja competitiva Martha Lucía Moya Pardo y Héctor Manuel Gómez Gómez

147 Capítulo 10

Innovación y competitividad en las micro y pequeñas empresas del sector comercio al por menor en Hermosillo, Sonora, México Gil Arturo Quijano Vega, Abelardo Mancinas González y Lluvia Adriana Ramírez Arroyo 


\section{Capítulo 1}

Los factores competitivos que aportan las tecnologías de la información y comunicaciones para las MIPyMES

Miguel Ángel Palomo González Jorge Alberto Islas Pineda 
Miguel Ángel Palomo González, Universidad Autónoma de Nuevo León mpalomo2012@yahoo.com

Jorge Alberto Islas Pineda, Universidad Autónoma de Nuevo León jorge_islas@msn.com 


\title{
Capítulo 1
}

\section{Los factores competitivos que aportan}

\author{
las tecnologías de la información
}

y comunicaciones para las MIPyMES

\section{Introducción}

En la actualidad las tecnologías de la Información y la comunicación (TIC) son un componente importante para la competitividad de las economías, desarrolladas y en vías de desarrollo. En el caso de México, el reporte del Foro Económico Mundial (WEF, por sus siglas en inglés) (2014) sobre la competitividad de los países y las TI (incluye las Comunicaciones), posiciona a México en el lugar 79 - entre los 148 países clasificados-, con una capacidad competitiva cerca del 3.9, con relación a una escala del 1-7, donde 7 es el máximo en competitividad (i.e. 78 países son más competitivos que México). También se analizan de manera individual los factores de las TIC y su impacto en la economía, destacando el factor 7 "Uso de las TIC en los negocios" que, en el caso de México, su competitividad varía del lugar 59 al 76, como se muestra en la tabla 1; es decir, en este factor se posiciona en un lugar 68 promedio (i.e. 80 países son menos competitivos que México).

La situación de la integración de las TIC en los negocios de México, probablemente no sea de interés para el sector público, pero sí es preocupante para el sector privado que debe competir en un mercado nacional globalizado.

Tabla 1

México. Factor 7: Uso de las TICs en los Negocios

\begin{tabular}{lll}
\hline 7.01 & Absorción de la tecnología a nivel negocio & 64 \\
\hline 7.02 & Capacidad de Innovación & 75 \\
\hline 7.03 & PCT patentes, aplicaciones/mil. Población & 59 \\
\hline 7.04 & Uso de internet Business to Business & 64 \\
\hline 7.05 & Uso de Internet en Business to Consumer & 76 \\
\hline 7.06 & Capacitación del personal & 72 \\
\hline
\end{tabular}

Notas: Fuente WEF (2014). Traducción libre. 


\section{Importancia de las TIC}

Las TIC son un factor clave a nivel negocio en el siglo XXI, en innovaciones tecnológicas y en la mejora continua organizacional. La comprensión de cómo las TIC afectan favorablemente el desempeño de la empresa es un tema de investigación importante, ya que permite a los directivos de la empresa conocer el valor agregado de sus inversiones en tecnologías de la información y comunicación (TIC) (Liang, You, y Liu, 2010).

Una definición general de las TIC para las empresas MIPyMES es:

- Telefonía

- Correo electrónico

- Red Local

- Red Externa (Internet)

- Planificación de Recursos (ERP, por sus siglas en inglés) (almacenamiento, seguridad, inteligencia de negocio, etc.)

Luego viene la clasificación técnica, es decir, el software y hardware utilizado:

a. Software

- De sistemas (sistemas operativos, controladores, etc.)

- Programación (editores de texto, compiladores, etc.)

- Aplicaciones (ofimática empresarial, bases de datos, etc.)

b. Hardware

- Servidores (virtuales, no-virtuales)

- Telecomunicaciones (satelital, móviles, telefonía, software que permita comunicaciones de texto, voz y video -e.g. Skype-, software para el trabajo en grupo -e.g. Yammer-)

También, las TIC son percibidas cada vez más, como una ventaja de las empresas para apoyar los objetivos operativos y estratégicos de las empresas (Law y Ngai, 2007), proveen una oportunidad de mejorar y para hacer los procesos eficientes (Kandel y Hota, 2012). Las TIC han seguido con un continuo avance que podrían ayudar a nivelar o cambiar el juego competitivo para el desarrollo de las empresas, en comparación con la empresas grandes (Hanna, 2011).

El impacto de las TIC en el desempeño puede variar, según Boothy (2010, citado en Moriones, Billon, y López , 2013) el uso de tecnologías de la información más avanzadas, así como el tiempo de uso, puede generar una ventaja competitiva que tendrá un impacto positivo en el desempeño. Entre los impactos están: mejorar la eficiencia, reducción de costos, mejorar la atención al cliente, una cadena de suministro de bajo costo, flexibilidad de operación, reducir la ocurrencia de los errores en papel, tiempos de respuesta rápidos, y reducción en el costo de mano de obra (Afolayan et al., 2015).

En este sentido el avance de las TIC ha cambiado las formas de producción, administración, procesamiento y análisis de información; se han desarrollo visiones estratégicas que permiten el rediseño de procesos y trabajo colaborativo (Uhlenbruck, 2003; Attaran, 2004; Akhavan, 2006; citados en Lee, Chu, y Tseng, 2011).

\section{Importancia de las PyMES}

Las MIPyMES constituyen la columna vertebral de la economía en México, por su alto impacto en la generación de empleos y la producción nacional, de acuerdo con datos del censo económico del Instituto Nacional de Estadística, Geografía e Informática (INEGI, 2014). 
La figura 1 presenta el porcentaje de empresas por número de empleados por segmento de empresas; como se puede observar más del $94 \%$ de las empresas son MIPyMES.

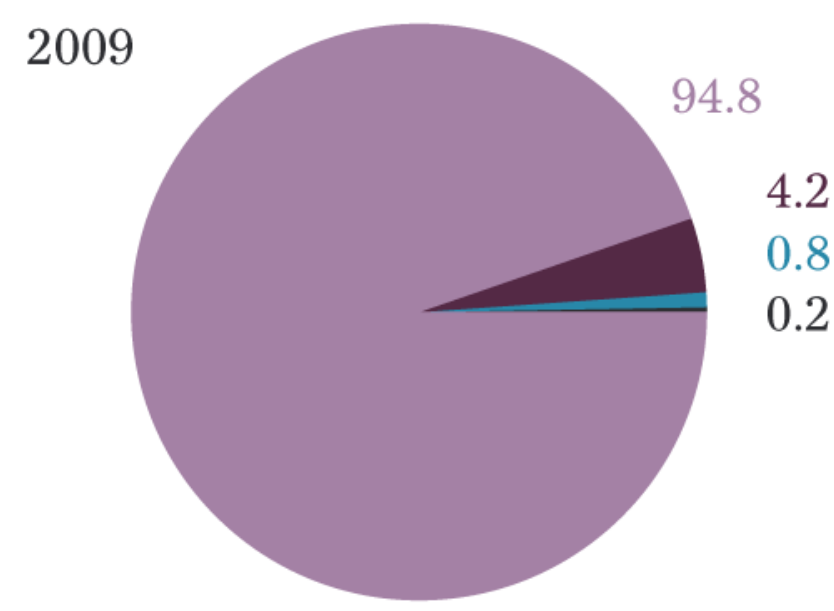

Micro (hasta 10 personas ocupadas)

Medianos (51 a 250)

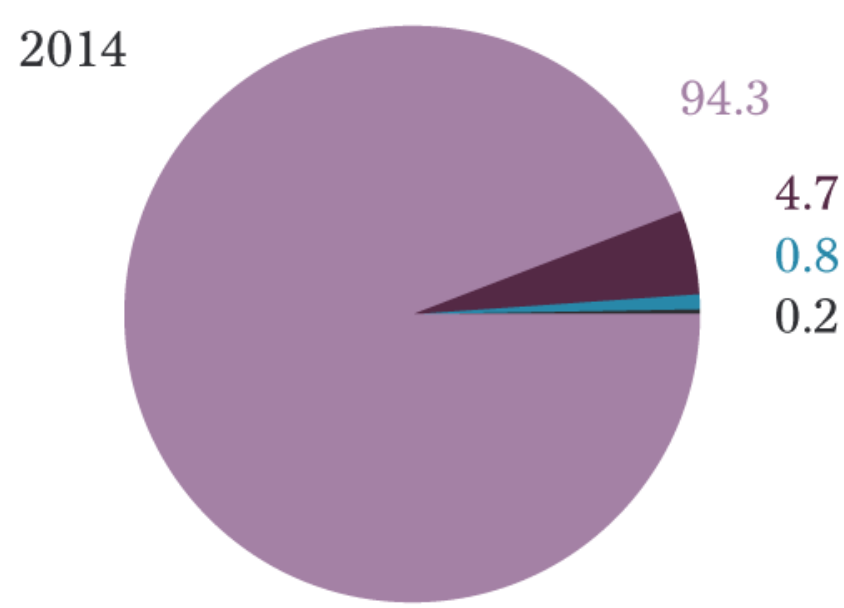

$\square \quad$ Pequeños (11 a 50)

- Grandes (251 y más)

Figura 1. Porcentaje de establecimientos según el número de personas ocupadas. Fuente: Censo Económico INEGI (2014).

La figura 2, detalla el número de empleados por segmento de empresas; también se puede observar que el $74 \%$ de los empleos en México son generados por las MIPyMES.

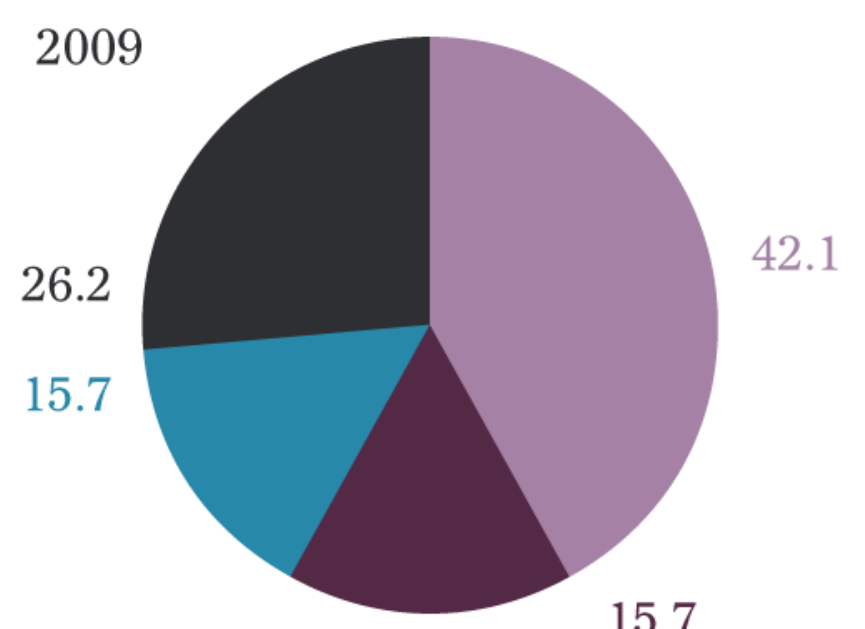

15.7

Hasta 10 personas ocupadas

51 a 250 personas

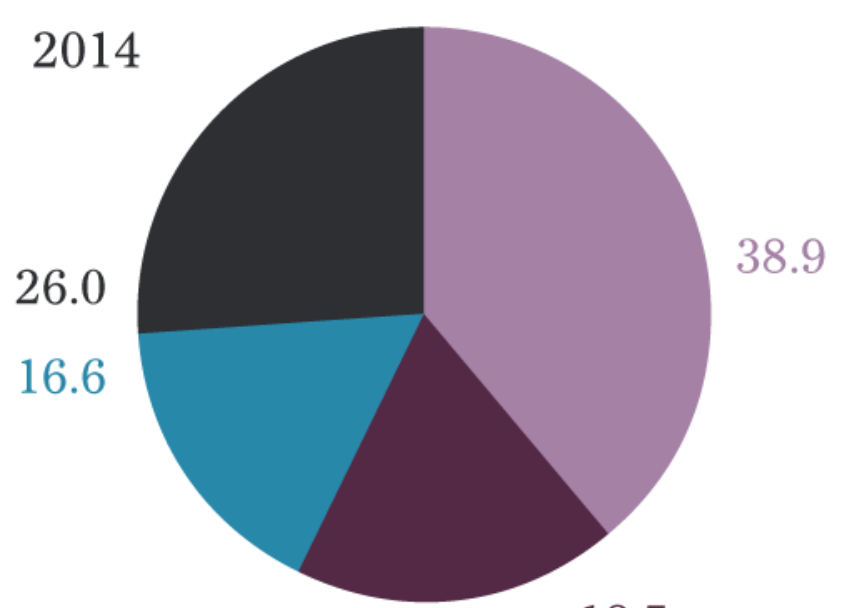

18.5

11 a 50 personas

251 y más

Figura 2. Porcentaje de personas empleadas por tamaño de empresas.

Fuente: Censo Económico INEGI (2014).

Aunque las MIPyMES son un factor clave en el desarrollo de la economía de los países, estas a veces enfrentan grandes diferencias entre su producción y desempeño en comparación con las grandes empresas (Cataldo, McQueen, y Sepúlveda, 2011). En México a pesar de la contribución tan significativa a la economía las MIPyMES, en principio, no han alcanzado un grado de competitividad suficiente para posicionarse en el mercado, ni 
en la integración de las TIC, ni para integrarse plenamente como proveedores de grandes empresas o como empresa global (Tan, et al., 2007; WEF, 2014).

Actualmente existe evidencia que sugiere que las TIC ofrecen nuevas oportunidades a las pequeñas empresas, que les permiten compensar desventajas competitivas, tales como: tamaño, recursos y de mercado. A pesar de estos potenciales beneficios, el uso de las TIC ha sido lento (Regan y Wymer, 2011).

Sin embargo la mayor parte de esta evidencia fue realizada para grandes empresas de países desarrollados (e.g. Johnson \& Johnson, Walmart, KMart), (Tarut囚 y Gatautis, 2014; Fernández, Ferreras, Alegre, y Chiva, 2014; Piget y Kossai, 2013; Chung, Byrd, y Lewis, 2005).

El análisis de la competencias de las TIC de Fernández et al. (2014) o las capacidades de las TIC de Ghobakhloo, Hong y Jabben (2015), sugieren que el desarrollo de estas contribuye a crear ventajas competitivas que permiten mejorar el desempeño de las empresas.

Los problemas de las PyMES de los países desarrollados no son los mismos que en los países en vías de desarrollo, por ejemplo en Inglaterra se analizaron las expectativas de crecimiento de las PYMES y se encontró que no son prioritarias las necesidades de flujo de efectivo, ni el acceso al crédito o la adopción de la tecnología pero, por otra parte, sí son problemas que frenan su crecimiento, las competencias del personal, la investigación y el desarrollo de productos, así como el conocimiento de los mercados de exportación; en la tabla 2 se muestran los resultados sobre las prioridades en las barreras para el crecimiento de una muestra de 1,080 PyMES (Albion, 2015).

\section{Tabla 2}

PyMEs: Importancia de las barreras para el crecimiento

\begin{tabular}{ll}
\hline Reglamentaciones & 1 \\
\hline Encontrar Staff capacitado & 2 \\
\hline Flujo de Efectivo & 3 \\
\hline Cambio en regulaciones & 4 \\
\hline Dificultad para accesar nuevos mercados & 5 \\
\hline Falta de acceso al financiamiento & 6 \\
\hline Falta de personal con expertise de gestión & 7 \\
\hline Ambición en la Gestión del negocio & 8 \\
\hline Productividad & 9 \\
\hline Limitaciones tecnológicas & 10 \\
\hline Actualización tecnológica & 11 \\
\hline Falta de Guía para el negocio & 12 \\
\hline Encontrar Staff sin habilidades & 13 \\
\hline
\end{tabular}

Notas: Fuente Albion Ventures (2015). Traducción libre.

Debido a la relevancia de las MIPyMES en México, es ompirtante instrumentar acciones para mejorar su entorno, creando condiciones que contribuyan a su crecimiento y consolidación, mediante la adopción y uso de las TIC, que ayude a mitigar problemas en la cadena de suministro, como descontrol de inventarios, mal servicio, mala atención al cliente o ventas insuficientes. Por lo que resulta trascendental determinar qué factores de las TIC contribuyen a mejorar el rendimiento de las MIPyMES de México. 


\section{Factores competitivos de las TIC en las MIPyMES}

Aunque las MIPyMES, son un factor clave para el desarrollo económico de los países, estas enfrentan regularmente diferencias entre su producción y su desempeño, en comparación con las grandes empresas, por lo que no han podido posicionarse en el mercado, ni integrarse como proveedores de grandes empresas o como empresas globales (Cataldo et al., 2011).

Desde mediados de la década de los 90, las inversiones en las tecnologías de la información y comunicaciones (TIC), se incrementaron de manera acelerada, lo que provocó el crecimiento de la productividad y el desempeño de las empresas en países desarrollados, en empresas grandes donde fueron aplicados diferentes estudios (e.g. Walmart, Ford, Caterpillar, entre otras) (Bharadwaj, 2000; Piget, y Kossai, 2013).

La revisión de literatura muestra la relación que existe entre las TIC y el desempeño de las empresas, por lo que existen diferentes teorías que se han utilizado para estudiar este fenómeno, como la teoría de la riqueza de medios de Banker (2006 citado en Liang et al., 2010) y la teoría de costos de transacción que mencionan Li y Ye (1999); estas teorías tienen diferentes campos de aplicación, por ejemplo la primera ha sido utilizada para explicar la selección de un software en particular, la segunda ha sido ampliamente utilizada para explicar el outsourcing en las TIC.

Sin embargo, la teoría más adoptada para explicar la relación entra las TIC y el desempeño de la empresa mediante una ventaja competitiva, es la teoría basada en recursos, bajo el argumento de que el desempeño de la empresa está determinado por sus propios recursos, es decir, la empresa con un recurso valioso difícil de imitar por la competencia tienen una mayor probabilidad de generar una ventaja competitiva sostenible (Liang et al., 2010).

La teoría basada en recursos (Resources base view) fue desarrollada por Penrose (1959), se considera la base de la ventaja competitiva de una empresa, ya que, según la autora, el crecimiento de las empresas es motivado y, a la vez, limitado por la administración en su búsqueda de un uso óptimo de los valiosos recursos tangibles o intangibles de que dispone la empresa.

Para Rivard, Raymond, y Verreault (2006) — citando a Mata, Fuerst y Barney (1995)— la teoría de recursos se basa en dos afirmaciones fundamentales, el de la heterogeneidad de los recursos, es decir, recursos y capacidades propios de la empresa, y el de la inmovilidad de recursos que se refiere a la duración de estos.

Si un mismo recurso es utilizado por varios competidores, significa que el recurso no es heterogéneo y que no puede contribuir a una ventaja competitiva. La heterogeneidad es la condición que se requiere para obtener una ventaja competitiva sostenida mediante los recursos de la empresa.

Para Barney (1991) los recursos son todos los activos, capacidades, procesos, atributos, conocimiento y el "saber cómo" (know-how) que pertenece a una empresa, y que se pueden utilizar para desarrollar y aplicar estrategias competitivas. La ventaja competitiva sostenida es determinada por los recursos clave de la empresa y deben tener las siguientes características:

- Valioso. El recurso debe permitir a una empresa implementar estrategias para mejorar su eficiencia y efectividad.

- Raro. El valioso recurso no puede ser utilizado o procesado por diferentes competidores.

- No imitable. El valioso recurso no debe ser fácil de imitar.

- No sustituible. El valioso recurso no debe ser fácil de reemplazar por sustitutos. 
De acuerdo con lo anterior, las TIC como tal, no podrían ser un recurso valioso, pues en la actualidad las empresas en general las han adoptado, pero también se argumenta que los procesos o el "saber cómo" (la forma en que este recurso es aprovechado), desarrollado con el propósito de generar una ventaja competitiva sostenida, puede explicar la diferencia entre mejorar o no el rendimiento de la empresa.

Las empresas grandes, cuentan con recursos que les ayudan a mejorar el aprovechamiento de las TIC y decidir cuál tecnología es la mejor para mejorar su rendimiento. Aunque existen diferencias de tamaño y recursos entre las empresas grandes y las MIPyMES, la teoría basada en recursos puede ayudar a explicar los efectos de las TIC en el desempeño de la empresa.

En este sentido, la perspectiva basada en recursos, tiene como primer objetivo desarrollar y explotar recursos que permitan mejorar el desempeño de la empresa a largo plazo, mediante los recursos y una ventaja competitiva sostenible. Con base en esta teoría, las TIC pueden ser vistas como un recurso que permita obtener una ventaja competitiva sostenible, debido que permite a la empresa crear un recurso raro, no sustituible, no imitable y valioso (Barney, 1991).

Desde la perspectiva basada en recursos de Liang et al. (2010), se analizaron 50 artículos relacionados con las TIC y el rendimiento del negocio, específicamente el financiero, se identificaron 169 variables que ayudan a estudiar esta relación. Los autores sugieren que las TIC tienen impacto en la generación de capacidades que permiten mejorar el rendimiento financiero de las empresas.

Específicamente sobre el rendimiento, Consoli (2012) en su artículo sobre los factores de las TIC que impactan el rendimiento de las PyMES, agrupa la literatura de los factores determinantes para la adopción y uso de las TIC, en individuales, organizacionales, ambientales, tecnológicos, económicos, además de las competencias que las empresas pueden desarrollar mediante el uso de las TIC como la innovación de negocios, mejoras en la cadena de suministro o crecimiento de ventas.

Sobre el impacto en el rendimiento de PyMES, Tarutė y Gatautisa (2014) agregan que el impacto de las TIC en las empresas es principalmente en el "rendimiento financiero"y "rendimiento estratégico" ya que el impacto se refleja en el crecimiento, rendimiento, nuevos productos y la expansión, con base en tres condiciones que deben ser cubiertas: infraestructura, conocimiento y habilidades del personal de TIC, y presupuesto asignado para la inversión en TIC.

Otros autores sugieren que la contribución de las TI en el desempeño del negocio se ha estudiado desde dos perspectivas principalmente: 1) la perspectiva como estrategia de posicionamiento, que pone de relieve un imperativo poder de mercado; 2) la perspectiva basada en los recursos, que conceptualiza la empresa como un "paquete de recursos únicos” (Rivard et al., 2006).

Para Iyamu y Mphahlele (2014), la “alineación”entre las TIC y el negocio es visto como un importante catalizador para la eficacia y la eficiencia de la organización, para el logro de una ventaja competitiva mediante la arquitectura empresarial (enterprise architecture, EA) que es vista como el puente sobre la brecha que existe, entre las TIC y los obejtivos de la empresa, el cual sigue siendo un problema en muchas organizaciones. La EA afecta la alineación entre las unidades de negocio y las TIC, mejorando los procesos.

La competencia de las TIC, de acuerdo a Pérez-López y Alegre (2012), desarrollada por Tippins y Sohi (2003), agrupa el “conocimiento", las “operaciones" y la "infraestructura" de las TIC, y cómo estas competencias impactan los procesos de las empresas que, finalmente, permiten mejorar el rendimiento del negocio. 
La mejora de procesos mediante las capacidades de infraestructura de tecnologías de la información (IT infrastructure capabilities) (Law \& Ngai, 2007), está asociada con el gobierno de tecnologías de información (IT Goverment). Aunque se ha discutido la relación de la adopción de las TIC y cambios de proceso de negocios con los factores organizacionales como el liderazgo en las TI, los autores sugieren que no se ha intentado investigar qué aspectos de las TIC son afectados por lo que se conoce como gobernabilidad TI (IT governance) y cuáles no. Lo cual ayudaría a conocer los factores que favorecen los resultados de las inversiones en TIC, así como determinar el tamaño de los montos y los tipos de tecnologías en que se debería de invertir.

También acerca de la mejora de procesos (Wu,Yeniyurt, Kim y Cavusgil, 2006) sugieren que las TIC tienen impacto en la cadena de suministro y el desempeño de la empresa, identificando dos indicadores claves de desempeño (KPI, key performance indicator): "IT advancement", que mide el grado en que una empresa aplica la tecnología de última generación, para aumentar sus capacidades de la cadena de suministro, mientras que el "IT alignment"refleja el énfasis estratégico de una empresa en la coordinación y la integración de sus socios de la cadena de suministro. La investigación de estos dos recursos relacionados con TIC que se incrustan organizativamente, evita el problema de tratar a las TI como un recurso autónomo, lo que lleva a una evaluación más sólida del potencial de las TI para influir en los resultados empresariales.

Sobre las capacidades, Mithas, Ramasubbu, y Sambamurthy (2011), identifican los estudios y variables que han sido utilizados para estudiar las capacidades que contribuyen a mejorar el rendimiento del negocio y sugieren que los líderes en las empresas deben enfocarse en crear condicione necesarias para el desarrollo de las TIC, porque estas juegan un papel fundamental en la mejora del rendimiento del negocio.

Regan y Wymer (2011) analizan la adopción y uso de e-commerce en las PyMES mediante los modelos TAM, TAM2 y teoría sobre la innovación de Rogers; los autores identificaron 25 factores, agrupados en las siguientes categorías: organizacionales, ambientales, de conocimiento y tecnológicos, de los cuales 14 fueron importantes para la adopción y uso de TIC de comercio electrónico y 4 fueron considerados como barreras.

\section{Retos de las MIPyMES}

Pettey (2016) alude a la importancia del cómputo en la nube, debido a que esta tecnología será determinante para el diseño de soluciones de tecnologías de la información para todas las empresas, por lo que se sugiere que estas cuenten con una estrategia al respecto.

Algunos de los beneficios clave, son algunas de las soluciones actuales en la nube, como infraestructura como servicio (IaaS, infrastructure as a service) y plataformas como servicio (PaaS, platform as a service), que proveen la ventaja de poner las aplicaciones más cerca de los clientes y una mejor experiencia, debido a que estas plataformas garantizas la alta disponibilidad de las TIC.

Un sistema SaaS o Software as a Service, es un modelo de distribución, en el que tanto el software como los datos manejados son centralizados y alojados en un único servidor externo a la empresa. Esto implica que el software utilizado por la empresa no se encuentra en la misma, sino que un proveedor se ocupa del hosting en la nube, así como del mantenimiento y el soporte que permita la alta disponibilidad para la operación diaria.

Aunque tiene ventajas, como la reducción de costos, pues no es necesario que las empresas cuente con áreas especializadas de soporte para los sistemas, la empresa se puede enfocarse a hacer crecer su negocio; generalmente no se pagan licencias sólo el uso del sis- 
tema, con altos estándares de seguridad; existe una desventaja principal, y es que, si la empresa no cuenta con servicio de internet no tendrá acceso a su sistema, aunque básicamente el problema se soluciona si el acceso es desde cualquier otro punto que tenga internet.

Oracle ofrece soluciones empresariales como: Oracle RPM, un sistema para la planeación de recursos; Oracle Analytics, que es utilizado por lo que hoy en día se conoce como negocios inteligentes; Oracle HR para recursos humanos. También podemos encontrar soluciones de Sales Force, sistemas CRM.

La infraestructura como servicio (IaaS) también es similar a SaaS. La gran diferencia es que en lugar de vender programas y licencias, los proveedores de este servicio arriendan sus servidores para que otras empresas puedan usarlos como quieran. Gartner, una de las empresas de investigación de tecnología de la información más importante del mundo, define IaaS como: "una oferta automatizada y estandarizada, donde recursos de computo, complementados con opciones de almacenamiento y capacidades de red, son propiedad del proveedor y son ofrecidos al consumidor para que los consuma cuando quiera".

La IaaS es un servicio que permite desarrollar y ajustar las máquinas virtuales a las necesidades del equipo. Para que un servicio sea considerado dentro de la categoría de IaaS, se debe cumplir una serie de características. Según Microsoft (2011), el servicio debe ser 'on-demand': el consumidor debe tener la posibilidad de usar los recursos de computación sin tener que acudir a un humano. La solución también debe tener banda ancha. Una aplicación de misión crítica no puede depender de la conexión. Se tiene que garantizar una red amplia, segura y confiable.

Sin embargo, lo más importante y valioso es la posibilidad de ajustar los recursos a la carga del cliente. Los proveedores de infraestructura deben permitir que sus clientes puedan aumentar o disminuir los recursos de cómputo y almacenamiento a medida que cambian los requerimientos. Si una página web, por ejemplo, sabe que va a tener un día extraordinariamente pesado de tráfico, puede aumentar su máquina virtual para garantizar el servicio.

Lo mismo debe ocurrir hacia abajo. El cliente puede disminuir los recursos, lo que debería bajar el costo de la solución. Con esta flexibilidad, los gerentes de TI pueden ser más cuidadosos con sus gastos y más eficientes en su trabajo y su inversión.

Otra de las grandes ventajas es que no hay que comprar servidores. Una compañía que no tiene su foco en tecnología puede hacer inversiones de capital en lugares más estratégicos y optar por un modelo de servicio para suplir las necesidades de infraestructura de TI. Además, como es un servicio contratado, no tendrá que preocuparse por gastos de mantenimiento y seguridad.Y como el servidor está en un centro de datos, siempre estará actualizado con la más reciente tecnología. El cliente no se tiene que preocuparse por eso $\mathrm{y}$, si tiene un problema, simplemente cambia de proveedor.

Existen empresas como Amazon y Google que proporcionan servicios de infraestructura de TI para empresas, en forma de servicios web, donde se paga por el uso del hardware, y permite la instalación de ambiente open source, principalmente Linux, que también tiene servicios gratis.

Las ventajas que pueden obtener las MIPyMES mediante el uso de IaaS o SaaS pueden ser vistas como ventaja competitiva, ya que estas soluciones permiten a las empresas enfocarse en su negocio. Además, la existencia de software open source como sistemas operativos Linux, aplicaciones de oficina como Open office, sistemas ERP como OpenERP, también puede beneficiar empresas reduciendo costos al no pagar licencias de software.

El verdadero reto de la MIPyMES es que, para que sean competitivas y puedan seguir creciendo en ventas y obtener una participación de mercado mayor, en el futuro inmediato 
debe enfocarse en la mejora continua, lo cual implica la actualización y la adopción de la siguiente generación de aplicaciones de Tecnologías de Información y Tecnologías de Operación (TI/TO), la integración de los Sistemas de Planeación de Recursos de la Empresa (ERP, enterprise resource planning), de Gestión del Ciclo de Vida del Producto (PLM, product life cycle) y los Sistemas de Ejecución de Manufactura (MES, manufacturing execution system). La integración es con una Arquitectura Orientada al Servicio (SOA, services oriented architecture) y con el compromiso de la dirección, los beneficios esperados son: un mejor desempeño financiero, reducción en el costo operacional, flujo eficiente del diseño de productos y servicios, eliminación de re-trabajos o re-procesos y la reducción de tiempo al mercado (Atos, 2012).

\section{Modelo Propuesto}

Con base en la revisión de la literatura y en la investigación sobre los factores de las TIC con impacto en el desempeño competitivo de las MIPyMES, se propone un modelo de causa y efecto donde los factores de las TIC son la estrategia, las inversiones, la infraestructura, las operaciones, los conocimientos y las capacidades (Islas y Palomo, 2016).

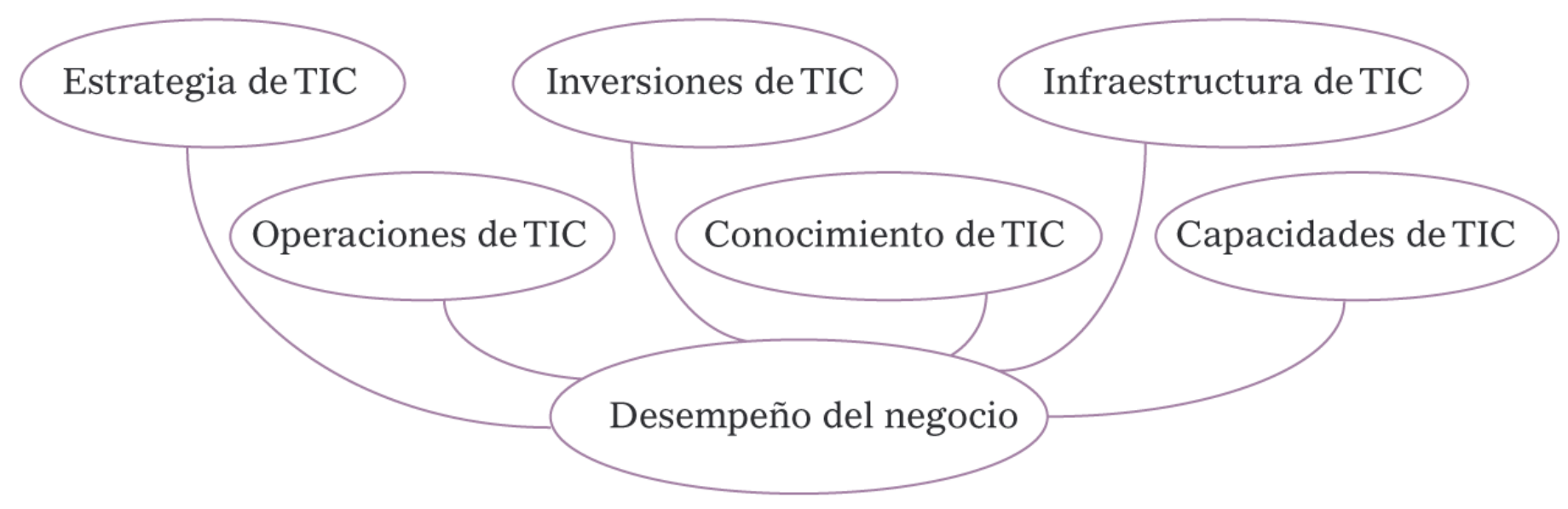

Figura 3. Modelo propuesto causa-efecto. Fuente: Elaboracion propia.

El modelo es analizado desde la perspectiva basada en recursos y está en proceso de validación en las empresas del área metropolitana de Monterrey, Nuevo León (México). En la tabla 3 se presenta el resumen de los autores y los factores de las TIC con impacto en el desempeño competitivo de las MIPyMES. 


\section{Tabla 3}

Relación de los autores y factores de las TIC con impacto en el desempeño competitivo de las MIPyMES

\begin{tabular}{|c|c|}
\hline Factores & Autor \\
\hline $\begin{array}{l}\text { Rendimiento } \\
\text { del negocio }\end{array}$ & $\begin{array}{l}\text { Ghobakhloo, Hong, y Jabeen (2015), Consoli (2012), Liu, Ke, } \\
\text { Wei, y Hua (2013), Moriones, Billon, y López (2013), Lee, } \\
\text { Chu, y Tseng, (2011), Liang, You, y Liu (2010), Rivard, Ray- } \\
\text { mond, y Verreault (2006), Johannessen, Olaisen, y Olsen, } \\
\text { (1999), Bharadwaj (2000), Li y Ye (1999) }\end{array}$ \\
\hline Estrategia de TI & $\begin{array}{l}\text { Fernandez, Ferreras, Alegre, \& Chiva, (2014), Ullah y Lai, } \\
\text { (2013), Leidner, Lo, y Preston (2011), Haki y Forte (2010), } \\
\text { Schwarz, Kalika, y Kefi (2010), Johnson y Lederer (2010), } \\
\text { Rivard, Raymond, y Verreault (2006), Newkirk y Lederer } \\
\text { (2006), Tanriverdi (2006), Bergerona, Raymond, y Rivard } \\
\text { (2004), Li y Ye (1999) }\end{array}$ \\
\hline Inversiones de TI & $\begin{array}{l}\text { Fernandez, Ferreras, Alegre, y Chiva (2014), Moriones, Bi- } \\
\text { llon, y Lopez (2013), Lee, Chu, y Tseng, (2011), Johannessen, } \\
\text { Olaisen, y Olsen (1999), Li yYe (1999), Rai, Patnayakuni, y } \\
\text { Patnayakuni (1997) }\end{array}$ \\
\hline Infraestructura de TI & $\begin{array}{l}\text { Fernandez, Ferreras, Alegre, y Chiva (2014), Liu, Ke, Wei, y } \\
\text { Hua (2013), Holsapple y Wu (2011), Perez y Alegre (2012), } \\
\text { Qureshil, Kamal, y Wolcott (2009), Tanriverdi (2006), Bha- } \\
\text { radwaj (2000). }\end{array}$ \\
\hline Conocimientos de TI & $\begin{array}{l}\text { Fernandez, Ferreras, Alegre, y Chiva (2014), Liu, Ke, Wei, y } \\
\text { Hua (2013), Holsapple y Wu (2011), Perez y Alegre (2012), } \\
\text { Qureshil, Kamal, y Wolcott (2009), Tanriverdi (2006), Subba- } \\
\text { Narasimha, Ahmad, y Mallya (2003, Bharadwaj (2000) }\end{array}$ \\
\hline Operaciones de TI & $\begin{array}{l}\text { Fernandez, Ferreras, Alegre, y Chiva (2014), Liu, Ke, Wei, y } \\
\text { Hua (2013), Perez y Alegre (2012) }\end{array}$ \\
\hline Capacidades de TI & $\begin{array}{l}\text { Ghobakhloo, Hong, y Jabeen, (2015), Liu, Ke, Wei, y Hua } \\
\text { (2013), Wu, sengun, y Kim, (2006), Bharadwaj (2000) }\end{array}$ \\
\hline $\begin{array}{l}\text { Resources Base View } \\
\qquad(\mathrm{RBV})\end{array}$ & $\begin{array}{l}\text { Ghobakhloo, Hong, y Jabeen (2015), Moriones, Billon, y Lo- } \\
\text { pez (2013), Schwarz, Kalika, y Kefi (2010), Liang, You, y Liu } \\
\text { (2010), Qureshil, Kamal, y Wolcott (2009), Rivard, Raymond, } \\
\text { y Verreault (2006), Bharadwaj (2000), Li y Ye (1999) }\end{array}$ \\
\hline
\end{tabular}




\section{Referencias}

Afoloyan A., Plant E., White G.R.T., Jones P., \& Beynon-Davis P. (2015). Information Technology Usage in SMEs in a Developing Economy. Strat. Change 24, 483-498. http://doi.org/10.1002/jsc.2023

Albion Ventures. (2015). The Albion Growth Report. Recuperado de https://www.albionventures.co.uk/publications/growth-reports

Atos (2012). Ascent Journey 2016. Enterprise without Boundaries. Recuperado de https:// hr.atos.net/content/dam/global/ascent-whitepapers/ascent-journey-2016.pdf

Barney, J. (1991). Firm Resources and Sustained Competitive Advantage. Jornal of Management, 17(1), 99-120.

Bharadwaj, A.S. (2000, Marzo). A Resource-Based Perspective onn Information Technology Capability and Firm Performance: An Empirical Investigation. (M. Quarterly, Ed.) Management Information Systems Research, 169-196.

Cataldo, A., McQueen, R., \& Sepúlveda, M. (2011). Big IT for small companies. Industrial Engineering, 48-54.

Chung, S.H., Byrd, T.A., \& Lewis, B.R. (2005). An Empirical Study of the Relationships Between IT Infrastructure Flexibility, Mass Cutomization and Business Process. (SIGMIS, Ed.) ACM SIGMIS Database, 36(2), 26-44.

Consoli, D. (2012, October 24). Literature analysis on determinant factors and the impact of ICT in SME's. (S. Direct, Ed.) Procedia - Social and Behavioral Sciences, 62, 93-97.

Fernández, M.A., Ferreras, J.M., Alegre, J., \& Chiva, R. (2014). IT competency and the commercial success of innovation. Industrial Management \& Data Systems, 114(4), 550-567.

Gartner (s.f.). Infrastructure as a Service (IaaS). IT Glossary. Recuperado de http://www. gartner.com/it-glossary/infrastructure-as-a-service-iaas/

Ghobakhloo, M., Hong, T.S., \& Jabeen, S. (2015). IT Resources, IT-Enabled Capabilities, and Business Performance. (I. Global, Ed.) Encyclopedia of Information Science and Technology, 4129-4139.

Hanna, K.N. (2011). Implications of ICT Revolution, Challenges and Oportunities for Developing World. Transformation Goverment and Building the Information Society, 320.

Instituto Nacional de Estadística y Geografía (INEGI). (2014). Censos Económicos 2014. Recuperadodehttp://www.inegi.org.mx/est/contenidos/espanol/proyectos/censos/ce2014/

Islas, J.A., \& Palomo, M.A. (2016). Modelos de adopción de las TIC para competitividad de las PyMEs. En Paradigmas Emergentes en Ciencias Administrativas y desarrollo regional: Interrelaciones de la Tecnología, la innovación y las Ciencias Sociales. Aguascalientes, México: Instituto Tecnológico de Aguascalientes.

Iyamu, T., \& Mphahlele, L. (2014). The impact of organisational structure on enterprise architecture deployment. Journal of Systems and Information Technology, 16(1), 2-19.

Kandel, B.K., \& Hota, J. (2012). InformationTechnology Adoption in Small Family Businesses for Developing Economies. IUP Journal Of Entrepreneurship Development, 7-37.

Law, C., \& Ngai, E. (2007). IT Infrastructure Capabilities and Business Process Inprovements. Information Resources Management Journal, 20(4), 25-47.

Lee,Y.-C., Chu, P.-Y., \& Tseng, H.-L. (2011). Corporate performance of ICT-enabled business process re-engineering. Industrial Management \& Data Systems, 111(5), 735-754. 
Li, M., \& Ye, R.L. (1999, Diciembre). Information technology and firm performance: Linking with environmental, strategic and managerial contexts. Information \& Management, 35(1), 43- 51. http://doi.org/10.1016/S0378-7206(98)00075-5

Liang, T.-P., You, J.-J., \& Liu, C.-C. (2010). A resource-based perspective on information technology and firm performance:a meta analysis. (E. Insight, Ed.) Industrial Management \& Data Systems, 110(8), 1138-1158.

Microsoft. (2011). Cloud Computing: What is infrastructure as a service. TechNet Magazine. Recuperado de https://technet.microsoft.com/en-us/library/hh509051.aspx

Mithas, S., Ramasubbu, N., \& Sambamurthy, V. (2011). How Information Management Capability Influences Firm Performance. MIS Quartely, 35(1), 237-256. Recuperado de https://terpconnect.umd.edu/ smithas/papers/mithasetal2011 misq.pdf

Moriones, A.B., Billon, M., \& López, F.L. (2013). Percieved performance effects of ICT in manufacturing SMEs. Industrial Management \& Data Systems, 113(1), 117-135.

Penrose, E.T. (1959). The Theory of the Growth of the Firm. New York: Wiley.

Pérez-López, S., \& Alegre, J. (2012). Industrial Management \& Data Systems. Information technology competency, knowledge process and firm performance, 112(4), 644-662.

Pettey, C. (2016). Why CIOs Still Need a Cloud Strategy. Smarter With Gartner. Recuperado de http://www.gartner.com/smarterwithgartner/why-cios-still-need-a-cloud-strategy/

Piget, P., \& Kossai, M. (2013). The Relationship between Information and Comunication Technology Use and Firm Performance in Developing Countries: A Case Study of Electrical and Electronic Goods Manufacturing SMEs inTunisia. African Development Review, 25(3), 330-343.

Regan, E., \& Wymer, S. (2011, January-March). Influential factors in the adoption and use of e-business and e-commerce information technology (EEIT) by small \& medium business. Journal of Electronic Commerce in Organizations, 56.

Rivard, S., Raymond, L., \& Verreault, D. (2006). Resource-based view and competitive strategy: An integrated model of the contribution of information technology to firm performance. (S. Direct, Ed.) Journal of Strategic Information Systems, 15, 29-50.

Tan, H., López-Acevedo, G., Lima, F.R., Sanchez, R.M., Slota, E.T., \& Busjeet, B.G. (2007). Evaluando los programas de apoyo a las pequeñas y medianas empresas en México. Washington: Banco Internacional de Reconstrucción y Fomento/BANCO MUNDIAL.

Tarute, A., \& Gatautis, R. (2014, January 24). ICT impact on SMEs performance. (ScienceDirect, Ed.) Procedia - Social and Behavioral Sciences, 110, 1218-1225.

Tippins, M.J., \& Sohi, R.S. (2003). IT Competency and Firm Performance Is Organizational Learning a Missing Link? Strategic Management Journal, 24(8), 745-761.

World Economic Forum (WEF). (2014). Global IT Report.

Wu, F., Yeniyurt, S., Kim, D.C., \& Cavusgil, S.T. (2006). The impact of information technology on suply chain cpabilities and firm performance: A resource-based view. (ScienceDirect, Ed.) Industrial Marketing Management, 35, 499-504. 
Capítulo 2 
Antonio Emmanuel Pérez Brito, Universidad Autónoma de Yucatán antonio.perez@correo.uady.mx

Martha Isabel Bojórquez Zapata, Universidad autónoma de Yucatán mbzapata@correo.uady.mx 


\section{Capítulo 2}

\section{La Filosofía Lean y la Competitividad}

\section{en la Ganadería Bovina en Yucatán}

\section{Introducción}

La carne es un elemento importante en la alimentación del hombre y, en el contexto dietético mundial el nivel de consumo es considerado como un indicador de vida de la población (Organización para la Cooperación y el Desarrollo Económico, OCDE, 2009).

De acuerdo a información proporcionada por la Organización de las Naciones Unidas para la Agricultura y la Alimentación (FAO, 2013), el ganado representa el $40 \%$ del valor mundial de la producción agrícola y es la base de los medios de subsistencia y la seguridad alimentaria de casi mil millones de personas. El sector pecuario, impulsado por el incremento de los ingresos y apoyado por los cambios tecnológicos y estructurales, es uno de los segmentos de crecimiento más rápido de la economía agrícola. El progreso y la transformación del sector ofrecen oportunidades de desarrollo agrícola, reducción de la pobreza y mejora de la seguridad alimentaria, pero el rápido ritmo del cambio podría marginar a los pequeños agricultores, y, por otro lado, deben abordarse los riesgos sistémicos para el medio ambiente y la salud humana con vistas a garantizar la sostenibilidad.

González (2006) mencionó que la actividad ganadera en México se realiza a lo largo de todo el país; afirmó que el 56 \% del territorio nacional está dedicado a la ganadería, aproximadamente 110 millones de hectáreas.

El Sistema de Cuentas Nacionales de México elaborado por el Instituto Nacional de Estadística y Geografía (INEGI, 2010b), señaló que en el estado de Yucatán el sector agropecuario y pesquero representan el 6.7 \% del Producto Interno Bruto total de dicha entidad.

De acuerdo con Anderson, Santos, Boden y Wadsworth (2012), la ganadería bovina en el estado de Yucatán constituye una actividad económica relevante, esto debido a que ocupa cerca del 30 \% de la superficie del territorio yucateco. Estos mismos autores señalan que la zona oriente del estado de Yucatán concentra la mayor cantidad de reses bovinas. Los municipios ubicados en la zona oriente son: Sucilá, Espita, San Felipe, Panabá,Tizimín, Buctzotz y Valladolid, siendo Tizimín el municipio que agrupa el 90 \% de dicha producción. 
Con base en el XIII Censo General de Población y Vivienda 2010 efectuado por el INEGI, la población económicamente activa, alcanza las 43,256 personas, de las cuales 21,280 se reportan como ocupadas.

Dicho censo informa también que los ingresos por persona de la población son bajos, pues del total de la población ocupada, 14,111 personas perciben un sueldo entre uno y dos salarios mínimos y sólo 3,210 personas perciben más de cinco salarios mínimos, éstos últimos debido a que laboran en la ciudad de Mérida y en algunas otras localidades del estado de Quintana Roo. Por tal razón la región oriente del estado de Yucatán está considerada como de extrema marginación.

Según el INEGI (2010a), los ingresos de la población ocupada por sector se integran de la siguiente manera: 8,205 personas obtienen ingresos del sector primario, 4,114 del sector secundario y 8,961 del terciario, el cual se ha saturado y cada vez proporciona menos ingresos a quienes se dedican a estas actividades.

Un mercado empresarial importante a considerar, aprovechando la cercanía con el mismo, es el estado de Quintana Roo. De información obtenida de la Secretaría de Economía (SE, 2009), se señala que dicho estado vecino para satisfacer las necesidades de abasto necesita obtener producto agrícola y ganadero de otros lados pues la creciente industria turística y la demografía atípica hacen que la producción interna sea insuficiente para satisfacer la propia demanda.

Datos obtenidos de la XL Asamblea Nacional de la Asociación de Secretarios de Desarrollo Agropecuario (AMSDA, 2011) señalan que actualmente hay más de un millón doscientos mil habitantes en el estado de Quintana Roo, y que al año, llegan aproximadamente once millones de turistas, es por ello que el consumo de productos agropecuarios no sólo debe abastecer a la población, sino también a los visitantes.

La información anterior también menciona que el crecimiento poblacional a nivel nacional es del uno por ciento anual, mientras que en Quintana Roo en promedio en la totalidad como estado, se registra un cinco por ciento al año y en el municipio de Solidaridad (Riviera Maya) el crecimiento es del veinte por ciento anual.

El objetivo general de esta investigación será el de aplicar la filosofía Lean como herramienta para la generación de valor agregado en los productores de carne de ganado bovino de Yucatán.

\section{Planteamiento del problema}

La desorganización de los productores de ganado bovino de la región, la problemática en la integración en los diferentes eslabones de la cadena productiva-consumo (Hernández et al., 2011), el desempleo originado por la escasa oportunidad para los pobladores en el campo que trae como consecuencia la ausencia de tecnología y de conocimiento para generar innovación en las unidades de producción así como los limitados recursos financieros con los que cuentan dichas unidades, los cuales proporcionen como resultado el crecimiento y la generación de valor al conjunto de las actividades (Vera y Ganga, 2007), son parte de los principales problemas a los que se enfrenta este sector agropecuario en Yucatán.

\section{Revisión teórica}

\section{La Filosofía Lean Enterprise}

Para Tones y Womack (2003), el principal problema en las organizaciones es el despilfarro (muda), en otras palabras, toda aquella actividad humana que absorbe recursos, pero que no crea valor, sin embargo es importante señalar que el despilfarro se encuentra en todas 
partes. Para estos autores un antídoto poderoso para el despilfarro es la filosofía Lean. Esta filosofía surge en la industria automotriz japonesa, es en la empresa Toyota donde se desarrolla este pensamiento, el cual proporciona una metodología para especificar valor, alinear las acciones creadoras de valor con la secuencia óptima, llevar a cabo estas actividades sin interrupción siempre que alguien las solicite y realizarlas de forma cada vez más eficaz, es decir, hacer más y más con menos y menos; menos esfuerzo humano, menos equipamiento, menos tiempo y menos espacio, al tiempo que se acerca más y más a ofrecer a los clientes aquello que quieren exactamente.

Según Tones y Womack (2003), los puntos básicos a considerar al desarrollar este método son:

1. Especificar el valor.

2. Identificar el flujo de valor.

3. El flujo.

4. El pull (atracción).

5. La perfección.

1. Especificar el valor: el concepto medular del método lean es el valor, concepto que solamente puede definir el consumidor final y únicamente es significativo cuando se expresa en términos de un producto específico (un bien o servicio o ambos a la vez) que satisface las necesidades de consumidor a un precio concreto, en un momento determinado.

En la filosofía Lean el valor no depende de maquinarias de última tecnología, poderosas y costosas, el valor lo crea el productor, esta es la razón desde el punto de vista del cliente por la que existen los productores.

La tarea más importante en la especificación de valor, una vez que se ha definido el producto, es la determinación de un costo objetivo basado en la cantidad de recursos y esfuerzos necesarios para fabricar un producto con unas capacidades y especificaciones determinadas. Las iniciativas lean analizan el conjunto de precios y características que están siendo ofrecidos a los consumidores por las empresas convencionales y luego se preguntan qué parte del costo se puede eliminar mediante una aplicación completa de la filosofía lean. Dado que el objetivo ciertamente debe estar bastante por debajo de los costos soportados por los competidores, la empresa lean dispone de varias alternativas: reducir precios; añadir características o capacidades al producto; añadir servicios al producto físico para crear valor adicional; ampliar la red de distribución y servicio o dedicar beneficios en apoyo de nuevos productos.

2. El flujo de valor: es el conjunto de todas las acciones específicas requeridas para pasar un producto determinado por las tres tareas de gestión críticas de cualquier entidad, las cuales son:

a. La tarea de solución de problemas, que se inicia en la concepción, sigue en el diseño detallado e ingeniería y finaliza en el lanzamiento de la producción.

b. La tarea de gestión de la información, que va desde la recepción del pedido a la entrega, a través de una programación detallada.

c. La tarea de transformación física, que se basa en los procesos existentes desde la materia prima hasta el producto acabado en manos del consumidor.

De acuerdo con Tones y Womack (2003) el análisis de flujo de valor señalará la existencia de tres tipos de acciones a lo largo de éste: (1) se descubrirán muchos pasos cuya creación de valor es inequívoca, (2) se denunciarán muchos otros pasos que no crean valor 
alguno, pero que son inevitables de acuerdo con la tecnología actual y los activos de producción disponibles y (3) se identificarán pasos adicionales que no crean valor pero que pueden evitarse de manera inmediata.

3. El flujo: en esta etapa lo fundamental se basa en hacer que fluyan los procesos creadores de valor que quedan. En las organizaciones, el flujo se desarrolla a través de procesos en lotes o en colas, sin embargo, los lotes representan largas esperas mientras el producto se encuentra aguardando la preparación del departamento para el tipo de actividad a la que el producto necesita someterse a continuación. La propuesta lean consiste en redefinir la operación de funciones, departamentos y empresas, de modo que puedan hacer una contribución positiva a la creación de valor y dirigirse a las necesidades reales de los empleados en cada punto del flujo, de forma que sea realmente de interés hacer que el valor fluya. Esto representa, no sólo la creación de una iniciativa lean para cada producto, sino también el replanteo de las empresas, funciones y carreras profesionales y el desarrollo de una estrategia lean.

Una vez que se ha definido el valor y se ha identificado la totalidad del flujo de valor, el primer paso es concentrarse en el objeto real, el diseño específico, el pedido específico y el propio producto y no perderlo nunca de vista desde el principio al fin. El segundo paso, que hace posible el primero, es ignorar los límites y fronteras tradicionales de puestos de trabajo, carreras profesionales, funciones y empresas, para así constituir una iniciativa lean, que elimine todos los impedimentos al flujo continuo del producto o familia de productos específica. El tercer paso es replantear prácticas y herramientas específicas que eliminen flujos hacia atrás, desechos e interrupciones de todo tipo, para que el diseño, pedidos y producción del producto específico puedan seguir avanzando de forma continua. Estas tres etapas deben llevarse a cabo conjuntamente.

4. El pull (atracción): esta etapa propone olvidarse de las previsiones de venta y fabricar lo que los consumidores realmente dicen que necesitan, es decir, dejar que sea el cliente quien atraiga ( $p u l l$ ) el producto de acuerdo con las necesidades, en lugar de empujar (push) productos no deseados hacia el consumidor, además la demanda del consumidor tiende a ser mucho más estable cuando sabe que puede conseguir lo que sea, de un modo inmediato, que cuando los fabricantes ofrecen periódicas campañas de descuento de precios diseñadas para colocar productos ya fabricados que nadie desea. El mejor modo de comprender la lógica y el desafío del pensamiento pull es empezar con un consumidor real, que manifieste una demanda por un producto real y trabajar hacia atrás pasando por todas las etapas necesarias para llevar el producto deseado al cliente. Significa que nadie aguas arriba debería producir un bien o servicios hasta que el consumidor, aguas abajo, lo solicite.

5. La perfección: al hacer que el valor fluya más rápidamente, siempre se deja al descubierto el despilfarro que estaba oculto y cuanto más empuje se haga, más se pondrán de manifiesto los obstáculos al flujo, que en esta etapa podrán ser eliminados.

Parker y Slaughter (1988), definen la producción lean, como el arte de la gestión por el estrés, y Fucini y Fucini (1990), la señalan como la sensibilidad a las necesidades de los trabajadores. Olivella, Cuatrecasas y Gavilán (2008), señalan que en cada proceso de producción lean, existe una estandarización y una reglamentación. 
Martínez y Moyano (2011), en una investigación en la industria aeronáutica a nivel mundial encontraron que en cuanto a la aplicabilidad, la evidencia empírica muestra que los problemas para implantar lean en la industria aeronáutica no son, necesariamente, más difíciles que en otros sectores industriales. Los retos son diferentes, pero no más difíciles. No obstante, los desafíos de la implantación son reales y resultan difíciles para muchas empresas, por lo que existe la necesidad de atender a las necesidades únicas de las organizaciones cuando deciden implantar lean. Respecto a los resultados logrados con la implantación de lean establecen estos mismos autores, predominan las historias de éxito. Además, se destaca el predominio de evidencia en torno a los resultados operativos, mientras que existe una falta de evidencia en relación a los resultados financieros.

Para Sunjka y Murphy (2014), la filosofía lean se acerca más a proporcionar una visión holística de los sistemas de gestión empresarial, encarnando un conjunto unido de los preceptos y prácticas de apoyo mutuo que impulsan la generación de valor en las operaciones. Otras teorías como la Six Sigma y la de las Restricciones, señalan Sunjka y Murphy (2014), carecen de una amplia orientación holística, coherente e integral como la que posee la filosofía lean. Asimismo en un estudio realizado en el sector de mantenimiento de los sistemas de la industria aeronáutica en Sudáfrica identificaron que el mantenimiento de los sistemas de las aeronaves, por la naturaleza, es impredecible debido a los defectos que se pueden encontrar durante la realización de una revisión de mantenimiento. Sin embargo el uso de la filosofía lean para reducir los eventos de mantenimiento no programadas y el tiempo que se necesita para responder a ellas puede tener un enorme impacto en la productividad y en las utilidades del mismo. El sector del mantenimiento de los sistemas en la aeronáutica sudafricana es importante por ser un generador de empleos y también por proporcionar una valiosa contribución a la creación de un sector aeroespacial sostenible y competitivo.

Saboo, Garza-Reyes, Er y Kumar (2014), en un estudio realizado en las pequeñas y medianas industrias manufactureras de la India, identificaron que un factor importante para lograr la competitividad y la generación de valor en las mismas, es la capacidad de una empresa para implementar eficazmente una filosofía que le permita mejorar continuamente y sistemáticamente los procesos, así como el desempeño operativo general. Según Taj (2008), la filosofía lean es una de las principales, utilizadas por varias organizaciones en todo el mundo para mejorar y maximizar el rendimiento operativo general. Saboo et al. (2014), concluyeron que hoy en día la aplicación de la filosofía lean en el sector manufacturero de la India está creciendo, y que la aplicación exitosa podría representar una estrategia importante para las pequeñas y medianas empresas para cumplir con los desafíos de un mercado industrial en crecimiento.

\section{Metodología}

En el presente trabajo se aplica un tipo de investigación por intervención; respecto a que se identificó un proceso en un rancho productor de carne de ganado bovino con el fin de hacerlo más eficiente y que genere valor agregado al mismo. Fermoso (1994), define la intervención como una mezcla de investigación, aprendizaje, educación y acción.

Este estudio según la dimensión temporal es de corte transversal, no experimental, porque trata de determinar los procesos adecuados que llevarán a los productores de carne de ganado bovino del estado deYucatán a la mejora y a la generación de valor. El año en el que se trabajó es el 2014. 
Para la intervención, se desarrolló el análisis con un productor de carne de ganado bovino, ubicado en el municipio de Tizimín, Yucatán, en el km 73 en la carretera Tizimín-Río Lagartos, el cual cuenta con aproximadamente 600 cabezas de ganado bovino, y con una extensión territorial de aproximadamente 800 hectáreas, cuyo giro principal es la cría, engorda y comercialización de carne de ganado bovino y que posee entre las principales razas la cruza de suizo-europeo con cebú.

Esta etapa se divide en tres partes:

a. Visita previa a la entrevista

Antes de iniciar la recolección de datos, se visitó el rancho en cuestión. Se habló con el propietario, se le expuso el motivo de la investigación y se le explicó en general el tema a investigar. Se le pidió permiso para tener acceso a las instalaciones y se prometió confidencialidad en el estudio.

\section{b. Recolección de datos}

Como herramienta de recolección de datos se diseñó una entrevista estructurada siguiendo los instrumentos y guías propuestos por los siguientes autores:

Cédula de diagnóstico de planeación estratégica (Valdez y Amaro, 2003).

Instrumento para diagnóstico (Cantú, 2001).

Guía de diagnóstico (Fleitman, 2007).

Estos instrumentos fueron elegidos en virtud de ser los más completos y se adecuaban a las necesidades del diagnóstico para este estudio.

Durante la recolección de datos, se realizaron varias entrevistas estructuradas con el propietario del rancho sirviendo como guía los instrumentos antes mencionados, teniendo como objetivo lograr una aproximación a la realidad operativa de la entidad en cuestión.

En las visitas de campo se cumplieron cabalmente los horarios para las citas con el propietario. De nuevo se le hizo mención de la confidencialidad de la información. Durante la entrevista se siguió a profundidad el guión de la misma, dejando al entrevistado hablar y relatar libremente acerca de los temas de interés y se tomó nota de los detalles relevantes.

Posteriormente, se realizó una entrevista con el encargado del rancho para corroborar la información relativa a los procesos operativos desarrollados en el mismo así como con todo lo relacionado con la administración del personal.

Durante la visita al rancho se realizaron entrevistas con los empleados para verificar la información relativa a la cría, producción y comercialización.

Para la observación, en compañía del propietario, se procedió a realizar visitas por las instalaciones del rancho y se observó el proceso de manejo y alimentación del ganado bovino. Se tomaron fotografías de las instalaciones así como de los animales.

\section{c. Finalización del trabajo de campo, análisis y conclusiones}

Esta es la última sección del estudio y comprende los puntos que aquí se explican:

En el presente estudio, se seleccionó un rancho de producción de carne de ganado bovino para llevar a cabo la investigación.

El tiempo fue un factor importante, ya que el investigador tiene la obligación de respetar y ponerse a las condiciones del propietario del rancho y de los trabajadores, personas que por el tipo de trabajo que desempeñan tienen limitantes para ofrecer este tipo de servicios. 
Por último, es necesario mencionar que toda la información obtenida se integró para conseguir un esquema amplio de la empresa que permitan plasmar la realidad, hacer un diagnóstico de la situación del rancho, y poder diseñar un programa de procesos aplicable al mismo.

\section{Análisis de datos}

El rancho sujeto de este estudio tuvo origen en el muncipio de Tizimín, Yucatán cuando fue fundado en 1947 por los abuelos maternos del actual dueño, con la idea de aprovechar los recursos naturales, propensos para el desarrollo de la ganadería en la región oriente del estado. Tuvo inicio en el municipio de Tizimín en 1947, cuando los dueños con conocimientos de ganadería decidieron abrir un pequeño rancho en un terreno de aproximadamente 100 hectáreas que tenían en propiedad.

En los años setenta, el rancho adquirió un nombre formal y a finales de los años ochenta, inicia la venta de ganado hacia otros municipios vecinos del estado de Yucatán asimismo en ese año adquirió unas 300 hectáreas más e inicia también con la mejora del hato ganadero, adquiriendo ganado de registro. En 2002, adquiere 200 hectáreas más y es cuando le ceden la propiedad a quien hasta la presente fecha lo dirige. En 2006, participa por primera ocasión en la feria de X'matkuil, la cual se considera de las principales ferias expositoras de ganado bovino en la península y la cual representa el principal escaparate estatal de la ganadería local. En total, este rancho cuenta con una extensión de 600 hectáreas y con aproximadamente 620 cabezas de ganado de raza cebú, igualmente se cuenta con 19 empleados en el mismo.

Actualmente, la administración del rancho se encuentra a cargo del propietario, quien cuenta con 23 años de experiencia en la rama de la ganadería al haber estado inmerso en la misma desde la niñez. El propietario es originario del municipio de Tizimín, Yucatán. Tiene 40 años y estudió la Licenciatura en Veterinaria y Zootecnia en la Facultad de Veterinaria de la Universidad Autónoma de Yucatán.

Por tratarse de un rancho familiar, al momento de tomar decisiones, el propietario las consensa con el resto de la familia. Con respecto a la administración del rancho, no cuenta con departamentos, sino con personas encargadas de estas funciones. En ocasiones, una sola persona se encarga de más de una función. Estas personas son, el mismo propietario y los dos hermanos.

El tema de la alimentación del ganado es importante para Tizimín y en general para la región ganadera de Yucatán, debido a que es un municipio que tiene como principal actividad la producción, cría y comercialización de bovinos, por eso es primordial definir una metodología que genere un valor agregado en el manejo de ganado, en la alimentación y el proceso de crecimiento (Sánchez y Rebollar, 2009).

La sobreexplotación de los recursos alimenticios para el ganado ha provocado el detrimento, por lo que es necesario optimizarlos y ofrecer alternativas de alimento para no acabar con ellos (Lee, 2006). En esta parte del trabajo se evaluará el efecto de la dieta sobre el crecimiento de becerros en pastoreo.

El desarrollo, la modernidad, el crecimiento poblacional, la deforestación son procesos que están produciendo cambios a nivel mundial y regional que afectan aspectos culturales, sociales, económicos y ambientales, lo que repercute en el agotamiento de nuestros recursos naturales. La vegetación juega un papel importante en el equilibrio del ecosistema, sin embargo, los bosques están siendo deforestados por la necesidad de pastizales para la alimentación del ganado (Hernández et al., 2008). 
Por lo anterior, es necesario optimizar y modernizar la utilización de los recursos para proveer alimento a los animales a costo bajo y de calidad. Una alternativa, además del pastoreo, es proveerle de alimentos comerciales y procesados como el ensilado.

Por otro lado, debido al grado de marginación y pobreza de la gente del campo yucateco, el gobierno de México ha considerado a Yucatán dentro de los programas prioritarios de apoyo económico, y ha instaurado adaptar en estos lugares actividades productivas alternativas (Toral y Gómez, 2008).

Esta ganadería se ha caracterizado por ser de tipo extensivo, y la alimentación del ganado está basada casi exclusivamente del pastoreo de gramíneas tropicales que se caracterizan por la baja calidad debido a la marcada estacionalidad de esta zona (Medina et al., 2008).

La intervención se llevó a cabo durante 4 meses, los cuales incluyen un mes de adaptación y tres meses siguientes de experimentación, en el cuarto mes se evaluaron los resultados. Se utilizaron 10 becerros suizos europeos, de 6 meses de edad, con un peso promedio de $186 \mathrm{~kg}$. Los animales se escogieron al azar, con dos tratamientos y cuatro repeticiones por tratamiento. Las dietas fueron: D1(intervención): Sorgo ensilado + Alimento comercial y Pastoreo, D2 (antes): Sorgo ensilado + pastoreo, todas al 1\% del peso vivo de los animales (esto significa que de acuerdo al peso del animal se les proporciona una ración de sorgo del 1\% del total del peso y lo mismo aplica para la ración del alimento comercial; en el caso del pastoreo, una vez que a los animales se les deja salir a pastar, cada uno consume lo que requiere para satisfacerse). El peso de cada animal se determinó todos los días antes y después de proporcionar los alimentos. Asimismo los animales se pesaron al inicio y al final del experimento.

Cabe mencionar que el máximo de crecimiento que debe tener un animal para ser considerado para venta, dentro de la región es un promedio entre 250 y 290 Kilos, ya que se considera éste como el peso ideal para obtener una carne suave para el consumidor, lo que se logra entre los 4 y 5 meses con el alimento comercial + sorgo + pastoreo, y entre los 10 y 12 meses con el de sorgo + pastoreo.

El ensilado y el grano de sorgo se obtuvo comercialmente con productores de la región y el alimento comercial se adquirió con un distribuidor autorizado de marca CAMPI.

De esta manera las dietas proporcionadas a los animales provienen de los productores locales asegurando la disponibilidad de los mismos.

Los animales pertenecen al hato del rancho estudiado y fueron alimentados durante el período de adaptación con pasto brisanta.

La estrategia de alimentación fue de la siguiente manera: por la mañana (7 am) se situaronn en encierros para proporcionarles las dos dietas, las cuales eran: D1: Sorgo ensilado + Alimento comercial y Pastoreo, D2: Sorgo ensilado + pastoreo.

Posteriormente, por la tarde, el vaquero a partir de las 3:00 pm suelta al ganado para que pastoreen hasta las 6:00 am del día siguiente. Los horarios de alimentación se escogieron de acuerdo a Espinoza, Alejo y Folache (2008), quienes estiman que las horas de mayor ingestión de pasto y de rumia, es por la tarde y en la noche.Y el mejor momento para variar la alimentación es por las mañanas.

Asimismo, con ayuda del vaquero, se determinó el peso antes de proveérselas a los becerros y después de que se alimentaran, para poder determinar la tasa de consumo ya que con base en ello, se hace el cálculo del $1 \%$.

Adicionalmente, aunque no contemplado como un parte del proceso experimental, pero sí de manejo de los animales, se programaron de manera trimestral, desparasitaciones, vacunaciones, adición de vitaminas y tratamientos profilácticos. 
Tabla 1

Análisis de costos para el D-1 (intervención)

a) El costo del kilo de sorgo es de $\$ 0.80$

Si el promedio de lo que come un animal es de:

\begin{tabular}{ccr} 
Mes 1 & $1.92 \times \$ 0.80=$ & $\$ 1.53 \times 30$ días $=\$ 46.15$ \\
\hline Mes 2 & $1.98 \times \$ 0.80=$ & $\$ 1.58 \times 30$ días $=\$ 47.52$ \\
\hline Mes 3 & $2.24 \times \$ 0.80=$ & $\$ 1.79 \times 30$ días $=\$ 53.76$ \\
\hline Mes 4 & $2.48 \times \$ 0.80=$ & $\$ 1.98 \times 30$ días $=\$ 59.52$ \\
\hline Total por animal con sorgo & $\$ 206.95$ \\
\hline b) El costo del kilo de alimento es de $\$ 8.75$ & $\$ 16.80 \times 30$ días $=\$ 504.00$ \\
\hline Mes 1 & $1.92 \times \$ 8.75=$ & $\$ 17.32 \times 30$ días $=\$ 519.75$ \\
\hline Mes 2 & $1.98 \times \$ 8.75=$ & $\$ 19.60 \times 30$ días $=\$ 588.00$ \\
\hline Mes 3 & $2.24 \times \$ 8.75=$ & $\$ 21.70 \times 30$ días $=\$ 651.00$ \\
\hline Mes 4 & $2.48 \times \$ 8.75=$ & $\$ 2,262.75$ \\
\hline & Total por animal en alimento & \\
\hline & Total general & \\
\hline
\end{tabular}

Tabla 2

Análisis de costos para el D-2 (antes)

a) El costo del kilo de sorgo es de $\$ 0.80$

Si el promedio de lo que come un animal es de:

\begin{tabular}{rlr} 
Mes 1 & $1.92 \times \$ 0.80=$ & $\$ 1.53 \times 30$ días $=\$ 46.15$ \\
\hline Mes 2 & $1.91 \times \$ 0.80=$ & $\$ 1.53 \times 30$ días $=\$ 45.90$ \\
\hline Mes 3 & $1.91 \times \$ 0.80=$ & $\$ 1.53 \times 30$ días $=\$ 45.90$ \\
\hline Mes 4 & $1.93 \times \$ 0.80=$ & $\$ 1.54 \times 30$ días $=\$ 46.20$ \\
\hline Mes 5 & $1.97 \times \$ 0.80=$ & $\$ 1.58 \times 30$ días $=\$ 47.40$ \\
\hline Mes 6 & $2.01 \times \$ 0.80=$ & $\$ 1.61 \times 30$ días $=\$ 48.30$ \\
\hline Mes 7 & $2.11 \times \$ 0.80=$ & $\$ 1.69 \times 30$ días $=\$ 50.70$ \\
\hline Mes 8 & $2.23 \times \$ 0.80=$ & $\$ 1.78 \times 30$ días $=\$ 53.40$ \\
\hline Mes 9 & $2.30 \times \$ 0.80=$ & $\$ 1.84 \times 30$ días $=\$ 55.20$ \\
\hline Mes 10 & $2.36 \times \$ 0.80=$ & $\$ 1.89 \times 30$ días $=\$ 56.70$ \\
\hline Mes 11 & $2.41 \times \$ 0.80=$ & $\$ 1.93 \times 30$ días $=\$ 57.90$ \\
\hline Mes 12 & $2.48 \times \$ 0.80=$ & $\$ 1.98 \times 30$ días $=\$ 59.40$ \\
\hline & Total por animal con sorgo & \\
\hline
\end{tabular}


Tal y como se esperaba, los animales con mejor crecimiento fueron los alimentados con el alimento comercial + sorgo + pastoreo. El peso promedio ganado por los animales alimentados con el alimento comercial + sorgo + pastoreo, fue de $56.50 \mathrm{~kg}$, con el silo fue de $24.63 \mathrm{~kg}$

Al realizar el análisis de costos de la alimentación se pudo observar que la opción D1 (intervención) alimento comercial + sorgo + pastoreo, aparentemente es más costosa que la D2 (antes) sorgo + pastoreo; sin embargo, la D1 permite llegar al promedio requerido para la venta de los animales en un período menor de tiempo a diferencia de la otra opción en la cual se necesita un plazo mayor, por lo que al agregarle a ambas opciones los otros conceptos que integran el costo de producción (mano de obra de $\$ 10,000.00$ mensuales en promedio y otros indirectos de fabricación de $\$ 2,500.00$ mensuales en promedio) resulta más redituable (menos costosa) la D1 que la D2 (ya que el total del costo de producción durante los 4 meses para la D1 es de $\$ 52,469.70$ contra los $\$ 150,613.15$ del costo total de producción durante los 12 meses de la D2), esto permite una mayor ganancia sobre todo para los grandes ganaderos que son los que tienen al menos 1000 cabezas de ganado ya que se obtiene un ahorro de $\$ 98,143.45$.

La alimentación de los animales con sólo pasto es una alternativa mejor, dado el bajo costo que esta representa; sin embargo, la disponibilidad de alimento está sujeta a las condiciones climáticas por lo que representa un riesgo para el productor debido a que en época de seca los animales podrían morir.

Esto comprueba que la aplicación de la filosofía lean genera valor agregado tal y como se presentó en la intervención realizada, lo cual permitirá a los ganaderos ser más eficientes en el costo del producto, lo cual coincide con lo establecido en dicha filosofía.

\section{Conclusiones}

La filosofía lean permitirá a los productores de carne de ganado bovino evitar la muda o las actividades que no generan valor, ya que genera procesos eficientes que repercuten en el producto final; sin embargo, tal y como la filosofía señala, cada proceso siempre podrá ser mejorado con el día a día lo cual dará como resultado una cadena de valor con actividades que realmente generen valor agregado.

Se recomienda, aplicar de manera continua metodologías en los procesos operativos y administrativos como la filosofía lean con el fin de generar valor agregado en los productos. Igualmente apoyar en lo económico así como con la disponibilidad de información y de tiempo a instituciones o universidades para futuras investigaciones que mejoren las condiciones de la ganadería bovina en Yucatán. 


\section{Referencias}

Anderson, S., Santos, J., Boden, R., \& Wadsworth, J. (2012). Characterization of Cattle Production Systems in the State ofYucatan. Dual Purpose Cattle Production Research. México. Fundación Internacional para la Ciencia. 40(2), 187-192.

Asamblea Nacional de la Asociación de Secretarios de Desarrollo Agropecuario (AMSDA). (2011). XL Asamblea Nacional. Recuperado de http://amsda.com.mx/Boletines/ Boletin/Boletin \%20de \%20la\%20XL \%20Asamblea $\% 20$ General $\% 20 \mathrm{del} \% 20$ AMSDA. pdf

Cantú, H. (2001). Desarrollo de una cultura de calidad. México: Mc Graw Hill.

Espinoza, F., Alejo, R., \& Folache, L. (2008). Etología de vaquillas doble propósito en un sistema silvopastoril durante el período seco en una sabana tropical. Zootecnia Tropical, 26(4),429-437.

Fermoso, P. (1994). Pedagogía Social. Fundamentación Científica. España: Herder.

Fleitman, J. (2007). Evaluación integral para implantar modelos de calidad. Ciudad de México: Pax.

Fucini, J., \& Fucini, S. (1990). Working for the Japanese: Inside Mazda's American Auto Plant. New York: Free Press.

González, E., (2006). La Sanidad y el Estado Sanitario del Hato Nacional de Bovinos para Carne. CONASA.

Hernández, H., González, H., Ramírez R., Fernández, J., Cepeda, R., \& Torres, F. (2008). Cambios nutricionales en dos fenofases de arbustos forrajeros. Zootecnia Tropical, 26(3), 215-222.

Hernández, J., Rebollar, S, González, F., Guzmán, E., Albarrán, P., \& García, M. (2011). La cadena productiva de ganado bovino en el sur del estado de México. México. Revista Mexicana de Agronegocios, 29(15), 672-680.

Instituto Nacional de Estadística y Geografía (INEGI). (2010a). Censo de Población y Vivienda 2010. Recuperado de http://operativos.inegi.org.mx/sistemas/iter/entidad_ indicador.aspx?ev=5

Instituto Nacional de Estadística y Geografía (INEGI). (2010b). Sistema de Cuentas Nacionales de México. México. XIII Censo General de Población y Vivienda 2010. Recuperado de http://www.inegi.org.mx/est/contenidos/proyectos/ccpv/cpv2010/ presentacion.asp

Lee, R. (2006). Producción de bovinos. Consideraciones para productores de carne y leche basados en pastoreo. ATTRA, 24(2), 24-37.

Martínez, P., \& Moyano, J. (2011). Lean Production y Gestión de la Cadena de Suministro en la Industria Aeronáutica. Investigaciones Europeas de Dirección y Economía de la Empresa, 1(17), 137-157.

Medina, M., García, D., Cova, L., Soca, M., Baldizán, A., \& Pizzani, P. (2008). Preferencia de rumiantes por el follaje de árboles, arbustos y herbáceas en la zona baja del estado Trujillo. Zootecnia Tropical, 26(3), 1-15.

Olivella, J., Cuatrecasas, L., \& Gavilan, N. (2008). Work organization practices for lean production. Journal of Manufacturing Technology Management, 7(19), 798-811.

Organización para la Cooperación y el Desarrollo Económico (OCDE). (2009). Información Básica del Sector Agropecuario, Subregión Norte de America Latina y el Caribe.

Organización de las Naciones Unidas para la Agricultura y la Alimentación (FAO). (2013). El Estado Mundial de la Agricultura y la Alimentación. Recuperado de http://www. fao.org/docrep/018/i3300e/i3300e00.htm 
Parker, M., \& Slaughter, J. (1988). Choosing Sides: Unions and the Team Concept. Boston: South End Press.

Saboo, A., Garza-Reyes, J., Er, A., \& Kumar,V. (2014). AVSM Improvement-Based Approach for Lean Operations in an Indian Manufacturing SME. International Journal Lean Enterprise Research, 1(1). 41-58.

Sánchez, R., \& Rebollar, S. (2009). Deforestación en la península de Yucatán, los retos que enfrentar. Madera y bosques. Zootecnia Tropical, 2(1), 3-17.

Secretaría de Economía. (SE). (2009). Sectores Agropecuarios. Recuperado de http//:www. economia.gob.mx

Sunjka, B., \& Murphy, S. (2014). Lean Implementation within South African Aircraft Maintenance Organisations. International Journal Lean Enterprise Research, 1(1), $59-80$.

Taj, S. (2008). Lean Manufacturing Performance in China: Assessment of 65 Manufacturing Plants. Journal of Manufacturing Technology Management, 2(19), 217-234.

Tones, D., \& Womack, J. (2003). Lean Thinking. Nueva York: Simon \& Schuster.

Toral, O., \& Gómez, I. (2008). Selectividad de especies arbóreas potencialmente útiles para sistemas de producción ganaderos. Zootecnia Tropical, 26(3), 197-217.

Valdez, S. \& Amaro, O. (2003). Diagnóstico empresarial Método para identificar, resolver y controlar problemas en las empresas. México: Trillas.

Vera, J., \& Ganga, F. (2007). Los Clústeres Industriales: Precisión Conceptual y Desarrollo Teórico. Colombia. Cuadernos de Administración, 20(33), 303-323. 
Capítulo 3 
Leonardo Vázquez Rueda, Universidad Autónoma de Sinaloa leovazquez21@hotmail.com

Blanca Isela Ramírez, Universidad Autónoma de Sinaloa resistencia20112011@hotmail.com

Concepción Suástegui Barrera, Universidad Autónoma de Sinaloa conchissua@hotmail.com 


\title{
Capítulo 3
}

\section{Factores Endógenos de competitividad}

\author{
de empresas sociales
}

\section{Introducción}

Las empresas sociales son agentes económicos derivados de la economía social y solidaria que constituyen una oportunidad para la inserción socio-productiva de la población en condiciones de pobreza, "porque representan una fuente de ocupación laboral y brindan diferentes beneficios tanto a quienes las conforman, como a sus familiares y sus comunidades"(Vázquez, Solís, y Ramírez, 2015b).

El propósito de ese trabajo es presentar a partir de la teoría de valor de Porter (1991) los factores y variables que influyen en la competitividad interna de empresas sociales. Estos factores y variables se presentan en la tabla 1 y fue la base para elaborar parcialmente el cuestionario, que se aplicó a 48 unidades productivas de las comunidades de La Urraca, El Vainillo, La Tuna, San Francisquito, Loma de Monterrey y Escamillas, ubicadas en la sindicatura de Villa Unión, en el municipio de Mazatlán, Sinaloa, México. Estas empresas representan la muestra de estudio del proyecto aprobado por el Programa para el Desarrollo Profesional Docente (PRODEP) al Cuerpo Académico Competitividad en las Organizaciones.

En un primer apartado de este trabajo se hace un acercamiento teórico a partir de la cadena de valor de Porter, para distinguir los factores endógenos de competitividad empresarial.

En el segundo apartado se presentan de manera sintetizada los elementos que constituyen el diseño de investigación del proyecto, denominado"Factores de competitividad de empresas sociales que son determinantes de un mayor impacto socioeconómico. Análisis de unidades productivas ubicadas en seis comunidades rurales del municipio de Mazatlán, Sinaloa, pertenecientes a la sindicatura de Villa Unión”, del cual se deriva este trabajo.

La cadena de valor de Porter distingue a la administración de recursos humanos, la administración de las operaciones, la administración de la mercadotecnia y las ventas, la administración financiera, la administración del desarrollo tecnológico y de la estructura organizativa, como los principales factores endógenos de competitividad empresarial. En el tercer apartado se muestran las variables determinadas para cada uno de estos factores.

Por último, se presentan las conclusiones surgidas de las reflexiones realizadas hasta esta etapa del proyecto, así como la bibliografía consultada. 


\section{Revisión Teórica}

Vázquez (2014) considera que la competitividad es un concepto clásico en la teoría económica que hace alusión directa a la capacidad de competir de una persona o una unidad productiva en función de objetivos predeterminados. Así, mismo señala que Porter argumenta que la competitividad está definida por la posición competitiva de una empresa en busca de la ventaja competitiva.

Actualmente existe un interés público, académico y político, para fomentar la competitividad de las empresas de economía social y solidaria, porque poseen potencial suficiente para la inclusión productiva de personas en condiciones de vulnerabilidad (Fotheringham y Saunders, 2014). Estos espacios productivos ayudan a minimizar los estragos de un crecimiento económico inequitativo que ha prestado una excesiva atención al incremento de rendimientos financieros en el ámbito empresarial tradicional y que ha ocasionado el surgimiento de demandas sociales que ni el estado, ni la empresa privada han podido satisfacer (Amin, 2009; Azzellini, 2009; Neamtan, 2009; Singer, 2009; Romero y Hurtado, 2011; Chaves y Monzón, 2012).

Las empresas sociales son entes productivos que tienen la capacidad para generar fuentes de empleo y de ingresos a aquellas personas que se encuentran incrustadas en contextos socioeconómicos tradicionalmente excluidos de los beneficios generados por un sistema que ha privilegiado la obtención de ganancias económicas y ha dejado de lado los beneficios sociales.

En este estudio se entiende por empresa social“una organización empresarial dirigida por personas de escasos recursos que a través de procesos y estrategias diversas buscan obtener beneficios sociales y económicos para sus integrantes y para sus comunidades" (Vázquez, Ramírez y Suástegui, 2014).

La investigación de la que se deriva este trabajo (Vázquez et, al. 2015a), se sustenta en la teoría de la economía social y solidaria (Robinson y Hanson, 1995 citado en Benemérita Universidad Autónoma de Puebla [BUAP], 2009); la teoría de la cadena de valor (Porter, 1991) y la teoría del diamante de la competitividad (Porter 2008a; 2008b). La primera se utiliza para determinar las características que distinguen a las empresas sociales por un lado, así como los resultados que se deben alcanzar, mientras que las dos últimas servirán de base para determinar el modelo competitivo de empresa social.

De igual manera el estudio retoma diferentes perspectivas que fueron de utilidad para la determinación de las condiciones que debe cumplir el impacto socioeconómico de las empresas sociales en estudio, específicamente en los niveles individual, empresarial y comunitario (Programa de las Naciones Unidas para el Desarrollo, 2012b; Alkire, 2002, citado en Programa de las Naciones Unidas para el Desarrollo, 2012a; Díaz y Marcuello, 2010; Kerlin, 2010; Romero y Hurtado, 2011; Amat y Perramon, 2011).

El marco teórico para esta etapa de la investigación retoma las siguientes propuestas de la cadena de valor de Porter (1991):

a. Los procesos dinámicos que tienen un efecto sobre un desempeño empresarial superior no necesariamente están separados de aquellos que crean posiciones competitivas de mercado o de las habilidades de las firmas.

b. El éxito de una empresa es mantener una posición competitiva que la lleve a obtener un desempeño superior, dichos beneficios deben de ayudar a cumplir objetivos sociales. Para explicar el éxito competitivo de una firma se necesita una teoría que vincule a las condiciones ambientales con el comportamiento de la firma en sus resultados de mercado. 
c. Una posición atractiva es el resultado de la ventaja competitiva dentro de un alcance determinado, esto implica fijar la atención en el costo, la diferenciación y el alcance, lo cual hace necesaria una teoría que ponga atención en lo que las firmas hacen.

d. La teoría de la cadena de valor propone que las actividades internas que se realizan en una firma pueden ser centrales o de apoyo. Dichas actividades no tienen valor por sí solas, sino en conjunto. La realización de dichas actividades puede generar activos tangibles e intangibles, tanto internos como externos. El valor para los clientes se crea cuando las firmas disminuyen sus costos o incrementan su desempeño.

e. Los puntos fuertes y débiles de una compañía representan su perfil de activos y sus habilidades en relación con la competencia como recursos, situación tecnológica, identificación de marca entre otras cosas. Los valores personales son los motivos y necesidades de los principales ejecutivos y de otros empleados que se encargan de implementar la estrategia escogida. Los puntos fuertes y débiles, combinados con los valores, determinan los límites internos de la estrategia competitiva que una compañía puede adoptar exitosamente.

Con base en los puntos anterioriores, para este trabajo es importante distinguir los factores internos que influyen en la competitividad de empresas sociales porque representa un mecanismo para lograr los efectos esperados de su operación y permitirá a estas unidades productivas lograr el propósito social por el cual fueron creadas, brindando herramientas concretas para el establecimiento de estrategias de negocios pertinentes.

Siguiendo a Porter (1991), se distinguen la administración de la mercadotecnia y las ventas, la administración financiera, la administración de recursos humanos, la administración de operaciones y del desarrollo tecnológico y la estructura organizativa, como los principales factores endógenos de competitividad empresarial. A continuación se abordan los referentes teóricos que orientaron la determinación de las variables relacionadas con los factores de competitividad interna empresarial.

Administración de la mercadotecnia y las ventas

Coraggio (2011), apunta que las PyMES pueden superar sus desventajas al buscar redes de colaboración con otras empresas, como es el caso del establecimiento de alianzas, así como con diversas instituciones de las cuales se pueden obtener apoyos.

La confianza existente entre actores productivos diversos es un elemento central del capital social, estos factores han aparecido relacionados positivamente con el desarrollo económico (Galaso, 2005; Rojas y Marin, 2006). Los empresarios sociales deben de realizar mayores esfuerzos por fortalecer sus relaciones productivas cooperativas y convertirlo en un recurso, mejor conocido como capital social, que sirva para facilitar el logro de los objetivos organizacionales.

El capital social de las organizaciones e instituciones contribuye a su mejoramiento (BUAP, 2009, p. 45; Weber y Weber, 2010, pp. 44-45; Helliwell y Huang, 2010, p. 222; Carr, Cole, Kirk, y Blettner, 2011, pp. 1208-1209). Diversos autores recomiendan promover diversas formas de capital social o redes de colaboración entre las cuales se encuentran los vínculos extra-locales y extra-organizacionales, relacionados con las alianzas empresariales (Porter, 1991; Austin, Stevenson, y Wei-Skillern, 2006; Birch y Whittam, 2008; Michelini, 2012).

\section{Administración Financiera}


Amat y Perramon (2011) observan que las cooperativas exitosas manifiestan tener un alto nivel de ventas, pero un bajo nivel de utilidad, derivado de los gastos operativos en los que tienen que incurrir. Aunque los autores citados anteriormente, recomiendan que estas unidades productivas realicen un mayor esfuerzo por mejorar su sostenibilidad financiera. De igual manera diversos autores afirman que la economía pública debería financiar y subsidiar la operación de empresas sociales, al menos hasta que se puedan sostener por cuenta propia (Neamtan, 2009; Coraggio, 2011; Chavez y Monzón, 2012).

\section{Administración de Recursos Humanos}

Las empresas sociales tienden a poner a las personas por encima del capital, es decir, la inversión en las personas es mayor aunque esta decisión pueda mermar la obtención de rendimientos financieros (Chavez y Monzón, 2012; Amat y Perramon, 2011; Fekete, 2010). Por otra parte, Borzaga y Tortia (2007) reconocen que no todas las personas tienen el mismo tipo de motivaciones en el trabajo, pero en el caso de las empresas sociales los participantes elevan su interés cuando logran identificarse con el propósito social de las organizaciones.

Relacionado con lo anterior, Ohana y Meyer (2010) reconocen que el compromiso de los integrantes con las organizaciones sociales es una variable relacionada con el deseo de permanecer en la organización, mientras que la satisfacción laboral está fuertemente relacionada con el deseo de dejar la empresa, por ello recomiendan incrementar los esfuerzos en mejorar ambas variables independientes.

\section{Administración del Desarrollo tecnológico}

La literatura señala que en cualquier tipo de organización la innovación debería convertirse en una capacidad incremental (Oliveira y Werther, 2013) y que en las pequeñas empresas se ha visto que existe un vínculo entre su posición competitiva y los esfuerzos innovativos (Lefebvre y Lefbvre, 1993). En el caso de las organizaciones de economía social y solidaria la innovación y el desarrollo tecnológico forman parte de su esencia operativa (Sullivan, Weerawardena, y Carnegie, 2003; Centro Internacional de Formación de la Organización Internacional del Trabajo [CIFOIT], 2011; Michelini, 2012), además de que representan una ventaja competitiva tendiente a la diferenciación (Sanchis y Campos, 2007). Este tipo de empresas son en sí mismas una fuente de innovación considerada de tipo social, porque surgen de las necesidades insatisfechas, tanto por el mercado como por el estado (Laville, Levesque, y Mendell, 2006, p. 26).

Adicionalmente, Coraggio (2011) afirma que las empresas más pequeñas y por lo tanto con mayores debilidades para competir en el mercado, pueden encontrar herramientas que les permita superar sus debilidades cuanto más se acerquen a la ciencia y la tecnología.

\section{Estructura Organizativa}

La coordinación entre los integrantes de la empresa es un elemento central del capital social, estos factores han aparecido relacionados positivamente con el desarrollo económico (Galaso, 2005; Rojas y Marin, 2006). Los empresarios sociales deben de realizar mayores esfuerzos por fortalecer sus relaciones productivas cooperativas y convertirlo en un recurso, mejor conocido como capital social, que sirva para facilitar el logro de los objetivos organizacionales.

Para mejorar el capital social se necesita invertir diferentes recursos entre los que 
destaca el tiempo, ya que crece en la medida en que se utiliza y va deteriorándose cuando no se renueva (Coleman, 1990, citado en Mazzotti, 2006).

Borzaga y Galera (2012), afirman que los trabajadores de empresas sociales experimentan niveles altos de autonomía, interés e involucramiento en las operaciones empresariales. Otros programas gubernamentales tendientes a apoyar el desarrollo de empresas sociales en sectores marginados, han identificado también como un factor de éxito de los proyectos productivos implementados al nivel de compromiso que tienen los socios en la operación organizacional, mientras que la carencia de este factor y/o una inapropiada capacitación y acompañamiento por parte de los representantes de gobierno puede conducir al fracaso empresarial (Universidad Autónoma de Chapingo, 2008).

\section{Metodología}

La investigación de la que se deriva este trabajo tiene como objetivo diseñar un modelo de competitividad estadístico que sea determinante de un mayor impacto social y económico de las empresas ubicadas en seis comunidades rurales de la sindicatura de Villa Unión en el municipio de Mazatlán, Sinaloa. Entendiendo por modelo de competitividad un conjunto de variables asociadas mayormente al éxito o consolidación de una empresa (Vázquez et al., 2014).

En esta sección se presenta de manera sintetizada los elementos que constituyen el diseño de investigación del proyecto antes mencionado dado que éstos fueron desarrollados en Vázquez et al. (2015a).

Se ha aplicado el enfoque cuantitativo, el alcance será explicativo porque está dirigido a reconocer causas de un evento social, al intentar identificar los factores competitivos que originan un mayor impacto socioeconómico de las empresas sociales. Adicionalmente a través de los resultados se espera obtener un mayor entendimiento del fenómeno estudiado (Hernández, Fernández, y Baptista, 2010).

Del total de 82 empresas sociales de la base de datos de la Cámara Nacional del Comercio en Pequeño (CANACOPE), se seleccionaron de forma aleatoria 48, distribuidas en las comunidades de la Urraca, ElVainillo, LaTuna, San Francisquito, Loma de Monterrey, Escamillas. El levantamiento de información fue a través de un cuestionario que se aplicó a los responsables de las empresas.

La hipótesis que se plantea para este estudio es la siguiente: existen factores endógenos, incluidos en la cadena de valor de una empresa social, entre los que se encuentran la administración de recursos humanos, la administración de las operaciones, la administración de la mercadotecnia y las ventas, la administración financiera, la administración del desarrollo tecnológico y la estructura organizativa, que están relacionados y son determinantes de un mayor impacto socioeconómico de estas organizaciones, entendido como el mejoramiento de las condiciones de vida de sus integrantes, los resultados de negocios, así como de los beneficios aportados a la comunidad.

Factores y variables relacionadas con la competitividad interna de empresas sociales En la tabla 1 se desglosan los factores endógenos considerados para el estudio, mismos que se encuentran incluidos en la hipótesis, así como las variables consideradas en cada uno de dichos factores. 


\section{Tabla 1}

Factores endógenos y variables relacionados con la competitividad de empresas sociales

\section{FACTOR}

\section{VARIABLES}

1. Mejoramiento del proceso productivo o de prestación de servicios en:

a. Maquinaria o equipo

b. Materias primas e insumos

c. Organización

d. Instalaciones

e. Conocimiento del proceso

\section{Ventajas de la comercialización y/o distribución} de la producción:

a. El mercado al que dirige el producto ha trascendido lo local

b. El producto se comercializa en la misma empresa y otros lugares

c. Existen vías de comunicación

d. Se han ampliado los contactos/clientes

e. Se conoce mejor al mercado

f. La intermediación ha disminuido

g. El medio de transporte que se utiliza

h. Los principales compradores están cerca

Mercado y comercialización

i. Se utilizan las nuevas tecnologías

j. Los precios los determina la empresa con base a la ganancia que se quiere obtener

k. Las ventas han mejorado

2. Factores que han tenido influencia en el comportamiento de las ventas:

a. Calidad del producto

b. Atención al cliente por parte de trabajadores

c. Mayor demanda de los productos o servicios

d. Presión o agresividad de los competidores

e. Alianza con otras empresas

f. Innovación del proceso productivo

g. Apoyos del gobierno 
h. Nuevas inversiones en la empresa

i. Capacitación de los trabajadores

j. Satisfacción de los integrantes de la empresa

Mercado y comercialización

k. Imagen de la empresa y conocimiento de la marca

1. Realización de estudios de mercado

m. Precios de los productos o servicios

n. Análisis de los competidores

o. La buena relación con los vecinos

3. Perspectiva futura de mercado para la empresa social

1. Nivel de la empresa en los siguientes aspectos:

a. Deudas por pagar

b. Monto de ventas

c. Utilidad

d. Liquidez para solventar gastos

e. Inversiones

2. Fuentes de financiamiento de la empresa:

a. Socios/propietarios

Finanzas b. Prestamistas locales

c. Familiares

d. Banca privada

e. Instituciones gubernamentales

f. Proveedores

g. Clientes

h. Casas de empeño

3. Mantenimiento de registros contables de las operaciones de la empresa

\section{Capacidad académica de los empleados}

2. Capacitación permanente de los empleados relacionada con la actividad productiva de la empresa

Recursos humanos

3. Características de las relaciones laborales de la empresa:

a. Participación de los trabajadores en la toma de decisiones

b. Entrenamiento y capacitación permanentes

c. Trato equitativo en el reparto de beneficios 
d. Confianza y respeto entre líderes y colaboradores

e. Estrategia diferenciada de trato al personal

Recursos humanos

f. Prestaciones sociales a los trabajadores

g. Sueldos competitivos

h. Baja rotación de personal

i. Identificación de los trabajadores con la empresa

\section{Aspectos en los que se han realizado innovaciones:}

a. Procesos productivos

b. Sistemas de comercialización

c. Productos o servicios ofrecidos

Desarrollo tecnológico

d. Sistemas de distribución

e. Manejo de trabajadores

f. Aspectos de la organización empresarial

g. Manejo de las finanzas

h. Uso de software

1. Empresas o instituciones con las cuales se mantienen relaciones comerciales, productivas y de intercambio tecnológico frecuentes:
a. Empresas privadas
b. Empresas sociales
c. Organizaciones políticas
d. Instituciones financieras
e. Instituciones gubernamentales

Estructura

de la empresa

\section{f. Instituciones Educativas}

2. Recepción de alguna institución para contratar asistencia técnica o capacitación de alguna empresa consultora, asesor o especialista

3. Características organizativas que distinguen a la empresa:

a. Los integrantes de la empresa conocen sus funciones

b. El trabajo se realiza en base a un plan previamente establecido

c. Todos pueden participar en la toma de decisiones 
d. Existe un compromiso de todos por mejorar día con día

\begin{tabular}{|c|c|}
\hline \multirow{6}{*}{$\begin{array}{c}\text { Estructura } \\
\text { de la empresa }\end{array}$} & e. Las relaciones entre los integrantes son cordiales \\
\hline & $\begin{array}{l}\text { f. Existe apoyo entre los integrantes para la solución } \\
\text { de problemas }\end{array}$ \\
\hline & g. Se realizan reuniones de trabajo al menos cada mes \\
\hline & $\begin{array}{l}\text { h. Cada quien sabe cómo se realizan las tareas que } \\
\text { le corresponden }\end{array}$ \\
\hline & i. La empresa o proyecto tiene la confianza de la comunidad \\
\hline & j. Se usa la improvisación para sortear los problemas diarios \\
\hline
\end{tabular}

Nota: Adaptado de Vázquez (2014). Este esquema contribuyó a la elaboración parcial del cuestionario (mediante la aplicación ISURVEY), que se aplicó a las empresas en estudio.

\section{Conclusiones}

Analizar y relacionar los factores y variables que influyen en la competitividad interna de empresas sociales y socializarlos permitirá a estas unidades productivas incrementar su capacidad de competir en función de los objetivos predeterminados.

Así mismo los elementos de la tabla 1, contribuyen a diseñar de manera parcial un modelo de competitividad teórico hipotético, que sea determinante de un mayor impacto social y económico de las empresas sociales.

Lo que se pretende con este modelo es identificar los principales factores internos y externos que influyen directamente en el impacto socioeconómico de las empresas sociales ubicadas en las comunidades de La Urraca, El Vainillo, La Tuna, San Francisquito, Loma de Monterrey y Escamillas, ubicadas en la sindicatura de Villa Unión, en el municipio de Mazatlán, Sinaloa, México. y que además podría ser replicado en el análisis de otras organizaciones empresariales, independientemente de que sean derivadas de la economía social y solidaria o no.

De esta manera se podrían desplegar las bondades propuestas por la economía social y solidaria, al replicar las experiencias exitosas a través de un modelo de gestión que ayude a elevar la competitividad de otras empresas sociales y que posibilite el logro de su finalidad social, asegurando que repercutan en el bienestar de los individuos que las integran, la consolidación de la unidad productiva, así como un adecuado impacto comunitario. 


\section{Referencias}

Amat, O., \& Perramon, J. (2011). High-Growth cooperatives: Financial profile and key factors for competitiveness. CIRIEC-España. Revista de Economía, Publica, Social y Cooperativa, (73), 81-98.

Amin, A. (2009). Locating the social economy. En The social economy. International perspectives on economic solidarity (pp. 3-21). London: Zed books.

Austin, J., Stevenson, H., \& Wei-Skillern, J. (2006). Social and commercial entrepreneurship: Same, different, or both? Entrepreneurship, Theory and Practice, January, 1-22.

Azzellini, D. (2009). Venezuela's solidarity economy: collective ownership, expropriation and workers self-management. Working USA: The Journal of Labor and Society, 12, 171-191.

Benemérita Universidad Autónoma de Puebla (BUAP). (2009). Evaluación Integral Externa 2008-2009 del Fondo Nacional de Apoyos para Empresas en Solidaridad. Puebla: BUAP. Recuperado de http://www.inaes.gob.mx/doctos/pdf/transparencia/Evaluacion \% 20 Integral \% 202008-2009\%20FONAES.pdf

Birch, K., \& Whittam, G. (2008). The third sector and the regional development of social capital. Regional Studies, 42(3), 437-450. http://doi.org/10.1080/00343400701874222

Borzaga, C., \& Galera, G. (2012). The concept and practice of social Enterprise. Lessons from the Italian experience. International Review of Social Research, 2(2), 95-112.

Borzaga, C., \& Tortia, E. (2007). Social economy organizations in the theory of the firm. En A. Noya, \& E. Clarence (Ed.), The Social Economy. Building inclusive economies (pp. 23-60). París: OECD. Recuperado de http://browse.oecdbookshop.org/oecd/pdfs/ product/8407051e.pdf

Carr, J.C., Cole, M.S., Kirk, R.J., \& Blettner, D.P. (2011). A measure of variations in internal social capital among family firms. Entrepreneurship theory and practice, 35(6), 12071227. http://doi.org/10.1111/j.1540-6520.2011.00499.x

Centro Internacional de Formación de la Organización Internacional del Trabajo (CIFOIT). (2011). Economía social y solidaria: Nuestro camino común hacia el trabajo decente. Recuperado de http://www.ilo.org/wcmsp5/groups/public/---ed_emp/---emp_ent/--coop/documents/instructionalmaterial/wcms_166369.pdf

Coraggio, J.L. (2011). Economía social y solidaria. El trabajo antes que el capital. Quito: Ediciones Abya-Yala.

Chaves, R., \& Monzón, J.L. (2012). Beyond the crisis: The social economy, prop of a new model of sustainable economic development. Serv. Bus., 6, 5-26. http://doi.org/10.1007/ s11628-011-0125-7

Díaz, F.M., \& Marcuello, S.C. (2010). Impacto económico de las cooperativas. La generación de empleo en las sociedades cooperativas y su relación con el PIB. CIRIEC-España. Revista de Economía, Publica, Social y Cooperativa, (67), 23-44.

Fekete, E.G. (2010). Geographical aspects of social and solidarity economy. Business Studies, 7( 2), 47-59.

Fotheringham, S., \& Saunders, C. (2014). Social enterprise as poverty reducing strategy for women. Social Enterprise Journal, 10(3), 176-199. http://doi.org/10.1108/SEJ-06-20130028

Galaso, R.P. (2005). Capital social y desarrollo económico. Los casos de Silicon Valley y Villa El Salvador. Noesis. Revista de Ciencias Sociales y Humanidades, 15(27), 161188. 
Helliwell, J.F., \& Huang, H. (2010). How's the job? Well-being and social capital in the workplace. Industrial and Labor Relations Review, 63, (2), 205-227.

Hernández, S.P., Fernández, C.C., \& Baptista, L.P. (2010). Metodología de la Investigación. Ciudad de México: McGraw-Hill.

Kerlin, J.A. (2010). A Comparative Analysis of the Global Emergence of Social Enterprise. Voluntas, 21, 162-179. http://doi.org/10.1007/s11266-010-9126-8

Laville, J.L., Levesque, B., \& Mendell, M. (2006). The social economy: Diverse approaches and practices in Europe and Canada. Cahier de l'ARUC-ES, (11), 1-46.

Lefebvre, L.A., \& Lefebvre, B. (1993). Competitive positioning and innovative efforts in SMEs. Small Business Economics, (5), 297-305.

Mazzotti, P.G. (2006). Capital social y desarrollo: propuesta crítica de capital social para evaluar programas y proyectos de desarrollo social en México. Polis: Investigación y Análisis sociopolítico y Psicosocial, 2(1), 75-104.

Michelini, L. (2012). Social Innovation and New Business Models. Creating shared value in low-income markets. http://doi.org/10.1007/978-3-642-32150-4

Neamtan, N. (2009). Social economy: concepts and challenges. UniversitasForum, 1(3), 1-5.

Ohana, M., \& Meyer, M. (2010). Should I stay or should I go now? Investigating the intention to quit of the permanent staff in social enterprises. European Management Journal, 28(6), 441-454. http://doi.org/10.1016/j.emj.2010.06.007

Oliveira, T.E., \& Werther Jr., W.B. (2013). Resilience: Continuous renewal of competitive advantage. Business Horizons, 1031 (Article in Press), 1-10.

Porter, M.E. (1991). Towards a dynamic theory of strategy. Strategic Management Journal, 12, 95-117.

Porter, M.E. (2008a). The Competitive Advantage of Nations. En M.E. Porter (Ed.), On competition (pp. 171-211). Boston: The Harvard business review book series.

Porter, M.E. (2008b). Competing across locations. En M.E. Porter (Ed.), On competition (pp. 305-344). Boston: The Harvard business review book series.

Programa de las Naciones Unidas para el Desarrollo (PNUD). (2012a). Evaluación Especifica de Costo-Beneficio 2011 del Programa Nacional de Apoyos para Empresas en Solidaridad (FONAES). Ciudad de México: PNUD. Recuperado de http://www. inaes.gob.mx/doctos/pdf/transparencia/INFORME_EECB_FONAES.pdf

Programa de las Naciones Unidas para el Desarrollo (PNUD). (2012b). Informe sobre competitividad social en México 2012. Ciudad de México: PNUD. Recuperado de www.undp.org.mx/desarrollohumano

Rojas, L.M.D., \& Marin, S.P. (2006). Aproximaciones a la medición de la confianza. Dyna, 73 (150), 119-130.

Romero, G.R.M., \& Hurtado, M.J. (2011). La empresa social. Una opción de desarrollo local en la comunidad indígena de San Idelfonso. Gestión y Estrategia, (39), 19-28.

Singer, P. (2009). Relaciones entre sociedad y estado en la economía solidaria. Iconos, Revista de Ciencias Sociales, (33), 51-65.

Sanchis, P.J.R., \& Campos, C.V. (2007). La dirección estratégica en la economía social: Utilización de herramientas de análisis estratégico en las cooperativas. CIRIECEspaña, Revista de Economía Pública, Social y Cooperativa, (59), 237-258.

Sullivan, M.G., Weerawardena, J., \& Carnegie, K. (2003). Social entrepreneurship: Towards conceptualisation. International Journal of Non Profit andVoluntary Sector Marketing, 8(1), 76-88. 
Universidad Autónoma de Chapingo. (2008). Evaluación Externa de Impacto 2008 del Fondo para el Apoyo a Proyectos Productivos en Núcleos Agrarios (FAPPA 20052006). Recuperado de http://www.sra.gob.mx/sraweb/datastore/programas/2010/ fappa/Evaluacion_IMPACTO_FAPPA_2008.pdf

Vázquez, R. L. (2014). Modelo de competitividad determinante del impacto socioeconómico de empresas sociales. Análisis de proyectos productivos apoyados por FONAES en el sur de Sinaloa (Tesis Doctoral). Universidad Popular Autónoma del Estado de Puebla, Puebla.

Vázquez, R. L., Ramírez, B., y Suástegui, B. C. (2014). Modelo teórico de competitividad determinante del impacto socioeconómico de empresas sociales. XIV Asamblea General de la ALAFEC, Panamá, Panamá.

Vázquez R, L., Ramírez, B., y Suástegui B. C. (2015a). Factores de competitividad en empresas sociales. En A. Olivares, J. Ochoa, y J.A. Coronado (Coordinadores), Estudios de Competitividad (pp. 43-52). Hermosillo: Qartuppi. http://doi.org/10.29410/QTP.15.02

Vázquez, R. L., Solís, O. D., y Ramírez, B. (2015b).Gestión administrativa e innovación para el desarrollo de empresas sociales rurales. Revista de Investigación en Tecnologías de la Información, 3(5), 1-9. Recuperado de http://casesis.net/riti/2015/download/266/

Weber, C., y Weber, B. (2010). Social capital and knowledge relatedness as promoters of organizational performance. An exploratory study of corporate venture capital activity. Int. Studies of Mgt. \& Org., 40(3), 23-49. 
Capítulo 4 
Amado Olivares Leal, Universidad de Sonora olivares@pitic.uson.mx

Josefina Ochoa Ruiz, Universidad de Sonora jochoa@pitic.uson.mx

Elda Patricia Castro Cota, Instituto Tecnológico de la Paz lepatrichia1371@hotmail.com

Pabla Peralta Miranda, Universidad Simón Bolívar peperaltam@gmail.com

Francisco Espinoza Morales, Universidad de Sonora fespinoz@navojoa.uson.mx 


\section{Capítulo 4}

\section{Subcontratación (outsourcing) integral}

en una empresa minera como factor explicativo

de competitividad empresarial

\section{Introducción}

En la actualidad el concepto de outsourcing (OUTG) es sinónimo de subcontratación, productividad, adaptabilidad, flexibilidad, modernidad y competitividad, para aquellas empresas que requieren estar a la vanguardia en el segmento donde participan a nivel mundial. Dada la globalización, las empresas han venido de menos a más por el adelgazamiento de las organizaciones; lo anterior es señalado por la sociedad misma, como el fin del desperdicio, la ineficiencia y las ostentaciones de opulencia, implicando además una mayor concentración en las ventajas competitivas por parte de las organizaciones que están transfiriendo trabajos a contratistas, “esta tendencia también podría ser un indicio de que la industria está llegando a un acuerdo con un ambiente más exigente y de necesidad de maximizar los recursos y reducir el desperdicio"(Rothery, 1997 citado en Aguilar et al., 2011).

Esta investigación tiene como objeto evaluar la aceptación de la herramienta OUTG en los diferentes tipos de mantenimiento (MANTTO) a equipos de proceso metalúrgico en una empresa minera, situada en el estado de Sonora, México, donde se analizan los antecedentes de esta herramienta aplicada en otro tipo de industria y la minería misma, así como los resultados obtenidos de la metodología aplicada para la confirmación de las hipótesis propuestas.

\section{Antecedentes}

El OUTG evolucionó en los últimos 30 años, cuando se suscitaron cambios significativos en la industria automotriz respecto a las relaciones entre ensambladoras y fabricantes de piezas y componentes (Sica, Scarlan, Rossini, Beinstein, y Figueroa, 2014, p. 60); esta herramienta se adoptó lentamente en Europa con una práctica tradicional de subcontratación (multisourcing) con base a costos más bajos y seguridad en el suministro, surgiendo alianzas estratégicas con proveedores únicos de partes.

El OUTG como herramienta dentro de la reingeniería de proceso del negocio, se determina como un buena alternativa para continuar implementando el OUTG en áreas no 
utilizadas actualmente como es el MANTTO en equipos de proceso en la empresas, para aumentar el nivel de disponibilidad de los mismos y reducir sus costos directos de producción y a la vez convertir algunos en costos variables de producción, aumentando su eficiencia y efectividad para elevar la rentabilidad del negocio. Permitiendo, además, la facilidad de encontrar más rápido el camino al liderazgo.

Los aspectos que contribuyen a justificar la investigación en la aplicación del OUTG en MANTTO para la empresa minera, son los siguientes:

- Analizar la herramienta del OUTG en el área de MANTTO, permitiendo aportar resultados diferentes en el nivel de disponibilidad de los equipos, los costos y el MANTTO mismo, facilitando a los superintendentes, gerentes y directores mejorar la reingeniería, ya que refuerza las alternativas estratégicas de desempeño como el costo, la calidad y la velocidad. Es decir, trabajar de una manera diferente a la tradicional. Por lo tanto, el OUTG se beneficiará de la reingeniería y esta a su vez le permite abrir nuevas opciones.

- Los resultados de la investigación romperán paradigmas tradicionales en el MANTTO de los equipos de proceso y permitirá una mejor aceptación de los ejecutivos de la empresa.

- El nivel de disponibilidad de los equipos a través del OUTG, permitirá a la empresa participar con firmeza en sus nichos de mercado.

- Los resultados obtenidos facilitarán una gama de alternativas para aplicar el OUTG en otras áreas de la empresa.

- La información de la investigación permitirá conocer realmente el nivel de disponibilidad de los equipos que se encuentra actualmente en la empresa minera. Así como conocer las ventajas competitivas, como la innovación tecnología, personal capacitado y experiencia para desarrollar un MANTTO en las diferentes disciplinas.

- Los resultados obtenidos de este ejercicio sensibilizarán al personal de la organización a pensar en el OUTG como parte de la herramienta en la reingeniería y como parte de sus ventajas competitivas.

\section{Marco teórico}

OUTG (Subcontratación)

El OUTG, de acuerdo a Ferry de Kraker (citado por Rothery y Robenson, 1997), se le ha llamado de diferentes formas: "administración adelgazada”, "subcontratación”, "empresas de manufactura conjunto", "cofabricación”y"tercerización”(p. 4).

Como definición, el OUTG, en el sector de la minería se refiere a la prestación de servicios y suministro de componentes por parte de una empresa, que anteriormente se realizaba internamente en una organización, con el fin de buscar flexibilidad y habilidad para ajustarse a las condiciones cambiantes, lo cual permitirá no desviarse de su misión. Entre más especializada sea una empresa mayor probabilidad existe de encontrar ayuda experta fuera de ella. Ya que tratar de agregar un departamento adicional, no es la mejor solución para una organización.

Actualmente, algunas empresas se han decidido tomar esta tendencia con fervor y convicción, pero sin medir las consecuencias ocultas de esta herramienta, como concluye Hendry (1996), mencionando que cualquier movimiento hacia el OUTG debería evaluarse profundamente, debido a que produce un fuerte impacto en las características de la organización. 
Conceptos que se manejan con relación al OUTG

Ferry de Kraker (citado en Rothery y Roberson, 1997) define al OUTG como la selección de nuevos proveedores y nuevas formas de asegurar la entrega de materias primas, artículos, componentes y servicios, que permita utilizar el conocimiento, las experiencias y la creatividad de nuevos proveedores a los que anteriormente no se recurría. Jones (1997) y Neale (citado en Bragg, 2000) describen al OUTG como la práctica de transferir la planeación, administración y operación de ciertas funciones a una tercera parte independiente.

Con la implementación de una producción en serie, las fabricas pasaros a establecer programas mínimos de producción por lo cual empezaron a sentir la necesidad de crear equipos que pudieran efectuar el mantenimiento de las máquinas de la línea de producción en el menor tiempo posible.

De acuerdo a Tavares (2000), "así surgió un órgano subordinado a la operación, cuyo objetivo básico era la ejecución del mantenimiento hoy conocido como "mantenimiento correctivo"”(MCORR) (p. 1). Esta situación se mantuvo hasta la década de 1930 (p. 2).

Alrededor de 1950 "se seguía las recomendaciones de los fabricantes de equipo acerca de los cuidados que se debían tener en la operación y mantenimiento de máquinas y sus dispositivos"(Martínez, 2009 p. 38). Esta nueva forma o tendencia de mantenimiento se llamó mantenimiento preventivo (MPREV).

A partir de 1966, con la difusión de las computadoras [...] y la sofisticación de los instrumentos de protección y medición, la Ingeniería de Mantenimiento pasó a desarrollar criterios de predicción o previsión de fallas, con el objetivo de optimizar el desempeño de los grupos de ejecución del mantenimiento. (Tavares, 2000, p. 3).

Estos criterios fueron conocidos como mantenimiento predictivo (MPRED), los cuales fueron asociados a métodos de planeamiento y control de mantenimiento.

"Diez años [después], tomó lugar la globalización del mercado creando nuevos modelos de mantenimiento para así lograr una mejor calidad y una mejor excelencia."(Romero, 2013, p. 31). Estos modelos son:

- Mantenimiento productivo total (TPM, Total Productive Maintenance);

- $5 S$, práctica de calidad referida al "mantenimiento Integral”;

- Kaissen, modelo que se caracteriza por desarrollar una cultura y dar participación a todos los trabajadores;

- Mantenimiento centrado en fiabilidad (RCM, Reliability Centered Maintenance), metodología para el desarrollo de un plan de mantenimiento basada en el análisis de fallos de la instalación.

Para la aplicación de este tipo de modelos, es necesario contar con equipos de trabajo especializado; sin embargo, cuando las empresas sobrepasan su capacidad de reacción, se hace necesario buscar alternativas. En la tabla 1se mencionan los factores internos y externos que influyen en la empresa para considerar el OUTG y en la tabla 2 se indican las ventajas y desventajas. 
Tabla 1

Factores internos y externos que influyen en la empresa para considerar el outsourcing

\begin{tabular}{cc} 
Factores Internos & Factores Externos \\
Falta de experiencia & Oferta \\
\hline Rotación de personal & Mercado regulador \\
\hline Problemas sindicales & Avance tecnológico \\
\hline Tecnología obsoleta & Globalización \\
\hline Falta de disponibilidad de equipo & Benchmarking \\
\hline
\end{tabular}

Tabla 2

Ventajas y desventajas del outsourcing

\begin{tabular}{ll} 
Reducción de costos, & \multicolumn{1}{c}{ Pentajas } \\
\hline $\begin{array}{l}\text { Permite enfocarse en las partes } \\
\text { estratégicas de la empresa }\end{array}$ & $\begin{array}{l}\text { Posible inflexibilidad en necesidades } \\
\text { cambiantes de la organización }\end{array}$ \\
\hline Mejora el profesionalismo de los servicios & Posible comunicación escasa \\
\hline $\begin{array}{l}\text { Acceso a la tecnología } \\
\text { sin inversión de capital }\end{array}$ & Resistencia interna \\
\hline $\begin{array}{l}\text { Convierte el centro de costos } \\
\text { a centro de ganancias }\end{array}$ & Costos de conversión \\
\hline $\begin{array}{l}\text { Ganancia y transferencia } \\
\text { de conocimientos y experiencias }\end{array}$ & $\begin{array}{l}\text { Requiere atención por parte } \\
\text { de la alta administración }\end{array}$ \\
\hline $\begin{array}{l}\text { Mejoramiento de la velocidad } \\
\text { de desarrollo }\end{array}$ & $\begin{array}{l}\text { Pérdida de control sobre futuros } \\
\text { desarrollos, habilidades, experiencia, etc. }\end{array}$ \\
\hline $\begin{array}{l}\text { Flexibilidad con el personal outsourcer } \\
\text { Pérdida de fuerza sindical }\end{array}$ & \\
\hline
\end{tabular}

\section{Metodología}

La metodología empleada en la realización de esta investigación consta de la descripción general de la metodología empleada y concepción de la idea de investigación.

El tipo de diseño de esta investigación es transversal, exploratoria y descriptiva; se llevó a cabo en la planta de beneficio de la empresa minera Mexicana de Cobre S.A. de C.V., ubicada en la región del Noroeste de México en la población de Nacozari de García, Sonora, México, en el periodo 2013-2015. Se realizó una evaluación correlacional, para medir el grado de relación que existe entre los conceptos y variables del contexto de la investigación. 
La empresa ha reducido su personal al mínimo y ha eliminado totalmente el tiempo extra, así como el factor que no está considerado como parte de las estrategias, pero que ha contribuido en la afectación de la productividad de las plantas, como la rotación del personal y el incremento del índice de personal sin experiencia, lo cual ha evitado llevar a cabo un buen mantenimiento (MPRED, MPREV y MCORR) en los equipos de proceso e instalaciones de las plantas, situación que podría tener consecuencias trascendentales a corto, mediano y largo plazo.

Desde inicio de sus operaciones ha acudido a la subcontratación en las áreas de servicios, que corresponde a MPREV y MCORR, por lo tanto, no existe una cultura de aplicación de esta herramienta en las actividades de mantenimiento de equipos de proceso que ayudaría aumentar el nivel de disponibilidad de los mismos.

\section{Objetivos de la investigación}

\section{Objetivo general}

Determinar cómo el establecimiento del OUTG influye en el nivel de MANTTO, la disposición de los equipos de proceso de la planta beneficio (productividad, recursos humanos, situación actual) y el costo de mantenimiento (mano de obra, materiales, componentes y tecnología) que se lleva internamente en la empresa, generando ventajas competitivas en el caso de Mexicana de Cobre, S.A. de C.V. y replicarse en empresas mineras.

\section{Definición de las hipótesis de investigación}

\section{Hipótesis General}

La inserción de la herramienta del OUTG en el MANTTO de los equipos de proceso de la planta beneficio, en el nivel de mantenimiento predictivo, preventivo y correctivo, se relaciona directamente con el nivel actual de MANTTO, mientras que con el costo de mantenimiento se relaciona indirectamente con el nivel actual de MANTTO.

Con base en lo anterior, en la figura 1 se esquematizan las interrelaciones entre variables que participan en la investigación.

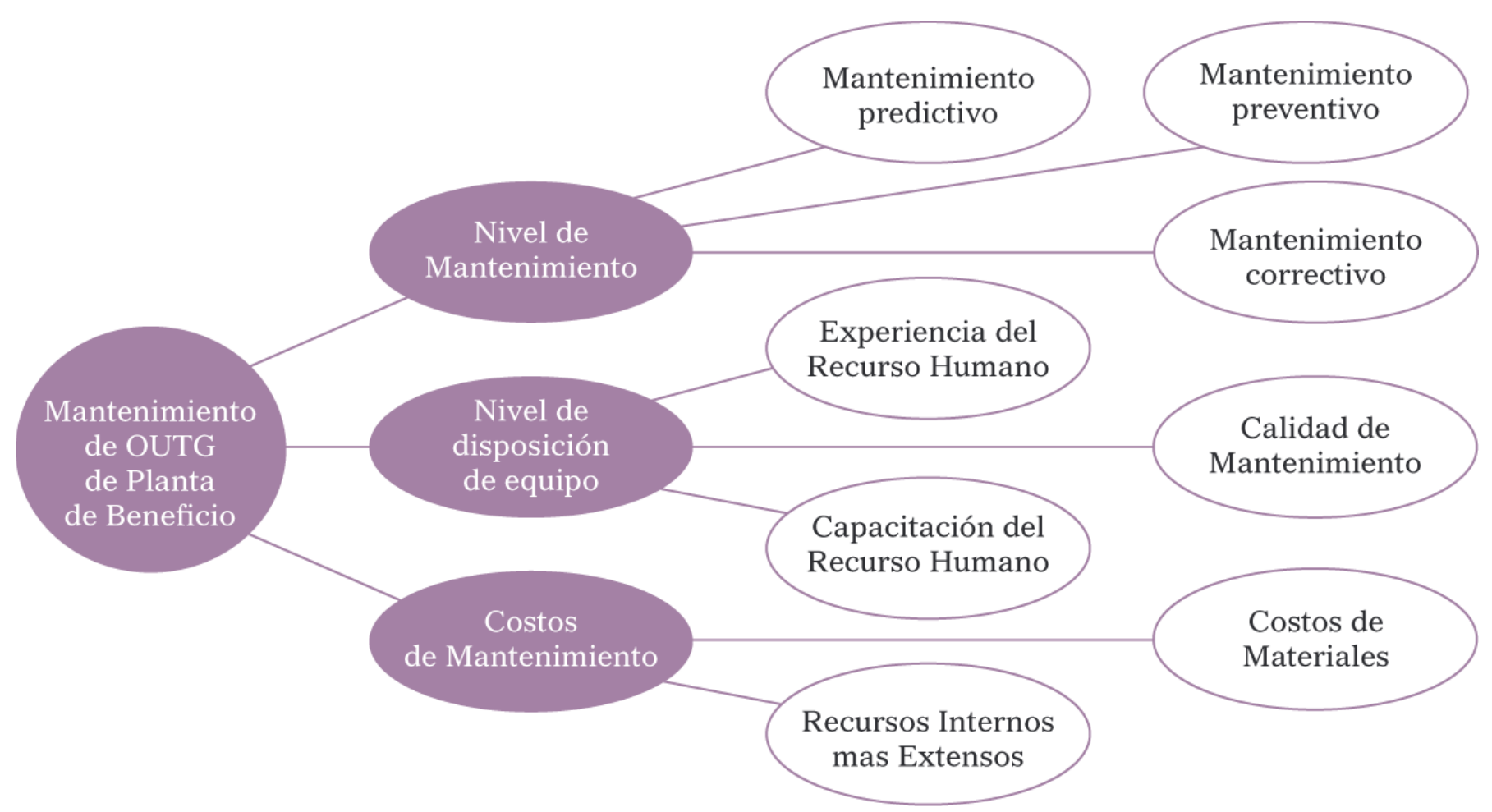

Figura 1. Modelo propuesto para la valoracion del OUTG.

Fuente: elaboración propia utilizando el paquete AMOS. 


\section{Instrumentos de recolección de datos}

\section{Cuestionario}

Para recopilar datos primordiales del estudio se utilizó como herramienta el cuestionario, diseñado con un total de 42 preguntas (ver anexo 1) y una Escala de Likert del 1 al 5, con un intervalo de 1 hasta 20, seccionado de cuatro en cuatro (tabla 3 ) con la finalidad de tener una acentuación más exacta de la respuesta del personal involucrado directamente en el MANTTO de los equipos de proceso.

\section{Tabla 3}

Escala Likert

$\begin{array}{ccccc}1 & 2 & 3 & 4 & 5 \\ 1234 & 5678 & 9101112 & 13141516 & 17181920\end{array}$

En el trabajo de campo, se realizó una prueba piloto, consistente en aplicar los cuestionarios al personal (10 personas), lo cual nos permitió mejorar la entrevista y el cuestionario en la etapa definitiva. Cabe aclarar que para validar la confiabilidad del cuestionario se utilizó el paquete estadístico SPSS (Satatistic Package Social Science) versión 16.1 y obtuvimos el coeficiente alfa de Cronbach y arrojó un valor de .89, lo que expresa una consistencia interna y alta confiabilidad.

Para la encuesta, la disposición de personal para participar directamente en el MANTTO por nivel en términos numéricos, es de 2 superintendentes, 6 jefes de área, 11 jefes de departamento y 1 supervisor, en total 20 personas.

\section{Definición del universo y selección de la muestra} Valores

$\mathrm{N}$ = tamaño de la población (20 personas )

$\mathrm{S}^{2}=$ varianza de la muestra

$\mathrm{Se}=$ error estándar $=.015$

$\mathrm{V}^{2}=$ varianza de la población

n' = tamaño de la muestra sin ajustar

$\mathrm{n}=$ tamaño de la muestra

Sustituyendo valores tenemos que:

Mantenimiento

$$
\begin{array}{ll}
\mathrm{S}^{2}=\mathrm{p}(1-\mathrm{p}) & \mathrm{S}^{2}=0.9(1-0.9)=0.09 \\
\mathrm{~V}=(\mathrm{Se})^{2} & \mathrm{~V}=(.15)^{2}=0.000225 \\
\mathrm{n}^{\prime}=\frac{\mathrm{S}^{2}}{\mathrm{~V}^{2}} & \\
\mathrm{n}^{\prime}=\frac{0.09}{0.000225}
\end{array}
$$




$$
\begin{gathered}
\mathrm{n}^{\prime}=400 \\
\mathrm{n}=\frac{\mathrm{n}^{\prime}}{1+\mathrm{n}^{\prime} / \mathrm{N}} \\
\mathrm{n}=400 \\
1+400 / 20 \\
\mathrm{n}=19.05
\end{gathered}
$$

\section{Análisis de datos}

A continuación se presentan los datos obtenidos de los cuestionarios.

\section{Nivel de tipo de mantenimiento}

Aunado a la crisis de la empresa, cuando se realizó este estudio el nivel de mantenimiento predictivo seguía aún predominando con un $54.75 \%$, seguido por el mantenimiento preventivo con un $52.75 \%$ y el mantenimiento correctivo con un $31.50 \%$, por todo lo anterior se observa una correcta programación de los tres tipos de mantenimiento adecuado.

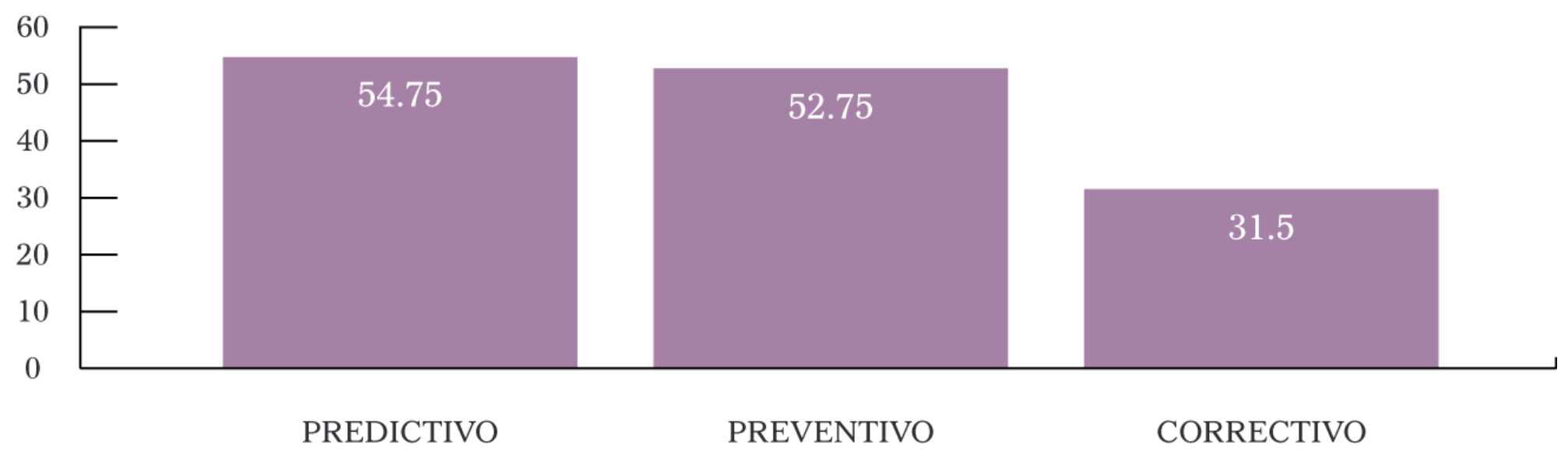

Figura 2. Tipos de matenimiento en los niveles de mantenimiento.

a. Eficiencia

Aún con la situación que prevalece en la empresa, en la fecha que se realizó el estudio predominan los paros programados de un $88.75 \%$ seguido por la variable de paros de fallas ocultas de un $86.25 \%$, paros imprevistos del $85 \%$ y finalmente paros frecuentes de fallas del $84.75 \%$, por lo tanto se refleja un nivel alto de eficiencia de los equipos.

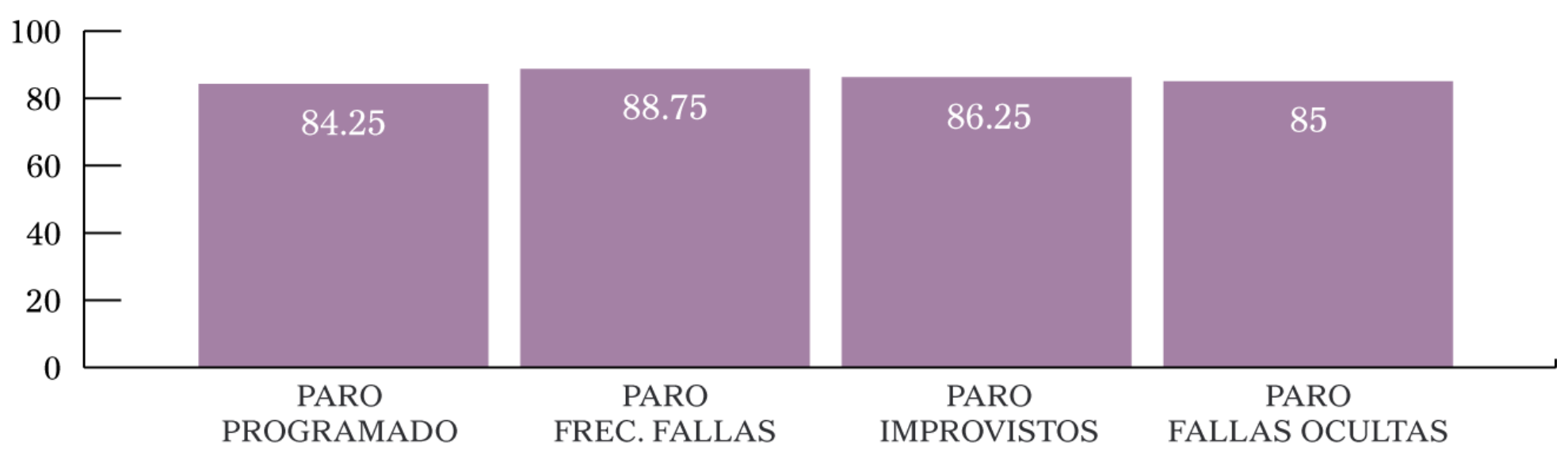

Figura 3. Eficiencia de los equipos en los niveles de mantenimiento. 
a. Productividad

De acuerdo al porcentaje de programación oportuna de mantenimiento de un $86.25 \%$ se define que la productividad es aceptable.

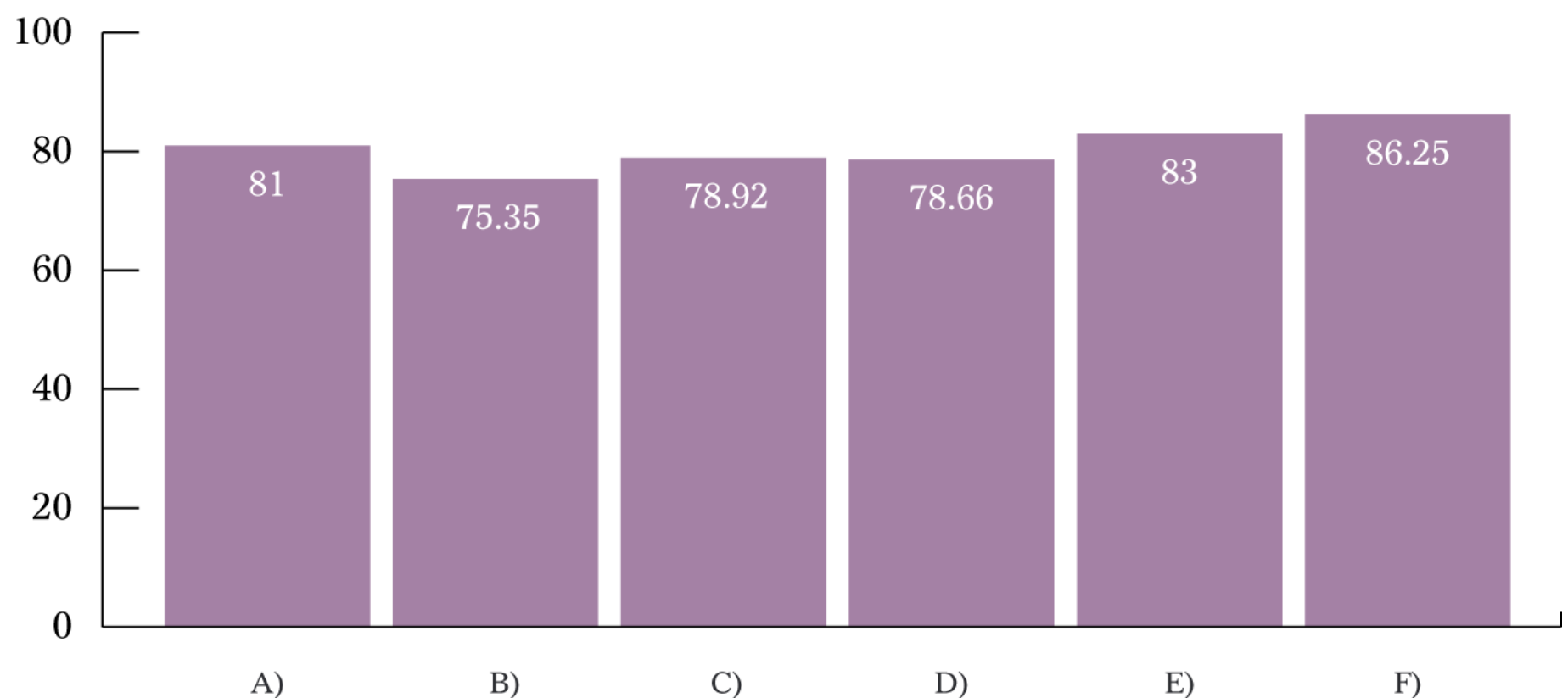

Figura 4. Productividad de los niveles de disponibilidad de equipos.

Clave: A) Productividad B) Satisfacción C) Calidad D) Rendimiento

E) Templazo de componentes de equipo F) Programación oportuna

b. Recursos humanos

De acuerdo al estudio se observa un promedio de 13.50 años en la antigüedad de los trabajadores que, traduciendo los datos a la escala Likert, de un 13.50 años promedio de antigüedad de los empleados nos da una puntuación del 3.50.

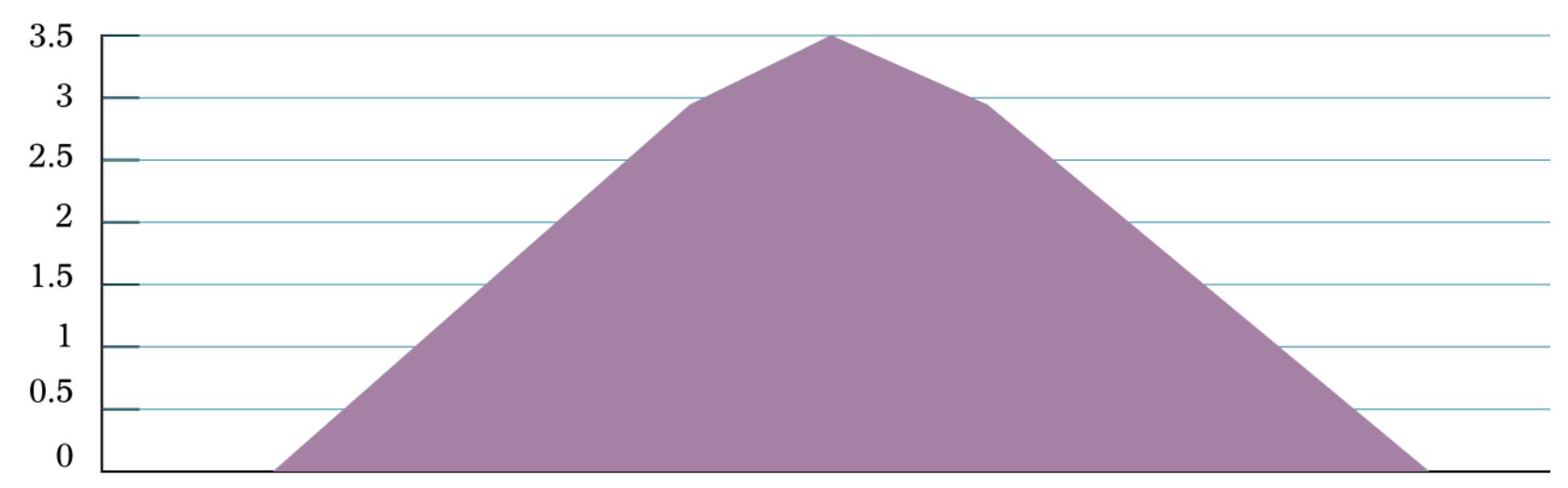

Figura 5. Escala Licker de recursos humanos de los niveles de disponibildad de equipos.

De acuerdo a las variables analizadas de recursos humanos, se observa que existe un alto porcentaje de integración de equipo de trabajo $(81.25 \%)$, e índice de higiene y (72.36 $\%)$ y bajo porcentaje de retroalimentación de reporte de desempeño (42\%), motivación $(48.25 \%$ ) y capacitación (59.75\%). Por lo tanto se deberá buscar una suavización de motivación y disminuir el índice de seguridad, así como exigencia de reportes de desempeño y mayor integración de equipo. 

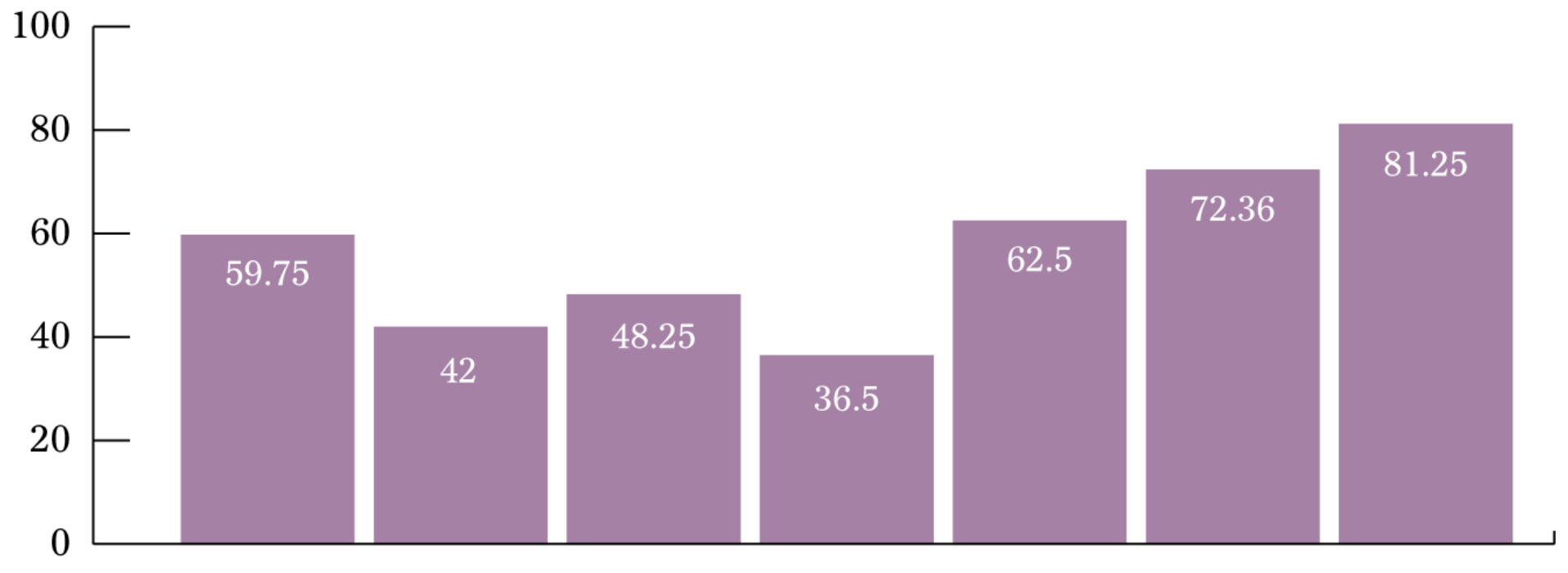

A)

B)

C)

D)

E)

F)

G)

Figura 6. Variables de recursos humanos.

Clave: A) Capacitación B) Reporte de Desempeño C) Motivación del Personal D) Ausentismo

E) Rotación de Personal F) Higiene y Salud G) Integración de equipos de Trabajow

c. Materiales, componentes y tecnología

Se consideran bajos los niveles de disponibilidad de materiales y componentes; los porcentajes de nivel de inventarios y suministro oportuno son de $65.25 \%$ y $65.75 \%$, respectivamente.

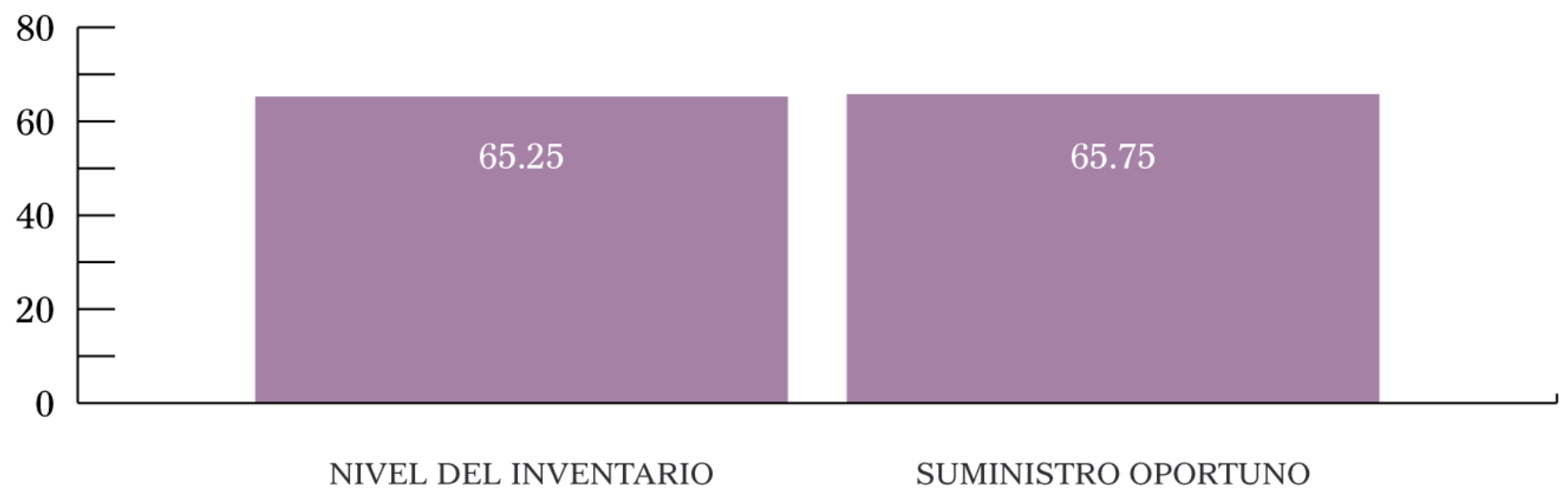

Figura 7. Disponibilidad de materiales y componentes.

Se consideran bajos los niveles de disponibilidad de tecnología. Los porcentajes de nivel de inventarios y suministro oportuno son de $65.25 \%$ y $65.75 \%$, respectivamente.

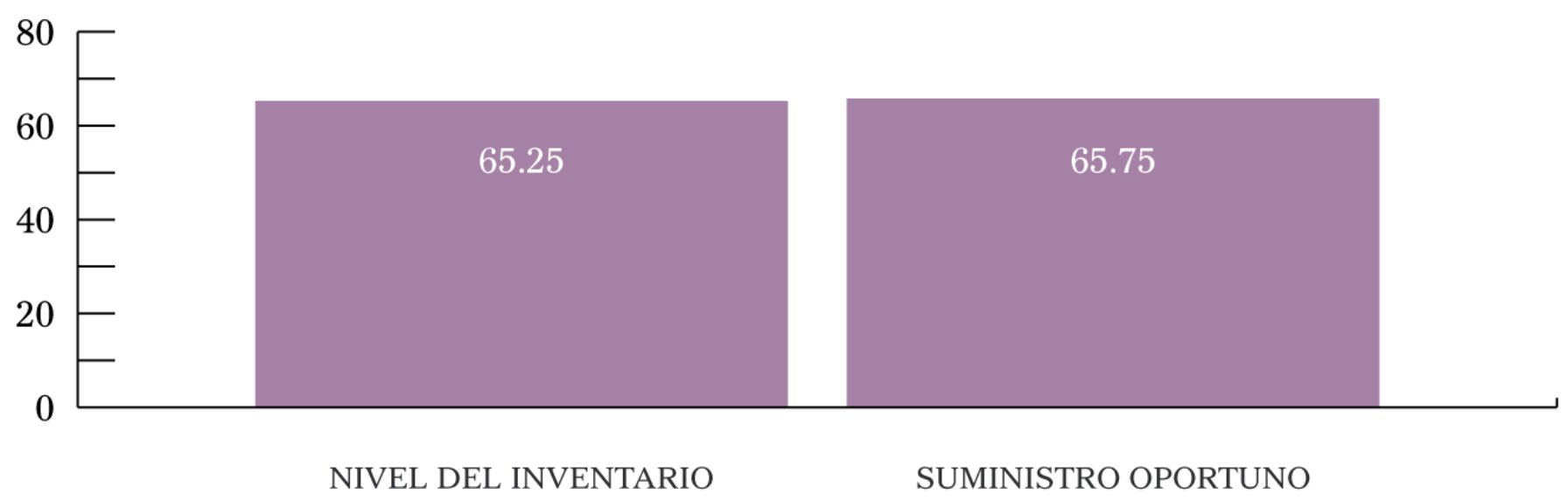

Figura 8. Disponiblidad de tecnología. 


\section{Costos de mantenimiento}

Los costos de mantenimiento son más elevados con recursos internos que con recursos externos. En la figura 9 se observa que los porcentajes de los costos de mantenimiento con recursos externos de mano de obra $(22.50 \%)$, materiales $(32.50 \%)$ y componentes $(32.00$ $\%)$ son mucho menores que los porcentajes de los costos de mantenimiento con recursos internos de mano de obra (71.25\%), materiales $(72.25 \%)$ y componentes $(71.25 \%)$.

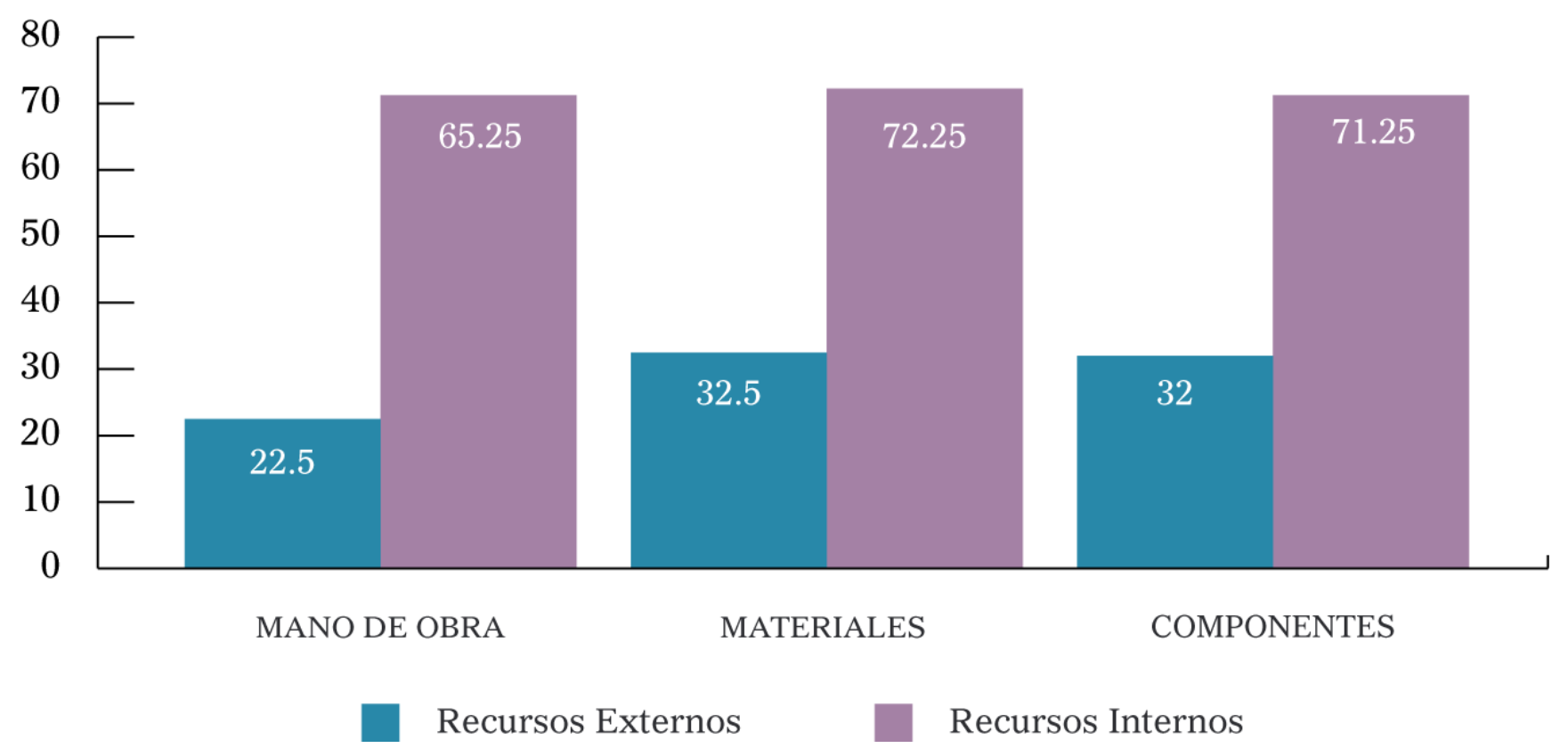

Figura 9. Comparativa de costos de recursos internos y exteronos sobre los costos de matenimiento.

\section{Coeficiente de correlación ( $r$ ) y de determinación $\left(r^{2}\right)$}

El criterio utilizado para esta investigación para interpretar la correlación bivariada es con el nivel de significancia menor o igual a $5 \%(\mathrm{P}<5 \%)$ que es cuando un conjunto de datos caen en el área de aceptación de la distribución normal y significa que influye en la variable dependiente y el valor del coeficiente de Pearson toma un valor de $-1<r<+1$ y el coeficiente de determinación de $0<r^{2}<1$.

\section{Tabla 4}

Interpretación de los valores de $r$

\begin{tabular}{cc} 
Valores de $r$ & Interpretación \\
$r<.20$ & Correlación leve, casi insignificante. \\
\hline$r$ de .20 a .40 & Baja correlación, definida, pero baja. \\
\hline$r$ de .40 a .70 & Correlación moderada, sustancial. \\
\hline$r$ de .70 a .90 & Correlación marcada, alta. \\
\hline$r$ de .90 a 1.00 & Correlación muy alta, muy significativa. \\
\hline
\end{tabular}

Con los datos obtenidos a continuación se presenta la matriz de correlación de Pearson ( $r$ ) para las variables independientes. 
Tabla 5

Matriz de Correlación de las variables independientes y la variable dependiente NIVMTTO

\begin{tabular}{ccccc} 
& & NIVMTTO & EFICIENC & TIPOMTTO \\
& NIVMTTO & 1.000 & 0.592 & 0.774 \\
\cline { 2 - 5 } Pearson & EFICIENC & 0.592 & 1.000 & -0.051 \\
\cline { 2 - 5 } & TIPOMTTO & 0.774 & -0.051 & 1.000 \\
\hline \multirow{3}{*}{ NIVMTTO } & - & 0.003 & 0.000 \\
\hline
\end{tabular}

Nota: Información obtenida de la investigación de campo. NIVMTTO = nivel de mantenimiento; EFICIENC = eficiencia; TIPOMTTO = tipo de mantenimiento.

Existe una correlación marcada alta en el nivel de mantenimiento con los tipos de mantenimiento (predictivo, preventivo y correctivo).

Tabla 6

Matriz de correlación de las variables independientes de la variable dependiente DISPEQUIPO

\begin{tabular}{cccccc} 
& DISPEQUI & PRODUCTI & RECHUMAN & MATECOMP & TECNOLOG \\
DISPEQUI & 1.000 & .864 & .772 & .649 & .593 \\
\hline PRODUCTI & .864 & 1.000 & .532 & .458 & .372 \\
\hline RECHUMAN & .772 & .532 & 1.000 & .301 & .167 \\
\hline MATECOMP & .649 & .458 & .301 & 1.000 & .478 \\
\hline TECNOLOG & .593 & .372 & .167 & .478 & 1.000 \\
\hline
\end{tabular}

Nota: Información obtenida de la investigación de campo. DISPEQUI = disponibilidad de equipos; PRODUCTI = productividad RECHUMAN = recursos humanos; MATECOMP = materiales y componentes; TECNOLOG = tecnología.

Se refleja una correlación marcada alta entre las variables independientes productividad (0.864) y recursos humanos (0.772) versus la variable dependiente disponibilidad de equipo, así mismo se observa una correlación moderada sustancial en las variables independientes materiales y componentes (0.649) y tecnología (0.593) versus la variable dependiente. Por lo tanto las demás variables son no significativas.

Se refleja una correlación marcada alta entre las variables independientes como recursos internos $(0.728)$ versus la variable dependiente. Y una correlación moderada sustancial de la variable independiente pérdidas (0.551) versus la variable dependiente.

La matriz de correlación trata de identificar el contenido de las variables que explican el parámetro de correlación, también para reducir los datos e identificar un pequeño número de factores mejor que la correlación observada en un gran número de variables manifestadas. Para los datos de esta investigación se utilizó el paquete SPSS versión 16.21 para el análisis de correlación de extracción, con el criterio del principal componente. 
Tabla 7

Matriz de correlación de las variables independientes de la variable dependiente COSTOS

\begin{tabular}{cccccc} 
& & COSTOS & RECEXTER & RECINTER & PÉRDIDAS \\
\cline { 2 - 6 } Pearson & COSTOS & 1.000 & .362 & .728 & .551 \\
\cline { 2 - 6 } & RECEXTER & .362 & 1.000 & .081 & -.094 \\
\cline { 2 - 6 } & RECINTER & .728 & .081 & 1.000 & -.045 \\
\cline { 2 - 6 } & PÉRDIDAS & .551 & -.094 & -.045 & 1.000 \\
\hline
\end{tabular}

Nota: Información obtenida de la investigación de campo. RECEXTER = recursos externos; RECINTER = recursos internos.

\section{Conclusiones y recomendaciones}

Basado en la metodología empleada y los resultados obtenidos en el caso Mantenimiento de los Equipos de proceso de la Planta de Beneficio de Mexicana de Cobre, S.A. DE C.V. se podrá implementar en otras plantas de este sector. Los objetivos primordiales de esta investigación fue conocer en qué nivel se encuentran los tres tipos de MANTTO y en qué medida influye el nivel de disponibilidad de los equipos y los costos de MANTTO al aplicar la herramienta del OUTG. Lo cual confirma o cambia el camino estratégico actual de MANTTO de los equipos de proceso de la planta de beneficio basada en la hipótesis general implementada para este caso.

Una vez analizados los datos se observa que el nivel de tipo de mantenimiento predictivo sigue aún predominando con respecto a los demás, dando por consecuencia una correcta programación de MANTTO y un nivel alto de eficiencia de los equipos, debido a que los paros programados sobresalen con respecto a las demás variables independientes analizadas.

Con respecto al nivel de disponibilidad de equipos, la productividad se considera que es aceptable, con una antigüedad de mano de obra de 13.5 años, traduciéndolo a la escala de Likert de 3.50 considerándose en un rango de bueno. Por otro lado se refleja un alto porcentaje de integración de equipos de trabajo y seguridad en los trabajos a realizar. Sin embargo, los porcentajes de retroalimentación de reportes de desempeño, motivación y capacitación se consideran bajos. Y los materiales, componentes y tecnología también se consideran bajos con respecto a la disponibilidad de estos puntos. Los costos de mantenimiento con recursos internos versus recursos externos son más elevados.

Una vez realizadas las matrices de correlación para las variables independientes de las tres variables dependientes, se obtuvo que para la variable dependiente nivel de mantenimiento existe una correlación marcada alta con respecto a los tipos de mantenimiento.

Para la variable dependiente disponibilidad de equipo versus la variable independiente productividad y recursos humanos existe una correlación marcada alta.

Con referencia a la variable dependiente costos de mantenimiento versus la variable independiente recursos internos se refleja una correlación marcada alta. 
Por último, en la regresión múltiple para la variable dependiente costos todas las variables son diferentes a 0 por lo tanto influyen en los costos de mantenimiento, sobre todo el indicador de rendimientos interno de mano de obra. Por todo lo anterior concluimos que la inclusión del OUTG es aceptada para que el mantenimiento de los equipos pueda realizarse con recursos externos de la empresa, siempre y cuando los niveles de mantenimiento, disponibilidad de los equipos y los costos de mantenimientos se mantengan o mejoren los estándares que la empresa desearía para ser más competitivos en ese nicho de mercado. 


\section{Referencias}

Aguilar, A., López,V., Cabral, A., Alvarado, L., Alvarado, T., \& Moreno, S. (2011). La técnica de la consultoría externa (“Outsourcing") en la administración de los agronegocios. Revista Mexicana de Agronegocios, XV(29), 775-785. Recuperado de http://www. redalyc.org/pdf/141/14119052015.pdf

Bragg, S. (2000). Outsourcing. A Guide To... Selecting the Correct Business Unit... Negotiating the Contract... Maintaining Control of the Process. Nueva York: Wiley.

Hendry, J. (1996). El costo oculto del Outsourcing. Revista Gestión, 1(2), 116-123.

Martínez, I. (2009). Diseño de un modelo para aplicar el mantenimiento productivo total a los sectores de bienes y servicios. (Tesis de Maestría). Instituto Politécnico Nacional, Ciudad de México. Recuperado de http://tesis.ipn.mx:8080/xmlui/bitstream/ handle/123456789/5992/1447.pdf?sequence=1\&isAllowed=y

Romero, I. (2013). Elaboración de procedimientos de encendido y apagado para mantenimiento preventivo. (Memoria para obtener el título de Técnico Superior). Universidad Tecnológica de Querétaro, Santiago de Querétaro, México.

Rothery, B., \& Roberson, I. (1997). Outsourcing. Ciudad de México: Limusa.

Sica, D.E., Scarlan, M.A., Rossini, D.E., Beinstein, J., \& Figueroa, D.E. ( 2014). El futuro del sector automotriz en el mundo 2025: fuerzas impulsoras y tecnologías clave para su desarrollo en el marco de políticas que promuevan la calidad de vida y la conservación del medio ambiente y de los recursos naturales. Buenos Aires: Ministerio de Ciencia, Tecnología e Innovación Productiva.

Tavares, L.A. (2000). Administración moderna de mantenimiento. Recuperado de http:// www.cosego.com.ar/Principal/Libro\%201.htm 


\section{ANEXO 1 \\ CUESTIONARIO}

El objetivo de esta investigación es si la inserción del Outsourcing en el mantenimiento de los equipos de proceso incide en el nivel de disponibilidad de los equipos, así como en sus costos.

Datos generales:

Nombre de la empresa

Unidad

Planta

Nombre del entrevistado

Puesto

Disciplina

Se le pide contestar sobre una escala del 1 al 20 de la siguiente manera:

NUNCA -A VECES - BAJA FRECUENCIA- FRECUENTEMENTE-EXCELENTE

\begin{tabular}{lccccc}
\hline 1234 & 5678 & 9101112 & 13141516 & 17181920 \\
\hline NULO & BAJO & MEDIO BAJO MEDIO ALTO ALTO
\end{tabular}

\section{EFICIENCIA}

1. Del mantenimiento programado, sus actividades se concluyen en su totalidad, a tiempo.

2. El nivel de frecuencia y el nivel de mantenimiento imprevisto no programados es

3. El nivel de fallas ocultas es:

\section{TIPOS DE MANTENIMIENTO}

4. Actualmente, cual es el nivel de los tres tipos de mantenimiento.

\section{PRODUCTIVIDAD}

5. El mantenimiento programado se inicia, termina y se lleva a cabo a tiempo.

6. Como considera el grado de satisfacción del cliente:

7. Bajo las actuales circunstancias ¿qué grado de satisfacción Usted contempla

en trabajo de mantenimiento una vez que se realiza?

8. ¿ Qué grado en términos de satisfacción Ud. Desearía como mínimo

en su área de responsabilidad para aplicar al mantenimiento que se realiza?

9. ¿Cómo considera actualmente la calidad de mantenimiento en los tres tipos?.

10. ¿Cómo considera actualmente el rendimiento en mano de obra para el mantenimiento?

11. ¿Como considera actualmente el rendimiento en materiales para llevar

a cabo el mantenimiento?

12. Como afecta el mantenimiento correctivo?

13. El índice de reemplazo de componentes o equipo antes de su vida útil es:

14. La programación actual de mantenimiento ¿considera que está dentro en los tiempos de tolerancia para cumplir con la vida útil de los equipos?

\section{RECURSOS HUMANOS}

15. Antigüedad promedio del trabajador en la empresa por categorías: Años.

16. ¿Qué grado promedio académico tiene el personal a su cargo?

PRIMARIA SECUNDARIA PREPARATORIA LICENCIATURA MAESTR. 
17. ¿Qué grado de conocimientos prácticos, promedio cuenta el personal a su cargo?

18. La capacitación de personal en mantenimiento ¿cómo la considera actualmente

19. ¿Los obreros reciben periódicamente reportes por escrito de desempeño

y productividad?

20. La motivación de personal ¿cómo la consideras?

21. El nivel de ausentismo ¿cómo lo considera?

22. La rotación de personal ¿cómo se considera?

23. El índice de accidentes ¿cómo lo considera?

24. La seguridad para realizar el mantenimiento ¿Cómo es?

25. ¿Cómo considera la capacidad de integración del personal a equipos de trabajo?

\section{MATERIALES Y COMPONENTES}

26. El nivel de inventarios de materiales y componentes.

27. El suministro de materiales y componentes para llevar a cabo un mantenimiento es.

\section{TECNOLOGÍA}

28. ¿Cómo considera la tecnología como herramienta para lleva a cabo el mantenimiento a través de la subcontratación?

29. La innovación tecnológica para el mantenimiento dentro de la empresa ¿cómo la considera?

30. El índice de modificación de equipos durante su vida útil.

31. ¿Cómo considera las herramientas de trabajo para realizar el mantenimiento actualmente?

32. ¿Como considera las herramientas de trabajo para realizar el mantenimiento actualmente?

\section{RECURSOS EXTERNOS}

33. ¿Qué apreciación tiene Ud. en cuanto a control de costo en mano de obra, si se lleva el mantenimiento a través de la subcontratación?

34. ¿Qué apreciación tiene Ud. en cuanto a control de costo en materiales, si se lleva el Mantenimiento a través de la subcontratación?

35. ¿Qué apreciación tiene Ud. en cuanto a control de costo en componentes, si se lleva el mantenimiento a través de la subcontratación.

\section{RECURSOS INTERNOS}

36. ¿Qué apreciación tiene Ud. en cuanto a control de costo en mano de obra, si se lleva el mantenimiento con recursos internos de la empresa?

37. ¿Qué apreciación tiene Ud. en cuanto a control de costos en materiales, si se lleva el mantenimiento con recursos internos de la empresa?

38. ¿Qué apreciación tiene Ud. en cuanto a control de costos en componentes si se lleva el mantenimiento con recursos internos de la empresa?

39. ¿Cómo considera el costo en la puesta en marcha de los equipos con respecto al costo de producción?

40. ¿Cómo considera el costo promedio de defecto de calidad con respecto al costo de mantenimiento?

41. ¿Cómo considera el costo promedio de paros de los equipos con respecto al costo de producción?

42. La frecuencia de marcha en vacío ¿cómo lo considera? 


\section{Capítulo 5}

Fórmula para determinar la conveniencia del endeudamiento a largo plazo en una empresa

José María Güereña de la Llata 
José María Güereña de la Llata, Universidad de Sonora jmguerenall@pitic.uson.mx 


\section{Capítulo 5}

\section{Fórmula para determinar la conveniencia}

\section{del endeudamiento a largo plazo en una empresa}

\section{Introducción}

El propósito de este trabajo es el de presentar una fórmula que permita a las empresas determinar el mínimo nivel de ventas que se requiere para que le sea viable pedir crédito. Ésta es una aportación totalmente nueva, ya que hasta ahora, este problema se resuelve con una serie de igualdades que se prestan a confusión, como se presenta más adelante, de allí la conveniencia de idear una forma más fácil de resolver esta situación, ya que es común que en caso de necesidad de financiamiento se recurra a deuda y ello no siempre le conviene a la empresa.

El criterio que se utilizó es el de considerar como mejor opción de financiamiento a aquella que maximice la utilidad por acción.

\section{Objetivo}

Diseño de una fórmula totalmente nueva que sirva para determinar la conveniencia del endeudamiento a largo plazo como forma de financiamiento.

\section{Metodología}

En la elaboración de este trabajo se utilizó el método descriptivo y de diseño transversal. Primeramente veremos un ejemplo de manera ilustrativa, para ver el efecto del endeudamiento en el rendimiento del capital contable, el de los dueños en otras palabras, y después se procederá a determinar la mejor alternativa de financiamiento para una empresa en marcha, siendo en esta segunda parte donde veremos la fórmula diseñada para determinar la viabilidad del endeudamiento como forma de financiamiento.

\section{Efecto del riesgo financiero sobre el rendimiento del capital contable}

En esta primera parte se ilustra el efecto del riesgo financiero causado por el endeudamiento sobre las utilidades de los accionistas, considerando en el ejemplo el caso de tres empresas del mismo tamaño y giro, una llamada "A" que no tiene endeudamiento alguno, otra "B" que considera un endeudamiento del $50 \%$ del activo total y la tercera la llamamos "C" cuyo endeudamiento es del $80 \%$. Nuestro análisis lo haremos a partir de la utilidad antes de intereses e impuestos (UAII) suponiendo la tasa del impuesto sobre la renta (ISR) del $40 \%$ en todos los casos, viendo el impacto del grado de endeudamiento sobre las utilidades de los accionistas. 
Tabla 1

Ejemplo de endeudamiento en tres empresas del mismo tamaño y giro

\begin{tabular}{lrrr} 
& \multicolumn{2}{c}{ A } & B \\
Activo Total & $\$ 1000$ & $\$ 1000$ & $\$ 1000$ \\
\hline Pasivo Total (15\% interés) & 0 & 500 & 800 \\
\hline Capital Contable & $\$ 1000$ & $\$ 500$ & $\$ 200$ \\
\hline
\end{tabular}

Tabla 2

Primer caso: suponiendo una UAII de \$120 para las tres empresas

\begin{tabular}{lrrr} 
& \multicolumn{2}{c}{ A } & C \\
UAII & $\$ 120$ & $\$ 120$ & $\$ 120$ \\
\hline Intereses & 0 & 75 & 120 \\
\hline Utilidades Antes de Impuestos & 120 & 45 & 0 \\
\hline Impuestos (40\%) & 48 & 18 & 0 \\
\hline Utilidad Neta & 72 & 27 & 0 \\
\hline + Capital Contable & 1000 & 500 & 200 \\
\hline Rendimiento del Capital Contable & $7.2 \%$ & $5.4 \%$ & $0.0 \%$ \\
\hline & $\uparrow$ & &
\end{tabular}

Tabla 3

Segundo caso: considerar la UAII de $\$ 200$

\begin{tabular}{lrrr} 
& \multicolumn{2}{c}{} & $\mathrm{C}$ \\
UAII & $\$ 200$ & $\$ 200$ & $\$ 200$ \\
\hline Intereses & 0 & 75 & 120 \\
\hline Utilidades Antes de Impuestos & 200 & 125 & 80 \\
\hline Impuestos & 80 & 50 & 32 \\
\hline Utilidad Neta & 120 & 75 & 48 \\
\hline+ Capital Contable & 1000 & 500 & 200 \\
\hline Rendimiento del Capital Contable & $12 \%$ & $15 \%$ & $24 \%$ \\
\hline & & & 个
\end{tabular}


Tabla 4

Tercer caso: considerar la UAII de \$150

\begin{tabular}{lrrr} 
& \multicolumn{2}{c}{$\mathrm{A}$} & $\mathrm{C}$ \\
UAII & $\$ 150$ & $\$ 150$ & $\$ 150$ \\
\hline Intereses & 0 & 75 & 120 \\
\hline Utilidades Antes de Impuestos & 150 & 75 & 30 \\
\hline Impuestos & 60 & 30 & 12 \\
\hline Utilidad Neta & 90 & 45 & 18 \\
\hline+ Capital Contable & 1000 & 500 & 200 \\
\hline Rendimiento del Capital Contable & $9 \%$ & $9 \%$ & $9 \%$ \\
\hline
\end{tabular}

Por lo tanto, antes de decidir cuál financiamiento es el más adecuado para una empresa, debemos conocer su poder de ganancia básica (PGB) y ver si es mayor o menor al costo del dinero en el caso de endeudamiento. El PGB se obtiene dividiendo la utilidad antes de intereses e impuestos entre el activo total (UAII/AT) y representa el rendimiento que se está obteniendo con el efectivo invertido en la empresa, que obviamente deberá ser mayor que el costo del dinero.

\section{Primer caso}

El Poder de Ganancia Básica (PGB) es de $120 \div 1000=12 \%$, representando el rendimiento que se obtendría con el efectivo que se invirtiese en la empresa, pero considerando que el costo del dinero (intereses) es del $15 \%$, por lo que no sería conveniente endeudarse, ya que por cada peso de deuda tendríamos un déficit de 3 centavos, por ello, la mejor alternativa fue la de la empresa "A", ya que es la de menor deuda. En conclusión diremos que si el PGB es menor al interés, lo mejor sería NO ENDEUDARSE.

\section{Segundo caso}

El Poder de Ganancia Básica es de: $200 \div 1000=20 \%$ y el costo del dinero $15 \%$, por lo que aquí se obtendría un rendimiento de $5 \%$ en cada peso que se pidiera prestado, por ello se selecciona como la empresa mejor financiada a "C", ya que es la de mayor deuda. Obviamente tendríamos que hacer un flujo de efectivo para asegurarnos que habría efectivo suficiente para cubrir los intereses y los pagos de principal. Se puede concluir diciendo que si el PGB es mayor al costo del interés, la mejor sería SÍ ENDEUDARSE.

\section{Tercer caso}

El Poder de Ganancia Básica es de $150 \div 1000=15 \%$, misma cantidad que se ve en el costo de los intereses, por lo que si se pide prestado un peso con el $15 \%$ de intereses y se obtiene una ganancia del 15\% también, entonces ni se ganaría ni perdería con el crédito. Concluyendo diríamos que si el PGB = intereses, es INDIFERENTE cómo se financie la empresa. 


\section{Determinación de la mejor alternativa de financiamiento a largo plazo}

Ahora iremos al tema central de este capítulo, que es el caso de empresas en marcha que requieren financiamiento a largo plazo, que es para lo que se desarrolló la fórmula que se presentará.

En finanzas corporativas como en cualquier área de la administración de empresas, se considera como la mejor alternativa la que maximice el rendimiento de los dueños o accionistas en el largo plazo, por supuesto con ética y responsabilidad social. Para medir lo anterior, la mejor opción es la utilidad por acción.

Para proceder a determinar cuál es la mejor alternativa de financiamiento a largo plazo, se necesita tener el estado de resultados de los últimos 365 días o, en su caso, 12 meses, requiriéndose además conocer cuál es la cantidad a financiarse. A manera de ejemplo supondremos lo siguiente:

La compañía Industrial Sonorense, S. A. se encuentra en un proceso de reingeniería con un costo de $\$ 40000$ 000. Su último estado de resultados se muestra en la tabla 5.

Tabla 5

Estado de resultados de "Industrial Sonorense, S.A."

\begin{tabular}{lr}
\hline Ventas & $\$ 190000000$ \\
\hline Costos Variables (45\%) & 8550000 \\
\hline Margen de Contribución & 104500000 \\
\hline Costos Fijos & 62000000 \\
\hline Utilidad antes de intereses e impuestos & 42500000 \\
\hline Intereses & 18000000 \\
\hline Utilidad antes de impuestos & 24500000 \\
\hline Impuestos (40\%) & 9800000 \\
\hline Utilidad neta & 14700000 \\
\hline+ Número de Acciones Comunes & 1000000 \\
\hline Utilidad por Acción & 14.70 \\
\hline
\end{tabular}

Con el equipo nuevo, más eficiente que el anterior, los costos variables se reducirían a un $41 \%$ de las ventas, mientras que los costos fijos se incrementarían a \$ 67000000 .

Alternativas para el financiamiento

1. Con un crédito de $\$ 32000000$ al $15 \%$ de interés y el resto con una emisión de acciones comunes que se podrían colocar a $\$ 250$ neto c/u.

2. Mitad deuda y mitad acciones comunes, en las mismas condiciones del punto anterior.

3. $\$ 10000000$ con deuda y el resto con acciones comunes.

4. Todo con acciones comunes. 
Si se espera un incremento en ventas del $10 \%$, ¿cuál alternativa de financiamiento es recomendable? Para poder seleccionar la mejor alternativa de financiamiento de la manera tradicional, tendríamos que ver cómo quedaría el estado de resultados con cada alternativa y escoger aquella que nos dé la mayor utilidad por acción.

Empezaremos calculando cuál es el interés total a pagar (000) con cada alternativa, así como también, el número de acciones que se tendrían.

Tabla 6

Cálculo del interés total

\begin{tabular}{lrrrr}
\multicolumn{1}{r}{ Alternativas } & 1 & 2 & 3 & 4 \\
Interés nueva deuda & $\$ 4800$ & $\$ 3000$ & $\$ 1500$ & $\$ 0$ \\
\hline+ interés actual & 18000 & 18000 & 18000 & 18000 \\
\hline Capital Contable & 22800 & 21000 & 19500 & 18000 \\
\hline
\end{tabular}

Tabla 7

Cálculo del total de acciones

\begin{tabular}{lrrrr}
\multicolumn{1}{c}{ Alternativas } & 1 & 2 & 3 & \multicolumn{1}{c}{4} \\
Acciones a emitirse & 32000 & 80000 & 120000 & 160000 \\
\hline Acciones actuales & 1000000 & 1000000 & 1000000 & 1000000 \\
\hline Total de Acciones & 1032000 & 1080000 & 1120000 & 1160000 \\
\hline
\end{tabular}

Con la información anterior, obtendremos los estados de resultados para cada alternativa: (miles de pesos).

Tabla 8

Estado de resultados para cada alternativa (miles de pesos)

\begin{tabular}{lr}
\hline Ventas & $\$ 209000$ \\
\hline Costos variables & 85690 \\
\hline Margen de Contribución & 123310 \\
\hline Costos Fijos & 67000 \\
\hline UAII & $\$ 56310$ \\
\hline
\end{tabular}

\begin{tabular}{lrrrr}
\multicolumn{1}{c}{ Alternativas } & \multicolumn{2}{c}{} & 3 & 4 \\
Intereses & 22800 & 21000 & 19500 & 18000 \\
\hline Utilidad antes de impuestos & 33510 & 35310 & 36810 & 38310 \\
\hline Impuestos & 13404 & 14124 & 14724 & 15324 \\
\hline Utilidad Neta & 20106 & 21186 & 22086 & 22986 \\
\hline+ Número de Acciones & 1032 & 1080 & 1120 & 1160 \\
\hline Utilidad por Acción & 19.48 & 19.62 & 19.72 & 19.82 \\
\hline
\end{tabular}


En el caso anterior podemos decir que la mejor alternativa de financiamiento es la 4, sin deuda, por ser la que ofrece una mayor utilidad por acción a los dueños de la empresa, pero haciendo la aclaración de que esto sucede cuando el nivel de ventas es de \$209000 000, ya que si cambiase el nivel de ventas podría cambiar la decisión.

Supondremos ahora un nivel de ventas de $\$ 220000000$.

\section{Tabla 9}

Estado de resultados para cada alternativa (miles de pesos)

\begin{tabular}{lr}
\hline Ventas & $\$ 220000$ \\
\hline Costos variables & 90200 \\
\hline Margen de Contribución & 129800 \\
\hline Costos Fijos & 67000 \\
\hline UAII & $\$ 62800$ \\
\hline
\end{tabular}

\begin{tabular}{lrrrr}
\multicolumn{1}{c}{ Alternativas } & 1 & 2 & 3 & \multicolumn{1}{c}{4} \\
Intereses & 22800 & 21000 & 19500 & 18000 \\
\hline Utilidad antes de impuestos & 40000 & 41800 & 43300 & 44800 \\
\hline Impuestos & 16000 & 16720 & 17320 & 17920 \\
\hline Utilidad Neta & 24000 & 25080 & 25980 & 26880 \\
\hline + Número de Acciones & 1032 & 1080 & 1120 & 1160 \\
\hline Utilidad por Acción & 23.26 & 23.22 & 23.20 & 23.17 \\
\hline
\end{tabular}

Como se puede ver en el ejemplo anterior, con ventas de $\$ 220000000$, la alternativa 1 , es decir, solicitar un crédito de $\$ 32000000$ de los $\$ 40000000$ que se necesitan, es la mejor opción aunque es la alternativa de mayor deuda.

Si se siguiera haciendo cálculos con distintos niveles de ventas, veríamos que cuando las ventas exceden cierta cantidad, la mejor alternativa siempre sería la de mayor deuda, en este caso, la alternativa 1, pero en el caso de que las ventas no alcanzaran dicho nivel, siempre la mejor alternativa de financiamiento sería la de menor deuda, la alternativa 4 en este ejemplo. Las alternativas intermedias, 2 y 3 en este caso, nunca serán las mejores.

Método gráfico

Se pueden expresar gráficamente los efectos de las distintas alternativas de financiamiento en la utilidad por acción.

Sería difícil determinar con precisión las ventas en el punto de equilibrio $(\mathrm{P} / \mathrm{E})$ respecto a utilidad por acción por el método gráfico, por lo que propongo utilizar una fórmula que desarrollé, la cual determina con exactitud ese punto de equilibrio, es decir, el mínimo nivel de ventas que se requiere para que sea conveniente endeudarse. También es mucho más fácil y rápido que el método tradicional que han seguido algunos autores de libros de finanzas como los que se mencionan en el método tradicional.

Tanto el método tradicional como el propuesto en este trabajo utilizan sólo dos alternativas: la de mayor deuda (D) y la de mayor acciones (A) o menor deuda. 


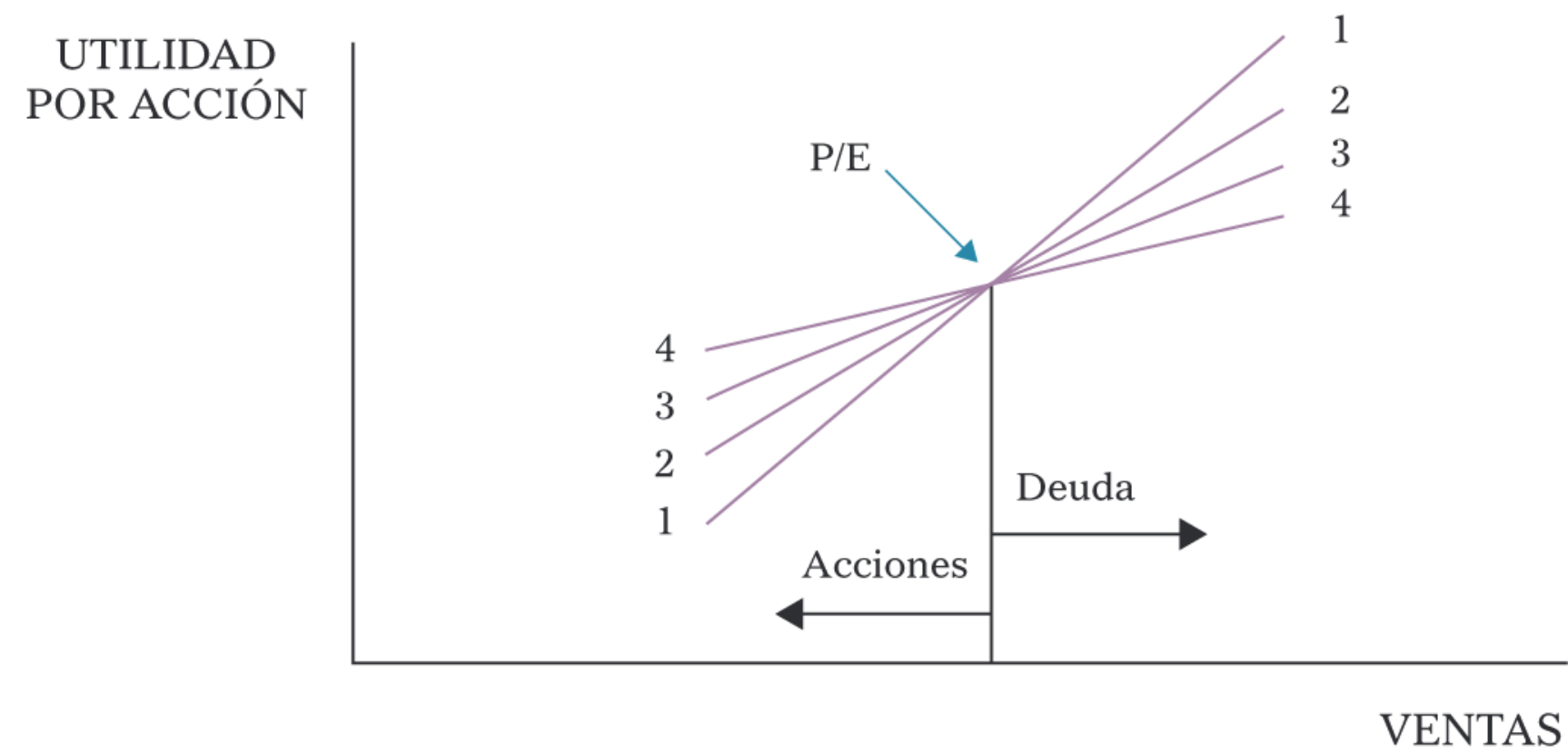

Figura 1. Efectos de las distintas alternativas de financiamiento en la utilidad por acción. Fuente: Elaboración propia.

Método tradicional

Varios autores que utilizan este método, entre ellos Brigham y Houston (2005), Besley y Brigham (2009) y Van Horne y Wachowicz (2010), parten del hecho de encontrar en forma algebraica el nivel de ventas en que ambas alternativas de financiamiento den la misma utilidad por acción. Expresando el estado de resultados de cada alternativa en forma algebraica quedaría de la siguiente manera:

$$
\frac{\left(\mathrm{V}-\mathrm{CF}-\mathrm{CV}-\mathrm{I}_{\mathrm{D}}\right)(1-\mathrm{t})}{\mathrm{ND}}=\frac{\left(\mathrm{V}-\mathrm{CF}-\mathrm{CV}-\mathrm{I}_{\mathrm{A}}\right)(1-\mathrm{t})}{\mathrm{NA}}
$$

$\mathrm{V}=$ ventas

$\mathrm{CF}=$ costos fijos totales

$\mathrm{CV}=$ costos variables

$\mathrm{I}_{\mathrm{D}} \quad$ = interés con la alternativa de mayor deuda

$\mathrm{I}_{\mathrm{A}} \quad=$ interés con la alternativa de más acciones

$\mathrm{N}_{\mathrm{D}}$ = número de acciones con la alternativa de mayor deuda

$\mathrm{N}_{\mathrm{A}}=$ número de acciones con la alternativa de más acciones.

$\mathrm{t} \quad=$ tasa del impuesto sobre la renta.

Se trata de despejar las ventas. Con el mismo ejemplo anterior, utilizando miles en los pesos y en el número de acciones.

$$
\frac{(\mathrm{V}-67000-0.41 \mathrm{~V}-22800) 0.6}{1032}=\frac{(\mathrm{V}-67000-0.41 \mathrm{~V}-18000) 0.6}{1160}
$$

Haciendo las restas:

$$
\frac{(0.59 \mathrm{~V}-89800) 0.6}{1032}=\frac{(0.59 \mathrm{~V}-85000) 0.6}{1160}
$$


Multiplicando por 0.6 cada lado de la igualdad:

$$
\frac{0.354 \mathrm{~V}-53880}{1032}=\frac{0.354 \mathrm{~V}-51000}{1160}
$$

Pasando los denominadores al otro lado de la igualdad:

$$
410.64 \mathrm{~V}-62500800=365.328 \mathrm{~V}-52632000
$$

Dejando las Vs a la izquierda de la igualdad:

$$
\begin{aligned}
& 410.64 \mathrm{~V}-365.328 \mathrm{~V}=62500800-52632000 \\
& 45.312 \mathrm{~V}=9868800 \\
& V=\$ 217796.6102 \text { miles }=\$ \mathbf{2 1 7 7 9 6 6 1 0 . 2 0}
\end{aligned}
$$

Este sería el nivel de ventas en el punto de equilibrio en cuanto a utilidad por acción.

Método propuesto

A continuación presento una nueva fórmula que desarrollé para el cálculo del punto de equilibrio (P/E) respecto a la utilidad por acción, es decir, el mínimo nivel de ventas que se requiere para que sea conveniente endeudarse. Esta nueva fórmula permite realizar el cálculo de una forma más fácil y rápida:

$$
\mathrm{P} / \mathrm{E}=\frac{\left(\mathrm{CF}\left(\mathrm{N}_{\mathrm{A}}-\mathrm{N}_{\mathrm{D}}\right)\right)+\left(\mathrm{I}_{\mathrm{D}} \times \mathrm{N}_{\mathrm{A}}\right)-\left(\mathrm{I}_{\mathrm{A}} \times \mathrm{N}_{\mathrm{D}}\right)}{M C\left(\mathrm{~N}_{\mathrm{A}}-\mathrm{N}_{\mathrm{D}}\right)}
$$

En donde:

$\mathrm{I}_{\mathrm{D}} \quad$ = interés total a pagar con la alternativa de mayor deuda.

$\mathrm{I}_{\mathrm{A}}=$ interés total a pagar con la alternativa de más acciones.

$\mathrm{N}_{\mathrm{D}} \quad$ = número de acciones con la alternativa de mayor deuda.

$\mathrm{N}_{\mathrm{A}}=$ número de acciones con la alternativa de más acciones.

$\mathrm{MC}=$ margen de Contribución expresado en decimales.

$\mathrm{CF}=$ costos fijos totales.

Aplicando esta fórmula al ejemplo con el que se ha venido trabajando tendríamos: $(67000000(1160000-1032000))+(22800000 \times 1160000)-(18000000 \times 1032000)$

$$
=\frac{0.59(1160000-1032000)}{75520}
$$

$$
\mathrm{P} / \mathrm{E}=\underline{\$ 217796610.20}
$$

Como se puede ver, tenemos el mismo resultado que el método tradicional pero más rápido y fácil. Ese punto de equilibrio representa el mínimo nivel de ventas que se requiere para poder endeudarse. 


\section{Conclusiones}

Es más fácil aplicar la nueva fórmula propuesta que despejar a través de igualdades la cantidad de ventas en el punto de equilibrio. También se demostró que el método gráfico es muy impreciso. Con la fórmula sabremos con certeza a partir de cuál nivel de ventas es más conveniente el endeudamiento a largo plazo que la aportación directa de los socios, sabiendo además cuándo se debe evitar a toda costa el endeudamiento. 


\section{Referencias}

Besley, S., \& Brigham, E. (2009). Fundamentos de Administración Financiera. Ciudad de México: Cengage Learning.

Brigham, E., \& Houston, J. (2005). Fundamentos de Administración Financiera. Ciudad de México: Thomson.

Van Horne, J., \& Wachowicz, J. (2010). Fundamentos de Administración Financiera. Estado de México: Pearson. 


\section{Capítulo 6}

Análisis económico de las PyMES mexicanas

y la aplicación de modelos estadísticos de optimización

para el incremento de la productividad

Guillermo Velázquez Valadez

Jesus Ivan Huerta Licona 
Guillermo Velázquez Valadez, Instituto Politécnico Nacional gvelazquezva@ipn.mx

Jesus Ivan Huerta Licona, Instituto Politécnico Nacional ivan-likona@hotmail.com 


\section{Capítulo 6}

\section{Análisis económico de las PyMES mexicanas \\ y la aplicación de modelos estadísticos de optimización}

para el incremento de la productividad

\section{Introducción}

En la actualidad las pequeñas y medianas empresas (pymes) en México son el pilar y el eslabón fundamental de la economía nacional, esto debido según al impacto en la generación de empleos $72 \%$ nivel nacional, y producción nacional $52 \%$ PIB, (Chiatchoua y Castañeda-González, 2015, p. 56) debido a su importancia representativa es necesario que existan condiciones para que las pymes desarrollen crecimiento, rentabilidad y estabilidad, esto con la finalidad de que superen los pronósticos de un año de vida, ayudando a un incremento en mas presencia de los productos mexicanos tanto dentro como fuera del país.

Al llegar al tiempo destinado de vida las pymes empiezan a preocuparse por su supervivencia recurriendo en diversos casos a financiamientos, pero después de cierto tiempo volverán a llegar a la misma situación. Una forma de solucionar este caso es el recurrir a la mejora de técnicas de producción u optimización de procesos. Ya que este es capaz de reducir drásticamente los costos y aumentar la productividad y ganancias. Para ello es necesario contar con personal capacitado para aplicar dichas mejoras, ya que estos requieren de conocimientos básicos de calidad y manejo de estadística aplicada llegando a cambiar los procesos técnicos necesarios.

En este trabajo se toman estas ideas con la finalidad de poder proporcionar una herramienta de mejora y optimización de procesos de las pymes enfocadas al sector productivo y de servicios, esto a partir del método de rango de aceptación que se utiliza para medir los tiempos de un proceso.

A partir de la experiencia y trabajo de campo se llegará a una mejora de dicho modelo, la cual nos proporcionará una mejor representación de los resultados y, a su vez, una forma sencilla de su análisis, pero para ello es necesario por lo menos una persona capacitada para la interpretación y aplicación de dicho método.

Finalmente con esta herramienta se pretende que las pymes puedan mejorar sus procesos y que exista la posibilidad de crecimiento para poder convertirse en una empresa estable y supere las estadísticas de tiempo de vida de supervivencia. 


\section{Problema de Investigación}

Un porcentaje importante del Producto Interno Bruto (PIB) de nuestro país, se genera directamente en las empresas pequeñas y medianas, puesto que estas generan el $77 \%$ del empleo y $73 \%$ del PIB. Sin embargo, aun siendo de vital necesidad para el país están clasificadas dentro del rango de alto riesgo y la mayoría de ellas no sobreviven más de 1 año, esto se produce a causa de la situación económica, el insuficiente financiamiento de la banca y, la más importante, mala administración de acuerdo a la Comisión Nacional para la Protección y Defensa de los Usuarios de Servicios Financieros (Condusef, 2011), esto debido a falta de asesoramiento, deficientes estructuras organizacionales, y personal con habilidades y capacidades necesarias para lograr mejoras continuas en sus procesos de producción, lo cual, ocasiona tener pérdidas al momento de la producción.

Por tales motivos se deben adoptar el uso de nuevas tecnologías, prácticas de desarrollo de capital y estrategias que aumenten la productividad, lo anterior con el objeto de obtener eficiencia y reducción de costos operativos, evitando el aumento excesivo en precios o la necesidad de despidos de empleados, para ello es necesario la aplicación adecuada de herramientas de optimización de los procesos, llegando a un control que mejore con seguridad la producción y que permita la mejora de resultados y utilidad, disminuyendo sus riesgos y pérdidas, tratando de eliminar las causas y situaciones que generan incumplimientos en los procesos, mejorando los resultados y obteniendo mayor eficiencia de los recursos.

Por lo tanto, la aplicación de funciones óptimas en la etapas de producción a través de usos tecnológicos, personal capacitado y la aplicación de métodos estadísticos conducen a una mejora en la producción; reducción de los costos; aumento en la productividad y por consiguiente una mejora en las utilidades, lo cual, es parte fundamental de los procesos productivos, mejoras continuas y supervivencia de las pymes en México.

\section{Objetivo}

Analizar el uso de funciones estadísticas de optimización en el ámbito empresarial, sobre todo en las pymes, con el propósito de concluir si tiene aplicación en la etapa de producción que derive en una mejora cuantitativa en la productividad.

\section{Hipótesis}

Actualmente en las empresas mexicanas se detecta un desperdicio de recursos y tiempos en los procesos productivos, lo cual se deriva de no contar con análisis matemáticos y estadísticos que permitan ver los puntos de quiebre en donde los procesos deben ser mejorados, por lo tanto, a partir de un enfoque óptimo de matemáticas aplicadas se logra obtener mejoras continuas en los procesos de producción.

\section{Teorías económicas y de la producción}

Para efectos del presente estudio se tomarán tres teorías que se consideran vitales para el análisis de las funciones estadísticas de optimización:

1. Para hacer un análisis detallado con respecto a las situaciones de las Pymes en México es necesario recurrir a información que nos explique los aspectos económicos, productivos y de recursos de estas empresas, para ello situaremos a la Teoría microeconomía como aquella que "se concentra en el estudio del comportamiento de agentes individuales [...]. El objeto de estudio [...] es en general individuos, familias y empresas. Se considera [...] como el estudio de la asignación de recursos escasos entre finalidades alternativas"(Anzil, 2006, párr. 1). 
2. Así mismo, con la finalidad de contar con una profundidad de tipo matemático con un rigor numérico y metodológico que nos proporcione cifras y datos para la manipulación y posteriormente la aplicación de una mejora cuantitativa, la Teoría de optimización se tomará como "al proceso de seleccionar, a partir de un conjunto de alternativas posibles, aquella que mejor satisfaga el o los objetivos propuestos" (Ferrero y Chiotti, 1999, p. 435).

3. Con el propósito de obtener una interrelación entre los aspectos matemáticos y microeconómicos, donde su principal función será encontrar una maximización o minimización de la variable producción dependiendo de la situación implicada, se utilizará la Teoría de la Producción, la cual señala que: "se fundamenta en la hipótesis de que la empresa desea emplear el conjunto de cantidades de insumos que minimizan los costos totales al obtener una producción determinada. Así, variando la producción es posible construir las relaciones producto-costo"(Ordoñez, 2016, p. 1).

\section{Las Pymes y el PIB de México}

El crecimiento económico se define como:

El incremento del producto nacional sin que implique necesariamente mejoría en el nivel de vida de la población, se expresa en la expansión del empleo, capital, volumen comercial y consumo en la economía nacional. Aumento de la producción de bienes y servicios de una sociedad en un periodo determinado. El crecimiento económico se define, generalmente, como el resultado que se obtiene, por ejemplo, al relacionar el valor del Producto Interno Bruto de un periodo respecto al mismo u otros periodos anteriores. (Banco de México, 2015).

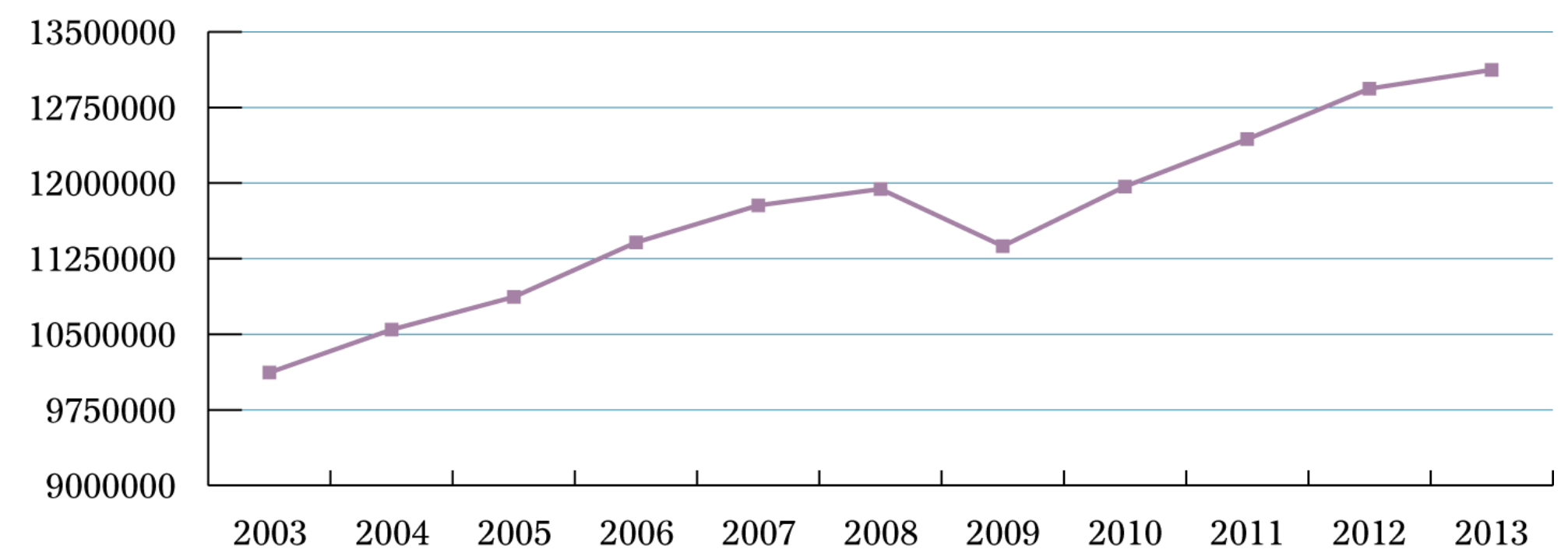

Figura 1. Evolución del PIB en México. Periodo 2003-2013.

Fuente: Banco de Información Económica (BIE) del INEGI.

La actividad económica que refleja el PIB por actividad, consta de tres sectores que se encuentran segmentados de acuerdo al tipo de actividad a realizar:

1. El primer sector, se dedica a realizar actividades relacionadas con la agricultura, la ganadería y la pesca,

2. El segundo sector, se enfoca principalmente a las manufacturas y a la construcción, y

3. El tercer sector relacionado con las actividades de servicios y comercio. 
Con el objeto de analizar la dinámica del crecimiento económico por sector en México en el año 2013, se realizó un comparativo entre los tres sectores donde se tomó el porcentaje de contribución que aporta cada sector al PIB total de la economía, lo anterior, con el propósito de observar la importancia de cada uno de ellos.

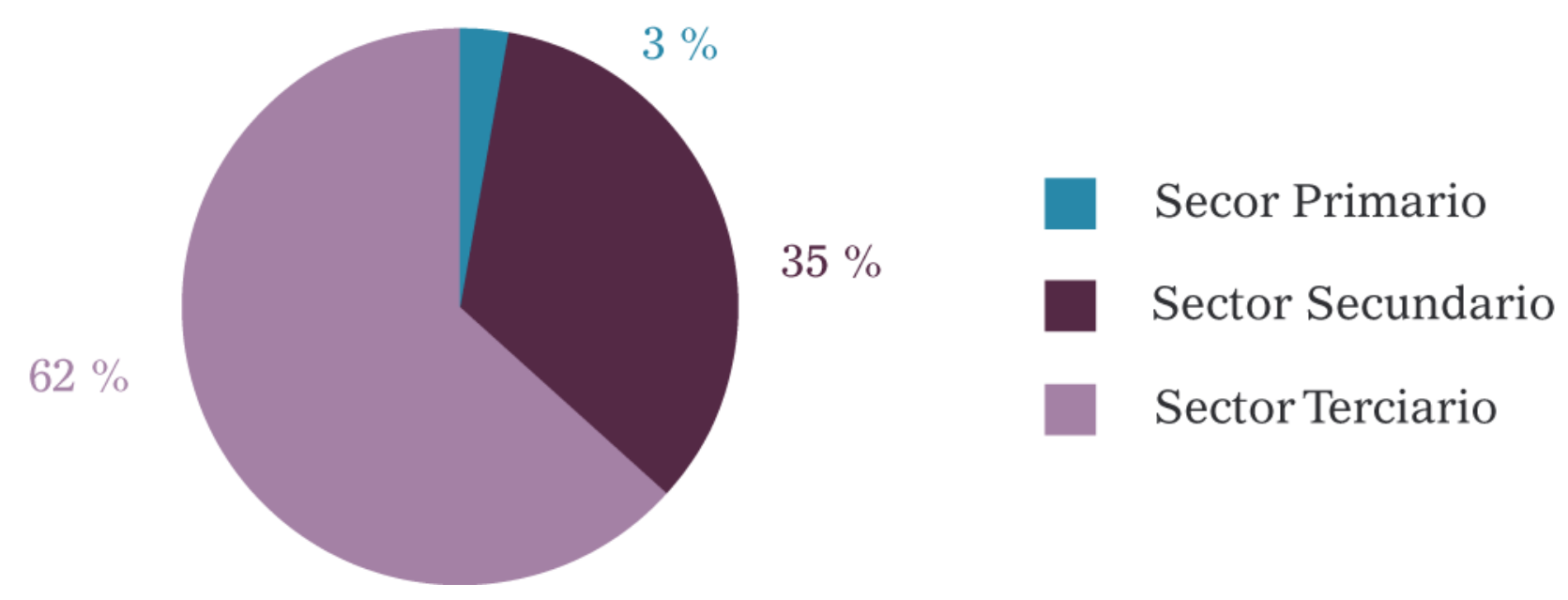

Figura 2. Porcentaje de Participación del PIB total de la Economía Mexicana por Sector Económico. Año 2013.

Fuente: Elaboración propia. Información Obtenida del Banco de Información Económica (BIE) del INEGI.

En la figura 2 se observa que el sector terciario es el que tiene un mayor porcentaje de participación en el crecimiento económico del país, al contribuir con el $62 \%$ del PIB nacional, por su parte el sector secundario aporta un $35 \%$ y al final se encuentra el sector primario con un $3 \%$.

En lo que respecta a las pymes en México, son aquellas que tienen de uno a un máximo de 250 empleados para su funcionamiento, su principal objetivo es el desarrollo regional, mejorar la economía y la generación de empleos, trayendo consigo el desarrollo y la cohesión social, tienen un rol importante por la aportación que hacen a la economía mediante la generación de empleos, ingresos y abastecimiento de aquellos nichos de mercado no cubiertos por la grande empresa, además de dinamizar la actividad productiva de las economías locales. De acuerdo con el INEGI (2015) este tipo de empresas constituyen el 99.8\% del total de unidades económicas del país, representan alrededor del $77 \%$ del PIB y contribuyen a generar más del $73 \%$ de los empleos en México. Además, las empresas de menor tamaño son preponderantes en las entidades con mayor rezago en términos de ingreso y presentan una alta participación de empleo informal.

Debido a lo anterior, es fundamental fortalecer a estos negocios como parte de la estrategia para aumentar los niveles de productividad del país, generar empleos estables, facilitar la transición a la formalidad y reducir las brechas regionales (Programa Nacional de Financiamiento del Desarrollo 2008-2012). 
Tabla 1

Estratificación de la empresas en México

\begin{tabular}{cccc}
\multirow{2}{*}{ Tamaño } & Sector & $\begin{array}{c}\text { Rango del número } \\
\text { de empleados }\end{array}$ & $\begin{array}{c}\text { Rango del número de } \\
\text { vicro }\end{array}$ \\
\multirow{2}{*}{ Pequeñas anuales (mdp) }
\end{tabular}

Nota: Estratificación de acuerdo a COMPITE (2012), mdp = millones de pesos mexicanos.

Aun siendo parte fundamental de la economía en México, las pymes tienden a fracasar y no tener un lapso de vida mayor a un año, esto se debe a la situación económica, el insuficiente financiamiento y una deficiente administración, este factor representa el $43 \%$ de las empresas que fracasan, ya que sólo 2 de 10 empresarios tiene una capacitación en cuestiones administrativas, además que los nuevos empresarios tienden a centralizar el poder (Marker, 2015).

Uno de los factores que se debe considerar es la solución de problemas y planeación de los procesos productivos, la falta de ellos limita el crecimiento de la empresa, tomando decisiones unilaterales sin estar preparado para situaciones de crisis. Sobre este contexto, 65 de cada 100 empresas de este tipo que se crean en un año, desaparecen a los 2 años de vida, principalmente por falta de conocimientos en administración y finanzas (Marker, 2015).

Sin embargo, las pymes presentan aspectos positivos, como son: representa un sector grande de unidades económicas respecto a lo que se refiere al número total de empresas en el país, su fortaleza en el emprendimiento y el autoempleo y su contribución al empleo, además la tasa de nacimiento de estas empresas es alta, lo que refleja un crecimiento sustancial al número de unidades y con ello un incremento en la producción de bienes y servicios, dando como resultando un incremento en la productividad por encima del promedio establecido para el tamaño de las microempresas.

Resulta de suma importancia crear los mecanismos administrativos, científicos y tecnológicos, con el propósito de llegar a la evolución y a la mejora de las pymes, esto a través de utilizar los recursos económicos y de inversión en nuevos activos, financiar el circulante, contratar nuevo personal, prospección de nuevos mercados y mejoras en la producción, todo lo anterior, con la finalidad de evitar la muerte prematura.

Tomando en consideración estos aspectos se definen los siguientes retos clave, de acuerdo a la OCDE (2013, p. 49):

- Aumentar la productividad y la rentabilidad en microempresas y reducir el tamaño y el alcance de la economía informal.

- Reequilibrar la economía de las pymes hacia mayores escalas de tamaño y facilitar la evolución de las empresas más pequeñas al tamaño mediano.

- Mejorar el desempeño innovador de las pymes. 
- Evitar que se siga perpetuando los desequilibrios económicos regionales al aumentar los nacimientos de empresas y el número de las existentes, así como el desempeño en productividad, rentabilidad y producción.

\section{Estudio de campo: Empresa Comercializadora de Abarrotes Metropolitana, S. A.}

Comercializadora de Abarrotes Metropolitana, S.A. es una empresa distribuidora y comercializadora de abarrotes establecida en 1984 en la ciudad de Irapuato, Guanajuato, México. Actualmente la empresa cuenta con una estructura de más de 800 empleados y presencia en el $85 \%$ de la República Mexicana, mediante el establecimiento de seis bodegas de porteo, mismas que se encuentran repartidas estratégicamente en distintos puntos del país, siete Centros de Distribución (CEDIS) y 14 mostradores.

\section{Misión}

Comercializar productos de consumo de máxima calidad, satisfaciendo a cada uno de nuestros consumidores mediante un servicio personalizado, surtiendo en tiempo y forma sus pedidos, siempre bajo precios competitivos. Asimismo, hacia el interior de nuestra empresa, mantener una operación rentable que cumpla y respete las leyes del país y que permita el crecimiento personal y profesional de nuestros colaboradores y familias mediante el trabajo honrado y dedicado.

\section{Visión}

Ser la empresa líder en el abastecimiento de productos de consumo a nivel nacional, satisfaciendo las necesidades de nuestros clientes a través de una administración profesional, con productos y servicios de calidad, brindando oportunidades de desarrollo, respeto y confianza a nuestros clientes, empleados y proveedores bajo un clima laboral de apertura y renovación constante.

\section{Valores}

- Personal: Somos personas que nos entregamos diariamente a las actividades que desempeñamos, queremos y respetamos nuestro trabajo porque cada uno de nosotros es un eslabón imprescindible en la cadena del proceso del que nos sentimos orgullosos.

- Productividad: Como principal encomienda de todos nuestros colaboradores y que se refleje de la misma manera hacia nuestros clientes y proveedores.

- Respeto: A la individualidad y dignidad de cada colaborador y a las ideas que impulsen a nuestra operación y actividades diarias.

- Calidad: No sólo en los productos que comercializamos sino en todas nuestras operaciones y procesos.

- Crecimiento: Para llegar cada día a más consumidores y nunca detenernos en nuestra lucha constante de desarrollo.

- Responsabilidad: Teniendo siempre en mente las consecuencias de nuestros actos, sirviendo como factor de evaluación en el momento de tomar decisiones.

- Confianza: Ofrecer seguridad, honestidad y transparencia en todas nuestras acciones.

- Tecnología: Para hacer cada día más dinámica, rápida y confiable nuestra operación interna y de distribución.

- Innovación: Para brindar nuevos procesos y beneficios que satisfagan las necesidades de nuestros clientes. 


\section{Modelo matemático}

Como ya fue señalado, para efectos de comprobar la hipótesis se tomaron los modelos estadísticos de optimización con el propósito de lograr los máximos beneficios, a través de la toma de decisión basada en un criterio matemático por parte de los directivos empresariales en la elección de la cantidad de mano de obra, capital y materias primas.

\section{Metodología}

Una vez reunidos los elementos de la investigación: problema, objetivo e hipótesis; se articuló un esquema de investigación científica, para tal efecto, se realizó una búsqueda documental que proporcionara información acerca del Producto Interno Bruto (PIB) y el porcentaje de participación de las pymes, por otra parte se revisó la literatura que hace referencia a los modelos matemáticos y su aplicación en las operaciones de las empresas, con ello se formó un marco teórico que sustentan el estudio. La investigación se define como descriptiva-correlacional, toda vez que busca mediante el análisis estadístico encontrar una correlación entre las variables que intervienen en un proceso operativo.

A continuación se muestra un modelo de optimización bajo el método rango de aceptación con sus variables originales (Tumero, 2015):

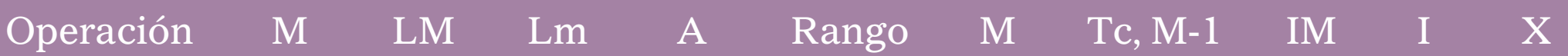

Fuente: I. Turmero (2015, p. 8).

Donde:

$$
\begin{gathered}
\mathrm{A}=0.5^{*}[|\mathrm{X}-\mathrm{LM}|+|\mathrm{X}-\mathrm{Lm}|] \\
\text { Rango de aceptación }[\mathrm{X}+\mathrm{A}, \mathrm{X}-\mathrm{A}]
\end{gathered}
$$

$\mathrm{M}=$ número de observaciones de la muestra.

$\mathrm{LM}=$ lectura mayor.

$\mathrm{Lm}=$ lectura menor.

A = Variación.

$\mathrm{IM}=$ intervalo de la muestra.

$\mathrm{I}=$ intervalo predefinido.

$\mathrm{X}=$ media de la muestra.

Tc,M-1= nivel de confianza al $90 \%$.

Con la finalidad de ajustar el modelo a la realidad de las pymes mexicanas del rubro de almacenaje y distribución, se formuló una modificación al método rango de aceptación, en este caso, se tomará un coeficiente de confianza del $95 \%$. Lo anterior, con la finalidad de crear un rango de valores, derivado de los estadísticos de la muestra, que posiblemente incluya el valor de la media poblacional desconocido. En esta modificación se trabajará con tamaños de muestra pequeños, situación que nos permite aplicarla probabilidad T-Student.

La modificación realizada cambia el orden de las variables para un mejor análisis, incluyendo un mejor uso estadístico. Cabe señalar que el rango ya modificado busca que el $95 \%$ de las situaciones que ocurren en los procesos productivos caigan en el rango propuesto y por lo tanto la toma de decisiones se realiza con mayor precisión. 
Donde:

$\mathrm{n}=$ tamaño de la muestra.

$\overline{\mathrm{X}}=$ promedio de la muestra.

$\mathrm{S}=$ desviación estándar de la muestra.

LCS = límite de Control Superior.

LC = límite Central.

LCI = límite de Control Inferior.

IC $95 \%$ = intervalo de Confianza al 95\%.

$\mathrm{I}=$ intervalo.

Al realizar estos cambios es necesario utilizar la estadística elemental que nos permita desarrollar un modelo confiable, el primer paso a llevar a cabo, es realizar dos tomas de muestras:

1. La primera será preliminar (n) y nos proporciona el primer acercamiento para obtener el tamaño de la muestra real que requerimos, y

2. La segunda nos proporciona el verdadero tamaño de muestra (n), se debe utilizar para futuras observaciones (se sugiere que las observaciones sean aleatorias para su correcto funcionamiento):

$$
\mathrm{n}=\left(\frac{40 \sqrt{\mathrm{n}^{\prime} \sum \mathrm{x}^{2}-\left(\sum \mathrm{x}\right)^{2}}}{\sum \mathrm{x}}\right)^{2}
$$

$\mathrm{n}=$ tamaño de la muestra que deseamos calcular (número de observaciones)

n’ = número de observaciones del estudio preliminar

$\Sigma=$ suma de los valores

$\mathrm{x}=$ valor de las observaciones

$40=$ constante para un nivel de confianza de $94.45 \%$

Ya establecido el número de observaciones y después de realizar dichas muestras el siguiente paso es obtener la media de la muestra, la cual se obtiene a partir de la siguiente fórmula:

$$
\overline{\mathrm{x}}=\frac{\sum_{\mathrm{i}=1}^{\mathrm{n}} \mathrm{x}_{\mathrm{i}}}{\mathrm{n}}
$$

$\overline{\mathrm{x}}=$ es la media de la muestra

$\mathrm{x}_{\mathrm{i}}=$ valor de las observaciones

$\mathrm{n}=$ tamaño de la muestra

A continuación se procede a obtener la desviación estándar (s) muestral, la cual, es la desviación típica, es la raíz cuadrada de la varianza. Es decir, la raíz cuadrada de la media de los cuadrados de las puntuaciones de desviación. Es una fórmula estadística que nos auxilia en el cálculo de muestras y que proporciona confiabilidad. 


$$
s=\sqrt{\frac{\sum_{i=1}^{n}\left(x_{i}-\bar{x}\right)^{2}}{n-1}}
$$

$\mathrm{x}_{\mathrm{i}}=$ valor de las observaciones

$\mathrm{n}=$ tamaño de la muestra

$\overline{\mathrm{X}}=$ es la media de la muestra

$\mathrm{s}=$ desviación estándar muestral

Posteriormente se procede a calcular los límites de especificación, en caso de que estos ya existan o ya estén establecidos en un manual estos se deben de respetar, en caso de lo contario se usará la siguiente fórmula para la obtención de los mismos, sabiendo que obtendremos el 99.38 \% de los datos, dando cabida a solo $0.62 \%$ de error o anomalías.

Límite de Control Superior: $\bar{x}+2 s$

Límite Central: $\bar{x}$

Límite de Control Superior: $\bar{x}-2 s$

Para la obtención de intervalos de confianza con $95 \%$, se aplicará la siguiente fórmula esta con n-1 grados de libertad ya que nos estamos basando en la distribución t de Student, (las tablas se anexan al final del documento):

$$
\overline{\mathrm{x}} \pm \mathrm{t}_{\frac{\alpha}{2}} \frac{\mathrm{s}}{\sqrt{\mathrm{n}}}=\overline{\mathrm{x}} \pm \mathrm{t}_{.025} \frac{\mathrm{s}}{\sqrt{\mathrm{n}}}
$$

$\mathrm{n}=$ tamaño de la muestra

$\bar{x}=$ es la media de la muestra

$\mathrm{s}=$ desviación estándar muestral

$\frac{t}{2}$ nivel de confianza (en este caso al 95\%)

Si queremos una modificación del intervalo de confianza se tiene que cambiar el valor de $t \frac{\text { Q }}{2}$ sto para valores de $90 \%, 85 \%$. Con toda esta información se puede observar el funcionamiento del modelo, para ello se realizó un estudio en una empresa de productos de consumo y se obtiene los siguientes resultados.

Toma de muestra

Con el propósito de reunir datos suficientes para la aplicación de modelo matemático diseñado, se realizó una toma de muestra que abarcó el periodo del 07-04-2016 al 18-04-2016, la cual, abarcó un total de 93 ítems, los cuales se muestran en la tabla 2. 
Tabla 2

Recolección de datos del proceso: carga y descarga de camiones

\begin{tabular}{|c|c|c|c|c|c|c|c|c|c|}
\hline Fecha & $\begin{array}{l}\text { Tiempo } \\
\text { /horas }\end{array}$ & Fecha & $\begin{array}{l}\text { Tiempo } \\
\text { /horas }\end{array}$ & Fecha & $\begin{array}{l}\text { Tiempo } \\
\text { /horas }\end{array}$ & Fecha & $\begin{array}{l}\text { Tiempo } \\
\text { /horas }\end{array}$ & Fecha & $\begin{array}{l}\text { Tiempo } \\
\text { /horas }\end{array}$ \\
\hline \multirow{20}{*}{7 abr. } & 5 & \multirow{20}{*}{8 abr. } & 7 & \multirow{20}{*}{12 abr. } & 4 & \multirow{20}{*}{14 abr. } & 5 & \multirow{20}{*}{18 abr. } & 6 \\
\hline & 4 & & 4 & & 4 & & 9 & & 7 \\
\hline & 6 & & 7 & & 8 & & 4 & & 5 \\
\hline & 7 & & 7 & & 5 & & 5 & & 7 \\
\hline & 6 & & 4 & & 4 & & 8 & & 4 \\
\hline & 4 & & 4 & & 7 & & 5 & & 4 \\
\hline & 6 & & 4 & & 8 & & 4 & & 5 \\
\hline & 6 & & 5 & & 8 & & 6 & & 5 \\
\hline & 4 & & 5 & & 6 & & 4 & & 6 \\
\hline & 4 & & 7 & & 9 & & 5 & & 7 \\
\hline & 6 & & 6 & & 7 & & 8 & & 8 \\
\hline & 6 & & 5 & & 4 & & 4 & & 6 \\
\hline & 6 & & 6 & & 6 & & 10 & & 7 \\
\hline & 5 & & 5 & & 8 & & 7 & & \\
\hline & 3 & & 5 & & 6 & & 5 & & \\
\hline & 7 & & 4 & & 7 & & 8 & & \\
\hline & 2 & & 7 & & 8 & & 5 & & \\
\hline & 5 & & 4 & & 6 & & 7 & & \\
\hline & 8 & & 8 & & 6 & & 4 & & \\
\hline & 8 & & 8 & & 8 & & 5 & & \\
\hline
\end{tabular}

Nota: Información de la Comercializadora de Abarrotes Metropolitana, S. A. durante el periodo 07/04/2016- 18/04/2016.

Método de rango de aceptación original

Con los datos de la tabla 2, se obtuvieron los siguientes datos apegados al método de rango de aceptación original:

\begin{tabular}{|c|c|c|c|c|c|c|c|c|c|}
\hline M & LM & $\mathrm{Lm}$ & $\mathrm{A}$ & Rango & M & Tc, M-1 & IM & I & $\mathrm{X}$ \\
\hline 93 & 10 & 2 & 4 & 8 & 93 & 1.66 & {$[2-10]$} & [1.8494-9.8494] & 5.84946237 \\
\hline \multicolumn{3}{|c|}{ X-LM } & \multicolumn{3}{|c|}{$\mathrm{X}-\operatorname{lm}$} & A & \multicolumn{2}{|r|}{ LI } & LS \\
\hline \multicolumn{3}{|c|}{4.150537634} & \multicolumn{3}{|c|}{3.849462366} & 4 & & 1.849462366 & 9.849462366 \\
\hline
\end{tabular}


Interpretación de los resultados encontrados

Este modelo no explica de qué tamaño debe ser el tamaño de muestra de la investigación para no existir variación, por otra parte, con el objeto de que no exista discrepancia en los resultados, se utiliza la misma fórmula para la obtención de tamaño de muestra, aunque es preciso dejar claro que ésta sólo se debe aplicar en el modelo del método de rango de aceptación modificado.

Los límites superior e inferior en este caso se consideran como anomalías ya que en la observación de la muestra estos sólo se presentan una sola vez, con ello el rango tiende a ser amplio.

La obtención de la variación encontrada en el total de los ítems tomados en términos de tiempo, es a partir de la media y los límites en valor absoluto, siendo ésta una operación sencilla con poca capacidad de representar a la misma.

Una de las deficiencias encontradas en este modelo, es que a partir de la variación se crean los intervalos de aceptación, los cuales, al presentan un rango amplio, contempla al límite inferior como una anomalía aceptable y en el caso del límite superior la aceptación sólo presenta una mínima distancia. Esta situación afecta directamente a los límites de aceptación en la realidad de las empresas, toda vez que el mayor número de datos se concentran alrededor de la media, por lo tanto, las anomalías representan un riesgo para el modelo al ser aceptadas como datos normales.

Si se parte del supuesto de que la T de Student es necesaria para crear los intervalos de confianza, encontramos que a pesar de que el modelo la incluye, no proporciona información clara de su aplicación en el mismo, lo anterior basado en que los intervalos se proporcionan por diferencia entre límite superior y límite inferior.

La forma en que se acomodan los datos no es óptima para su análisis o comprensión, esta aseveración tiene su fundamento en que el dato de la media muestral (X) al ser el primer dato representativo de las observaciones, es colocada al final de la tabla y no junto a los límites superior e inferior, en donde se encuentra el valor y significado de esta medida de tendencia central.

Método de rango de aceptación modificado

\begin{tabular}{|c|c|c|c|c|c|c|}
\hline $\mathrm{n}$ & $\overline{\mathrm{X}}$ & S & $\mathrm{LCI}$ & LCS & $\mathrm{LC}$ & IC $95 \%$ \\
\hline 93 & 5.84946237 & 1.58763042 & 2.67420152 & 9.02472321 & 5.84946237 & [5.5224-6.1764] \\
\hline & I & \multicolumn{3}{|c|}{ Student 95 \% confianza, 92 g.l } & $\mathrm{IC}(-)$ & $\mathrm{IC}(+)$ \\
\hline \multicolumn{2}{|c|}{ [2.6742-9.0247] } & \multicolumn{2}{|c|}{$\mathrm{t}=1.9861$} & \multicolumn{2}{|c|}{5.522491506} & 6.17643323 \\
\hline
\end{tabular}

Interpretación de los resultados encontrados con método de rango

de aceptación modificado

Este método nos permite, al aplicar la fórmula de tamaño de muestra, obtener la información apegada a la realidad de que tamaño debe ser la muestra, la cual será sometida al estudio propuesto.

La desviación estándar muestral obtenida con el método de aceptación modificado, se comporta dentro de los estándares normales, es decir, los datos se agrupan en torno a la media, lo cual, nos indica que es representativa (ver Figura 3). 


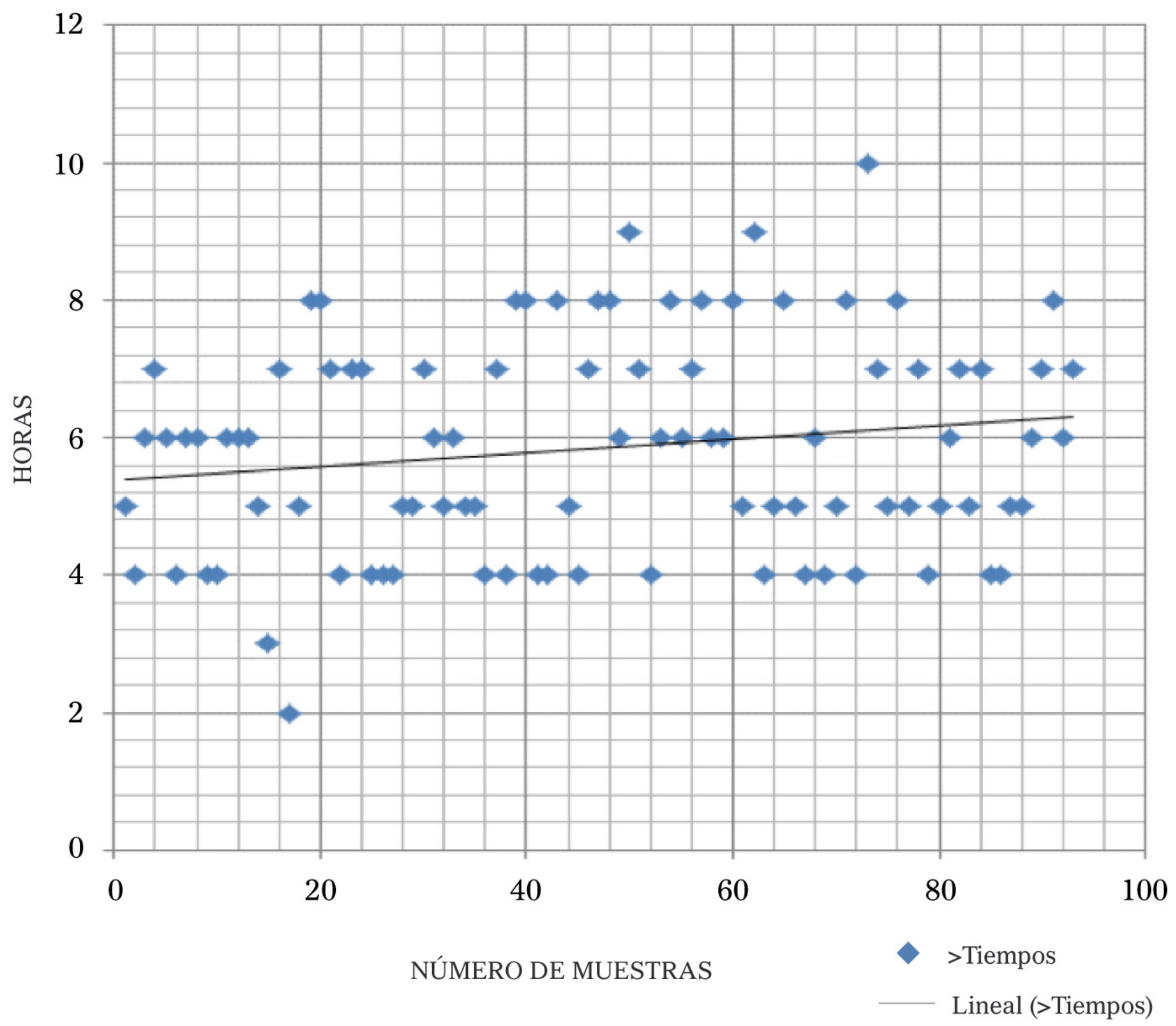

Figura 3. Diagrama de Dispersión

Fuente: Elaboración propia, con datos de Comercializadora de Abarrotes Metropolitana, S. A

Los límites de control son obtenidos a partir de fórmulas estadísticas, para tal efecto, se utilizó la desviación estándar y la media de la muestra $(\overline{\mathrm{x}} \pm 2 \mathrm{~s})$, esta situación engloba a la mayoría de los datos que se consideran en la muestra, además de no verse afectados por las anomalías, pues se incluyen en el cálculo realizado. Posteriormente se obtiene el intervalo de aceptación (2.6742 - 9.0247) con un margen de confianza del $99.2 \%$, donde las anomalías quedan excluidas.

Explica el uso de la función T de Student, para la obtención del intervalo de confianza, el cual, nos muestra que la media de la muestra (5.84946237) se encuentra dentro de los límites [5.5224-6.1764], este dato nos indican que el $95 \%$ de confianza de que los ítems están dentro de los límites establecidos.

\section{Análisis comparativo}

Una vez concluidos los dos cálculos bajo distintos métodos, se procede a realizar un análisis comparativo con el objeto de observar sus principales ventajas y desventajas de cada uno. En la tabla 3 se presenta el comparativo. 
Tabla 3

Comparativo de métodos de rango de aceptación: original vs modificado

\begin{tabular}{|c|c|c|}
\hline $\begin{array}{l}\text { Método de rango } \\
\text { de aceptación } \\
\text { original }\end{array}$ & $\begin{array}{l}\text { Método de rango } \\
\text { de aceptación } \\
\text { modificado }\end{array}$ & Observaciones \\
\hline $\mathrm{M}=93$ & $\mathrm{~N}=93$ & $\begin{array}{l}\text { Se toma el mismo tamaño de muestra para } \\
\text { evitar las discrepancias. }\end{array}$ \\
\hline$X=5.84946237$ & $X=5.84946237$ & $\begin{array}{l}\text { La media es el mismo valor, toda vez que se } \\
\text { obtiene bajo la misma fórmula. }\end{array}$ \\
\hline $\mathrm{A}=4$ & $\mathrm{~S}=1.58763042$ & $\begin{array}{l}\text { La obtención de la desviación estándar es } \\
\text { diferente, ya que la primera es resultado de } \\
\text { un método de rango y la segunda por una } \\
\text { fórmula estadística. Es importante señalar } \\
\text { que los datos bajo el método de rango son } \\
\text { muy dispersos, lo cual le resta confiabilidad. }\end{array}$ \\
\hline Rango $=8$ & Rango $=$ nulo & $\begin{array}{l}\text { Se considera un dato obsoleto, toda vez, que la } \\
\text { fórmula para obtener la desviación estándar } \\
\text { no lo requiere. }\end{array}$ \\
\hline Tc. $M-1=1.66$ & $\begin{array}{c}\mathrm{IC} 95 \%= \\
{[5.5224-6.1764]}\end{array}$ & $\begin{array}{l}\text { El valor de } \mathrm{T} \text { de Student difiere porque en el } \\
\text { método de rango sólo lo proporcionan sin } \\
\text { darle una utilidad. Por otra parte, en el método } \\
\text { de rango modificado nos dice que el intervalo } \\
\text { de confianza es del } 95 \% \text { y que la media cae } \\
\text { dentro de este intervalo de confianza, por lo } \\
\text { cual, es representativa. }\end{array}$ \\
\hline $\mathrm{IM}=[2-10]$ & $\mathrm{IM}=$ nulo & $\begin{array}{l}\text { El rango no es representativo para la obtención } \\
\text { del intervalo. }\end{array}$ \\
\hline $\mathrm{LM}=10$ & $\mathrm{LCS}=9.02472321$ & $\begin{array}{l}\text { El límite superior se reduce bajo el método } \\
\text { de rango modificado, además de indicar que } \\
\text { cualquier ítem que salga de este, se encuentra } \\
\text { fuera de la eficiencia operativa. }\end{array}$ \\
\hline $\mathrm{Lm}=2$ & $\mathrm{LCI}=2.67420152$ & $\begin{array}{l}\text { El límite inferior aumenta bajo el método } \\
\text { de rango modificado, además de indicar } \\
\text { que cualquier ítem que no llegue a este, se } \\
\text { encuentra fuera de la eficiencia operativa. }\end{array}$ \\
\hline$X=5.84946237$ & $\mathrm{LC}=5.84946237$ & $\begin{array}{l}\text { El límite central es representado en ambos } \\
\text { modelos como el promedio de la muestra. }\end{array}$ \\
\hline$I=[1.8494-9.8494]$ & $\mathrm{I}=[2.6742-9.0247]$ & $\begin{array}{l}\text { El intervalo de operación que se obtiene bajo } \\
\text { el método de rango modificado, presenta datos } \\
\text { más precisos que permiten deducir la eficiencia } \\
\text { y optimización de los tiempos, además de } \\
\text { excluir las anomalías. Con el método de rango } \\
\text { original al aceptar las anomalías el intervalo } \\
\text { es más amplio, lo cual lleva a las empresas a la } \\
\text { pérdida de eficiencia y de utilidades. }\end{array}$ \\
\hline
\end{tabular}




\section{Conclusiones}

Después de terminar con los cálculos matemáticos y la revisión bibliográfica, los hallazgos más relevantes de la investigación son los siguientes:

Se comprueba la hipótesis planteada sobre el desperdicio de recursos en las empresas mexicanas derivado de la ausencia de análisis matemáticos y estadísticos que permitan tomar decisiones apegadas a la realidad. Sobre esta base, al calcular el indicador matemático I (intervalo de proceso) se encuentra que al iniciar la investigación se tiene I = [1.8494-9.8494]; con las modificaciones realizadas con base a las observaciones y medida de tiempos se obtiene un nuevo intervalo que es: I = [2.6742-9.0247], el cual nos señala de forma precisa el rango en que el $99.38 \%$ de las operaciones de carga y descarga deben de realizarse.

$\mathrm{Al}$ analizar la tabla 2, acerca del proceso de carga y descarga de camiones, se observa que la Comercializadora de Abarrotes Metropolitana, S.A., realiza este proceso con una pérdida de tiempo, esto se debe principalmente a que las operaciones se realizan sin ningún cronómetro y se deja abierto el tiempo que debe tomar cada operación, es importante señalar que esto se traduce en pérdidas económicas al pagar un tiempo mayor que el que requiere para lograr sus metas en el proceso anteriormente señalado.

Un dato de suma importancia que se encontró en la investigación es el valor de la T de Students: IC $95 \%$ = [5.5224-6.1764], de donde se desprende que se cuenta con un intervalo de confianza y el uso del $95 \%$, es decir, que para efectos de realizar otras toma de muestras tenemos como constante el valor de T de Students. Por otra parte, nos señala el intervalo en que la media debe de caer para ser significativa, de otro modo la media no es representativa y el análisis carece de valor.

De acuerdo al problema de investigación, se refuerza la posición de que las pymes mexicanas hagan uso de métodos estadísticos de optimización, con el propósito de hacer más eficiente sus procesos y reducir los tiempos de operación, costos y utilización de equipo, así como generar un incremento en las utilidades. El aplicar un mayor número de los métodos anteriormente señalados, le garantiza a las empresas que no recurrirá a créditos bancarios con altas tasas de interés que merma su margen de utilidades, así como recorta en un alto porcentaje el ciclo de vida de la empresa.

Es importante señalar que el modelo propuesto se puede aplicar a distintas áreas de la empresa, con la finalidad de mejorar cada uno de los procesos de la compañía, esto con la finalidad de solidificar el posicionamiento, incrementar su margen de utilidad (EBITDA) y reducir los tiempo de operación y de equipo ocupado; con todos estos beneficios se tiene la posibilidad de que las empresas mexicanas cubran un mayor porcentaje de mercado, generen más empleos y paguen mejores sueldos. 


\section{Referencias}

Anzil,F.(2006).Microeconomía. Recuperado de http://www.zonaeconomica.com/definicion/ microeconomia

Banco de México. (2015). Glosario de términos, definiciones. Recuperado de www.banxico. org.mx/divulgacion/glosario/glosario.htm

Chiatchoua, C., \& Castañeda-González, Y. (2015). Influencia de las MIPyMES en la generación de empleos en la región XITexcoco, Estado de México (2000-2010). Revista Quivera. México: Universidad Autónoma del Estado de México.

Chiotti, O. (1999). Modelado, Simulación y Optimización de Procesos Químicos. Recuperado de http://www.edutecne.utn.edu.ar/modelado-proc-quim/modelado-proc-quim.pdf

Comisión Nacional para la Protección y Defensa de los Usuarios de Servicios Financieros (CONDUSEF). (2011).SHCP, Calificación de crédito empresarial (Pymes). Recuperado dehttp://www.condusef.gob.mx/index.php/prensa/comunicados-2011/261-calificadorde-credito-empresarial

COMPITE (2012). Política de Fomento a las PYMES en México. Recuperado de http://www. compite.org.mx/Eventos/2012/CIRS_Sandoval.pdf

Diario Oficial de la Federación (2008). Programa Nacional de Financiamiento del Desarrollo 2008-2012.Recuperadode http://dof.gob.mx/nota_detalle_popup.php?codigo=5047714

Ferrero, M.B., \& Chiotti, O.J.A. (1999). Optimización. En N. Scenna (Ed.), Modelado, Simulación y Optimización de Procesos Químicos (pp. 435-496). Recuperado de http:// www.edutecne.utn.edu.ar/modelado-proc-quim/modelado-proc-quim.pdf

Hernández, A. (2004). Curso básica de economía. Instituto Tecnológico de Tijuana, Tijuana. Instituto Nacional de Estadística y Geografía (INEGI). (2015). Boletín de prensa Núm. 283/15. Aguascalientes. Recuperado de http:/www.inegi.org.mx/saladeprensa/ boletines/2015/especiales/especiales2015_07_5.pdf

Marker, G. (2015). Casi la mitad de las PyMEs mexicanas fracasan por una mala gestión. Recuperado de http://www.gestion.org/estrategia-empresarial/35717/casi-la-mitadde-las-pymes-mexicanas-fracasan-por-una-mala-gestion/

Morris, H. (2011). Probability and statistics. Boston: Pearson.

Organización para la Cooperación y el Desarrollo Económicos (OCDE). (2013). Temas y políticas sobre Pymes y emprendimiento en México. México: OECD Publishing.

Ordoñez, C. (2016). Teoría de la Producción. Guatemala: Universidad Mariano Gálvez.

Programa Nacional de Financiamiento del Desarrollo 2008-2012. (2008, junio 25). Decreto. Diario Oficial de la Federación 25-06-2008. Recuperado de http://dof.gob.mx/nota_ detalle.php?codigo $=5047713 \&$ fecha $=25 / 06 / 2008$

Secretaría de Economía (2011). Compite, Diario Oficial de la Federación 16/03/2016. Recuperado de http://www.compite.org.mx/DOFNuevaEstratificacionDeLasPyMEs. htm

Turmero, I. (2015). Estudio de ingeniería de métodos. UNEXPO, Puerto Ordaz, Venezuela. Velazquez-Valadez, G. (2015). Economía empresarial en el contexo mexicano. México: Ecorfan. 


\section{Capítulo 7}

Estrés laboral en centro de atención telefónica de empresa distribuidora y comercializadora de energía eléctrica en el noroeste de México

María Elena Saavedra Cota José Ángel Coronado Quintana 
María Elena Saavedra Cota, Universidad de Sonora maelena@pitic.uson.mx

José Ángel Coronado Quintana, Universidad de Sonora coronado@pitic.uson.mx 


\section{Capítulo 7}

\section{Estrés laboral en centro de atención telefónica \\ de empresa distribuidora y comercializadora \\ de energía eléctrica en el noroeste de México}

\section{Introducción}

Las organizaciones desean obtener altos estándares de productividad, para lo cual, establecen estrategias que les permitan proveer servicios de calidad a sus clientes (Du Gay, 1996; Schneider \& Bowen, 1995). En el desarrollo de dichas estrategias, se han considerado a los centros de atención telefónica (call centers) como importantes centros de servicio y contacto entre las organizaciones y sus clientes.

Los centros de atención telefónica desde los años 1990, han resultado la más importante forma de contacto con los clientes. Se han convertido en un generador de empleos para millones de personas en Estados Unidos y cientos de miles en selectos países de Europa, Australia y recientemente en India (Rusell, 2008), sin embargo, algunos centros de atención telefónica, dada la naturaleza de la gestión, conllevan una alta carga de tensión para quienes tienen, por una parte, la responsabilidad de atender con calidez y calidad a los clientes, pero por otra, colocar productos, cobrar adeudos, resolver problemas y/o satisfacer las demandas de clientes exigentes.

Desde que Selye introdujo en el ámbito de la salud el término estrés, éste se ha convertido en una de las palabras más utilizadas, tanto por los profesionales de las distintas ciencias de la salud, como en el lenguaje coloquial (Escribá-Agüir, 2005, p. 6). Selye (1956) definió el estrés como una respuesta general del organismo ante cualquier estímulo estresor o situación estresante. No obstante se han realizado múltiples trabajos sobre el estrés que han aportado diversas conceptualizaciones, la más comprensible, lo definiría como un exceso de demandas ambientales sobre la capacidad del individuo para resolverlos (Fernández et al., 1995).

Las teorías del estrés, en relación con los factores emocionales y los acontecimientos que suceden en el ambiente han sido publicadas por Lazarus y Folkman (1995). La emoción entra en juego cuando la gente valora algunos acontecimientos ambientales como amenazantes o desafiantes para su bienestar. Dependiendo de la citada valoración, las personas realizan acciones que, a manera de recursos internos, puedan hacer uso de sus capacidades para afrontar y resolver aquellos desafíos ambientales, que les permitan motivar el comportamiento que reducirá las sensaciones negativas y realzará las positivas. Muchos críticos han observado una serie de factores que pueden también explicar, en parte, las relaciones (Brief, Burke, George, Robinson y Webster, 1988). 
La mayoría de modelos de estrés laboral postulan un flujo causal general de las condiciones del medio ambiente (factores de estrés de trabajo) para empleados de centros de trabajo de salud y de bienestar; en lo que respecta a estresores de trabajo, para finales del siglo XX, se habían estudiado un número relativamente pequeño de dimensiones. Jex y Beehr (1991), en su revisión de esta área, ha identificado: la falta de control, los conflictos interpersonales, las limitaciones de la organización, la ambigüedad de rol, el conflicto de rol, y la carga de trabajo como potencialmente importantes. El presente trabajo, por lo tanto, únicamente se enfocó en medir los efectos de algunas situaciones que pudieran ser consideradas, desde la percepción de los trabajadores del centro de atención telefónica estudiada, como estresantes y de potencial impacto en su salud emocional.

\section{Planteamiento del problema}

En las encuestas de clima organizacional que la empresa realizó previamente al estudio, el estrés de este centro de trabajo se reflejaba con áreas de oportunidad, es decir, con calificaciones menores a las reflejadas por los trabajadores en la media nacional $(82.68 \leq 85)$ para el indicador estrés laboral (CFE. 2012). Por ese mismo lapso, la plantilla de personal recibía 12'587,167 llamadas, tanto de clientes divisionales (Sonora y Sinaloa), como de los clientes del Valle de México, por lo que el promedio llamadas diarias por persona, era de 73, considerando un lapso de 20 días hábiles; sin embargo, el estándar requerido por el supervisor era de 90, es decir, una llamada cada seis minutos, en jornada de siete horas, sin tomarse en cuenta la complejidad ni el tipo de servicio que el cliente demandaba. Por otra parte, se presentaron 71 casos de incapacidad por enfermedad general en 1,463 días, es decir, 20.60 días de incapacidad por caso (7.9 días de incapacidad por trabajador expuesto vs. 2.8 días del promedio nacional), lo cual implicaba un ausentismo cercano de 8 días al año por trabajador expuesto - foco rojo para el indicador ausentismo en la institución estudiadaOtros factores como permisos y faltas injustificadas, fueron considerados como manifestaciones secundarias a problemas laborales que, finalmente, resultaron en reclamos de los colaboradores ante su representación sindical.

\section{Revisión teórica}

La Organización Mundial de la Salud (OMS) define al estrés como: "Un conjunto de reacciones fisiológicas que preparan al organismo para la acción". Es un proceso que se inicia ante demandas ambientales que recibe el individuo, a las cuales éste debe ofrecer una respuesta adecuada, poniendo en marcha sus recursos de afrontamiento. Cuando la demanda del ambiente (laboral, social, económico, familiar, etc.) es excesiva frente a los recursos de afrontamiento que se poseen, se va a desarrollar una serie de reacciones adaptativas de movilización de recursos, que implican activación fisiológica. Esta reacción de estrés incluye una serie de reacciones emocionales negativas (desagradables), de las cuales las más importantes son: la ansiedad, la ira y la depresión (Cano, s.f.).

El estrés por lo tanto, es el resultado de la relación entre el individuo y su entorno. Si el individuo evalúa a dicho entorno como amenazante y que además pone en peligro su bienestar, inmediatamente reaccionará protegiéndose; es por eso que uno de los mecanismos de respuesta ante el estrés puede ser la lucha o la huida; éstas dependerán de tipo de estresor. Por ejemplo, la huida del individuo ante algún factor estresante, puede repercutir en el ámbito laboral y hacer que el colaborador se ausente del trabajo y si éste convive constantemente en ese círculo estresante, puede incluso enfermar y contribuir con la reducción de la productividad de la empresa (Whitaker, 2001). 
El estrés laboral se conceptualiza como el conjunto de fenómenos que se suceden en el organismo del trabajador debido a la participación de los agentes estresantes lesivos derivados directamente del trabajo, o que por motivo de éste, se puede afectar la salud del colaborador. Se considera, por lo tanto, que el estrés laboral afecta negativamente a la salud psicológica y física de los trabajadores y a la eficacia de las entidades para las que éstos trabajan (Leka, Griffiths y Cox, 2004).

Tanto en los países en vías de desarrollo como en los industrializados, el medio ambiente de trabajo, en conjunto con el estilo de vida, provocan la acción de factores psicológicos y sociales negativos. Por ello la importancia de su estudio desde el punto de vista profesional ha ido aumentando y sus alcances deben incluir, tanto los aspectos fisiológicos y psicológicos, como los efectos de los modos de producción y las relaciones laborales. Estos factores consisten en interacciones del trabajo, el medio ambiente laboral, la satisfacción laboral y las condiciones de la organización, por un lado, y por otra parte, las características personales del trabajador, sus necesidades, su cultura, sus experiencias y su percepción del mundo. La mayoría de modelos de estrés laboral postulan un flujo causal general de condiciones del medio ambiente (factores de estrés de trabajo) a empleados de centros de trabajo de los ámbitos de salud y bienestar. En lo que respecta al trabajo estresante, además de las contribuciones de Jex y Beehr (1991), otros autores han encontrado que la tensión de trabajo también está influenciada por el moderno estilo de vida americano (Kahn, Wolfe, Quinn, Snoek y Rosenthal, 1964); estos autores basaron su investigación desde la perspectiva de la teoría del rol. Trabajos más recientes han puesto de relieve la importancia de otros factores estresantes de trabajo, incluyendo conflicto interpersonal (Newton y Keenan, 1991) y el desempeño organizacional (Peters y O'Connor, 1980). El control administrativo, también ha sido un importante enfoque del estrés en el centro de trabajo, aunque a menudo, más como un moderador de las relaciones entre otras variables (Ganster y Fusilier, 1989).

Los principales factores psicosociales generadores de estrés presentes en el medio ambiente de trabajo, involucran aspectos de la organización, administración y sistemas de trabajo, y desde luego, la calidad de las relaciones humanas. Por ello el clima organizacional de una empresa se vincula no solamente a su estructura y a las condiciones de vida de la colectividad del trabajo, sino también a su contexto histórico con su conjunto de problemas demográficos, económicos y sociales. El crecimiento económico de la empresa, el progreso técnico, el aumento de la productividad y la estabilidad de la organización dependen, además, de los medios de producción, de las condiciones de trabajo, de los estilos de vida, así como del nivel de salud y bienestar de sus trabajadores.

$\mathrm{Si}$ bien es cierto que los cambios tecnológicos han contribuido al incremento de la eficacia, también lo es el hecho de que éstos han originado varios factores que producen estrés: presión por conservar el trabajo e inseguridad en el empleo. Los efectos de los cambios tecnológicos sobre el estrés han sido estudiados por Donaldson (1993), así como los costos de los efectos del estrés en las organizaciones (Manning, Jackson y Fusilier, 1996). Lo anterior es debido a que, cuando los trabajadores se sienten estresados, no pueden desarrollar sus capacidades al máximo, lo cual también repercute adversamente en su salud y en bajos niveles de productividad (Ho, 1997). Dicho lo anterior, el estrés laboral es una preocupación cada vez mayor entre los administradores debido a sus efectos disfuncionales sobre la eficacia organizacional.

Según la Organización Internacional del Trabajo (OIT, 1993) el estrés estuvo considerado como una de las más serias enfermedades del siglo XX. En los Estados Unidos de 
Norteamérica por ejemplo, el estrés costó a las industrias americanas alrededor de 200 billones de dólares anuales, y en el Reino Unido su costo se estimó hasta en un $10 \%$ del producto nacional bruto (Tang y Harumontree, 1992, citado en Ho, 1997). Por lo anterior, el objetivo de la presente investigación fue diagnosticar la presencia de estrés en empleados de un centro de atención telefónica y las repercusiones de éstos en la salud. La revisión de la literatura se muestra en la tabla 1.

\section{Tabla 1}

Definición de dimensiones y evidencias empíricas de los indicadores incluidos en el modelo utilizado para valorar las consecuencias emocionales del estrés

\begin{tabular}{|c|c|c|}
\hline Dimensión & $\begin{array}{l}\text { Literatura } \\
\text { revisada }\end{array}$ & Operacionalización del concepto \\
\hline \multirow{5}{*}{$\begin{array}{l}\text { Recursos } \\
\text { de Soporte }\end{array}$} & Cohen y Lazarus (1973). & $\begin{array}{l}\text { Actitud de estar alerta, sosteniendo conciencia, } \\
\text { comportamiento minucioso, activo, buscador, con } \\
\text { conocimiento, cuidadoso ante los estímulos estre- } \\
\text { sores. }\end{array}$ \\
\hline & $\begin{array}{l}\text { Cobb (1976); Kobasa } \\
\text { y Puccetti (1983). }\end{array}$ & $\begin{array}{l}\text { Conciencia de sentirse apoyado. Grado en el que } \\
\text { el individuo siente que hay gente con la que puede } \\
\text { contar en todo momento para obtener apoyo. }\end{array}$ \\
\hline & $\begin{array}{l}\text { Billings y Moss (1981); } \\
\text { Cohen y Lazarus (1973). }\end{array}$ & $\begin{array}{l}\text { Uso de estrategias que la persona utiliza para } \\
\text { afrontar, de manera positiva, los problemas y cuya } \\
\text { motivación se dirige a minimizar la percepción del } \\
\text { estrés. }\end{array}$ \\
\hline & $\begin{array}{l}\text { Siegrist (1996); } \\
\text { Fillion et al. (2007). }\end{array}$ & $\begin{array}{l}\text { Retirarse-encontrarse. Conducta de evitar pensar } \\
\text { en un trauma o sus consecuencias, a través de tener } \\
\text { conocimiento del proceso cognitivo y emocional del } \\
\text { trauma. }\end{array}$ \\
\hline & Coyne y Lazarus (1979). & $\begin{array}{l}\text { Actitud de ser sensible de eliminar el material que } \\
\text { esté en la conciencia o en la memoria a través de } \\
\text { comportamiento constructivo evitando recordar los } \\
\text { estresores. }\end{array}$ \\
\hline $\begin{array}{l}\text { Demandas } \\
\text { Laborales }\end{array}$ & $\begin{array}{c}\text { Van der Doef (1999); } \\
\text { Van Veldhoven, Taris, De } \\
\text { Jonge y Broensen (2005). }\end{array}$ & $\begin{array}{l}\text { Indicadores que facilitan y/o precipitan los efectos } \\
\text { emocionales del estrés y que repercuten en los } \\
\text { desajustes de la salud del trabajador. }\end{array}$ \\
\hline $\begin{array}{l}\text { Reacciones } \\
\text { emocionales } \\
\text { del estrés }\end{array}$ & $\begin{array}{l}\text { Norwack (2002); Van der } \\
\text { Doef (1999); Sacham } \\
\text { (1983); Richman, Wislar, } \\
\text { Flaherty, Fendrich, } \\
\text { y Rospenda (2004); } \\
\text { Jex, Bliese, Buzzell y } \\
\text { Primeau (2001). }\end{array}$ & $\begin{array}{l}\text { Síntomas que expresan afectación en la energía } \\
\text { emocional/psicológica, cognoscitiva, conductual y } \\
\text { física. Alteraciones que afectan el desempeño labo- } \\
\text { ral y que manifiestan insatisfacción, molestia, in- } \\
\text { comodidad, tendencias a la frustración, ira y otros } \\
\text { problemas derivados de una situación que avisa } \\
\text { a la persona que su energía está siendo llevada a } \\
\text { un nivel tal que no es el habitual. Dichos síntomas } \\
\text { pueden ir desde la impaciencia, imprudencia, inse- } \\
\text { guridad, falta de sueño, al consumo de sustancias } \\
\text { psicoactivas y a la búsqueda de otras soluciones or- } \\
\text { ganizacionales (cambiar de puesto, cambiar de tra- } \\
\text { bajo, etc.) }\end{array}$ \\
\hline
\end{tabular}




\section{Antecedentes}

Para la presente investigación, se tomaron en cuenta las evidencias empíricas en Fillion, et al. (2007) y la investigación sobre estrés —en Comisión Federal de Electricidad (CFE), División de Distribución Noroeste-, que efectuaron Coronado, Saavedra y Olicares (2012), en la cual se encontró que el personal de esta empresa distribuidora y comercializadora de energía eléctrica se encontraba con evidencia de estrés laboral.

En el estudio participaron 415 trabajadores seleccionados aleatoriamente, quienes respondieron a un cuestionario con escalamiento de Líkert, validado mediante análisis factorial y confiabilidad interna (Alpha de Cronbach, por dimensión). El modelo fue ajustado con ecuaciones estructurales (SPSS 16 y Amos 16), encontrándose una relación negativa entre Recursos de Soporte y Demandas Laborales (Covarianza $=-0.60, \mathrm{r}=-.232, \mathrm{P}$ $=0.007)$, aceptándose $\mathrm{H}_{\mathrm{a}}\left(x^{2}=87.77, \mathrm{gl}=40, \mathrm{p}=.000, x^{2} / \mathrm{gl}=2.19\right)$, cumpliendo los criterios $\mathrm{RMSEA}=.05$ y con los índices de comparación $\mathrm{CFI}=0.94$ y NFI $=.90$. Los resultados enfatizaron la importancia de que la empresa estudiada continuara asignando recursos para la estimulación de programas y estrategias para prevenir el estrés. Dado lo anterior, el modelo para este trabajo se muestra en la figura 1, el cual fue diseñado para medir efectos o salidas del estrés en el centro de atención telefónica regional de la misma empresa.

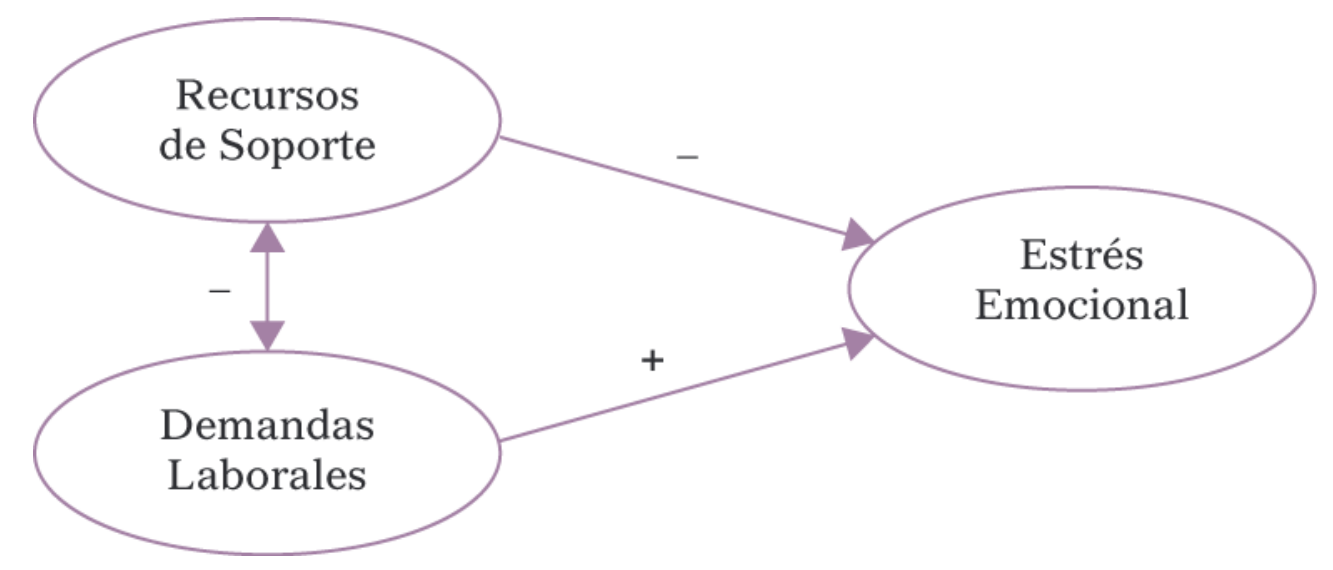

Figura 1. Modelo diseñado con recursos de soporte y demandas laborales, elaborado para medir el estrés emocional en el centro de atención telefónica regional de la CFE, División de Distribución Noroeste.

\section{Metodología}

Objetivos

Determinar si existe relación entre los Recursos de Soporte y las Demandas Laborales, se puede evidenciar estrés emocional en el personal del centro de atención telefónica regional de una empresa de servicio público, distribuidora y comercializadora de energía eléctrica en el noroeste de México.

\section{Objetivos Específicos}

- Saber si hay una relación negativa entre Recursos de Soporte y los Efectos Emocionales del estrés, en el personal del centro de atención telefónica regional de CFE, de la División de Distribución Noroeste.

- Saber si hay una relación positiva entre las demandas de trabajo y los Efectos emocionales del estrés.

- Determinar si en el modelo completo existiendo covarianza negativa entre Recursos de Soporte y las Demandas Laborales, se puede relacionar al estrés dada una rela- 
ción negativa entre los Recursos de Soporte y una relación positiva entre las Demandas Laborales y los Efectos emocionales de dicho estrés.

\section{Preguntas de Investigación}

1. ¿Los Recursos de Soporte (como indicadores de recursos de afrontamiento ante el estrés), pueden tener una relación negativa en los Efectos emocionales del estrés?

2. ¿Las Demandas Laborales (como dimensión indicadora de estresores), tienen una relación positiva en los Efectos emocionales del estrés?

3. En el modelo completo, para los colaboradores del centro de atención regional de CFE en la División de Distribución Noroeste, ¿existe una covarianza negativa entre Recursos de Soporte y Demandas Laborales, así como una relación negativa entre Recursos de Soporte y positiva entre Demandas Laborales y los Efectos emocionales del estrés?

\section{Justificación del estudio}

La Organización Mundial de la Salud (OMS) y la normatividad que, en materia de salud, aplica la empresa estudiada, destacan la importancia de evaluar los riesgos laborales a través de estrategias diagnósticas, con el fin de prevenir enfermedades, ausentismo y accidentes laborales. Por las razones anteriormente expuestas, tanto el Sindicato Único de Trabajadores Electricistas de la República Mexicana (SUTERM), como la CFE, empresa estudiada, a través de la Subgerencia de trabajo y servicios administrativos, y su Jefatura divisional de seguridad e higiene, requirieron del presente estudio empírico, el cual permitiera, a manera de diagnóstico, conocer los posibles riesgos asociados al trabajo y a la administración de la salud preventiva de su personal en el centro de atención telefónica regional noroeste.

\section{Alcance}

Para encontrar algunas salidas del estrés o consecuencias del estrés, hemos diseñado un modelo amplio, abarcando efectos fisiológicos, cognoscitivos, conductuales, entre otros; sin embargo, para el presente trabajo, sólo se publican los Efectos emocionales del estrés, considerándose para ello los factores de confiabilidad y validez del instrumento. También se comparten los resultados, resumiéndose las conclusiones de los hallazgos.

\section{Hipótesis}

La Organización Mundial de la Salud (OMS), indica que el estrés es un proceso que se inicia ante un conjunto de demandas ambientales que recibe el individuo, quien debe de responder de manera adecuada poniendo en marcha sus recursos de afrontamiento. Cuando la demanda del ambiente (laboral, social, económico, familiar, etc.) es muy grande frente a los recursos de afrontamiento que se poseen, se desarrollará una serie de reacciones adaptativas, de movilización de recursos, que implican una activación fisiológica. Esta reacción de estrés, incluye reacciones emocionales negativas como ansiedad, ira y depresión, por mencionar sólo las más importantes (Cano, s.f.). Con base en dichas evidencias, se plantearon las siguientes hipótesis:

\section{Hipótesis 1}

$\mathrm{H}_{\mathrm{a}}$ : Existe una relación negativa entre los Recursos de Soporte y los Efectos emocionales del estrés. (Es decir, entre más Recursos de Soporte tenga la persona para afrontar el estrés, menos efectos emocionales se presentan en los trabajadores). 


\section{Hipótesis 2}

$\mathrm{H}_{\mathrm{a}}$ : Existe una relación positiva entre las demandas laborales (a más estresores o demandas laborales, más efectos emocionales de estrés).

Hipótesis 3

$\mathrm{H}_{\mathrm{a}}$ : En el modelo completo y considerando una relación negativa entre Recursos de Soporte y Demandas Laborales, existe una relación negativa entre Recursos de Soporte y los Efectos emocionales del estrés, así como una relación positiva entre éstos y las Demandas Laborales.

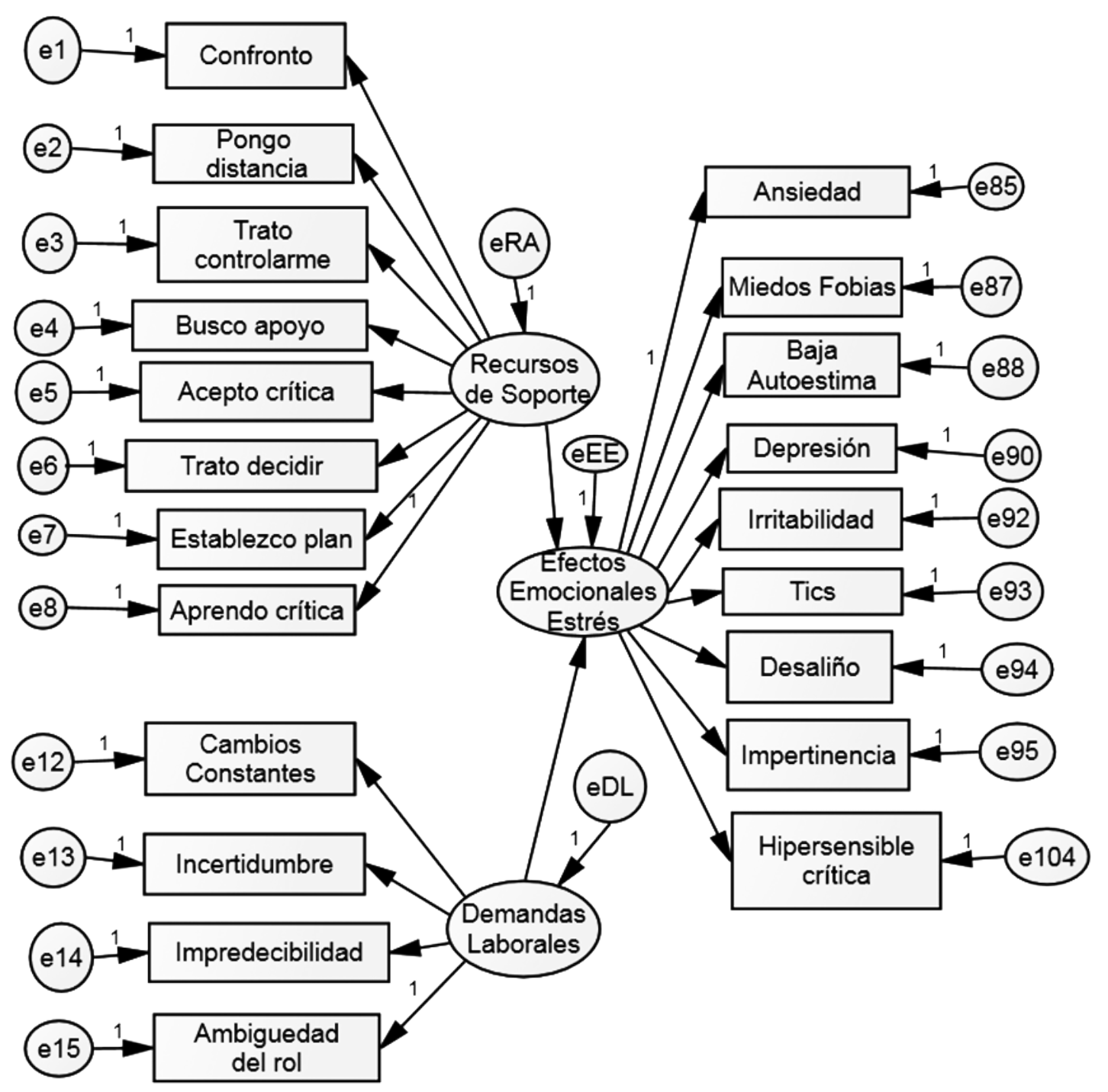

Figura 2. Relaciones esperadas entre los indicadores de las variables incluidas en el modelo completo.

\section{Análisis de datos}

Se encuestaron a 161 trabajadores, los cuales corresponden al total de la plantilla autorizada, para los tres turnos, del centro de atención telefónica de la División de Distribución Noroeste de CFE. Los participantes (59 \% hombres y $41 \%$ mujeres), refirieron una edad promedio de 29 años (D.E. = 5.16). El $54 \%$ eran solteros, $42.2 \%$ casados y $3.7 \%$ divorciados. El $60.9 \%$ tiene un contrato permanente sindicalizado y $2.5 \%$ permanente de confianza en puestos de supervisión. El 36 \% de los encuestados dijeron tener contrato temporal sindicalizado y el $.6 \%$ con contrato temporal de confianza. Para este estudio, diseñamos y desarrollamos un cuestionario, utilizado como instrumento de medición. Con el fin de analizar y determinar 
la confiabilidad interna de las preguntas para cada dimensión se utilizó el Alpha de Cronbach, así mismo, el análisis factorial a través de la prueba de KMO y Barlett. Para la reducción y reagrupamiento del cuestionario fue aplicado el método de componentes principales y el sistema de rotación octogonal denominado Varimax. Se efectuó también el análisis confirmatorio de los datos mediante la matriz de comunalidades para el nivel de varianza común de los ítems. Así mismo, se utilizó el criterio de auto valor en el cual se establece que, el costo mínimo de este criterio, sería mayor que uno para determinar el número de dimensiones. Con la intención de conservar las dimensiones como variables independientes, se empleó el procedimiento Varimax.

\section{Selección de los indicadores por componente}

Para dar respuesta a la primera hipótesis, una vez obtenido el análisis factorial y el análisis confirmatorio de los ítems que deberían incluirse en el componente de la dimensión Recursos de Soporte y habiéndose cumplido con la confiabilidad Alpha de Cronbach, se pudo apreciar que, con los indicadores: Busco Apoyo, Acepto Crítica, Establezco Plan de Trabajo y Aprendo del Problema, pudo medirse la dimensión Recursos de Soporte, siendo eliminados los indicadores: confronto el problema, pongo distancia del problema, trato de controlarme y evado decidir, por no cumplir con los criterios de inclusión (Hair, Anderson, Tatham y Black, 1999, p. 88).

Para dar respuesta a la segunda hipótesis, la dimensión Demandas Laborales pudo ser medida con los indicadores: Cambios Constantes, Incertidumbre en el Ambiente, Impredecibilidad del Tipo de Cliente, Ambigüedad entre el Enlace y/o Coordinación con otros Procesos de la CFE, habiéndose verificado que el componente cumpliera con los requisitos de ajuste y su confiabilidad Alpha de Cronbach.

Para la tercera Hipótesis, y una vez efectuado el análisis confirmatorio de los datos para las salidas del estrés, se pudo verificar que los efectos emocionales de éste resultaron con un adecuados criterios de ajuste y su respectiva Alpha de Cronbach, por lo que los Efectos emocionales del estrés pudieron ser medidos con los indicadores: Ansiedad, Miedos, Baja Autoestima, Depresión, Irritabilidad, Tics, Desaliño, Impertinencia e Hipersensibilidad a la Crítica. Para los tres componentes, las cargas factoriales y la correspondiente consistencia interna (coeficientes Alpha Cronbach), se muestran en las tablas 2, 3 y 4.

\section{Tabla 2}

Carga Factorial Varimax, KMO, Significancia de Barlett y Alpha Cronbach, por indicador de la dimensión Recursos de Soporte (Componente 1)

\begin{tabular}{|c|c|c|c|c|c|c|c|c|c|c|c|c|}
\hline $\begin{array}{l}\text { Nombre } \\
\text { Componente }\end{array}$ & Îtem & $\begin{array}{l}\text { Carga } \\
\text { Factorial } \\
\text { Varimax }\end{array}$ & $\begin{array}{c}\% \\
\text { Varianza } \\
\text { total } \\
\text { explicada }\end{array}$ & KMO & $\begin{array}{l}\text { Signifi- } \\
\text { cancia } \\
\text { Test } \\
\text { Barlett }\end{array}$ & $\begin{array}{l}\text { Alpha } \\
\text { si el } \\
\text { item } \\
\text { fuera }\end{array}$ & $\begin{array}{c}\text { Alpha } \\
\text { Cronbach }\end{array}$ & $\underset{\text { Gl }}{\text { Ch1/ }}$ & $\mathbf{p}$ & $\begin{array}{l}\text { RM- } \\
\text { SEA }\end{array}$ & CFI & NFI \\
\hline Busco apoyo & 4 & 0.65 & \multirow{4}{*}{53.47} & \multirow{4}{*}{0.7} & \multirow{4}{*}{0.000} & 0.59 & \multirow{4}{*}{0.7} & \multirow{4}{*}{1.55} & \multirow{4}{*}{0.21} & \multirow{4}{*}{0.058} & \multirow{4}{*}{0.99} & \multirow{4}{*}{0.99} \\
\hline Acepto crítica & 5 & 0.83 & & & & 0.55 & & & & & & \\
\hline $\begin{array}{l}\text { Establezco } \\
\text { plan }\end{array}$ & 7 & 0.7 & & & & 0.66 & & & & & & \\
\hline $\begin{array}{l}\text { Aprendo del } \\
\text { problema }\end{array}$ & 8 & 0.74 & & & & 0.63 & & & & & & \\
\hline Total de ítems & 4 & & & & & & & & & & & \\
\hline
\end{tabular}


Tabla 3

Carga Factorial Varimax, KMO, Significancia de Barlett y Alpha Cronbach, por indicador de la dimensión Demandas Laborales (Componente 2)

\begin{tabular}{|c|c|c|c|c|c|c|c|c|c|c|c|c|}
\hline $\begin{array}{c}\text { Nombre } \\
\text { Componente }\end{array}$ & Ítem & $\begin{array}{c}\text { Carga } \\
\text { Factorial } \\
\text { Varimax }\end{array}$ & $\begin{array}{c}\% \\
\text { Varianza } \\
\text { total } \\
\text { explicada }\end{array}$ & KMO & $\begin{array}{l}\text { Signifi- } \\
\text { cancia } \\
\text { Test } \\
\text { Barlett }\end{array}$ & $\begin{array}{l}\text { Alpha } \\
\text { si el } \\
\text { ítem } \\
\text { fuera }\end{array}$ & $\begin{array}{l}\text { Alpha } \\
\text { Cron- } \\
\text { bach }\end{array}$ & $\begin{array}{c}\mathrm{Ch} 1 / \\
\text { Gl }\end{array}$ & $\mathbf{p}$ & $\begin{array}{l}\text { RM- } \\
\text { SEA }\end{array}$ & CFI & NFI \\
\hline $\begin{array}{l}\text { Cambios } \\
\text { constantes }\end{array}$ & $\mathrm{p} 12$ & 0.71 & \multirow{4}{*}{63.88} & \multirow{4}{*}{0.79} & \multirow{4}{*}{0.000} & 0.766 & \multirow{4}{*}{0.811} & \multirow{4}{*}{0.027} & \multirow{4}{*}{0.973} & \multirow{4}{*}{0.000} & \multirow{4}{*}{1.0} & \multirow{4}{*}{1.0} \\
\hline Incertidumbre & $\mathrm{p} 13$ & 0.84 & & & & 0.72 & & & & & & \\
\hline Impredecibilidad & $\mathrm{p} 14$ & 0.66 & & & & 0.781 & & & & & & \\
\hline $\begin{array}{l}\text { Ambigüedad } \\
\text { enlace }\end{array}$ & p15 & 0.68 & & & & 0.78 & & & & & & \\
\hline Total de ítems & 4 & & & & & & & & & & & \\
\hline
\end{tabular}

\section{Tabla 4}

Carga Factorial Varimax, KMO, Significancia de Barlett y Alpha de Cronbach por indicador de la dimensión Efectos Emocionales del Estrés (Componente 3) en el centro de atención telefónica de CFE, División de Distribución Noroeste

\begin{tabular}{|c|c|c|c|c|c|c|c|c|c|c|c|c|}
\hline $\begin{array}{c}\text { Nombre } \\
\text { Componente }\end{array}$ & Ítem & $\begin{array}{c}\text { Carga } \\
\text { Factorial } \\
\text { Varimax }\end{array}$ & $\begin{array}{c}\% \\
\text { Varianza } \\
\text { total } \\
\text { explicada }\end{array}$ & KMO & $\begin{array}{c}\text { Signifi- } \\
\text { cancia } \\
\text { Test } \\
\text { Barlett }\end{array}$ & $\begin{array}{l}\text { Alpha } \\
\text { si el } \\
\text { ítem } \\
\text { fuera }\end{array}$ & $\begin{array}{l}\text { Alpha } \\
\text { Cron- } \\
\text { bach }\end{array}$ & $\begin{array}{c}\text { Chl/ } \\
\text { Gl }\end{array}$ & $\mathbf{p}$ & $\begin{array}{l}\text { RM- } \\
\text { SEA }\end{array}$ & CFI & NFI \\
\hline Ansiedad & p85 & 0.723 & \multirow{9}{*}{65.5} & \multirow{9}{*}{0.922} & \multirow{9}{*}{0.000} & 0.932 & \multirow{9}{*}{0.934} & \multirow{9}{*}{1.609} & \multirow{9}{*}{0.1} & \multirow{9}{*}{0.5} & \multirow{9}{*}{0.99} & \multirow{9}{*}{0.97} \\
\hline $\begin{array}{l}\text { Crisis emociona- } \\
\text { les / miedo }\end{array}$ & p87 & 0.865 & & & & 0.932 & & & & & & \\
\hline Baja autoestima & p88 & 0.815 & & & & 0.926 & & & & & & \\
\hline Depresión & p90 & 0.865 & & & & 0.922 & & & & & & \\
\hline Irritabilidad & p92 & 0.866 & & & & 0.922 & & & & & & \\
\hline Tics nerviosos & p93 & 0.804 & & & & 0.927 & & & & & & \\
\hline Desaliño & p94 & 0.752 & & & & 0.93 & & & & & & \\
\hline Impertinencia & p95 & 0.846 & & & & 0.924 & & & & & & \\
\hline $\begin{array}{l}\text { Hipersensibili- } \\
\text { dad crítica }\end{array}$ & p104 & 0.739 & & & & 0.931 & & & & & & \\
\hline Total de ítems & 9 & & & & & & & & & & & \\
\hline
\end{tabular}

La redacción de los constructos se realizó con base en la recopilación del sustento teórico, la evidencia empírica, así como considerando la valoración de expertos en psicología organizacional y los jefes de personal de la CFE. La muestra consideró al total de los trabajadores del Centro de Atención Telefónica Regional (CAR) de la CFE, el cual atiende llamadas del Número Telefónico 071, en los estados de Sonora y Sinaloa de la División de Distribución Noroeste. La tasa de respuesta para las 161 encuestas fue del $100 \%$, las cuales fueron aplicadas por personal de la empresa estudiada, debidamente entrenado para ello, contándose con el apoyo tanto de los líderes de la empresa, como del sindicato. Los empleados respondieron el instrumento utilizando escalamiento de Líkert 
(1 para desacuerdo y 5 para completamente de acuerdo). Para el análisis de los datos se utilizó el programa SPSS 19 y no fue eliminado ningún cuestionario. Para dar respuesta a las hipótesis se utilizó el método de ecuaciones estructurales, a través del programa Amos, versión 19. Para la bondad de ajuste se tomaron los parámetros citados en Arbuckle (1995, pp. 589-605), según las siguientes reglas: aceptar la hipótesis de ajuste cuando el RMSE $\leq .08, \mathrm{CFE}$ y $\mathrm{NFI}>.95, \mathrm{Chi}^{2} / \mathrm{gl} \leq 2$ y para $\mathrm{Chi}^{2}$ cuando el valor de $\mathrm{p}$ sea $>.05$. Previamente a la determinación de la bondad de ajuste de los indicadores respecto a las dimensiones, se verificó la inclusión o exclusión de éstos considerando el cumplimiento de los criterios mencionados por Arbucke (1995). Para la eliminación de ítems, se tomó en cuenta el criterio de Hair et al. (1999, p. 88).

\section{Resultados}

Primera hipótesis

Con los indicadores: Busco Apoyo $\left(\beta=.851^{* * *}\right)$, Aprendo del Problema $\left(\beta=.88^{* * *}\right)$, Acepto Crítica $(\beta=1.00)$ y Establezco Plan de Trabajo $\left(\beta=.827^{* * *}\right)$, de la dimensión Recursos de Soporte -como recursos de afrontamiento-, ésta resultó con una relación negativa $(\beta=-70$, D.E. $=.15$, C.R. $\left.=-4.68, \mathrm{p}={ }^{* * *}\right)$, por lo que se aceptó $\mathbf{H}_{\mathrm{a}}$.

\section{Segunda Hipótesis}

Con los indicadores: Cambios Constantes, Incertidumbre en el Ambiente, Impredecibilidad del Tipo de Cliente, Ambigüedad entre el Enlace y/o Coordinación con otros Procesos de la CFE, la dimensión Demandas Laborales se relacionó positivamente con los Efectos emocionales del estrés $(\beta=.89$, D.E. $=.145$, C.R. $=6.151, \mathrm{p}=* * *)$, aceptándose por ello la $\mathbf{H}_{\mathrm{a}}$ de la segunda hipótesis.

\section{Tercera Hipótesis}

Se aceptó también la Tercera Hipótesis de investigación, porque Recursos de Soporte se relacionaron de manera negativa con la variable Efectos Emocionales del Estrés y la dimensión Demandas Laborales, se relacionó positivamente con dichos efectos (Tabla 5). La covarianza entre Recursos de Afrontamiento y Demandas Laborales, aunque positiva, no resultó significativa $(\mathrm{p}<.05$, además de que arrojó un valor de relación muy débil $($ covarianza $=.19)$, como se aprecia en la figura 3.

\section{Tabla 5}

Resultados de los estimadores de regresión obtenidos para responder a la séptima hipótesis

\begin{tabular}{|c|c|c|c|c|c|c|c|c|c|c|}
\hline $\begin{array}{l}\text { Compo- } \\
\text { nente } \\
\text { No. }\end{array}$ & Dimensión & $\begin{array}{c}\text { Nombre } \\
\text { Componente }\end{array}$ & Ítem & Media & $\begin{array}{l}\text { Desviación } \\
\text { Estándar }\end{array}$ & $\begin{array}{c}\text { Alpha } \\
\text { Cronbach }\end{array}$ & $\beta$ & DE & C.R. & $\mathbf{P}$ \\
\hline \multirow{5}{*}{1} & \multirow{5}{*}{$\begin{array}{l}\text { Recursos } \\
\text { de } \\
\text { Soporte }\end{array}$} & Busco apoyo & 4 & 4 & 0.79 & \multirow{5}{*}{0.7} & 0.85 & 0.145 & 6.15 & $* * *$ \\
\hline & & Acepto crítica & 5 & 4.28 & 0.87 & & 1.00 & & & \\
\hline & & Establezco plan & 7 & 4.4 & 0.71 & & 0.827 & 0.143 & 5.767 & $* * *$ \\
\hline & & $\begin{array}{l}\text { Aprendo del } \\
\text { problema }\end{array}$ & 8 & 4.62 & 0.73 & & 0.88 & 0.880 & 0.139 & $* * *$ \\
\hline & & Promedio Rec. Afr. & & 4.33 & 0.78 & & & & & \\
\hline
\end{tabular}




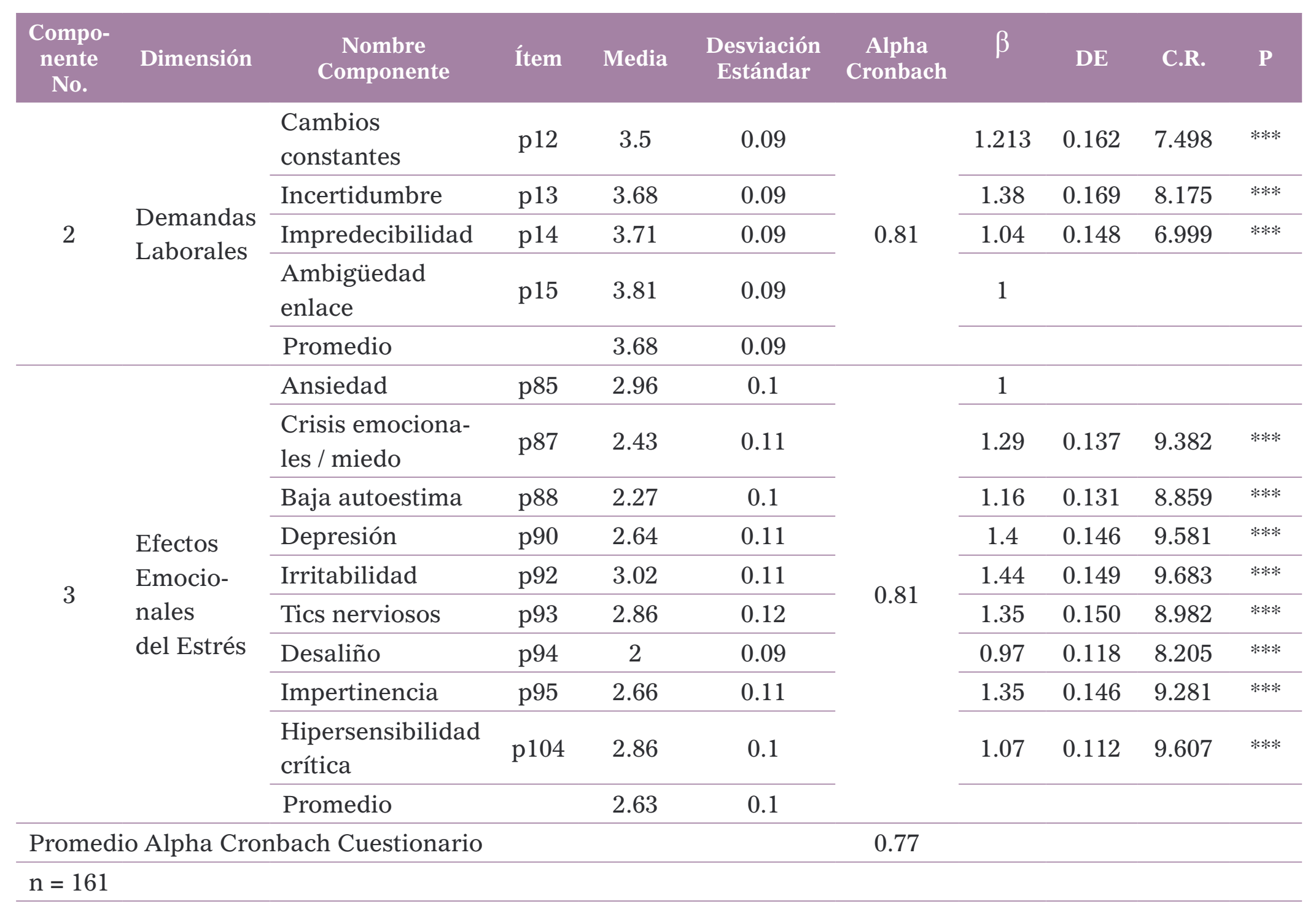

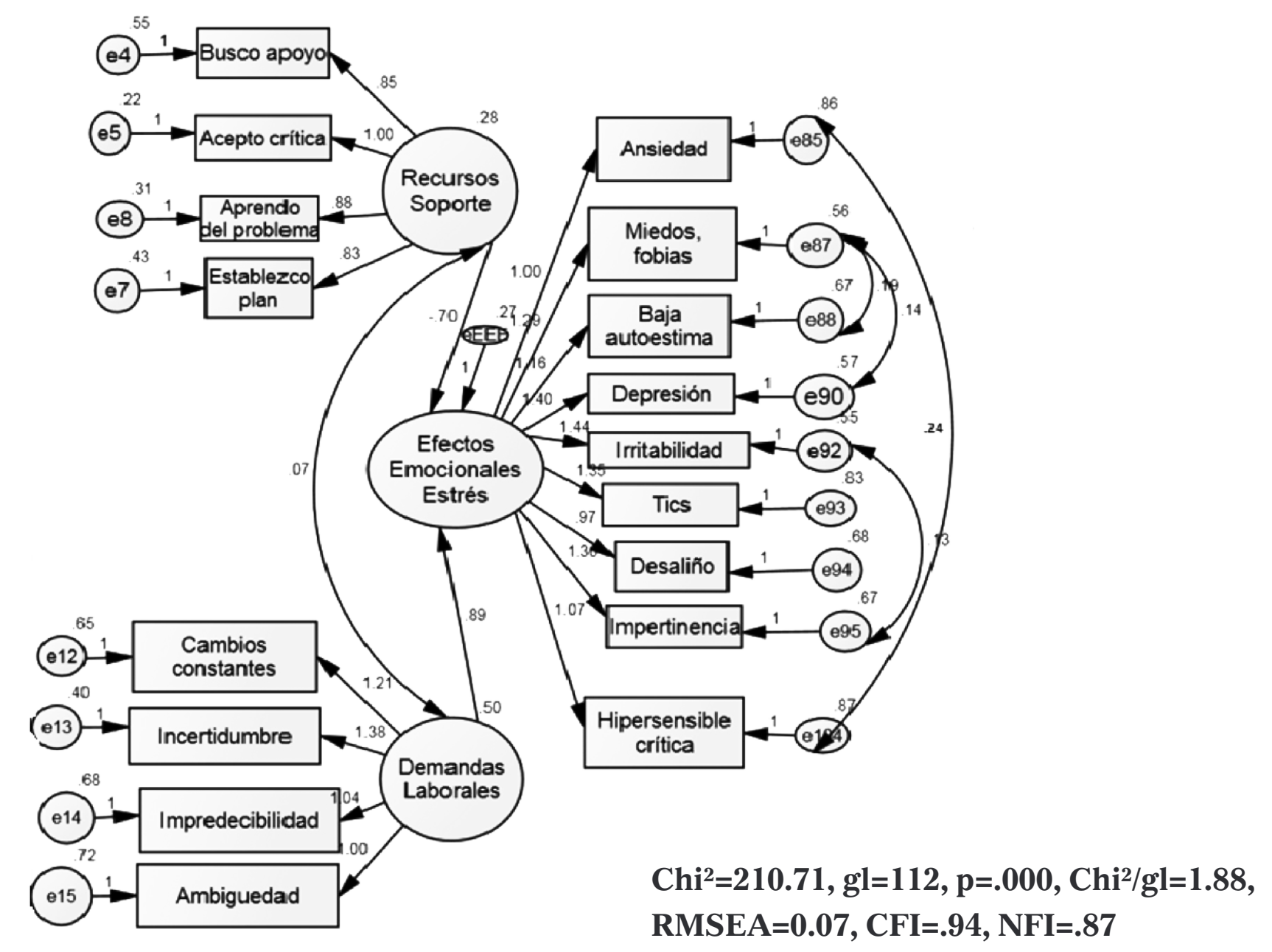

Figura 3. Resultados del modelo completo para medir Estrés Laboral en el Centro de Atención Telefónica Regional de CFE, División de Distribución Noroeste. 


\section{Conclusiones}

Concordando con Fillion et al. (2001) y con Coronado et al. (2012), en el centro de trabajo de la empresa estudiada, se encontró una relación negativa entre los Recursos de Soporte Laboral, positiva con las Demandas Laborales y los efectos del Estrés. Por otra parte, en la primera hipótesis el personal dijo contar con recursos $\left(\beta=-.70^{* * *}\right)$ que les permitiera paliar o enfrentar el estrés; el indicador que más contribuyó a ello fue: Acepto la Crítica $\left(\mathrm{R}^{2}=.57\right)$. Así mismo, se coincidió con Reed, Store y Anthony (2006), en el sentido de que los trabajadores encuestados encontraron algunos estresores que precipitan de manera positiva $\left(\beta=.89^{* * *}\right)$ los efectos del estrés, lo cual no les permite la percepción de tener un mejor clima en el trabajo, refiriendo que "Incertidumbre", fue el indicador que más contribuyó con estresar a las personas $\left(\mathrm{R}^{2}=.70\right)$ de este centro de trabajo.

Al igual que en las evidencias del Modelo de Fillion et al. (2007), en el Centro de Atención Telefónica 071, de CFE, División Noroeste, fueron encontrados desajustes emocionales (Emotional distress), como consecuencias del estrés. Entre las reacciones emocionales del estrés, se coincidió con Bell y Byrne (1978) y Byrne (1964), porque las personas encuestadas manifestaron ansiedad $(\beta=1.00)$. También en nuestro modelo, las salidas del estrés encontraron relación interesante entre: Baja autoestima asociada con miedos o fobias (covarianza $=.195^{* * *}$ ).

Los resultados permitieron tomar decisiones relativas a incrementar los Recursos de Soporte que permitieran a los trabajadores del Centro de Atención Telefónica, tener más soporte para afrontar o paliar el estrés inherente a un área de trabajo en la cual, dada la naturaleza de la tarea, se reciben quejas, reclamos y solicitudes de diferente tipo de servicios y distintos estilos de personalidad de los clientes de la empresa estudiada, así mismo, procurar balance entre el trabajo y la familia (Kobasa, Maddi y Kahn, 1981), mejorar el clima organizacional y la cultura participativa de los trabajadores -Fillion et al. (2007); Andrews y Kacmar (2001)_, y fomentar empoderamiento que les permita tener más control sobre su trabajo (Reed et al., 2006), acciones que incrementen el trabajo en equipo (Karasek y Theorell, 1990; Fillion et al.,2007), el afrontamiento positivo de los problemas (Nowack, 1989), y el reconocimiento por el trabajo bien hecho (Siegrist, 1996; Fillion et al., 2007). Así mismo reducir, en lo posible, los efectos negativos del estrés a través de promover el ejercicio físico (Nowack, 2002), canalizar a través del ejercicio y el coaching personalizado, la angustia y la desesperación (Nowack, 2002) y otras estrategias asociadas a minimizar la tensión laboral. 


\section{Referencias}

Arbuckle, J.L. (1995). Amos 18 Users's Guide. Chicago: Amos Development Corporation. Recuperado de http://www.sussex.ac.uk/its/pdfs/Amos_18_Users_Guide.pdf

Andrews, M.C., \& Kacmar, K.M. (2001). Confirmation and Extension of the Sources of Feedback Scale in Service-Based Organizations. The Journal of Business Communication, 38 (2).

Bell, P., \& Byrne, D. (1978). Ropression-sensitization. In H. London \& J. Exner (Eds.), Dimensions of personality (pp. 449-485). New York: Wiley.

Billings, A., \& Moss R. (1981). The Role of Coping Responses and Social Resources in Attenuating the Stress of Live Events. Journal of Behaviioral Medicine, 4, 139-157.

Brief, A. P., Burke, M. J., George, J. M., Robinson, B. S., \& Webster, J. (1988). Should negative affectivity remain an unmeasured variable in the study of job stress? Journal of Applied Psychology, 73, 193-198.

Byrne, D. (1964). Repression-sensitization as a dimension of personality. In B.A. Maber (Ed.), Progress in experimental personality research (Vol. 1, pp. 169-220). New York: Academic Press.

Cano, A. (s.f.). La naturaleza del estrés. Sociedad española de la Ansiedad y el Estrés. Recuperado de http://pendientedemigracion.ucm.es/info/seas/estres_lab/el_estres. htm

Cobb S. (1976). Social Support as a Moderator of Life Stress. Psychosomatic Medicine, 35, 375-379.

Cohen, F., \& Lazarus, R. (1973). Active coping processes, coping dispositions, and recovery from surgery. Psichosomatic Medicine, 35, 375-389.

Comisión Federal de Electricidad (CFE). (2012). Encuesta de Clima Organizacional de la Comisión Federal de Electricidad (Encuesta SICLO).

Coronado, J.A. Saavedra, M.E., \& Olivares, A. (2012), Estrés, demandas laborales y Recursos de Soporte en Instituciones Públicas. En Estudios Organizacionales para la Competitividad: estrés, demandas laborales y recursos de soporte en instituciones públicas. Ciudad de México: Pearson.

Coyne, J., \& Lazarus, R. (1979). The Ipsative-Normative Framework for the Longitudinal Study of Stress. Documento presentado en la convención annual de la American Psychological Association, Nueva York.

Donaldson, S.I. (1993). Effects of lifestyle and stress on the employee and organization: Implications for promoting health at work. Anxiety, Stress and Coping. An international Journal, 6(3).

Du Gay, P. (1996). Consumption and identy at work. London: Sage.

Escribá-Agüir, V. (2005). Ambiente psicosocial y salud de los trabajadores. Archivos de Prevención, Riesgos Labor, 9(1), 6-9. Recuperado de http://www.archivosdeprevencion. com/view_document.php?tpd=2\&i=1377

Fernández, M.I., Villagrasa, F.R., Fe Gamo, M., Vázquez, J., Cruz, E., Aguirre, M.V., \& Andradas, V. (1995). The study of occupacional satisfaction and its determining factors among health professional working in one of the areas in Madrid. Revista Española de Salud Pública, 69(6), 487-497.

Fillion, L., Tremblay, I., Truchon, M., Côté, D., Struthers, W., \& Dupuis R. (2007). Job Satisfaction and Emotional Distress Among Nurses Providing Palliative Care: Empirical Evience for an Integrative Occupational Stress-Model. International Journal of Stress Management, 14(1), 1-25. 
Ganster, D.C., \& Fusilier, M.R. (1989). Control in the workplace. In C.L. Cooper, \& I.T. Robertson (Eds.), International review of industrial and organizational psychology 1989 (pp. 236-280). Chichester, England: Wiley.

Hair, J.F, Anderson, R.E, Tatham R.L., \& Black, W.C (1999). Análisis Multivariante. Madrid: Prentice Hall Iberia.

Ho, J.T.S. (1997). Corporate wellness programmes in Singapore: effect on stress, satisfaction and absenteeism. Journal of Managerial Psychology, 12(3-4), 177-189.

Jex, S.M., \& Beehr,T.A. (1991). Emerging theoretical and methodological issues in the study of work-related stress. Research in Personnel and Human Resources Management, 9, 311-365.

Jex, S.M., Bliese, P.D., Buzzell, S., \& Primeau, J. (2001). The Impact of Self-Efficacy on Stressor-Strain Relations: Coping Style as an Explanatory Mechanism. Journal of Applied Psychology, 86(3), 401-409.

Kahn, R.L., Wolfe, D.M., Quinn, R.P., Snoek, J.D., \& Rosenthal, R.A. (1964). Organizational stress: Studies in role conflict and ambiguity. New York: Wiley.

Karasek, R., \& Theorell,T. (1990). Healthy work: stress, productivity and the reconstruction of the working life. Nueva York: Basic Books.

Kobasa, S.C., Maddi, S.R., \& Kahn, S. (1981). Hardiness and health: A prospective study. Journal of Personality and Social Psychology, 42, 168-177.

Kobasa, S.C., \& Puccetti, M.C. (1983). Personality and Social Ressources in Stress Resistence. Journal of Personality and Social Psychology. 45, 839-850.

Lazarus, R.S., \& Folkman, S. (Eds.). (1995). Stress, appraisal and coping. NewYork: Springer.

Leka S., Griffiths, A., \& Cox, T. (2004). La organización del trabajo y el estrés. Francia: Organización Mundial de la Salud. Recuperado de http://www.who.int/occupational_ health/publications/pwh3sp.pdf

Manning, M.R., Jackson, C.N., \& Fusilier, M.R. (1996). Ocupational stress and health care use. Journal of Ocupational Health Psychology, 1, 100-9.

Newton, T., \& Keenan, T. (1991). Further analyses of the dispositional argument in organizational behavior. Journal of Applied Psychology, 76, 781-787.

Nowack, K.M., \& Hanson, A.L. (1983). The Relationship Between Stress, Job Performance, and Bournout in College Student Resident Assistants. Journal of College Student Personnel, 24, 545-550.

Nowack, K.M. (2002). Perfil de Estrés. México: Manual Moderno.

Organización Mundial de la Salud (OMS). (2004). Recuperado de http://apps.who.int/iris/ browse?type $=$ mesh\&sort_by $=1 \&$ order $=$ ASC\&rpp $=20 \&$ etal $=-1 \&$ authority $=$ Stress + Dis orders $\% 2 \mathrm{C}+$ Traumatic\&starts_with $=\mathrm{E}$

Organización Internacional del Trabajo (OIT). (1993). Estrés en el trabajo. Trabajo en el Mundo (Ginebra), (6), 79-92.

Peters, L.H., \& O'Connor, E.J. (1980). Situational constraints and work outcomes: The influences of a frequently overlooked construct. Academy of Management Review, 5, 391-397.

Reed, P.L., Store, C.L., \& Anthony, J.C. (2006). Drug Dependence Enviromics: Job Strain in the Work Environment and Risk of Becoming Drug-Dependent. American Journal of Epidemiology 163(5), 404-411.

Richman, J.A., Wislar, J.S., Flaherty, J.A., Fendrich, M., \& Rospenda, K.M. (2004). Effects on Alcohol Use and Anxiety of the September 11, 2001, Attacks and Chronic Work Stressors: A Longitudinal Cohort Study. American Journal of Public Health, 94 (11). 
Russell, B. (2008). Call centers: A decade of research. International Journal of Management Reviews, 10(3), 195-219.

Sacham, S. (1983). A Shortened Version of the Profile of Mood States. Journal of Personality Assessment, 47, 305-306.

Siegrist, J. (1996). Adverse health effects of high-effor/low-reward conditions. Journal of Occupational Health Psychology, I, 27-41.

Schneider, B., \& Bowen, D. (1995). Winning the service game. Cambridge, MA: Harvard Business School Pres.

Van der Doef, M. (1999). The Job Demand-Control/Support). Model and Psychological WellBeing: A Review of 20 Years of Empirical Research. Work y Stress 13, pp. 87-114.

Van Veldhoven, M.,Taris,T.W., De Jonge, J., \& Broensen, S. (2005).The Relationship Between Work Characteristics and Employee Health and Well-Being: How Much Complexity to we Really Need? International Journal of Stress Management, 12. 3-28.

Whitaker, S.C. (2001). The Management of sickness absense. Occupational and Environmental Medicine, 58(6), 420-424. https://doi.org/10.1136/oem.58.6.420 


\section{Capítulo 8}

Competitividad en PyMES de confección textil.

Una perspectiva desde las habilidades humanas de sus directivos

Jesús Enrique García Guiliany Ronald Antonio Prieto Pulido

Ernesto Rafael García Cali 
Proyecto de investigación:

Competitividad en las Pymes manufactureras del sector textil. Estudio comparativo entre Colombia y Venezuela (2015-2016).

Jesús Enrique García Guiliany, Universidad de la Costa, Barranquilla-Colombia jgarcia60@cuc.edu.co

Ronald Antonio Prieto Pulido, Universidad Simón Bolívar, Barranquilla-Colombia rprieto1@unisimonbolivar.edu.co

Ernesto Rafael García Cali, Universidad de la Costa egarcia29@cuc.edu.co 


\section{Capítulo 8}

\section{Competitividad en PyMES de confección textil.}

\section{Una perspectiva desde las habilidades humanas de sus directivos}

\section{Introducción}

El reto actual de la dirección y gestión de las pequeñas y medianas empresas (Pyme) se basa en propiciar la competitividad de este tipo de organizaciones logrando la eficiencia, eficacia, y efectividad en sus procesos tanto administrativos como productivos, pudiendo así presentar mejores desempeños direccionados a su sostenibilidad económica en los mercados en los que se desarrollan.

En este sentido, en la búsqueda de la competitividad de las Pymes se considera de suma importancia el rol que desempeñan sus dirigentes, quienes en sus funciones gerenciales deben fortalecer los procesos que se desarrollan y las competencias de sus colaboradores (Prieto, Emonet, García y González, 2015).

Dentro de este orden de ideas, cabe destacar el protagonismo que han tenido las micro, pequeñas y medianas empresas en Colombia, las cuales según estudios propiciados por la Cámara de Comercio de Bogotá (2014), corresponden a un poco más del $96 \%$ de las organizaciones productivas en el país, generando por tanto un alto índice de empleabilidad y de ingresos al producto interno bruto.

Bajo este contexto, se inscriben las pymes del sector de confección-textil, las cuales en cifras del Departamento Administrativo Nacional de Estadística (DANE) en 2015 se registraron entre noviembre y diciembre de ese año un crecimiento de $4.8 \%$ en producción, $4.3 \%$ en ventas y $0.7 \%$ en generación de empleo; muy particularmente hilatura, tejeduría y acabado de productos textiles presentó un incremento de $1.5 \%$ en producción y $0.9 \%$ en ventas, en tanto que las confecciones subieron $5.9 \%$ y $4.1 \%$ en el referido período (El Espectador, 2016).

Estos excelentes resultados de las pymes del sector de confección textil, puede ser una consecuencia de las capacidades de sus gerentes, en forma particular las habilidades humanas, las cuales son aquellas que utilizan para liderar, motivar y empoderar a sus colaboradores, en pro del logro de los objetivos empresariales. Estas habilidades humanas, en criterio de Gimeno (2003) forman parte de su propia personalidad pero también pueden ser aprendidas, mencionando entre ellas: el carácter, la emocionalidad, el autoconocimiento, 
la auto regulación, la comunicación efectiva, el análisis de problemas, la gestión del tiempo, la capacidad de tomar decisiones, el trabajo en equipo, entre otras.

Es decir, estas habilidades humanas permiten el mejoramiento del clima laboral y la competitividad, pues facilitan y propician motivaciones, sentido de pertenencia y un mejor desempeño de las organizaciones.

Sobre esta base, el proyecto pretende analizar la competitividad en pymes de confección textil en el Departamento del Atlántico, Colombia, desde una perspectiva de las habilidades humanas de sus líderes, para lo cual se estructura en cuatro fases: la primera donde se desarrollan las bases teóricas abordando el estado del arte de la competitividad, e igualmente se profundiza sobre las habilidades humanas en directivos de pymes; segunda fase se señalan los aspectos metodológicos; tercera fase se muestra el análisis de datos y resultados; y una cuarta fase donde se presentan las conclusiones del presente estudio.

\section{Planteamiento del problema}

La capacidad gerencial, la estrategia y la colaboración del talento humano son aspectos requeridos para mantener la competitividad en las empresas. Al respecto, la Asociación Española de Contabilidad y Administración define competitividad como la capacidad de una organización para obtener y mantener sistemáticamente unas ventajas comparativas que le permiten alcanzar, sostener y mejorar una determinada posición en el entorno socioeconómico en que actúa (AECA, 2010, citado en Luna, Aguilar y Espinosa, 2014).

Cabe entonces establecer, que la competitividad de las empresas es concebida como las estrategias utilizadas en sus procesos administrativos y operativos, en la búsqueda permanente de la optimización de recursos para desarrollar su posicionamiento en el mercado.

En este contexto, Montoya, Montoya y Castellanos (2010) indican que en Colombia este desempeño competitivo, desde una dimensión microeconómica, es fundamental para el fortalecimiento de las empresas. Por su parte, el Gobierno Nacional de Colombia publica su política nacional de competitividad y productividad (CONPES 3527, 2008) — desarrollada por el Consejo Nacional de Política Económica y Social-, que apoyada en la ley sobre el desarrollo de cadenas productivas (Ley 811, 2003), establece en un informe las dificultades para que Colombia sea más competitiva, centrándose en los elementos mostrados en la tabla 1.

\section{Tabla 1}

Limitantes para que las empresas colombianas sean competitivas

\section{Dificultades para que Colombia sea más competitiva}

1. Poca sofisticación y baja agregación de valor en los procesos productivos.

2. Baja productividad y capacidad de generación de empleo en los sectores formales.

3. Altos niveles de informalidad empresarial y laboral.

4. Bajos niveles de innovación y absorción de tecnologías.

5. Poca profundidad y sofisticación del mercado financiero.

6. Estructura tributaria poco amigable a la competitividad.

7. Rezago en penetración de tecnologías de información y conectividad.

8. Debilidad de la institucionalidad relacionada con la competitividad. 
Por otro lado, Montoya et al. (2010) argumentan ante estas situaciones, que el Gobierno Nacional de Colombia ha realizado esfuerzos por propiciar un ambiente de competitividad favorecedor, llevando a cabo actividades como:

los encuentros de productividad y competitividad, la conformación de clústeres (Minindustria, 2010), conformación de cadenas productivas (Cámara de Comercio de Bogotá, 2007; Minindustria, 2010), los Comités Asesores Regionales de Comercio Exterior, Carce, la Agenda de conectividad, el Sistema Administrativo Nacional de Competitividad, la Ley Pyme, el Fondo Colombiano de Modernización y Desarrollo Tecnológico de las Micro, Pequeñas y Medianas Empresas, Fomipyme (Mincomercio, 2007) y la Visión 2019. (Montoya et al., 2010, p. 114).

En este orden de ideas, Morales (2007, citado en Montoya et al., 2010) señala que en Colombia, la Ley 590 permite crear bases para una competitividad sistémica, pero es evidente que la no articulación entre los actores involucrados en el fortalecimiento real del sector es un gran inconveniente, dado que aunque se tienen programas orientados al apoyo de los proyectos de las pyme, en algunos casos estos no son conocidos por quienes dirigen estas organizaciones, limitando la posibilidad de aprovechar las habilidades gerenciales de los directivos de las pymes en el país.

Entendiendo por habilidades gerenciales, al conjunto de capacidades y conocimientos que una persona necesita para poder realizar las actividades de administración y liderazgo en el rol de gerente de una organización determinada; Perdomo y Prieto (2009), plantean que la gerencia moderna implica desarrollar habilidades directivas, fomentar la creatividad y participación de todos los miembros de una empresa. De tal manera, que el gerente-líder debe ser visionario, agente de cambio, con visión y misión claras, integrador de equipo y sobre todo un buen comunicador.

Asimismo, Mahon (1999) plantea que las habilidades gerenciales deben responder a los requerimientos de cambio, a una compleja estrategia con la finalidad de transformar las creencias, actitudes, valores y estructura de las organizaciones, tal como las pyme, de modo que éstas puedan adaptarse mejor a nuevas tecnologías, otros mercados, y a desafíos para lograr ser exitosos, con la conducción de un líder con habilidades humanas. Por cuanto, esta condición de humanismo puede conjugar un ambiente laboral sano, con colaboradores motivados, empoderados y enfocados hacia el mejor desempeño de estas pymes.

A la realidad señalada, no escapan las pymes de confección textil en el Departamento del Atlántico, las cuales según Cidetexco (2009) y con datos de Procolombia (2014), presentan como debilidades: capital humano con baja calificación técnica, poca actualización en procesos tecnológicos, maquinarias con más de 20 años de uso, dificultades para satisfacer las demandas del mercado en procesos de lavado y tinturado, dificultad para abordar los costos de pruebas para el tratamiento de nuevas telas, altos desperdicios de materias primas, especialmente en procesos de hilatura, produciendo con sobre costos por pérdidas de materiales y poca integración de la cadena productiva; derivándose esto en oportunidades de mejora en su competitividad.

Con base a lo planteado, se considera relevante realizar una investigación orientada al análisis de la competitividad de las pymes de confección textil en el Departamento del Atlántico, desde la perspectiva de las habilidades humanas de sus directivos, que al disponer de un estilo gerencial basado en competencias humanas, posiblemente se puedan 
presentar oportunidades de mejora a las condiciones señaladas y por tanto conducir a las pymes de confección textil por mejores derroteros de competitividad.

Surgiendo entonces la interrogante que le da sentido a la investigación: ¿Cómo será la competitividad en pymes de confección textil, desde la perspectiva de las habilidades humanas de sus directivos?

\section{Revisión Teórica}

El estudio de la competitividad de las regiones ha tenido gran relevancia, a criterio de Bonnefoy (2003) esto ha sido con el propósito de mejorar el desempeño de las regiones y la calidad de vida de sus habitantes, identificando en qué aspectos la región presenta deficiencias y de esta manera desarrollar actividades que movilicen la acción colectiva de los ciudadanos, las empresas y las agencias públicas.

En atención al planteamiento anterior, Stoner et al. (1996, citados por Prieto, García y González, 2014) señalan que la competitividad es "la posición que tiene un competidor con relación a otros”. Esto se puede interpretar como las distintas estrategias que despliegan hoy en día las empresas y sectores industriales en sus procesos productivos, de comercialización, distribución y a lo largo de toda su cadena de valor, en la búsqueda permanente de la optimización de recursos para potenciar su posicionamiento en el mercado, sea este de índole local, nacional o internacional. La idea, no es buscar una posición destacada, sino la primera, entre sectores industriales de un mismo ramo, es el principio fundamental de la competitividad.

Perdomo y Prieto (2009) indican que:

Tal como lo expresa Siliceo, A. (1999), la competitividad es una condición de sobrevivencia, es una forma de aprender y crecer para poder enfrentar con éxito la vida, dentro de un proceso evolutivo de cambio, desarrollo y mejora continua. Aunado a ello, la competitividad es una medida de satisfacción del consumidor en un mercado globalizado, es una estrategia de sobrevivencia empresarial para el mediano y largo plazo fundamentada según los autores en mención, en los siguientes principios:

1. Espíritu innovador y manejo del cambio.

2. Fortalecimiento interno de la organización y trabajo en equipo.

3. Conocimiento del entorno, del mercado y de las necesidades del cliente.

4. Calidad, servicio y valor agregado.

5. Nuevos compromisos y exigencias de clase mundial y enfoque de negocio.

6. Promoción del capital intelectual y emocional de las organizaciones.

7. Conocimiento y valoración de los signos vitales de la organización.

8. Proceso de mejora continua.

9. Definición clara de la filosofía de la empresa: visión, misión, valores.

10. Sabiduría directiva. (Sección Competitividad y liderazgo, párrafo 3).

De acuerdo a Cabrera, López y Ramírez (2011):

En el caso colombiano, los primeros en realizar un estudio, en 1996, de las regiones fueron el Centro de Estudios Regionales Cafeteros y Empresariales (Crece) y la Corporación Misión Siglo XXI de Bogotá denominado "Escalafón de competitividad de los departamentos colombianos". En el año 2000, la Fundación Prodesarrollo, de Barranquilla, (CEPAL, 2007) realizó una estimación 
de los indicadores de competitividad de los departamentos de la Costa Atlántica, basándose en la metodología del Foro Económico Mundial. En ese mismo año, el Crece hizo nuevamente un ranking departamental, que se basa en una ponderación estadística de nueve factores (finanzas, administración, internacionalización, recurso humano, ciencia y tecnología, gobierno, fortaleza de la economía y medio ambiente) que determinan la competitividad de la región (Crece, 2000). (p. 18).

Posteriormente, indican:

En el año 2002, las cámaras de comercio de Bogotá, Cali, Medellín, la Confederación de Cámaras de Comercio (Confecámaras) y la CEPAL realizaron un estudio con el propósito de actualizar y profundizar el análisis y la información sobre la competitividad de todos los departamentos colombianos, denominado "Escalafón de competitividad de los departamentos en Colombia". En este estudio, aparte de abordar desde las regiones la preocupación por la competitividad, también se asumió la tarea de dar una visión de conjunto de los aspectos esenciales que se requiere afrontar, y ver los logros y rezagos de cada departamento en perspectiva de comparación. (p. 19).

El último estudio de la competitividad de las regiones en Colombia lo realizó la CEPAL en 2006, y se denomina "Escalafón de competitividad de los departamentos de Colombia”, en el mismo se muestra el estado de la competitividad en ese momento, además de la dinámica que han tenido las regiones entre 2000 y 2006. Los factores que se definieron para realizar el estudio fueron la fortaleza de la economía, el capital humano, infraestructura, la ciencia y la tecnología, finanzas públicas y el medio ambiente. (p. 19).

[...] la Comisión Nacional de Competitividad (CNC), del Departamento Nacional de Planeación, y el Consejo Privado de la Competitividad (CPC) promueven la competitividad de las regiones, y por ende del país, a través de la coordinación de esfuerzos entre el gobierno, empresas y la academia, con lo cual logran plantear las transformaciones que el país requiere para mantener el ritmo de crecimiento. Este trabajo es una evidencia de una coordinación y articulación permanente entre el sector público y el privado. (p. 19).

La Comisión Nacional de Competitividad (CNC) fija lineamientos estratégicos para empresarios, gobierno, academia y trabajadores. Formada por la Alta Consejería para la competitividad, el Departamento Nacional de Planeación, el Ministerio de Comercio Exterior, Industria y Turismo, y el Consejo Privado de Competitividad (CPC), publica el resultado de sus estudios en la Agenda interna para la productividad y la competitividad y en documentos sectoriales. La CNC busca diseñar planes de acción, programas y proyectos prioritarios para fomentar la productividad y la competitividad y aumentar la participación en los mercados (CNC, 2007). (p. 19).

Entre otros estudios sobre la competitividad empresarial, se encuentran los aportes de Rodríguez (2003) y Rodríguez y Román (2005) quienes al contextualizar en pymes, señalan que la competitividad es una medida de desempeño de una empresa que permite comparar su posición respecto a la de sus competidores, e identificar las fuentes de sus fortalezas y debilidades. Una empresa competitiva es aquella que logra producir, mercadear 
productos como los servicios en mejores condiciones de precio, calidad y oportunidad que sus competidores. A este respecto Sarmiento, Sánchez y Cruz (2009), comentan que la competitividad es la capacidad que tiene una empresa para penetrar, consolidar o ampliar su participación en el mercado. Dicha capacidad se expresa en la habilidad, la acción administrativa, el aprovechamiento oportuno de la capacidad instalada, manejo adecuado de los recursos financieros, humanos y materiales.

Para Paz, Harris y García (2015) no debe perderse de vista que para crear una habilidad distintiva, los recursos de la empresa deben ser únicos (que ninguna otra compañía los posea) y valiosos, ya que la ventaja surge de dos fuentes complementarias: los recursos (medios financieros, medios físicos, las personas, competencias tecnológicas y estructura organizacional) y las capacidades (habilidades de la empresa para coordinar y aprovechar el uso de los distintos recursos).

\section{Las Habilidades humanas en directivos de pymes}

Las habilidades humanas, representan la capacidad para trabajar eficazmente con las personas, y obtener resultados del trabajo en equipo. Es importante para los gerentes, disponer de un alto nivel de habilidades humanas, comunicarse con las personas, proporcionarles instrucción, para conducir la organización con motivación, representando por ello un importante recurso para la gerencia.

En este contexto, Koontz, Weihrich y Cannice (2012) plantean que todo grupo de personas, que llegan a alcanzar el máximo rendimiento posible, tienen a una persona hábil en el arte del liderazgo, tal elemento, al parecer, es una composición de al menos cuatro factores importantes: la destreza de utilizar el poder eficientemente y de manera responsable; comprender las fuerzas de motivación de las personas según las situaciones; inspirar así como actuar en forma tal que desarrolle un clima para conducir a las motivaciones, en este sentido, son las competencias humanas que el gerente utiliza en las organizaciones.

En opinión de Palmar y Valero (2014), para que el desempeño laboral de un gerente se dé con eficiencia y eficacia, éste debe estar capacitado para el desempeño de su trabajo. De igual manera, debe conocer y comprender las expectativas organizacionales antes de iniciar su labor; este conocimiento de prioridades debe ser correcto, de ser posible cuantitativo. Igualmente, debe tener una disposición humana de motivación, autoridad, trabajo en equipo, influencia y empoderamiento sobre los resultados esperados, ante esto, el gerente debe ser un buen comunicador, logrando entender a sus empleados mediante sus relaciones interpersonales, estableciendo sistemas de comunicaciones los cuales permitan a los involucrados sentirse bien en su trabajo.

Por tanto, quien lidera procesos mediante habilidades humanas requiere gestionar escenarios con clima organizacional sano, valorando a sus colaboradores y fortaleciendo sus capacidades. Debe compartir objetivos de actuación, para que se puedan conocer y alcanzar en el futuro; asumir y ayudar a sus compañeros a trabajar para que logren su autodesarrollo; identificar y eliminar obstáculos que afecten el rendimiento; y gestionar adecuadamente los conflictos.

Por consiguiente, para evaluar la función de los gerentes con habilidades humanas en las pymes, es importante basarse en estándares de actuación con comportamientos sociales que midan resultados, tomando en cuenta factores como: interacción laboral, disposición al cambio, cordialidad, cumplimiento de objetivos, disposición de tiempo, atención de conflictos (determinados por socializaciones), comunicación activa y permanente, reuniones, entrevistas, las cuales sirven como base objetiva para establecer acciones compartidas en búsqueda de metas alcanzadas y competitividad. 
Al respecto, Gimeno (2003) señala que la función que el gerente aplica evidencia su desempeño, considerando este último como la capacidad que tiene una persona para realizar un trabajo con calidad. En tal sentido, en la dimensión de las habilidades humanas es tarea de todo gerente, conocer el contexto laboral, así como al personal que dirige para promover acciones de crecimiento profesional, actualizaciones, capacitaciones, mejorando así el rendimiento y la satisfacción del personal que colabora en la empresa.

Por su parte, Blake y Mounton (1978), plantean que el estilo de liderazgo adoptado por el gerente evidencia sus habilidades y estas se desarrollan en su comportamiento cuando atienden el bienestar así como al desarrollo del personal de la empresa. Desde la perspectiva del directivo con habilidades humana, que pretende la competitividad en las pymes, éste se convierte en verdadero administrador de equipo, combina las necesidades de las personas mediante el interés común, con el propósito de obtener el máximo de beneficios para los miembros, además de colocar a la organización en un clima de confianza y respeto mutuo como una prioridad vital.

De igual manera, puede expresarse que el gerente con su habilidad humana en las pyme, gestiona la preparación técnica y profesional, puesto que supone una participación activa, conduce al compromiso, a la dedicación plena para el logro de los grandes objetivos; participa manteniendo la moral de la gente aplicando técnicas, integradas éstas en beneficio de la institución así como de las personas, por lo que este estilo, debe ser asumido por los directivos, los cuales deben gozar de alta moralidad además de conducta intachable, en la organización que dirigen.

Cuando el directivo con habilidad humana, en las pymes, mantiene la moral del personal en las condiciones deseadas surge el voluntariado, la espontaneidad, la sinceridad y la responsabilidad, que permite lograr la armoniosa relación entre los miembros y consolidar la estabilidad empresarial en la medida en que el compromiso y la responsabilidad son de todos. Las ideas y opiniones son importantes de modo que la participación en el logro de los objetivos es gratificante e interesante.

Igualmente, Blake y Mounton (2001) señalan que el comportamiento del gerente (con competencias humanísticas), debe mostrar una gran dosis de versatilidad para unir esfuerzos empresariales y solucionar los problemas en forma objetiva y real. Asimismo, la ejecución de las funciones administrativas, deben dirigirse en forma colaborativa utilizando los conocimientos; la participación de los colaboradores, pues esta es considerada importante porque contribuye a mejorar las decisiones.

El gerente ubicado en este estilo, crea las condiciones de trabajo para que todos entiendan los problemas, aporten ideas y participen en el desarrollo del trabajo en las pymes. La planificación la realiza en conjunto, se explica la problemática en su totalidad, se escuchan opiniones e ideas, se preparan las acciones de acuerdo al interés de los subordinados, se establecen los lapsos de tiempo necesarios para desarrollar las actividades conducentes al éxito de los resultados, comprometiéndolos en el logro de los fines y metas de las pymes.

Asimismo, se comparten los objetivos de la pymes, y las necesidades del personal. Hay integración equitativa entre los colaboradores y el rendimiento de la empresa. Se descubre la mejor solución a las necesidades planteadas. De allí que, la habilidad cognitiva del personal que conoce la situación por su preparación o experiencia es tomada en cuenta al formular lineamientos que satisfagan las necesidades individuales y organizacionales y la superación del personal.

Además, con la gestión humana de los gerentes en las pymes, las orientaciones se dan al comenzar las actividades y cada miembro asume su responsabilidad en forma 
consciente. La supervisión es orientadora, cooperativa, tiende a favorecer el rendimiento así como la satisfacción del personal. Los problemas son estudiados en conjunto sirviendo de experiencia para el futuro, la solución es compartida entre los miembros de la organización.

Es por ello, que para Prieto, Villasmil y Urdaneta (2011) el rol de la gestión humana en las organizaciones debe corresponder a un compromiso de actitud, con el deseo de pertenecer y alinear sus objetivos de su unidad con los corporativos y de esta forma convertirse en socio estratégico de la operación, la polivalencia debe estar enmarcada en los roles y no en los cargos que desempeñe cada persona, y es así como un jefe de gestión de personal forma parte del grupo corporativo de la organización.

Para controlar el trabajo, el gerente con habilidades humanas se reúne periódicamente con sus empleados, puede ser cada uno, o con el grupo o con la totalidad de acuerdo al tema a tratar; se estudia el desarrollo del trabajo, las críticas que sirven como autoaprendizaje. Los empleados motivados experimentan un alto grado de autocontrol y autoevaluación que es tomada en cuenta por el gerente, acción que permite el desarrollo personal de los miembros.

\section{Metodología}

A fin de alcanzar el objetivo planteado en el estudio, y atendiendo a la interrogante a la que se pretendió responder en la investigación, la misma se enmarca dentro de la modalidad descriptiva- documental, con diseño no experimental, transversal de campo, fundamentada en los criterios establecidos por Hernández, Fernández y Baptista (2014). En tal sentido, se detalla la competitividad en las pymes del sector confección textil en el Departamento del Atlántico, con base en las habilidades directivas de sus gerentes, para lo cual se tomó un muestreo no probabilístico de conveniencia o accidental, según Arias (2012); de tal forma que las población objeto de estudio, estuvo conformada por 20 personas que fungen como propietarios, gerentes o administradores de pymes de confección textil en Barranquilla Departamento del Atlántico, tal como se muestra en la tabla 2.

Tabla 2

Población objeto de estudio

Empresas del sector confección textil

Coinfex Industria de Confecciones S.A.S

Confecciones y Uniformes Kiatex Ltda.

Confecciones El Industrial Limitada

Comercializadora de Diseños y Confecciones de Modas S.A.

Confecciones Mercedita Ltda.

Barranquilla Industrial De Confecciones S.A.

Confecciones Valdin Limitada

Punto de Moda

Taller de Plisados Anturi

Confecciones Mep Ltda.

Inversiones Queens S.a.s

Decoraciones Bellohogar

Disinco Ltda.

TOTAL
Gerente/Propietario/Encargado

2

1

1

2

1

3

1

2

2

1

1

2

1


El análisis estadístico de la información se realizó sobre la base de la tabulación de datos, para ello se especificó una matriz de análisis en la cual se vaciaron los códigos de respuestas y los números de cada sujeto. Con esta tabla de doble entrada se procedió al análisis de la información, aplicando la estadística descriptiva con frecuencias y medidas de tendencia central; los datos obtenidos fueron caracterizados de acuerdo al baremo de interpretación de la media y la implementación de herramientas como Microsoft Excel 2010 y el programa estadístico SPSS 19.0, siendo este baremo el indicado en la tabla 3.

Tabla 3

Baremo

\begin{tabular}{ccc} 
Intervalos & & Categoría \\
1.00 & 1.80 & Muy baja \\
\hline 1.81 & 2.61 & Baja \\
\hline 2.62 & 3.42 & Moderada \\
\hline 3.43 & 4.23 & Alta \\
\hline 4.24 & 5.00 & Muy Alta \\
\hline
\end{tabular}

\section{Resultados}

Competitividad en pymes. Una perspectiva desde las habilidades humanas de sus directivos

Según Prieto, Emonet, García y González (2015) la creciente competencia exige a las empresas una mejora constante de su capacidad competitiva que les permita sobrevivir en un mundo cada vez más globalizado. La adaptación a esta nueva realidad y a los requerimientos del mercado, debe estar caracterizada por una y más elevada presión competitiva, lo que conlleva al desarrollo de innovadoras formas de organización, mayor flexibilidad, nuevas estrategias, modificar la imagen corporativa, mejorar las habilidades directivas, entre otras, que permitan tomar acciones cónsonas con la realidad que vive el mundo global.

Considerando los resultados obtenidos en el objetivo de la investigación, orientado al análisis de la competitividad de las pymes de confección textil en el Departamento del Atlántico, desde la perspectiva de las habilidades humanas de los directivos, se destaca que para el indicador Gestión del conflicto, éste logró una media de 2.19, refiriéndolo hacia una categoría baja, lo que deja ver un débil manejo de los conflictos en las pymes del sector textil. Tal como lo plantean Davis y Newstrom (2003, p. 343), entre las estrategias que permiten solucionar conflictos se encuentran las siguiente:

- evitación: distanciamiento físico del conflicto;

- suavizar: adaptación a los intereses de la otra parte; forzamiento: uso de tácticas de poder para obtener beneficios;

- negociación: búsqueda de un punto medio o disposición a renunciar a algo a cambio de obtener otra cosa, y;

- confrontación: enfrentamiento directo del conflicto en busca de una solución mutuamente satisfactoria.

En todo caso, es necesaria la tolerancia, debido a que allí pudieran aparecer nuevas ideas. 
Por su parte el indicador Comunicación obtuvo una media de 2.95 relacionándolo con una categoría moderada. En tal sentido, para Rincón (2013) y Prieto, Burgos, García y Rincón (2016), la comunicación organizacional desde la dimensión interna se considera imprescindible para desarrollar procedimientos de manera asertiva que garanticen la satisfacción de los colaboradores internos en el desarrollo de sus labores o funciones; de tal manera en la banca universal, la aplicación de una comunicación interna efectiva afianza la identidad de los clientes o colaboradores internos y su sentido de pertenencia y compromiso lo cual debe ser un reflejo en la calidad de servicio que este presta a sus clientes externos.

Para el caso del indicador Motivación, los resultados permitieron obtener una media de 2.07, lo cual según el baremo desarrollado se ubica en la categoría baja. Por cuanto, la motivación laboral es el proceso a través del cual la organización desarrolla acciones de estimulación para procurar en el trabajador mejor desempeño alcanzando los propósitos de la empresa. Por ello, el empleado de las pymes del sector textil del departamento del Atlántico, debiera estar preparado para tomar iniciativas y dar a los clientes un servicio con calidad. En concordancia a estos señalamientos, en este capítulo se asumen los postulados de Chruden y Sherman (2005), Robbins y Coulter (2010) y Prieto et al. (2016), cuando enmarca la motivación laboral en la disposición para desarrollar altos niveles de esfuerzo a fin de lograr metas.

Atendiendo a los resultados del indicador Interacción laboral, la media lograda mediante los resultados fue de 1.97, ubicándola en la categoría baja, presentando ciertas dificultades entre los miembros de las pymes y sus actividades laborales, lo que de acuerdo a Robbins y Coulter (2010) los estudios han mostrado que cuando la estructura de una organización proporciona apoyo explícito a la creatividad por medio de fuentes laborales y no laborales, mejora el desempeño creativo de un empleado. Bien pudiera ser ofreciendo apoyo emocional, a través de una comunicación abierta, sincera y asertiva, con escucha activa.

En estos casos la presencia emocional de la gerencia es inevitablemente necesaria a fin de incentivar los grupos de trabajo en las tareas, oír sus planteamientos en los cuales pueden surgir ideas nuevas u otras formas de ejecutarlas, de mejora de los procesos o los productos. De la misma forma es una oportunidad para que la gerencia comparta sus opiniones, en donde también pueden partir hechos interesantes para compartir y tomar decisiones.

El indicador Estímulo de trabajo en equipo, logró una media de 2.47, lo que se corresponde con una categoría moderada. Por lo que se hace necesario que el gerente incentive a los integrantes para que trabajen juntos, haciendo hincapié en que es su medio de vida y que todo progreso depende del aprendizaje, promover la responsabilidad con acciones éticas y congruentes que sobrepasen las expectativas, así como la proporción de utilidades que sobrepasen las usadas por la competencia, satisfactorias al equipo, en donde se considere a la empresa de su propiedad con sentido de pertenencia, tal como lo expresa Robbins y Coulter (2010.

Así mismo, el indicador Relaciones interpersonales resultó con una media de 2.17 logrando una categoría baja, según el baremo. Lo que según Rincón (2013) considera como un proceso de integración y complementariedad de los individuos para la obtención de logros comunes, constituyéndose en un elemento clave en la gestión de organizaciones. En el caso del indicador Disposición de tiempo, los resultados revelan que la media obtenida es de 2.60, con una categoría baja, mientras que para el indicador Cordialidad, la categoría 
lograda fue moderada con base a la media obtenida. Tal como lo expresan Robbins y Coulter (2010) cuando dicen que la esencia del equipo está en la interdependencia de sus integrantes, del apoyo de cada uno. En este sentido, funciona neuronalmente de forma equitativa y equilibrada, con conocimientos complementarios, comprometidos con la visión, responsables de sus acciones con el progreso y éxito mutuo. Con apoyo de los gerentes y líderes del equipo.

Con estos datos, se puede determinar que la competitividad de las pymes de confección textil en el Departamento del Atlántico, desde la perspectiva de las habilidades humanas de sus directivos, se ubicó en una categoría moderada basada en la media aritmética obtenida de 2.40. De esta forma, estadísticamente se califica un nivel medio de competitividad en estas pymes, presentándose oportunidades de mejora para las habilidades humanas en sus gerentes-directivos. (Ver Tabla 4).

Tabla 4

Habilidades humanísticas para la competitividad

\begin{tabular}{|c|c|c|c|c|c|c|c|c|}
\hline Estadística & $\begin{array}{l}\text { Gestión } \\
\text { del } \\
\text { conflicto }\end{array}$ & $\begin{array}{l}\text { Comuni- } \\
\text { cación }\end{array}$ & $\begin{array}{l}\text { Motiva- } \\
\text { ción }\end{array}$ & $\begin{array}{c}\text { Interacción } \\
\text { laboral }\end{array}$ & $\begin{array}{l}\text { Estimulo } \\
\text { de trabajo } \\
\text { en equipo }\end{array}$ & $\begin{array}{c}\text { Relaciones } \\
\text { interperso- } \\
\text { nales }\end{array}$ & $\begin{array}{c}\text { Disposición } \\
\text { de tiempo }\end{array}$ & $\begin{array}{l}\text { Cordia- } \\
\text { lidad }\end{array}$ \\
\hline Sumatoria & 65 & 88 & 62 & 59 & 74 & 65 & 78 & 85 \\
\hline Media & 2,19 & 2,95 & 2,07 & 1,97 & 2,47 & 2,17 & 2,60 & 2,83 \\
\hline Mediana & 2,00 & 3,00 & 2,00 & 2,00 & 2,00 & 2,00 & 3,00 & 3,00 \\
\hline Moda & 2,00 & 4,00 & 2,00 & 1,00 & 2,00 & 3,00 & 3,00 & 3,00 \\
\hline DesvStda & 0,75 & 1,17 & 0,78 & 0,85 & 0,51 & 0,79 & 0,50 & 0,83 \\
\hline Coef Var & 34,46 & 39,97 & 37,98 & 43,23 & 20,57 & 36,53 & 19,16 & 29,43 \\
\hline Categoría & Baja & Mod & Baja & Baja & Mod & Baja & Baja & Mod \\
\hline \multicolumn{3}{|c|}{ Dimensión } & \multicolumn{3}{|c|}{ Media } & \multicolumn{3}{|c|}{ Categoría } \\
\hline \multicolumn{3}{|c|}{ Habilidades Humanísticas } & \multicolumn{3}{|c|}{2.40} & \multicolumn{3}{|c|}{ Moderada } \\
\hline
\end{tabular}

Nota: Elaboración propia (2016).

\section{Conclusiones}

En el ámbito empresarial mundial se están presentando una serie de cambios y transformaciones, producto de la dinámica global, que los empuja a generar innovaciones en sus estructuras para poder mantenerse competitivos en el mercado, en un mundo cada vez más complejo. Por ello, es de gran importancia la participación de directivos capaces, que guíen de forma asertiva al talento humano, quienes se encargarán de conducir de una manera estratégica, la transición al cambio y su implementación efectiva en la organización.

El éxito en la aplicación de la estrategia en la organización dependerá de la forma como los gerentes asimilen y manejen la información, principalmente debe haber pleno convencimiento de la evolución que se quiere, para que el mensaje no se convierta en un trauma para los trabajadores.

En este orden de ideas, los resultados de la investigación, permiten alcanzar el objetivo propuesto, es decir, analizar la competitividad de las pymes de confección textil, en el Departamento del Atlántico, desde la perspectiva de las habilidades humanas de sus 
directivos. En este sentido, se verificó la presencia de las habilidades humanas puestas de manifiesto por los gerentes de las pymes estudiadas, que sustentan el nivel actual de la competitividad de estas empresas.

De esta forma, se evidenció que los aspectos de comunicación, estímulo de trabajo en equipo y cordialidad en los gerentes de las empresas están ubicados en una moderada condición, presentando por tanto oportunidades de mejora con reflexiones personales de estos gerentes enfocándose más en acercamientos y acompañamientos con sus colaboradores, propiciando mayores niveles de competitividad de las pymes.

Por otra parte, las mayores debilidades (representadas por un bajo nivel en el baremo) se encuentran en las habilidades de gestión del conflicto, motivación para sus colaboradores, las relaciones interpersonales y disposición de tiempo; aspectos estos de suma importancia para la adecuación de un clima organizacional más sano, el fortalecimiento del sentido de pertenencia de los empleados, la relación empleador-empleado y la gestión del tiempo del gerente para la atención oportuna de las situaciones organizacionales. Se requiere así, de talleres de capacitación en temas de gestión de conflictos, motivación, manejo de emociones y gestión del tiempo, para sensibilizar a estos directivos en la consecución de mayores valores en la dimensión humana de su gestión gerencial, tendente a incrementar la competitividad en las pymes de confección textil del departamento del Atlántico. 


\section{Referencias}

Arias, F. (2012). El proyecto de investigación. Introducción a la metodología científica. Caracas: Editorial Epísteme.

Bonnefoy, J.C. (2003). Los indicadores de evaluación del desempeño: Una herramienta para la gestión por resultados en América Latina. Boletín del Instituto-ILPES, 13. Recuperado de http://repositorio.cepal.org/bitstream/handle/11362/9939/S2003659_ es.pdf?sequence $=1 \&$ is Allowed $=y$

Blake, R., \& Mouton, J. (1978). The new managerial grid. Houston, TX: Gulf.

Cabrera, A.M., López, P.A., \& Ramírez, C. (2011). La competitividad empresarial: un marco conceptual para su estudio. Documentos de Investigación, Universidad Central, 4. Recuperado de https://www.ucentral.edu.co/images/documentos/editorial/2015_ competitividad_empresarial_001.pdf

Cámara de Comercio de Bogotá.(2014). Informe de posicionamiento competitivo. Documento en línea. Recuperado de https:/www.ccb.org.co/content/download/2963/37688/file/ Informe $\% 20 \mathrm{de} \% 20$ Posicionamiento $\% 20$ competitivo $\% 20 \mathrm{de} \% 20$ Bogot $\% \mathrm{C} 3 \% \mathrm{~A} 1 \% 20$ 2014..pdf

Centro de Investigación y Desarrollo Tecnológico Textil Confección de Colombia (CIDETEXCO). (2009). Informe técnico.

Chruden, H., \& Sherman, A. (2005). Administración de Personal. Colombia: Mc Graw Hill.

CONPES 3527. (2008, junio 23). Política nacional de competitividad y productividad. Consejo Nacional de Política Económica y Social República de Colombia (CONPES). Departamento Nacional de Planeación. Recuperado de http://www. colombiacompetitiva.gov.co/sncei/Documents/Conpes-3527-de-2008.pdf

Davis, K., \& Newstrom, J. (2003). Comportamiento humano en el trabajo. Ciudad de México: McGraw-Hill.

El Espectador (2016, febrero 17). En 2015 la producción real industrial aumentó 0,9 \%, según el DANE. Documento en línea. Recuperado de http://www.elespectador. com/noticias/economia/2015-produccion-real-industrial-aumento-09-segun-el-danarticulo-617156

Gimeno, E. (2003). Transformaciones de la gerencia escolar. Madrid: Editorial Narcea.

Hernández, R., Fernández, C., y Baptista P. (2008). Metodología de la investigación. Ciudad de México: Mc Graw Hill.

Koontz, H., Weirich, H., \& Cannice, M. (2012). Administración una Perspectiva Global y empresarial. Ciudad de México: McGraw-Hill Interamericana.

LEY 811 (2003, junio 26). Creación de las organizaciones de cadenas en el sector agropecuario, pesquero, forestal, acuícola, las Sociedades Agrarias de Transformación, SAT, y se dictan otras disposiciones. Diario Oficial No. 45.236 de 2 de julio de 2003. Congreso de Colombia. Recuperado de http://www.secretariasenado.gov.co/senado/basedoc/ ley_0811_2003.html

Luna,J.E.,Aguilar, M.J., \& Espinosa, R.(2014). Modelo de competitividad del capital humano: una palanca estratégica en las organizaciones inteligentes. Cofin Habana, 8(3), 1-7. Recuperado de http://www.cofinhab.uh.cu/index.php/cofin/article/viewFile/129/128

Mahón, H. (1999). Planificación estratégica. Textos didácticos. Venezuela: Universidad de Carabobo. 
Montoya, A., Montoya, I., \& Castellanos, O. (2010). Situación de la competitividad de las Pyme en Colombia: elementos actuales y retos. Revista Agronomía Colombiana 28(1), 107-117. Recuperado de http://www.revistas.unal.edu.co/index.php/agrocol/rt/ printerFriendly/17600/37350

Palmar, R.S., \& Valero, J.M. (2014). Competencias y desempeño laboral de los gerentes en los institutos autónomos dependientes de la Alcaldía del municipio Mara del estado Zulia. Espacios Públicos, 17(39), 159-188. Universidad Autónoma del Estado de México.

Paz. A., Harris. J., \& García, J. (2015). Toma de decisiones: reto para crear ventajas competitivas en las distribuidoras de alimentos gourmet. Desarrollo gerencial, 7(2). Universidad Simón Bolívar, Barranquilla-Colombia.

Perdomo, Y., \& Prieto, R. (2009). El liderazgo como herramienta de competitividad para la gerencia del servicio. CICAG, 6(2), 19-31. Universidad Dr. Rafael Belloso Chacín, Maracaibo-Venezuela. Recuperado de http://publicaciones.urbe.edu/index.php/cicag/ article/viewArticle/469/1154

Prieto, R., Villasmil, M., \& Urdaneta, L. (2011). Gestión humana en organizaciones postmodernas. Base fundamental hacia la excelencia organizacional. CICAG, 8(2), 1-12. Universidad Dr. Rafael Belloso Chacín, Maracaibo-Venezuela.

Prieto, R., García, J., \& González, D. (2014). Liderazgo Estratégico: factor de competitividad del Sector Industrial de la Región Caribe Colombiana. Ponencia presentada y publicada en memorias del I Congreso Internacional de Investigación Dr. Adolfo Calimán "Visión transdisciplinaria e integradora de la investigación". Universidad Dr. José Gregorio Hernández, Maracaibo-Venezuela.

Prieto, R., Emonet, P., García, J., \& González, D. (2015). Cambio organizacional como estrategia de gestión en las empresas mixtas del sector petrolero. Revista de Ciencias Sociales, 21(3). Universidad del Zulia, Maracaibo-Venezuela.

Prieto, R., Burgos, C., García, J., \& Rincón, Y. (2016). Mercadeo interno para optimizar la calidad de servicio en la banca universal. Revista Venezolana de Gerencia, 21(73). Universidad del Zulia, Maracaibo-Venezuela.

Procolombia. (2014). Informe de gestión. Documento recuperado de: http://www. procolombia.co/sites/default/files/procolombia_informe_de_gestion_2014.pdf

Rincón, Y. (2013). Comunicación Organizacional. Construcción de una gestión eficiente. Revista DIRCOM, Especial gestión de la comunicación, (8), 65-66.

Robbins, S., \& Coulter, M. (2010). Administración. Ciudad de México: Prentice Hall.

Rodríguez, A. (2003). La realidad de la Pyme colombiana: desafío para el desarrollo. Bogotá: Fundes.

Rodríguez, P. \& Román, C. (2005). El capital social como factor de competitividad y desarrollo empresarial. Ekonomíaz, 59(2).

Sarmiento, S., Sánchez, A., \& Cruz, M. (2009). Competitividad y desarrollo sustentable empresarial. Revista internacional La Nueva Gestión Organizacional, 4(8), 112-134. 


\section{Capítulo 9}

Modelos de madurez de la gestión del talento humano para el desarrollo del capital intelectual como ventaja competitiva

Martha Lucía Moya Pardo Héctor Manuel Gómez Gómez 
Martha Lucía Moya Pardo, Fundación Universitaria para el Desarrollo Humano UNINPAHU mmoya@uninpahu.edu.co

Héctor Manuel Gómez Gómez,

Fundación Universitaria para el Desarrollo Humano UNINPAHU hectormgg@gmail.com 


\section{Capítulo 9}

\section{Modelos de madurez de la gestión del talento \\ humano para el desarrollo del capital intelectual \\ como ventaja competitiva}

\section{Introducción}

Las organizaciones para generar ventaja competitiva deben centrar su atención en factores que permitan el desarrollo de capacidades organizacionales, indispensables para la creación del capital intelectual, lo que a su vez exige el desarrollo de estrategias fundamentadas en la gestión del talento humano, con el fin de acrecentarlo a partir de sus tres pilares: el capital humano, en aspectos tales como innovación, talentos y habilidades; el estructural, referente a patentes, servicios, entre otros; y el relacional referente a servicio, satisfacción y atención al cliente (Moya y Mancilla, 2015, p. 91).

El conocimiento se convierte, entonces, en el valor más importante de la organización para generar ventaja competitiva, y el individuo es la fuente donde se origina. Por tanto, los esfuerzos deben centrarse en crear, generar y consolidar, nuevas y mejores estrategias, empleando procesos permanentes orientados a identificar, evaluar, desarrollar y optimizar tanto el capital tangible como el intangible que interactúa dentro y fuera de sus propias estructuras organizacionales. (Moya y Ochoa, 2012, citado en Moya y Mancilla, 2015, p. 91).

\section{La gestión del talento humano como ventaja competitiva}

La gestión del conocimiento (aplicación del conocimiento en los procesos productivos como generador de valor) y la generación de capital intelectual (humano, estructural y relacional), han puesto de manifiesto la necesidad de replantear las estrategias organizacionales, en las cuales el área de talento humano juega un papel primordial, al gestionar el activo más importante. Por tal motivo, esta evolución conlleva mayores exigencias y las ha obligado a modernizar sus estructuras, roles y prácticas, a fin de convertirse en generadoras de valor para sus compañías (Boston Consulting Group, 2008, citado en Calderón, Naranjo y Álvarez, 2010). 
Jiménez (2011), afirma que la gestión de personas ${ }^{1}$ es un factor clave de competitividad empresarial, porque tiene impacto en ingresos y en gastos, y es inseparable de la gestión del negocio; sostiene además, que problemas como la baja productividad, la escasa creatividad e innovación, y la carencia de espíritu emprendedor, se solucionarían, si se mejorara la capacidad de gestionar el talento humano (GTH), con un plan claro, objetivos que establezcan prioridades, una estructura de responsabilidad, unos sistemas de información, es decir, desde su estrategia hasta su concreción. Esta depende de tres factores, la situación de la empresa y su estrategia, la cultura corporativa, y las circunstancias del mercado laboral donde se opera.

Calderón, Naranjo y Álvarez (2010) respecto a la concepción de gestión humana, indican que:

se percibe una dinámica de desarrollo relacionada con la vinculación de sus procesos internos a los aspectos estratégicos del negocio, esto es, se empieza a percibir un trabajo más fuerte y focalizado para generar la cultura propicia y adecuada que sostenga la estrategia y la competitividad de las organizaciones. (p.23).

Calderón (2008, citado en Calderón, Naranjo y Álvarez, 2010) concluyó que "las áreas de gestión humana sí generan valor para las empresas en cinco dimensiones: proyección organizacional (orientación estratégica), gestión del cambio, infraestructura organizacional (eficiencia y eficacia), liderazgo de las personas y responsabilidad social”(p. 16).

En otras palabra, la gestión humana está estrechamente relacionada con la estrategia, la cultura organizacional, la gestión del conocimiento, la calidad, la productividad y la innovación; por consiguiente, tanto el capital humano como el área que los dirige, desempeñan un papel fundamental, el primero como fuente de talentos y la segunda como capacidad de soporte (Barney y Wright, 1998; Becker, Huselid, Pickus y Spratt, 1997; Jiménez y Sanz, 2005; citados en Calderón, Naranjo y Álvarez, 2010, p. 17).

Respecto a los retos que genera la gestión del talento humano desde sus procesos básicos, Calderón, Naranjo y Álvarez (2010, p. 27-29) identifican ocho: atracción y retención del talento, gestión para nuevas generaciones, percepción y análisis del contexto que la afecte, convertirse en un facilitador de la transformación organizacional, cambiar la creencia que las áreas de gestión humana son un centro de costos y no un centro de inversión, desarrollo del compromiso de los colaboradores con la organización, formación de directivos y formulación y gestión de indicadores. Respecto a la contribución a la competitividad identificaron seis aspectos en los que se agrega valor: atraer, desarrollar y retener el mejor capital humano, la creación de un ambiente y una cultura adecuados, alineamiento estratégico, rol de formador de líderes, articulación con las demás áreas y por último el ajuste o articulación entre los intereses de los individuos (tanto personales como laborales) y los intereses de la organización favorece la competitividad.

Para establecer los estadios de desarrollo de los procesos de gestión del Talento Humano los autores parten de la cadena de valor desarrollada por Moya y Mancilla (2014), la cual se despliega a partir de los cinco procesos básicos a saber: integrar, desarrollar, organizar, retener y auditar el capital humano.

1 Para efectos de términos, el autor lo denomina gestión del talento humano. 
A continuación se detalla cada proceso con sus respectivas características para poder posteriormente categorizar a partir de niveles de cumplimiento (Ver Figura 1).

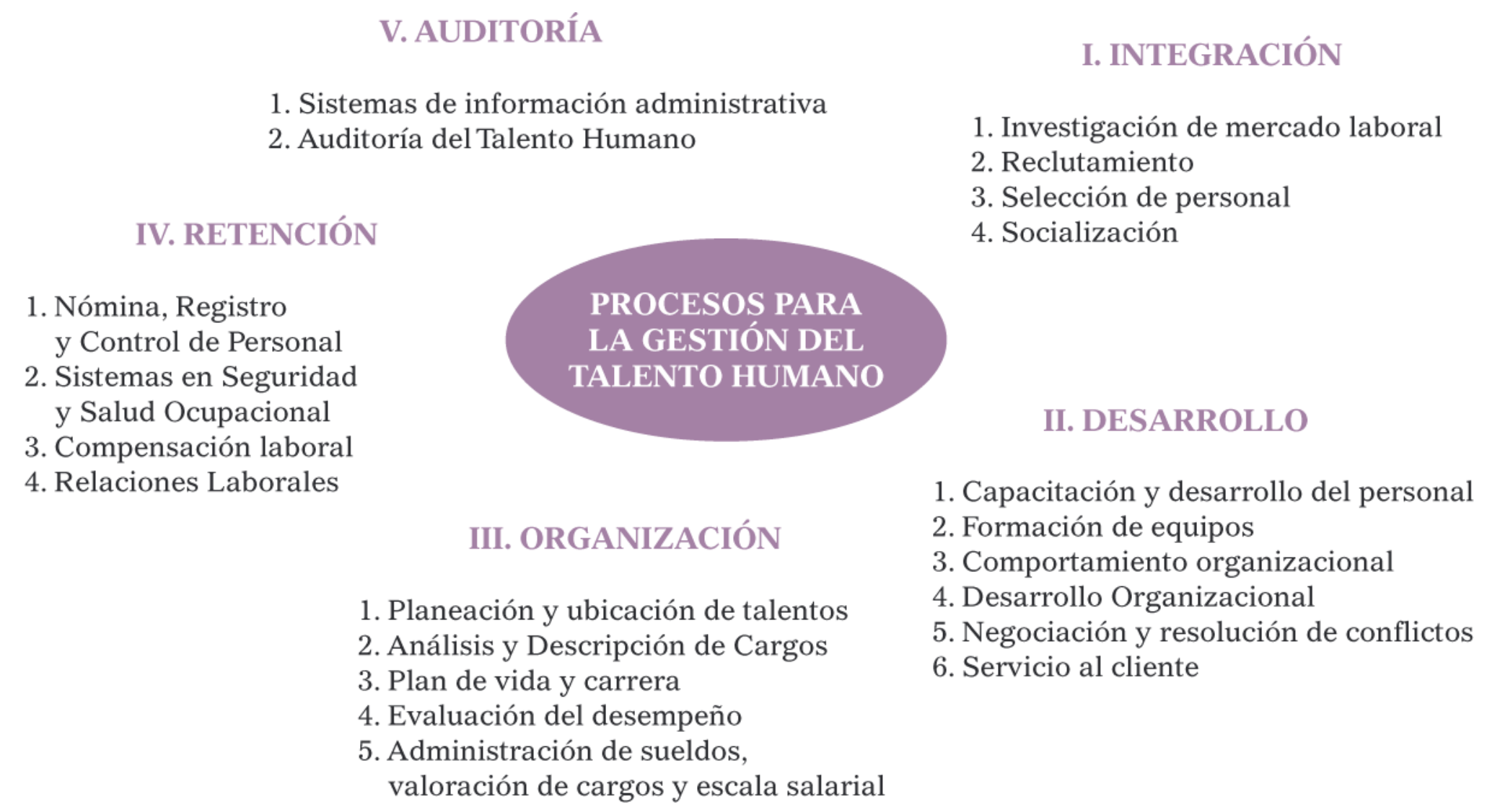

Figura 1. Procesos para la gestión del talento humano.

Fuente: Elaboración Propia (2016).

I. Integración: proceso de inserción y adaptación del individuo a una organización. Se refiere a incorporar a la organización el talento humano requerido a partir de clasificar y ubicar al personal, acorde con el banco de datos, determinar las habilidades y manejar técnicas en procesos de reclutamiento, selección, y socialización. Se integra de los siguientes subprocesos:

- Investigación del mercado laboral. Hace referencia a la oferta y demanda laboral como fuente de reclutamiento, las funciones específicas de este proceso son identificar el macro-enfoque (oferta-demanda) y el microambiente: (rotación y absentismo), determinar las fuentes de información de mayor uso, recopilar los datos e información sobre oferta y demanda laboral y compilar y consolidar la información para la interpretación de los resultados.

- Reclutamiento. Técnicas y procedimientos orientados a atraer candidatos potencialmente calificados y capaces de ocupar cargos dentro de la organización. $\mathrm{Su}$ objetivo es abastecer de candidatos para el proceso de selección. Las funciones específicas son identificar las necesidades laborales de la organización para su cubrimiento, determinar las técnicas y métodos de reclutamiento de mayor uso en su sector y definir el método más indicado para implementar su operacionalización.

- Selección de personal. Proceso mediante el cual se escoge los candidatos más adecuados para dar respuesta a las necesidades de la organización. Su objetivo, elegir y contratar al candidato que más se adapte al perfil de la vacante. Las funciones específicas son recibir y sistematizar las requisiciones de empleados de las distintas áreas, establecer las técnicas y herramientas efectivas para la ejecución del proceso 
de selección, analizar y evaluar los resultados del proceso de forma eficiente y eficaz, elegir y contratar al candidato más apto y que se ajuste al perfil solicitado.

- Socialización. Se define como la integración de los miembros que ingresan al sistema organizacional, se logra a través del programa de inducción. Este proceso permite al colaborador comprender y aceptar los valores, normas y convicciones que se postulan en la organización.

II. Desarrollo: estipula acciones que facilitan el aprendizaje organizacional, en procesos de educación, formación y aprendizaje para el desarrollo de las personas y equipos, y establece procesos de inducción y capacitación. Incluye los siguientes subprocesos:

- Capacitación y desarrollo de personal. Transmisión de conocimientos y habilidades organizadas, planificadas y evaluadas, que permita el desarrollo de habilidades, actitudes y conceptos. Su función principal es desarrollar y efectuar procesos de inducción, re-inducción, formación, capacitación y entrenamiento, con el fin de desarrollar el capital humano en las organizaciones.

- Formación de equipos. Estrategias que permitan el fomentoy construcción de personas con habilidades complementarias, que estén comprometidas con un propósito común, un método y metas de desempeño, por los cuales se responsabilizan mutuamente. Su función clave es la de apoyar, generar y desarrollar la integración de personas en equipos de trabajo.

- Comportamiento organizacional.Serefiereal estudioy aplicación delos conocimientos acerca de la forma en que las personas se comportan individual y grupalmente en las organizaciones. Sus objetivos son identificar y determinar sistemáticamente el comportamiento de las personas ante diferentes situaciones, fomentar estrategias que incrementen la comunicación, cultura y clima organizacional para mejorar la calidad de vida de los trabajadores e identificar los componentes del proceso de la comunicación personal y organizacional. Las funciones específicas se relacionan con el diseño de estrategias de mejoramiento de los procesos de comunicación, identificación de los elementos constitutivos de la cultura organizacional, la construcción de estrategias de sensibilización de la cultura y valores organizaciones, el establecimiento de los elementos que conformar el clima organizacional y el diseño y aplicación de instrumentos para la medición del clima organizacional.

- Desarrollo organizacional. Estudia la organización como sistema total y se compromete a mejorar la eficacia de la empresa a largo plazo mediante intervenciones constructivas en los procesos y en la estructura de la organización. Su objetivo principal es desarrollar e implementar estrategias educativas de intervención en las organizaciones, en la búsqueda de cambios planeados para aumentar la eficiencia, eficacia y productividad. Entre las funciones específicas se encuentra la identificación de los elementos de la Cultura, determinar las relaciones interpersonales/habilidades sociales, establecer elementos de clima, observar aspectos de resistencia (restrictivas, impulsoras, resistencias) con el propósito de efectuar el cambio, realizar el diagnóstico organizacional y proponer un proceso de intervención (asesoría, consultoría).

- Negociación y resolución de conflictos. Proceso que busca la mejor solución de problemas para las partes involucradas y la organización. Entre sus objetivos se encuentra determinar las instancias pertinentes para la negociación y la resolución de conflictos, establecer las técnicas de comunicación más asertivas, promover espacios de negociación para la resolución de conflictos e implementa protocolos para el 
manejo de los conflictos al interior de la empresa. Todo conflicto lleva en sí fuerzas constructivas que conducen a la innovación y al cambio, y fuerzas destructivas que llevan al desgaste y a la oposición.

- Servicio al cliente. Ofrecer y suministrar al cliente (interno y externo) el producto en el momento y lugar adecuado, asegurando un uso correcto del mismo. Identificar, entender y anticipar las necesidades de los clientes. Identificar clientes potenciales, captar y mantener clientes, medir la satisfacción del cliente, e implementa y administrar procesos de servicio.

III. Organización: el propósito de este proceso es planificar y estructurar los recursos disponibles (talentos humanos, financieros y materiales) de los que dispone la empresa, para alcanzar los objetivos deseados, incluye seis subprocesos:

- Planeación y ubicación del talento humano. Este proceso se hace con el fin de asegurar el número y el tipo correcto de personas en los puestos correctos y en el momento adecuado para lograr los objetivos y planes de la empresa. Su propósito es determinar los requerimientos de la fuerza de trabajo de las diferentes áreas y los medios requeridos para lograrlo. Esto se logra de acuerdo con las funciones específicas de proveer y asegurar de manera sistemática, la dotación de personal de forma adecuada y continua para cubrir la planta de personal, realizar el pronóstico de personal, identificar y determinar la demanda de personal, así como la oferta de recursos humanos, y establecer la planeación y programación del plan de acción.

- Sistema de calidad. Se define como un modelo participativo de administración, en el que se consideran los recursos humanos como talentos, capaces de entender su trabajo y realizarlos cumpliendo con normas de calidad y productividad. Orientar las actividades de la empresa para lograr el rendimiento organizacional a partir de la eficiencia, eficacia y competitividad. Identificar, determinar y caracterizar los procesos de gestión humana relacionados con cultura, comunicación y diseño de trabajo, entrenamiento, medición y evaluación, selección y plan de vida de carrera.

- Análisis y descripción de cargos. El análisis del cargo se ocupa de los requisitos, responsabilidades y condiciones que el puesto exige, mientras que la descripción consiste en enunciar las tareas o responsabilidades que lo conforman. Su objetivo es identificar tanto los aspectos intrínsecos (descripción y contenido) como extrínsecos (requisitos intelectuales, físicos, responsabilidades y condiciones de trabajo). Entre las funciones específicas se encuentran: elaborar los perfiles de cargos de una organización conformando el manual de funciones, identificar los contenidos del manual, determinar el marco y la estructura organizacional, establecer la planta de personal, y protocolizar el documento.

- Plan de vida y carrera. Plan de promoción y desarrollo del personal con el fin de proyectarlos a ocupar diferentes posiciones, cargos y actividades en una organización. Estructuración, diseño e implementación de planes de carrera para las personas en la organización. Integrar el plan y/o proyecto de vida de cada persona, con el escenario laboral (individuo-organización) en pro de su crecimiento y el de la organización. Entre las funciones específicas se encuentra: identificar las necesidades personales, definir los objetivos de cada persona, crear un plan de acción a corto y mediano plazo, controlar el plan propuesto y optimizar los conocimientos, capacidades y habilidades.

- Evaluación del desempeño. Valoración sistemática y objetiva de la actuación de cada persona en función de las actividades que desempeña, la consecución de metas 
y los resultados que debe alcanzar, donde la mejora de la actuación es el objetivo primordial. Evaluación y retroalimentación del desempeño y/o rendimiento de los trabajadores.

- Administración de sueldos, valuación de cargos y escala salarial. Proceso mediante el cual se establece la importancia relativa de los cargos para determinar una política salarial equitativa y justa respecto a los demás cargos de la propia organización y de las otras empresas que actúan en el mercado de trabajo. Las funciones específicas para este proceso son: aplicar técnicas de valuación de acuerdo con la complejidad de la estructura de cargos, que permita implementar un sistema de compensación; presentar propuestas de valuación y clasificación de sueldos, de acuerdo con la complejidad y niveles de competencia deseados; identificar la importancia de los cargos dentro del desarrollo organizacional; determinar los parámetros para la valuación de los cargos; establecer la clasificación de los puestos; realizar encuesta salarial, e implementar la estructura salarial.

IV. Retención: sistema de relaciones de intercambio entre las personas (contribuciones) y la organización (incentivos y premios, refuerzo positivo) para mantenerlos satisfechos y motivados, e inducirlos a permanecer en ella. Se establecieron cuatro subprocesos:

- Nómina, registro y control. Se refiere a los registros financieros de los sueldos de un empleado, los salarios, las bonificaciones y deducciones; cantidades pagadas a los empleados por los servicios prestados durante un cierto período de tiempo.

- Sistema de seguridad y salud en el trabajo. Actividades dirigidas a proteger y promover la salud de los trabajadores mediante la prevención y el control de enfermedades y accidentes, y la eliminación de los factores y condiciones que ponen en peligro la salud y la seguridad en el trabajo. El objetivo principal es identificar, articular e implementar el plan básico legal en salud ocupacional para incrementar un ambiente seguro en el trabajo. Sus objetivos específicos son: identificar, analizar y administrar las condiciones que pueden provocar riesgos; reconocer los factores de riesgos profesionales existentes en la actividad laboral; e incentivar y promover la conformación de un programa de salud ocupacional y el Comité Paritario de Salud Ocupacional (COPASO).

- Compensación laboral. Se refiere al sistema de estimulación del trabajo dirigida a alcanzar los objetivos y necesidades personales, tanto de los empleados, como los de la organización. Su función principal es la de implementar el área de Bienestar social con un programa de estímulos e incentivos, con el fin de incrementar la calidad de vida y dignidad humana del trabajador.

- Relaciones laborales. Proceso que enfoca, orienta y canaliza las relaciones laborales entre los trabajadores y la organización (de manera individual como colectiva), relacionadas con las demandas y requerimientos de la fuerza de trabajo con trascendencia social, económica y política. $\mathrm{Su}$ función principal es gestionar y resolver problemáticas referidas a la relación de la empresa con las asociaciones, sindicatos, federaciones y cámaras empresariales. Entre sus funciones específicas están: mantener una relación fluida con el sindicato, el ministerio de trabajo y los delegados de agremiaciones y asociaciones; negociar los convenios colectivos de trabajo; manejar las mesas de trabajo en temas relacionados con conflictos sindicales (mítines, huelgas, paros, plan tortuga, operación del reglamento, procesos disciplinarios, desvinculación de trabajadores, entre otros); y asistir a mediaciones o audiencias laborales en tribunales. 
V. Auditoría: reúne, procesa, almacena y difunde información para la administración del talento humano e implementa estrategias, proyectos y acciones para mejorar la eficiencia en los procesos organizacionales. Incluye dos subprocesos:

- Sistemas de Información Administrativa: El sistema de información gerencial (SIG) está planeado para recolectar, almacenar y divulgar información, de modo que los gerentes involucrados puedan tomar decisiones. Ocupa un lugar importante en el desempeño de los gerentes, en especial en tareas de planeación y control. El concepto se relaciona con la tecnología informática, que incluye el computador o una red de microcomputadores, además de programas específicos para procesar datos e información.

- Auditoría del talento humano. Asegurar que los subsistemas confluyan de una manera lógica para favorecer la acción que se desempeña desde Recursos Humanos. La auditoría de recursos humanos se define como "el análisis de las políticas y prácticas de personal de una empresa, y la evaluación de su funcionamiento actual, acompañados de sugerencias para mejorar"(Mee, 1958, p. 1077). El propósito principal es mostrar cómo está funcionando el programa, localizando prácticas y condiciones que son perjudiciales para la empresa o que no están justificando su costo, o prácticas y condiciones que deben incrementarse. La auditoría es un sistema de revisión y control para informar a la administración sobre la eficiencia y la eficacia del programa que se lleva a cabo, en especial cuando ese programa está descentralizado.

Importancia de la generación del capital intelectual en las organizaciones Barragán (2009), define la gestión del conocimiento como:

la habilidad individual o colectiva para generar, difundir, compartir y utilizar tanto el conocimiento tácito como explícito a partir de la asimilación de la información que se transfiere en forma de conocimiento y se transforma en experiencia de organizaciones o individuos; convirtiéndose así en una herramienta de aprendizaje útil que permite la aplicación del conocimiento para aportar valor dentro de una organización, economía o sociedad. (p.69).

También afirma que:

la gestión del conocimiento ha surgido como una disciplina cuyo objetivo se centra en generar, compartir y utilizar conocimiento existente en un espacio determinado para contribuir a dar solución a las necesidades de los individuos y el desarrollo de las comunidades. (Barragán, 2009, p.68).

Rodríguez (2005) se une al planteamiento de autores como Harvey y Lusch (1999), Caddy (2000), Konar y Cohen (2001), Porto (2003), Viedma (2003), García-Ayuso y Larrinaga (2004), García-Parra et al. (2004), Lozano y Fuentes (2005), entre otros, quienes proponen que el capital intelectual se calcule como la diferencia entre los activos intangibles de los que dispone la empresa y los pasivos intangibles que debe soportar. Si bien es cierto que el activo intangible genera valor a la organización, el pasivo intangible reduce el valor generado y lo posiciona frente a la competencia de manera negativa. (Moya y Mancilla, 2015, p. 93). 
De acuerdo a Moya y Mancilla (2015), respecto al capital intelectual, Edvinsson y Malone (1997), lo dividen en: capital humano, capital estructural y capital relacional."Esta clasificación conjuga las actitudes, aptitudes y capacidades de los seres humanos, con las rutinas, procesos y sistemas organizativos, y las redes o ámbitos de relación” (p. 93). "El capital humano, hace referencia al conocimiento (explícito o tácito) útil para la empresa que poseen las personas y equipos de la misma, así como su capacidad para regenerarlo" (p. 93); es decir, su capacidad de aprender;

es la base de la generación de los otros dos tipos de capital intelectual. En cuanto al capital estructural, este puede ser entendido como el conocimiento que la organización consigue explicitar, sistematizar e internalizar y que en un principio puede estar latente en las personas y equipos de la empresa. Y el capital relacional involucra el valor que tiene para una empresa el conjunto de relaciones que mantiene con el exterior. (Moya y Mancilla, 2015, p. 93)

El capital relacional es la transferencia de "saber qué" y "saber cómo" de una organización a sus stakeholders externos y viceversa, lo cual implica un gran aprendizaje organizacional (Rodríguez, 2005).

El modelo de Análisis de la Gestión del Capital Intelectual propuesto por Romero y Pascual (2010), partió del planteamiento de las tres dimensiones del capital; humano (capacidades, habilidades, destrezas, satisfacción del empleado, educación y entrenamiento) estructural (cultura, procesos y tecnología) y relacional (clientes, proveedores, socios y comunidad), desde una perspectiva socio-técnica, como resultado de la vinculación entre las tecnologías y sistemas de información, la cultura y el capital humano con la gestión del conocimiento organizacional para determinan un nivel de madurez de las capacidades.

Es decir, se asume que en la medida en que las pymes logren desarrollar y adoptar en su vida diaria: (a) una plataforma tecnológica que soporte los procesos destinados al manejo de información y conocimiento; (b) una cultura organizacional basada en el libre intercambio de información, trabajo en equipo y mejora continua; y (c) un capital humano preparado para enfrentar los retos del manejo de la información y el conocimiento, apoyándose y enriqueciendo sus experiencia, su formación general y técnica; podrán avanzar y desarrollar sus capacidades para gestionar el conocimiento organizacional y por ende alcanzar, un niveles de madurez aceptable para gestionar su capital intelectual. (Romero y Pascual, 2010, p. 870).

En cuanto a la gestión de conocimiento, se enfocan en el conocimiento en sí mismo y asumen como base fundamental:

el enfoque de "espacio de información" (i-space) propuesto por el Profesor Max Boisot (Boisot, 1999), donde identifica la gestión del conocimiento como un conjunto de procesos para crear conocimiento, reunirlo, compartirlo, distribuirlo y aplicarlo en la organización, apoyándose en los procesos de codificación, abstracción, difusión y uso de la información y el conocimiento. (Romero y Pascual, 2010, p. 870). 
El estudio permitió concluir que:

el modelo propuesto es válido y a través de él se comprobó que las pymes latinoamericanas, aunque poseen capacidades para gestionar su capital intelectual, no son capaces de potenciarlas desde el punto de vista socio-técnico, es decir no aprovechan las TI/SI y las competencias del recurso humano para lograr desarrollar una cultura orientada a la gestión del conocimiento. (Romero y Pascual, 2010, p. 876).

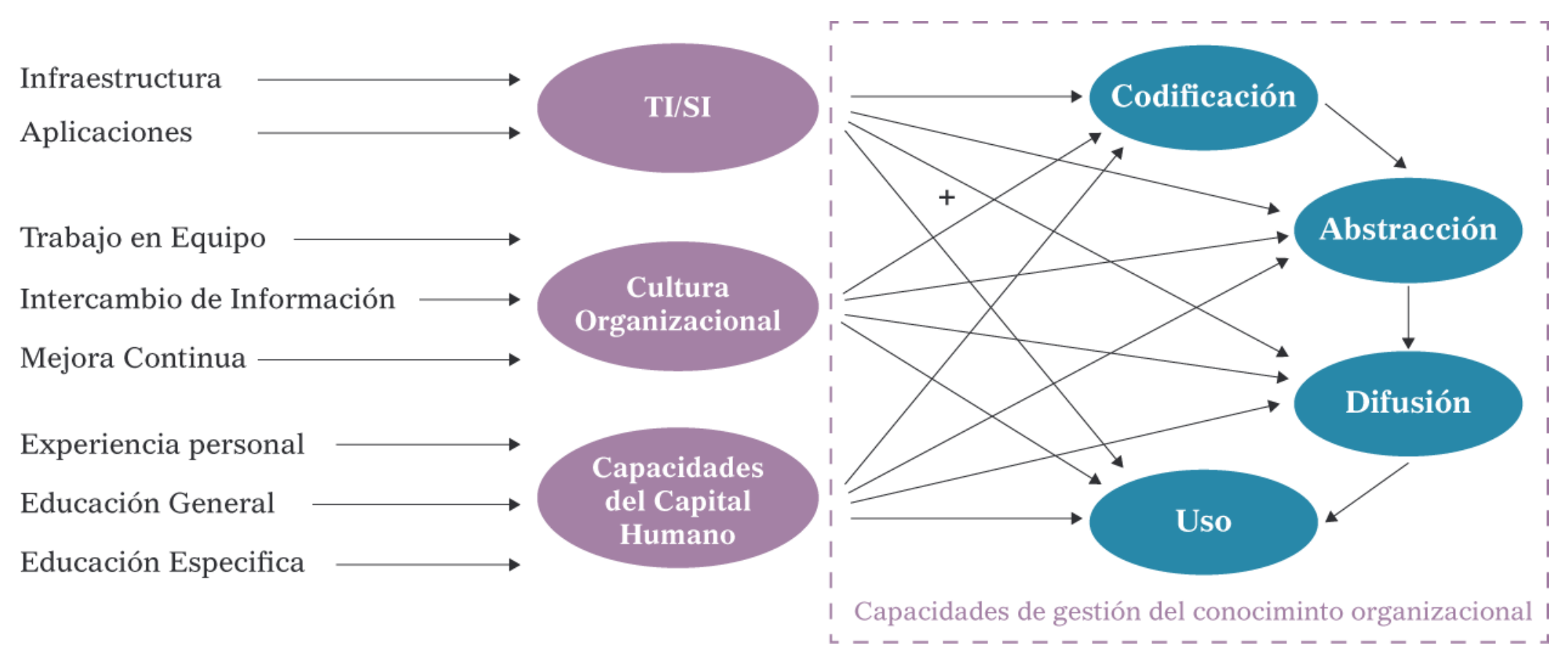

Figura 2. Modelo de análisis de la gestión de capital intelectual.

Fuente: D. Romero y F. Pascual (2010, p. 872).

\section{Los modelos de madurez del talento humano}

De acuerdo con De Bruin y Freeze (2005) se han desarrollado más de 150 modelos para evaluar la madurez organizacional de aspectos como: gerencia de procesos de negocio, gestión de proyectos, gerencia de innovación, gestión del talento humano y gestión del conocimiento.

Montaño et al. (2010) definen la madurez organizacional como"la posibilidad real que tiene una organización de aprender y utilizar los conocimientos adquiridos en el tiempo, de forma tal que le permitan convertirse en una empresa cada vez más exitosa"(p. 394); es decir, conciben la madurez como un proceso de mejoramiento continuo que le permite a las empresas ser más competitivas y sostenibles.

Para el propósito de este capítulo la revisión se centrará en los modelos de recursos humanos. El Modelo de Madurez de Capacidad en Recursos Humanos (People-CMM) de Curtis, Hefley y Miller (2009) ha sido ampliamente usado por compañías de distintos tamaños y sectores alrededor del mundo, con el objeto de mejorar la capacidad de su fuerza de trabajo, entendida como el nivel de conocimientos, habilidades y capacidades disponibles para mejorar el desempeño del negocio. El Modelo plantea cinco niveles de madurez en la gestión del talento humano (p. 18): 
- Nivel inicial: Gerencia inconsistente

- Nivel de administración: Gerencia de personal

- Nivel de definición: Gerencia de competencias

- Nivel de predicción: Gerencia de capacidades

- Nivel de optimización: Gerencia del cambio

Valor Empresario (2012) establece los siguientes criterios para evaluar la madurez de la gerencia de recursos humanos en las organizaciones:

- Los procesos de recursos humanos cubiertos, de acuerdo con el mapa de procesos recursos humanos

- Las competencias de recursos humanos cubiertas, de acuerdo con el mapa de competencias centrales de recursos humanos

- El grado de descentralización de la actividad de recursos humanos

- El alcance de los procesos de sistematización de recursos humanos

- La subcontratación de procesos de recursos humanos

Para efectos del sustento teórico del modelo, los autores se basan en el modelo planteado por Ballesta (2012) que propone una evaluación de la madurez de la gestión de recursos humanos en torno a cuatro dimensiones, dos del ámbito de las personas (reclutamiento y selección de personal; gestión de desempeño y desarrollo) y dos del ámbito de la organización (clima, cultura y gestión del cambio; impacto estratégico), a partir de las cuales establece los siguientes niveles:

- Nivel 1: Administración de personal (orientación a la tarea)

- Nivel 2: Gestión de recursos humanos (orientación a la función)

- Nivel 3: Gestión de capital humano (orientación a procesos)

- Nivel 4: Gestión del talento (orientación a las personas)

- Nivel 5: Gestión de personas en red (orientación a la innovación)

Más tarde, Ballesta (2016) plantea el nuevo modelo de madurez de Gestión de Personas (Figura 3), que contempla cuatro dimensiones inherentes a los ámbitos de actividad, decisión, y dirección, de quienes gestionan personas en las empresas: Atracción y Selección (A), Gestión de desempeño y desarrollo (B), Clima, cultura y gestión del Cambio (C) e Influencia estratégica (D). Establece cinco vectores transformadores: 1) Sistema de indicadores de gestión (un nuevo vector, no incluido en el modelo de 2012); 2) Impacto en la cultura como agente de cambio; 3) Uso de aplicaciones tecnológicas, compromiso y bienestar de personas;4) Influencia directiva.

En Colombia también se han venido desarrollando modelos de madurez aplicados a la gerencia de las organizaciones, tales como el MMGO - Modelo de Modernización para la Gestión de Organizaciones, desarrollado por investigadores de la Universidad EAN (Pérez et al., 2009), con el fin de establecer una ruta de mejoramiento especialmente para pequeñas y medianas empresas. Este modelo se erige a partir de 12 componentes de diagnóstico organizacional: seguimiento y comprensión del entorno, dirección estratégica, gestión del conocimiento, comunicación e información, gestión de mercadeo, importaciones y exportaciones, gestión financiera, gestión de operaciones, gestión humana, estructura y cultura organizacional, asociatividad, y por último, responsabilidad social y gestión ambiental. A partir del grado de desarrollo de cada uno de estos componentes, los autores establecieron cuatro estadios que permiten a los gerentes evaluar el grado de modernización de la gestión de su organización y por consiguiente trazar una ruta de mejoramiento. 
Por su parte, investigadores de la Universidad Autónoma Latinoamericana, con sede en Medellín, como resultado del proyecto de investigación "Diagnóstico sobre las capacidades organizacionales con fines de internacionalización en las pequeñas y medianas empresas del Municipio de Medellín”, determinaron cinco niveles de madurez de la capacidad organizacional: inicial, repetible, definido, gestionado y optimizado, a partir de la evaluación de cuatro aspectos: direccionamiento estratégico, producción, gestión de recursos y, mercadeo y relacionamiento (Henao y Vásquez, 2015).

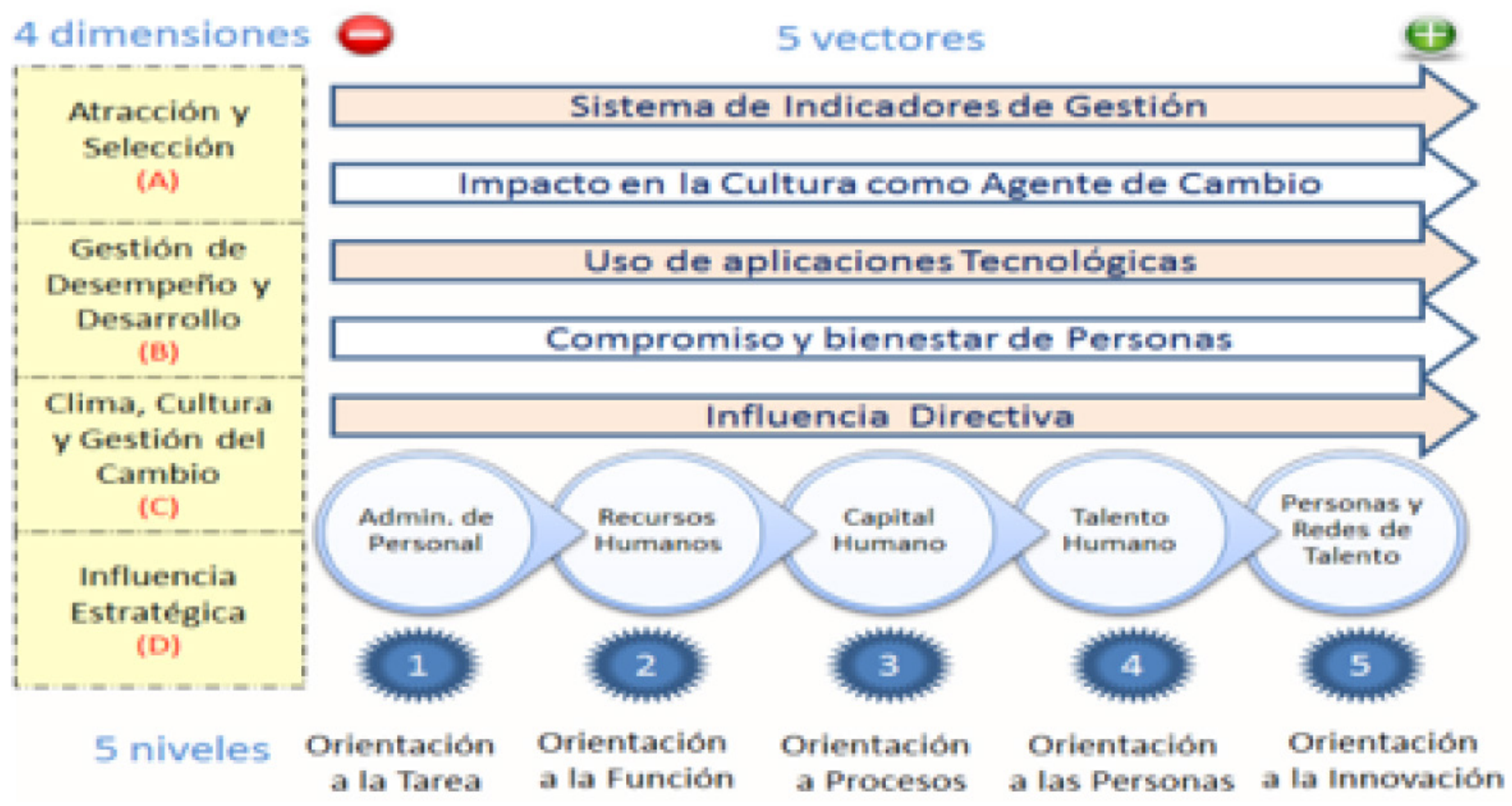

Figura 3. Modelo de madurez de gestión de personas.

Fuente: O. Ballestas (2016).

\section{Conclusión}

La gestión humana está estrechamente relacionada con "la estrategia, la cultura organizacional, la gestión del conocimiento, la calidad, la productividad y la innovación “(Calderón et al., 2010, p. 17); por consiguiente, tanto el capital humano como el área que los dirige, desempeñan un papel fundamental, el primero como fuente de talentos y la segunda como capacidad de soporte (p. 17).

Para gestionar el conocimiento en la organización y generar ventaja competitiva a través del capital intelectual, es importante desarrollar metodologías que permitan convertir el conocimiento tácito (capital humano) en explícito (capital estructural) y convertirlo en utilidad (capital relacional).

"La identificación e implementación de la Cadena de Valor de los procesos de gestión como herramienta estratégica, genera competitividad al crear, mantener y desarrollar el talento humano con habilidades, motivación y satisfacción por alcanzar los objetivos de la organización”(Moya y Mancilla, 2015, p. 107).

La madurez de los procesos de gestión humana impacta directamente en la gestión del conocimiento organizacional y, por consiguiente, en la generación de innovaciones, que agregan valor e incrementan el capital intelectual, permitiendo a las empresas desarrollar capacidades dinámicas para mejorar su adaptabilidad a entornos cambiantes y por consiguiente su competitividad y sostenibilidad en el mercado. 
La revisión bibliográfica permitió reconocer que aun cuando existen modelos de madurez para la gestión humana, ninguno establece una relación directa entre los niveles de madurez y la generación de capital intelectual en las organizaciones, no porque no la haya, sino porque al parecer no se ha estudiado suficientemente, lo cual deja abierta una brecha investigativa, que se complejiza aún más cuando se incorporan variables como gestión del conocimiento, gestión de la cultura, el liderazgo y la innovación.

Por lo anterior, en una segunda fase de la investigación buscamos diseñar un modelo de madurez de los procesos de talento humano para generar capital intelectual en las organizaciones, posteriormente, desarrollar una metodología para evaluar el estadio de desarrollo en que se encuentran las organizaciones y, finalmente, formular rutas de mejoramiento que les permitan alcanzar los estadios de madurez establecidos. 


\section{Referencias}

Ballesta, O. (2012). De la Administración de Personal a la Gestión de Personas en Red. Un Modelo de Madurez para RRHH. [Entrada de blog]. Recuperado de http:// talentoenexpansion.com/2012/11/30/de-la-administracion-de-personal-a-la-gestionde-personas-en-red-un-modelo-de-madurez-para-rrhh/

Ballesta, O. (2016). Hacia un nuevo modelo de madurez para la gestión de personas. [Entrada de blog]. Recuperado de https://talentoenexpansion.com/2016/03/14/modelode-madurez-para-recursos-humanos/

Barragán, A. (2009). Aproximación a una taxonomía de modelos de gestión del conocimiento. Intangible Capital, 5(1), 65-101. 10.3926/ic.2009.v5n1.p65-101

Calderón G., Naranjo, J., \& Álvarez, C. (2007). La gestión humana en Colombia: Características y tendencias de la práctica y de la investigación. Revista Estudios Gerenciales, 23(103), 39-63. Universidad ICESI Colombia.

Calderón G., Naranjo, J., \& Álvarez, C. (2010). Gestión humana en la empresa colombiana: sus características, retos y aportes. Una aproximación a un sistema integral. Cuadernos de Administración, 23(41), 13-36. Recuperado de http://www.scielo.org.co/pdf/cadm/ v23n41/v23n41a02.pdf

Curtis, B., Hefley, B., \& Miller, S. (2009). People Capability Maturity Model (P-CMM) Versión 2.0. Hanscom AFB, MA: Carnegie Mellon University. Recuperado de https://www.sei. cmu.edu/reports/09tr003.pdf

De Bruin, T. \& Freeze, R. (2005). Understanding the Main Phases of Developing a Maturity Assessment Model. ACIS 2005 Proceedings, 109.

Edvinsson, L., \& Malone, M. (1997). El capital intelectual: Cómo identificar y calcular el valor intangible de su empresa. (Trad. Jorge Cárdenas, 1999). Barcelona: Gestión 2000.

Henao, R., \& Vásquez, J. (2015). Aproximación metodológica al diseño de un instrumento para la realización de diagnósticos sobre las capacidades organizacionales con fines de internacionalización en las pequeñas y medianas empresas del municipio de Medellín. Revista Civilizar de Empresa y Economía, 4(8), 97-127. Recuperado de http://revistas.usergioarboleda.edu.co/index.php/ceye/article/download/261/221

Jiménez, A., (2011). Condicionantes de la estrategia de capital humano. En A. Jiménez, S. Marcos, E. Arce \& C. Hilllier, Gestión del talento y competitividad (pp.11- 118) España: Almuzara.

Mee, J.F. (1958). Personnel Handbook. Nueva York: Ronald Press.

Montaño, O., Corona, J., Pérez, A., \& Medina, J. (2010). Modelo que identifica la madurez de los procesos. Caso: Pequeña empresa manufacturera. Revista Dyna , 85(5), 392-400.

Moya, M., \& Mancilla J. (2014). La Cadena de Valor del Talento Humano como Herramienta Estratégica. Revista UNINPAHU Investigaciones, 10, 113 - 127.

Moya, M., \& Mancilla, J. (2015). La Gestión de la cadena de valor del Talento Humano como ventaja competitiva. En A. Olivares, J. Ochoa \& J.A. Coronado (Coords.), Estudios de Competitividad (pp. 91-110). México: Qartuppi. http://doi.org/10.29410/QTP.15.02

Moya, M., \& Gómez, H. (2016). Gestión del talento humano y modelos de madurez organizacional, como fundamentos teóricos y metodológicos para la generación de capital intelectual. En R. Ojeda \& L. López (Coord.), Gestión social: Organizaciones humanas para una sociedad global incluyente (p.p. 6228-6257). Mérida, México: Universidad Autónoma de Yucatán. 
Pérez, R., Nieto, M., Velásquez A., Castellanos, G., Garzón, M., Vargas, H., ..., \& López J. (2009). MMGO Modelo de Modernización para la Gestión de Organizaciones. Bogotá: Universidad EAN.

Rodríguez, J.M. (2005). El capital intelectual como diferencia entre los activos y los pasivos intangibles. Revista madri+d. Aula Abierta, Conocimiento y creatividad, 28. Recuperado de http://www.madrimasd.org/revista/revista28/sumario.asp

Romero, D., \& Pascual, F. (2010). Propuesta de un Modelo de Análisis de la Gestión del Capital Intelectual en las PYMES Latinoamericanas. XIV Congreso de Ingeniería de Organización. Donostia-San Sebastián, España. Recuperado de http://www.adingor. es/congresos/web/uploads/cio/cio2010/KNOWLEDGE_MANAGEMENT/869-878.pdf

Valor Empresario - Gestión Humana y Estrategia (2012). Criterios para analizar la madurez de las áreas RH. Recuperado de https://valorempresario.wordpress.com/2012/11/16/ criterios-para-analizar-la-madurez-de-las-areas-rh/ 


\section{Capítulo 10}

Innovación y competitividad en las micro y pequeñas empresas del sector comercio al por menor en Hermosillo, Sonora, México

Gil Arturo Quijano Vega Abelardo Mancinas González Lluvia Adriana Ramírez Arroyo 
Gil Arturo Quijano Vega, Instituto Tecnológico de Hermosillo gilarturoquijano@hotmail.com

Abelardo Mancinas González, Instituto Tecnológico de Hermosillo amancinas@ith.edu.mx

Lluvia Adriana Ramírez Arroyo, Instituto Tecnológico de Hermosillo lluviadrianar@gmail.com 


\section{Capítulo 10}

\section{Innovación y competitividad en \\ las micro y pequeñas empresas \\ del sector comercio al por menor \\ en Hermosillo, Sonora, México}

\section{Introducción}

El presente capítulo pretende aportar elementos teóricos y metodológicos factibles de ser puestos en marcha y que, al hacerlo, permitan la permanencia de las micro y pequeñas empresas hermosillenses en el sector comercio, de manera que sean competitivas primero a escala local para que después puedan tener penetración a nivel nacional o internacional. Para esto, la propuesta principal radica en que es necesario fortalecer el factor innovación hacia adentro de estas empresas, para que a su vez, éste tenga impacto en su nivel de competitividad. De inicio es necesario identificar aquellos factores de innovación y competitividad aplicables al sector y al tamaño de negocios elegido, para que posteriormente sean medidos y analizados.

El Sistema de Información Estadística del Estado de Sonora (SIEES) proporciona datos claros con respecto a la actividad económica en la entidad, los cuales son:

- La Ciudad de Hermosillo, capital del Estado de Sonora, cuenta con aproximadamente 800,954 habitantes y representa alrededor de un tercio de la población total del Estado de Sonora. Es, también, una de las ciudades con mayor desarrollo en la región.

- Las tres primeras actividades preponderantes en el Estado son: la industria manufacturera, el comercio y el sector de servicio inmobiliarios y alquiler de bienes, muebles e intangibles, las cuales contribuyen con $\$ 41,813$; $\$ 34,303$ y; 23,083 millones de pesos respectivamente al PIB Estatal.

- El número de unidades económicas establecidas en Sonora al año 2008, tenía una representación del $39.60 \%$ solo para el sector del comercio al por menor, con respecto a las unidades de los sectores restantes del total Estatal. Por lo que se infiere que la capital del Estado de Sonora es la región más participativa poblacionalmente y a nivel de establecimiento de empresas del giro anteriormente mencionado. 
Los datos anteriores justifican de manera clara la necesidad de fortalecer el sector comercio en la ciudad, pero ¿por qué las micros y pequeñas empresas? Esto es básicamente por dos razones: primero, por lo general es posible observar fácilmente que dentro de los estudios técnicos, científicos y empresariales, las organizaciones más analizadas son las pequeñas y medianas, sin que muy a menudo se tome en cuenta a la micro empresa; $y$ segundo, la micro y pequeña empresa son la mayoría de los negocios en este sector en particular, predominan en número de unidades económicas, y en número de empleados. Es por esto que tomando en consideración la poca información que existe para este tamaño de empresas, se ha decidido incluir a las microempresas y excluir a las medianas.

En lo que se refiere a las micro y pequeñas empresas (MYPES) del sector comercio al por menor, basta poner atención a unas cuantas unidades que se encuentran en la ciudad de Hermosillo, para darse cuenta de la forma de operación básica con la que funcionan; desde la multifuncionalidad del propietario, la participación de familiares o conocidos, ausencia de pago de impuestos o prestaciones, entre otras. Este escenario ayuda en cierta manera a afianzar la supervivencia de las MYPES, sobre todo cuando la escasez de flujo de efectivo se presenta. Se puede generalizar que la mayoría de las MYPES se constituyen con poco capital, proliferan fácilmente, operan poco tiempo y mueren con más destreza de lo que iniciaron.

En este sentido, se trata de establecer qué impacto tiene la innovación en la competitividad de las MYPES del sector comercio dentro del área geográfica de Hermosillo, esto con la intención de detectar los factores que determinan su éxito, así como sus relaciones causales. Al final se busca comprobar el hecho de que las micro y pequeñas empresas del sector comercio de la Ciudad de Hermosillo que innovan tienen un impacto favorable directo en su competitividad.

Una vez que se conozcan los resultados que produce el adoptar la innovación, como medio para ser competitivo, los beneficios podrán ser aplicados de manera exitosa en los establecimientos del sector para lograr su éxito.

\section{Marco Teórico}

Como principal exponente del pensamiento clásico respecto al concepto innovación, se encuentra a Schumpeter (1944) quien analizó los cambios económicos, influenciados por agentes externos e internos. El autor hace referencia a que las modificaciones en la vida económica se deben en gran parte a los esfuerzos de la población por el mejoramiento de sus técnicas de producción, por alcanzar nuevos mercados y por la introducción de nuevas mercancías. Es así como las fluctuaciones en los ciclos económicos se originan por la introducción de nuevos procesos, los cuales son absorbidos bajo el marco institucional de la sociedad capitalista.

Fue en los años ochenta, cuando la innovación comienza a destacar debido a la introducción de numerosas tecnologías diferenciadas, como el televisor, ordenadores personales, conexiones remotas, entre otras. Se provoca con esto que las empresas buscaran el diferenciador en cada producto y en la forma de captación de consumidores, lo que se tradujo a innovación en la forma de comercialización (Calvo y Méndez, 1995).

La apertura comercial de los años noventa incrementó la competencia de bienes de alta tecnología y valor agregado. Esto dio como consecuencia la mortandad de PyMES y muchas empresas nacionales redujeron la variedad de productos para mantenerse dentro del mercado nacional. Por ello inicia una etapa de cambios en las políticas y en el fomento del desarrollo industrial y la innovación (Cardona y Tokatlian, 1991). 
Se infiere de este modo que la revolución económica, la cual había tenido efectos en la tecnología y en la comunicación masiva, empieza ahora a poner también atención en efectos diferenciadores en todas las áreas de una organización, en la producción de servicios y hasta en la forma de "hacer" el comercio.

El concepto de innovación

Como punto de partida se utiliza la conceptualización dada por Schumpeter (1978), caracterizada por una connotación de innovaciones radicales, y donde se incluyen los cinco puntos siguientes:

1. La introducción en el mercado de un nuevo bien, es decir, un bien con el cual los consumidores aún no están familiarizados, o de una nueva clase de bienes.

2. La introducción de un nuevo método de producción, es decir, un método aún no experimentado en la rama de la industria afectada, que requiere fundamentarse en un nuevo descubrimiento científico.

3. La apertura de un nuevo mercado en un país, tanto si el mercado ya existía en otro país como si no existía.

4. La conquista de una nueva fuente de suministro de materias primas o de productos semielaborados, nuevamente sin tener en cuenta si esta fuente ya existe, o bien ha de ser creada de nuevo.

5. La implantación de una nueva estructura en un mercado, como por ejemplo, la creación de una posición de monopolio.

Según Pavón y Goodman (1982) innovación "es el conjunto de actividades inscritas en un determinado periodo de tiempo y lugar que conducen a la introducción con éxito en el mercado, por primera vez, de una idea en forma de nuevos o mejores productos, servicios o técnicas de gestión y organización”. Por otra parte, Druker (1985) considera que la innovación es una herramienta específica que utilizan los empresarios para permanecer dentro del mercado; es el medio para generar cambios como una oportunidad para un negocio diferenciado:"La innovación crea un recurso diferenciado, mediante la transformación de la materia prima que le concede valor económico". El autor identificaba a los emprendedores como personas que pueden percibir cambios en las cosas ya estandarizadas, provocando con esto beneficio en la vida de las grandes corporaciones y de los pequeños negocios indistintamente.

El manual de OSLO (2007), dentro de la tercera edición implementa cambios fundamentales, tomando en cuenta la integración de factores empresariales acordes al entorno mercantil transitorio que se está dando; de esta forma una innovación es "la introducción de un nuevo, o significativamente mejorado producto (bien o servicio), de un proceso, de un nuevo método de comercialización o de un nuevo método organizativo, en las practicas internas de la empresa, la organización del lugar de trabajo o las relaciones exteriores"(p. 56).

Partiendo de las definiciones anteriores, y analizándolas detenidamente con un enfoque realista y aplicable al sector comercio, se determina que para efectos del presente estudio se entiende que "la innovación es la forma de comercialización diferenciada que agrega elementos creativos a la venta de productos con el fin de lograr vigencia dentro de la economía global, para de esta manera adaptarse de modo competitivo a los cambios en esta economía capitalista". 
Indicadores de innovación

Una vez desarrollado el concepto de innovación, ¿Cómo saber si realmente se está innovando?, ¿Cuáles son los elementos que determinan la innovación? El Manual de Bogotá (2001, p. 12) menciona que el seguimiento de los procesos de innovación debe apuntar no sólo a conocer sus magnitudes y características (aspectos cuantitativos y cualitativos, respectivamente), sino a obtener evidencias acerca del desarrollo de una economía, lo que aporta conocimiento para el control de estos procesos. A su vez el manual de OSLO (2007), la metodología de Pavón y Goodman (1982) y Schumpeter (1978) ofrecen el preámbulo para clasificar los factores de innovación utilizados en esta investigación.

La tabla 1 ejemplifica la coincidencia entre autores, acerca de que los productos y el mercado son un factor de medición de la innovación, seguido de los procesos y la organización.

Tabla 1

Matriz de indicadores de innovación clasificada por autores

\begin{tabular}{|c|c|c|c|}
\hline Manual de Bogotá (2001) & $\begin{array}{l}\text { AUTORES } \\
\text { Manual de OSLO } \\
(2007)\end{array}$ & Pavón y Goodman & $\begin{array}{l}\text { Schumpeter } \\
\text { (1978) }\end{array}$ \\
\hline $\begin{array}{c}\text { Impacto } \\
\text { (Ventas y nuevos productos) }\end{array}$ & Productos & Productos & Productos \\
\hline $\begin{array}{c}\text { Factores Productivos } \\
\text { (Innovación tecnológica, mano } \\
\text { de obra, materia prima) }\end{array}$ & Procesos & ------------ & Procesos \\
\hline $\begin{array}{c}\text { Esfuerzo Innovador } \\
\text { (Nuevos mercados y ventas) }\end{array}$ & Mercadotecnia & Mercados & Mercados \\
\hline $\begin{array}{l}\text { Difusión (Sectorización, } \\
\text { relevamiento de tecnología } \\
\text { avanzada) }\end{array}$ & Organización & Organización & ------------ \\
\hline Gastos & ------------- & ------------ & ------------- \\
\hline ------------- & ------------- & ------------- & Proveeduría \\
\hline
\end{tabular}

Nota: Elaboración propia en base a los factores de medición de la innovación por los autores.

El concepto de competitividad

Porter (2005) menciona que para comprender mejor el término competitividad, se necesitan variables como la prosperidad de un país y qué bien se puede medir por el nivel de vida, visto a través del valor de los bienes y servicios producidos por unidad de sus recursos humanos, económicos y naturales (p. 2). Para delimitar la competitividad empresarial, Krugman (1994) expone el hecho de que la competitividad es atribuible únicamente a las empresas por las características de compra-venta con las que compiten entre sí, con susceptibilidad de ir a bancarrota y desaparecer. A diferencia de las naciones, las cuales manifiestan alianzas mediante el comercio internacional y pueden llegar a manejarse bajo déficit presupuestarios sin desaparecer. 
La globalización de los mercados promueve procesos de competitividad económica que presentan una serie de retos a superar. Según Bateman y Snell (2005), las empresas que quieran ser efectivamente competitivas, necesitan administrar las adversidades mediante la habilidad para sacar provecho de la creatividad y la innovación en la solución de problemas, el incremento de la flexibilidad organizacional, la mejor perspectiva en un mercado diferenciado y la capacidad para atraer y conservar empleados motivados.

Profundizando en el concepto de competitividad, García, Serrano y Blasco (2005) afirman que:

ser competitivo es un resultado que se obtiene cuando el precio al que se ofrece el producto o servicio al cliente coincide con la voluntad de pago para adquirirlo, y esto sucede de forma rentable y duradera para quienes los ofrecen. De ahí se afirma que la empresa que tenga habilidades para la colocación de sus productos o servicios en el mercado y sepa gestionarlas, será una empresa competitiva. (p. 569).

La CEPAL (2006) utiliza el concepto definido por el informe de la comisión especial de la cámara de los Lores de Comercio Internacional (1985), donde afirma que:

una empresa es competitiva cuando puede producir productos y servicios de calidad superior y a costos inferiores que sus competidores. La competitividad es sinónimo del desempeño de rentabilidad de una empresa en el largo plazo y de su capacidad para remunerar a sus empleados y generar un mayor rendimiento para sus propietarios.

Por su parte, Porter (1991) define la competitividad como una mejora continua que se da con la aplicación y adquisición de nueva tecnología. Las personas deben de estar en condiciones de innovar para crear y comercializar nuevos o mejorados productos con tecnología de punta, capaces de competir a escala global avanzando con la misma rapidez que la competencia.

Tras el análisis de seis percepciones conceptualizadas de la palabra competitividad, cabe destacar que el constructo adecuado para el estudio consta de puntos esenciales mencionados por estos autores como: 1) Producción de bienes y servicios con reducción en los costos y aumento de calidad, a lo cual es pertinente complementarlo como: producción y/o comercialización de bienes y servicios; 2) Habilidades de gestión/organización; 3) Rendimientos crecientes para empleados y propietarios, y en menor grado de repetición pero no menos importante 4) Innovación.

\section{Indicadores de competitividad}

El método propuesto en este estudio se basa en la semejanzas de las metodologías propuestas por Aragón y Rubio (2006), Quiroga (2003), Banco Interamericano de Desarrollo (2013) y el Instituto Mexicano para la Competitividad (2012). (Ver Tabla 2).

Como se observa en la tabla 2, existe unanimidad entre los autores al considerar que la producción (calidad) y los recursos financieros son factores claves para evaluar la competitividad. También la mayoría coincide en que la planeación estratégica, la mercadotecnia, los recursos humanos y la investigación y desarrollo son factores determinantes de medición de esta variable. 
Tabla 2

Matriz de indicadores de competitividad clasificada por autores

\begin{tabular}{|c|c|c|c|}
\hline \multicolumn{4}{|c|}{ AUTORES } \\
\hline $\begin{array}{l}\text { Aragón y Rubio } \\
\qquad(2006)\end{array}$ & $\begin{array}{l}\text { Quiroga } \\
\text { (2003) }\end{array}$ & $\begin{array}{c}\text { Banco } \\
\text { Interamericano de } \\
\text { Desarrollo (2013) }\end{array}$ & $\begin{array}{l}\text { Instituto Mexicano } \\
\text { para la Competitivi- } \\
\text { dad. MyPes (2012) }\end{array}$ \\
\hline -------- & $\begin{array}{l}\text { Organización } \\
\text { interna }\end{array}$ & $\begin{array}{l}\text { Planeación } \\
\text { estratégica }\end{array}$ & $\begin{array}{c}\text { Conocimiento del } \\
\text { entorno- Estrategia. }\end{array}$ \\
\hline Calidad. & $\begin{array}{c}\text { Calidad, producción - } \\
\text { Compras. }\end{array}$ & $\begin{array}{l}\text { Producción } \\
\text { y operaciones } \\
\text {-calidad. }\end{array}$ & Propuestas de valor. \\
\hline Mercadotecnia. & --------------- & Comercialización. & $\begin{array}{c}\text { Clientes y Fuente } \\
\text { de ingresos. }\end{array}$ \\
\hline $\begin{array}{l}\text { Capacidades directi- } \\
\text { vas- Recursos } \\
\text { financieros. }\end{array}$ & $\begin{array}{c}\text { Capacidades directi- } \\
\text { vas- Recursos } \\
\text { financieros. }\end{array}$ & $\begin{array}{l}\text { Contabilidad } \\
\text { y finanzas. }\end{array}$ & Estructura de costos. \\
\hline Recursos Humanos. & Recursos Humanos. & Recursos Humanos. & --------------- \\
\hline --------------- & Indicadores externos. & --------------- & --------------- \\
\hline --------------- & --------------- & Informática & --------------- \\
\hline $\begin{array}{l}\text { Tecnología- } \\
\text { Investigación } \\
\text { y desarrollo. }\end{array}$ & $\begin{array}{l}\text { Tecnología- } \\
\text { Investigación y } \\
\text { desarrollo. }\end{array}$ & --------------- & $\begin{array}{c}\text { Alianzas-Propuesta } \\
\text { de valor. }\end{array}$ \\
\hline
\end{tabular}

Nota: Elaboración propia en base en los autores contenidos en la tabla.

El impacto de la innovación en la competitividad empresarial

Para considerar el impacto que tiene la innovación en la competitividad Parada, Parada, Ochoa, Olivares y Verdugo (2011) aseveran que "la innovación representa para las organizaciones una fuente de competitividad y diferenciación, así como un mayor crecimiento, tanto de la producción como de la productividad"(p. 75). Por su parte, Corona, et. al. (2010) mencionan que "la innovación se convierte en un proceso fundamental para alcanzar la competitividad debido a que los esfuerzos por mejorar han alcanzado su límite y ya no son suficientes, para seguir adelante se deben establecer metodologías y estrategias" (pp. 3-4).

En definitiva, existe una relación inminente entre innovación y competitividad, cada área o rama donde se presente la innovación tiene un impacto: a) con la innovación en procesos se maximizan los rendimientos de los factores de producción, donde se tiene mayor flexibilidad en los precios de los bienes o servicios y un incremento en la calidad, debido a la reducción de los costes; b) la innovación en productos hace posible la diferenciación de productos en el mercado y tiende a reducir la competencia por precios o por costes y, c) respecto a la innovación organizativa, beneficia en la dirección de las personas y por lo tanto permite colaboración de parte de estas que permite anticipar la demanda y las tendencias del mercado, lo cual contienen un impacto en la productividad dentro de la organización (Pavit, 1984). 
¿Es la innovación, entonces, la vía para lograr la prosperidad de la empresa? El análisis a través de esta investigación revela que en realidad hay fuerzas internas y externas que proporcionan elementos para lograr el éxito empresarial, el desarrollo de esta investigación examina la innovación en varios campos como condición preponderante, y no niegan la existencia de más variables para la competitividad total.

\section{Metodología}

Como la presente investigación está encaminada a indagar acerca de las causas de la competitividad en las empresas, de manera que sea posible crear un progreso tanto teórico como práctico, se hace necesario diseñar una metodología para regir el proceso y los pasos precisos hacia la obtención de respuestas.

Se parte mencionando que la investigación es de tipo no experimental, ya que sólo observará el fenómeno tal como se da en su contexto natural, para posteriormente analizarlo, es decir, la variable independiente no se manipula. Dado que la variable sólo se medirá en un periodo de tiempo, se considera que el estudio es de tipo transversal, así como correlacional, ya que tratará de describir la relación existente entre las variables incluidas en la investigación: Innovación y Competitividad (Hernández et al., 2010).

Para la conformación de la muestra, las empresas del sector comercio fueron fragmentadas de forma aleatoria en función de la guía proporcionada por el censo económico 2009 para el estado de Sonora, según Municipio de Hermosillo: Sector 46, Comercio al por menor. Subsector 466, Comercio al por menor de enseres domésticos, computadoras, artículos para la decoración de interiores y artículos usados.

Para calcular el tamaño de la muestra se utilizó la siguiente fórmula:

$$
n=\frac{N \sigma^{2} Z^{2}}{(N-1) e 2+\sigma^{2} Z^{2}}=64
$$

Donde:

\begin{tabular}{ccc} 
Valor denominativo & Valor numérico & Definición \\
$\mathrm{N}$ & 1081 & Tamaño de la población \\
\hline$\sigma$ & .5 & Desviación estánder de la población \\
\hline $\mathrm{Z}$ & $90 \%$ & Valor obtenido mediante niveles de confianza \\
\hline $\mathrm{E}$ & $10 \%$ & Límite aceptable de error muestral \\
\hline
\end{tabular}

Estructura del instrumento

La recolección de datos se realiza a través de la aplicación de una herramienta en esencia cualitativa, ya que el cuestionario recogerá la opinión personal de los empresarios sobre las variables estudiadas; sin embargo, dicho instrumento es medido con un enfoque de valores cuantitativos que involucran la conversión de algo abstracto, como lo es la apreciación, en una clase de escala numérica, dando mayor facilidad al manejo de los datos y el subsecuente análisis estadístico.

Para la elaboración del instrumento de medición de la innovación se toman como referencia: el manual de Oslo (2007), el manual de Bogotá (2001), Pavón y Goodman (1981) y Schumpeter (1934) (Ver Tabla 1), obteniendo cuatro indicadores de medición los cuales se pueden observar en la figura 1. 


\section{Variable}

Independiente
Indicadores

Factores / Ítems

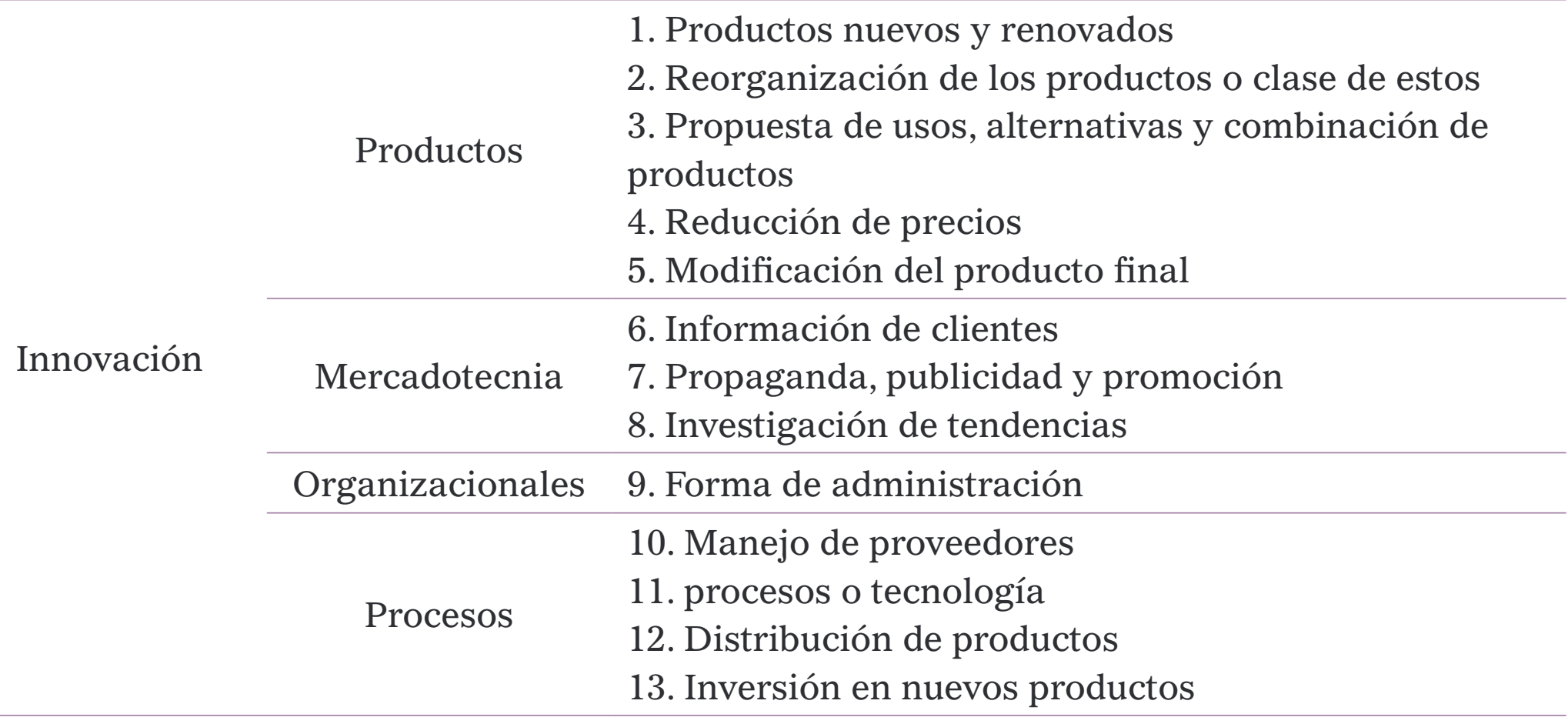

Figura 1. Modelo de medición de la variable innovación.

Fuente: Elaboración propia.

De manera similar, el instrumento de medición que manifiesta la variable competitividad está basado principalmente en la combinación de cuatro modelos: Quiroga (2003) y su modelo para medir la competitividad, el modelo de Aragón y Rubio (2005), las variables de la competitividad del Banco Interamericano de Desarrollo (2013), y el modelo del Instituto Mexicano para la competitividad (2009) en su modalidad de micro y pequeñas empresas. La figura 2 muestra el resumen del modelo de medición de la competitividad.

Las técnicas para la formulación y medición de las preguntas contenidas dentro de la herramienta de medición de la innovación y la competitividad son: Escala de Likert, preguntas abiertas y opción múltiple. La aplicación de las encuestas se realiza de manera personal (entrevistador a gerente) a micros y pequeñas empresas del sector comercio al por menor que cuenten, por lo menos, con cuatro años de antigüedad en el giro del negocio, las cuales están distribuidas en diversos puntos de las zonas Norponiente y Centro de la ciudad de Hermosillo.

Variable

Independiente

Competitividad
Indicadores

Planeación

estratégica

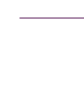
Operaciones
4. Disponibilidad de productos
5. Planificación
6. Rotación
7. Control de calidad

1. Ejecución de la planeación

2. Resultados esperados

3. Nuevas estrategias

\section{Factores / Ítems}


Variable

Independiente
Indicadores

Factores / Ítems

\begin{tabular}{|c|c|c|}
\hline \multirow{6}{*}{ Competitividad } & Ventas & $\begin{array}{l}\text { 8. Venta sugestiva } \\
\text { 9. Comparativo del comportamiento de ventas } \\
\text { 10. Retorno de los clientes } \\
\text { 11. Frecuencia de compra }\end{array}$ \\
\hline & Administración & $\begin{array}{l}\text { 12. Margen de ganancia por producto o grupo } \\
\text { 13. Reinversión sobra la utilidad } \\
\text { 14. Tendencias de gastos } \\
\text { 15. Costos por merma }\end{array}$ \\
\hline & $\begin{array}{l}\text { Recursos } \\
\text { Humanos }\end{array}$ & $\begin{array}{l}\text { 16. Plantilla } \\
\text { 17. Capacitación } \\
\text { 18. Habilidades de ventas de los empleados } \\
\text { 19. Rotación de empleados }\end{array}$ \\
\hline & Comunicación & $\begin{array}{l}\text { 20. Acercamiento de nuevos proveedores } \\
\text { 21. Información a empleados } \\
\text { 22. Información a clientes }\end{array}$ \\
\hline & $\begin{array}{c}\text { Tecnología } \\
\text { y Conocimiento }\end{array}$ & $\begin{array}{l}\text { 23. Conocimiento y crecimiento empresarial } \\
\text { 24. Alianzas estratégicas } \\
\text { 25. Utilización de tecnología y aumento de ventas }\end{array}$ \\
\hline & Factores externos & $\begin{array}{l}\text { 26. Socioeconomía } \\
\text { 27. Factores para el crecimiento de la empresa } \\
\text { 28. Ventajas competitivas de otros negocios }\end{array}$ \\
\hline
\end{tabular}

Figura 2. Modelo de medición de la variable competitividad.

Fuente: Elaboración propia.

\section{Análisis de Resultados}

Con la aplicación de la muestra piloto se procede a una revisión teórica para determinar los componentes más significativos dentro de las encuestas, motivo por el cual se establece una extracción de 10 indicadores de innovación y 12 de competitividad. Tras la primera extracción de componentes se realiza un análisis factorial y un análisis de correlación de Pearson, con lo que esta vez el procedimiento estadístico arroja resultados para la extracción de 14 variables (4 de innovación y 10 de competitividad). Posteriormente se obtiene la matriz de correlación para los catorce ítems anteriores, y los resultados de los principales cruces (que definirán el impacto de la innovación en la competitividad) se presentan a continuación:

a. Indicador de mercadotecnia. Investigación de nuevas tendencias o productos.

Esta sección permite conocer la inversión de la empresa en la investigación acerca de los nuevos productos, las mejoras que se les han añadido y la tendencia de los cambios. La tabla 3 indica que el impacto que causa la investigación de nuevos productos o tendencias que salen o van a salir al mercado, repercute directamente en mayores ventas, una mejor planeación y comunicación, así mismo en capacitación para el capital humano y en la acumulación de nuevo conocimiento. 
Tabla 3

Primer indicador de mercadotecnia y su impacto en la competitividad

\begin{tabular}{|c|c|c|c|}
\hline Subfactor & $\begin{array}{l}\text { Impacto en } \\
\text { el indicador }\end{array}$ & $\begin{array}{l}\text { Pregunta específica } \\
\text { del indicador }\end{array}$ & $\begin{array}{l}\text { Nivel de } \\
\text { correlación }\end{array}$ \\
\hline \multirow{8}{*}{$\begin{array}{c}\text { Se investigan } \\
\text { los nuevos } \\
\text { productos o } \\
\text { tendencias } \\
\text { que salen o } \\
\text { van a salir al } \\
\text { mercado. }\end{array}$} & \multirow{2}{*}{ Ventas } & $\begin{array}{l}\text { Los clientes realizaron compras } \\
\text { diferentes o mayores. }\end{array}$ & $\begin{array}{c}.557 \\
\text { (positiva fuerte) }\end{array}$ \\
\hline & & Las ventas aumentaron del 2013 al 2014 . & $\begin{array}{c}.568 \\
\text { (positiva fuerte) }\end{array}$ \\
\hline & \multirow{2}{*}{ Planeación } & $\begin{array}{l}\text { La planeación otorga } \\
\text { los resultados esperados. }\end{array}$ & $\begin{array}{c}.523 \\
\text { (positiva fuerte) }\end{array}$ \\
\hline & & $\begin{array}{l}\text { La planeación que hace se pone } \\
\text { en práctica. }\end{array}$ & $\begin{array}{c}.448 \\
\text { (positiva moderada) }\end{array}$ \\
\hline & Comunicación & $\begin{array}{l}\text { Nuevos proveedores se acercan a ofre- } \\
\text { cerle productos novedosos. }\end{array}$ & $\begin{array}{c}.520 \\
\text { (positiva fuerte) }\end{array}$ \\
\hline & $\begin{array}{l}\text { Capital } \\
\text { Humano }\end{array}$ & $\begin{array}{l}\text { Existe capacitación para los } \\
\text { niveles gerenciales y técnicos. }\end{array}$ & $\begin{array}{c}.446 \\
\text { (positiva moderada) }\end{array}$ \\
\hline & \multirow{2}{*}{ Conocimiento } & $\begin{array}{l}\text { Con el conocimiento del equipo aumen- } \\
\text { ta el crecimiento de la empresa. }\end{array}$ & $\begin{array}{c}.532 \\
\text { (positiva fuerte) }\end{array}$ \\
\hline & & $\begin{array}{l}\text { Utiliza alianzas estratégicas con otros } \\
\text { negocios o proveedores. }\end{array}$ & $\begin{array}{c}.434 \\
\text { (positiva moderada) }\end{array}$ \\
\hline
\end{tabular}

Nota: Elaboración propia en base al procesamiento de datos mediante SPSS.

b. Indicador de Mercadotecnia. Mejora las nuevas tendencias o productos respecto a la competencia

Este indicador representa la ventaja de tener una estrategia de innovación, en mercadotecnia, enfocada a la mejora de los productos o a un grupo de productos respecto a lo que ofrece la competencia. El resultado de introducir mejoras según las tendencias del mercado impacta, como se muestra en la tabla 4, en el incremento de la capacitación y atracción de nuevos clientes por parte del capital humano, seguido del aumento de recomendaciones de nuevos clientes y mayores compras, la comunicación por medio de nuevos proveedores, rediseño de la organización y vinculación o alianzas estratégicas para el crecimiento del negocio.

\section{c. Indicador organizacional. Mejoras en la administración}

Los cambios estructurales o de organización en las micro y pequeñas empresas del sector comercio, se definen por un sistema de creencias profundas y arraigadas sobre el "buen" desempeño de la organización y en el que se actúa para detectar, mejorar y superar retos.. (Ver Tabla 5).

d. Indicador de Mercadotecnia. En la publicidad sobresale información acerca de nuevos o mejorados productos

Una vez que se puso en operación el proceso de publicidad, es necesario que este contenga la información acerca de los productos nuevos o mejorados, resaltando las tendencias y al mismo tiempo proporcionando al cliente la información oportuna. La tabla 6 permite observar que si en la publicidad se resaltan los nuevos o mejorados productos, se proyectan aumentos en la capacitación del capital humano, en la práctica de la planeación y en el aumento de compra por parte de los clientes. 
Tabla 4

Primer indicador de mercadotecnia y su impacto en la competitividad

\begin{tabular}{|c|c|c|c|}
\hline Subfactor & $\begin{array}{l}\text { Impacto en } \\
\text { el indicador }\end{array}$ & $\begin{array}{l}\text { Pregunta específica } \\
\text { del indicador }\end{array}$ & $\begin{array}{l}\text { Nivel de } \\
\text { correlación }\end{array}$ \\
\hline \multirow{8}{*}{$\begin{array}{c}\text { Se investigan } \\
\text { los nuevos } \\
\text { productos o } \\
\text { tendencias } \\
\text { que salen o } \\
\text { van a salir al } \\
\text { mercado. }\end{array}$} & \multirow{2}{*}{ Ventas } & $\begin{array}{l}\text { Los clientes realizaron compras } \\
\text { diferentes o mayores. }\end{array}$ & $\begin{array}{c}.557 \\
\text { (positiva fuerte) }\end{array}$ \\
\hline & & Las ventas aumentaron del 2013 al 2014. & $\begin{array}{c}.568 \\
\text { (positiva fuerte) }\end{array}$ \\
\hline & \multirow{2}{*}{ Planeación } & $\begin{array}{l}\text { La planeación otorga } \\
\text { los resultados esperados. }\end{array}$ & $\begin{array}{c}.523 \\
\text { (positiva fuerte) }\end{array}$ \\
\hline & & $\begin{array}{l}\text { La planeación que hace se pone } \\
\text { en práctica. }\end{array}$ & $\begin{array}{c}.448 \\
\text { (positiva moderada) }\end{array}$ \\
\hline & Comunicación & $\begin{array}{l}\text { Nuevos proveedores se acercan a ofre- } \\
\text { cerle productos novedosos. }\end{array}$ & $\begin{array}{c}.520 \\
\text { (positiva fuerte) }\end{array}$ \\
\hline & $\begin{array}{l}\text { Capital } \\
\text { Humano }\end{array}$ & $\begin{array}{l}\text { Existe capacitación para los } \\
\text { niveles gerenciales y técnicos. }\end{array}$ & $\begin{array}{c}.446 \\
\text { (positiva moderada) }\end{array}$ \\
\hline & \multirow{2}{*}{ Conocimiento } & $\begin{array}{l}\text { Con el conocimiento del equipo aumen- } \\
\text { ta el crecimiento de la empresa. }\end{array}$ & $\begin{array}{c}.532 \\
\text { (positiva fuerte) }\end{array}$ \\
\hline & & $\begin{array}{l}\text { Utiliza alianzas estratégicas con otros } \\
\text { negocios o proveedores. }\end{array}$ & $\begin{array}{c}.434 \\
\text { (positiva moderada) }\end{array}$ \\
\hline
\end{tabular}

Nota: Elaboración propia en base al procesamiento de datos mediante SPSS.

Tabla 5

Pregunta del indicador organizacional y su impacto en la competitividad

\begin{tabular}{|c|c|c|c|}
\hline Subfactor & $\begin{array}{l}\text { Impacto en } \\
\text { el indicador }\end{array}$ & $\begin{array}{l}\text { Pregunta específica } \\
\text { del indicador }\end{array}$ & $\begin{array}{l}\text { Nivel de } \\
\text { correlación }\end{array}$ \\
\hline \multirow{8}{*}{$\begin{array}{c}\text { Se hacen } \\
\text { cambios de } \\
\text { mejora en } \\
\text { la forma de } \\
\text { administrar } \\
\text { la empresa. }\end{array}$} & $\begin{array}{l}\text { Capital } \\
\text { Humano }\end{array}$ & $\begin{array}{l}\text { Existe capacitación para los niveles } \\
\text { gerenciales y técnicos. }\end{array}$ & $\begin{array}{c}.584 \\
\text { (positiva fuerte) }\end{array}$ \\
\hline & \multirow{2}{*}{ Conocimiento } & $\begin{array}{l}\text { Con el conocimiento del equipo } \\
\text { aumenta el crecimiento de la empresa. }\end{array}$ & $\begin{array}{c}.554 \\
\text { (positiva fuerte) }\end{array}$ \\
\hline & & $\begin{array}{l}\text { Utiliza alianzas estratégicas con otros } \\
\text { negocios o proveedores. }\end{array}$ & $\begin{array}{c}.459 \\
\text { (positiva moderada) }\end{array}$ \\
\hline & \multirow{2}{*}{ Planeación } & $\begin{array}{l}\text { La planeación que hace se pone } \\
\text { en práctica. }\end{array}$ & $\begin{array}{c}.522 \\
\text { (positiva fuerte) }\end{array}$ \\
\hline & & $\begin{array}{l}\text { La planeación otorga los resultados } \\
\text { esperados. }\end{array}$ & $\begin{array}{c}.439 \\
\text { (positiva moderada) }\end{array}$ \\
\hline & \multirow{3}{*}{ Ventas } & $\begin{array}{l}\text { Los nuevos clientes llegan por } \\
\text { recomendación de otro cliente. }\end{array}$ & $\begin{array}{c}.556 \\
\text { (positiva fuerte) }\end{array}$ \\
\hline & & $\begin{array}{l}\text { Los clientes realizaron compras } \\
\text { diferentes o mayores. }\end{array}$ & $\begin{array}{c}.516 \\
\text { (positiva fuerte) }\end{array}$ \\
\hline & & Las ventas aumentaron del 2013 al 2014 . & $\begin{array}{c}.358 \\
\text { (positiva débil) }\end{array}$ \\
\hline & Comunicación & $\begin{array}{l}\text { Nuevos proveedores se acercan } \\
\text { a ofrecerle productos novedosos. }\end{array}$ & $\begin{array}{c}.437 \\
\text { (positiva moderada) }\end{array}$ \\
\hline
\end{tabular}

Nota: Elaboración propia en base al procesamiento de datos mediante SPSS. 
Tabla 6

Tercer indicador de mercadotecnia y su impacto en la competitividad

\begin{tabular}{cccc} 
Subfactor & $\begin{array}{c}\text { Impacto en } \\
\text { el indicador }\end{array}$ & \multicolumn{1}{c}{$\begin{array}{c}\text { Pregunta específica } \\
\text { del indicador }\end{array}$} & $\begin{array}{c}\text { Nivel de } \\
\text { correlación }\end{array}$ \\
\hline $\begin{array}{c}\text { En la publicidad } \\
\text { sobresale } \\
\text { información de } \\
\text { nuevos o } \\
\begin{array}{c}\text { mejorados } \\
\text { productos. }\end{array}\end{array}$ & $\begin{array}{c}\text { Capital } \\
\text { Humano }\end{array}$ & $\begin{array}{l}\text { Existe capacitación para los niveles } \\
\text { gerenciales y técnicos. }\end{array}$ & $\begin{array}{c}.470 \\
\text { (positiva moderada) }\end{array}$ \\
\cline { 2 - 4 } & Planeación & $\begin{array}{l}\text { La planeación que hace se pone } \\
\text { en práctica. }\end{array}$ & $\begin{array}{c}.422 \\
\text { (positiva moderada) }\end{array}$ \\
\hline
\end{tabular}

Nota: Elaboración propia en base al procesamiento de datos mediante SPSS.

En la elaboración del análisis factorial de variables, los resultados describen que el haber indagado en el lanzamiento de nuevos productos y mejorar lo que se ofrecía en el mercado, logró impactar en el hecho de que los clientes consumieran más de lo que tenía proyectado. Lo cual se confirma en la tabla 7 que proporciona información acerca del porcentaje de establecimientos que aumentaron sus ventas significativamente, de los cuales el $67 \%$ lograron tener un ampliación en el porcentaje de ventas que oscila entre el $5 \%$ y el $100 \%$.

Tabla 7

Aumento de ventas del 2013 al 2014

Porcentaje de establecimientos Aumento de ventas 2013 - 2014

\begin{tabular}{cc}
$13 \%$ & $10 \%$ \\
\hline $19 \%$ & $20 \%$ \\
\hline $8 \%$ & $50 \%$ \\
\hline $27 \%$ & $5-100 \%$ \\
\hline $20 \%$ & Sin información \\
\hline $13 \%$ & $-(70-20) \%$ \\
\hline
\end{tabular}

Nota: Elaboración propia en base al análisis de frecuencias.

Aumentar las ventas marca una tendencia a fidelizar a los clientes y genera un incremento de los ingresos, se abren las probabilidades a las recomendaciones llamadas boca-oído, tal como sucedió en este caso de estudio donde el $45 \%$ de las empresas establecen que sus clientes potenciales llegan por recomendaciones de sus clientes actuales.

Tras analizar los factores externos, los empresarios consideran que los retos socio económicos a los que se enfrentan como empresa están ligados en orden de importancia a:

1. La carga impositiva derivada del pago de impuestos.

2. Situaciones económicas y familiares que se les presentan a los trabajadores, afectando los índices de ausentismo y rotación.

3. La obtención de financiamientos, por la dificultad de trámites y requisitos.

4. La Seguridad pública y la cercanía que se tiene con E.U.A. consideran que afectan muy poco. 
El segundo punto se refiere a lo que los empresarios consideran que influye negativamente en el crecimiento de su empresa:

1. El acceso al capital para invertir y la competencia. El margen de ganancia ayuda en gran medida a completar el inventario, sin embargo, el aumento de este último se complica, al igual que la proliferación de negocios similares.

2. Gastos fijos del negocio correspondientes a renta, luz y transporte principalmente.

3. Planeación deficiente o el no poder aplicarla, darle seguimiento y controlarla.

4. Se considera que muy pocas veces afecta el crecimiento del negocio el personal y la atención que se le brinda al cliente.

Como tercer punto se indaga acerca de las ventajas que los empresarios consideran que su competencia tiene, los resultados arrojan:

1. Que el primer factor decisivo es el nombre o la marca que maneja la competencia en conjunto con su ubicación y número de sucursales.

2. El segundo aspecto es la fidelidad que los clientes habitualmente tienen con los competidores.

3. Las instalaciones y los productos constituyen un tercer factor de ventaja en la competencia.

4. Al igual que en los factores que afectan el crecimiento de la empresa, los empresarios no consideran que la capacitación de los empleados de la competencia sea un elemento clave que pueda aportar una ventaja competitiva entre sus competidores.

5. El tema del precio en los productos no reflejó un consenso. Los empresarios tienen concepciones diversas acerca de la importancia que los precios constituyan una ventaja para sus competidores.

\section{Conclusiones}

Dentro del contexto comercial, las empresas locales ubicadas en Hermosillo, Sonora, deben realizar reajustes básicos con el fin de ser competitivas. Gran parte de estos ajustes está impulsado por el sentido de negocio que sea capaz de desarrollar el dueño o gerente de la organización.

Los resultados obtenidos muestran que el objetivo general de la presente investigación se logra, en función al desarrollo del uso de la mercadotecnia y la mejora en la forma de organización, con lo que las modificaciones en el producto y procesos no aportan un impacto sustancial en la competitividad. Esto último, debido a que la naturaleza del sector no permite incorporar modificación o mejoras desde la manufactura del producto. De igual manera, se identificaron los factores de medición de la competitividad: planeación estratégica, ventas o comercialización, recursos humanos, comunicación, tecnología y conocimiento. Es concluyente que los factores referentes a operaciones y administración no son determinantes en el sector comercio, para establecer si las empresas son competitivas. Lo anterior se presenta principalmente porque las operaciones, dentro del sector comercio, están determinadas por el área de ventas o comercialización.

Una vez explicados los niveles de correlación entre los indicadores de la variable innovación y su impacto en los indicadores de la variable competitividad, se acepta la hipótesis. De manera que, invariablemente, las micros y pequeñas empresas del sector comercio del ciudad de Hermosillo que innovan mediante la utilización de un plan de mercadotecnia estructurado de investigación, mejora de la oferta y publicidad, en combinación con una administración adecuada; alcanzan un impacto favorable directo en 
su competitividad con resultados positivos fuertes en las ventas, la planeación estratégica, en los recursos humanos, la comunicación y el conocimiento. Las experiencias locales descubiertas en esta investigación y las áreas de oportunidad que se lograron detectar, crean un precedente en este rubro; dejando abierta la invitación para que los gobiernos municipales fortalezcan la interacción, a través de la Comisión de Fomento Económico o similares, con las micros y pequeñas empresas, creando vinculaciones con instituciones públicas y privadas. 


\section{Referencias}

Aragón, A., \& Rubio, A. (2005). Factores explicativos del éxito competitivo: el caso de las PyMEs del Estado de Veracruz. Revista de la Escuela de contaduría y Administración. UNAM, 216, 36-67.

Banco Interamericano de Desarrollo. (2013). División de competitividad, tecnología e innovación. Recuperado de http://www.iadb.org/es/temas/competitividad-tecnologiae-innovacion/indicadores,3074.html

Bateman, S., \& Snell, A. (2005). Administración. Un nuevo panorama competitivo. Ciudad de México: McGraw-Hill.

Calvo,T., \& Méndez, B. (1995). Micro y pequeñas empresas en México: Frente a los retos de la globalización. Centro de estudios mexicanos y Centroamérica: Miscelánea.

Cardona, D., \& Tokatlian, J. (1991). El sistema mundial en los noventas. Revista Colombiana Internacional, 13(1), 16-21.

Censos Económicos. (2009). Micro, pequeña, mediana y gran empresa: estratificación de los establecimientos: Censos Económicos 2009. México: Instituto Nacional de Estadística y Geografía (INEGI).

Comisión económica para América Latina y el Caribe (CEPAL). (2006). Concepto de competitividad e instrumento para medirla. Ciudad de México: CEPAL sede subregional México.

Corona, J.R., Montaño, O., \& Ramírez, I. (2010). Innovación en la Pymes: Desarrollo de un modelo para el estado de Hidalgo. ACACIA (Ed), XIV Congreso Anual de la Academia de Ciencias Administrativas.

Druker, P. (1985). Innovation and entrepreneurship. New York: HarperCollins.

García, E., Serrano, C., \& Blasco, B. (2005). ¿Competitividad e innovación en la micro y pequeña empresa? Retos a superar. Estudios de economía aplicada, 23(3), 559-581. Recuperado de http://www.redalyc.org/pdf/301/30123303.pdf

Hernández, R., Fernández, C., \& Baptista, P. (2010). Metodología de la investigación. Perú: McGraw-Hill.

Instituto Mexicano para la Competitividad (IMCO). (2009). Desarrollando las PYMES que el país requiere. Instituto Mexicano para la Competitividad. Cuaderno de trabajo. Recuperado de http://imco.org.mx/wp-

Krugman, P. (1994) Competitiveness: A dangerous obsession. Foreign Affairs, 73(2), 28-44.

Manual de Bogotá. (2001). Normalización de indicadores de innovación tecnológica para América Latina y el Caribe. Colombia: Red Iberoamericana de Indicadores de Ciencia y Tecnología/ Organización de Estados Americanos /PROGRAMA CYTED COLCIENCIAS/OCYT. Recuperado de http://www.ricyt.org/manuales/doc_view/5manual-de-bogota

Manual de OSLO. (2007). Guía para la recogida e interpretación de datos sobre innovación. Noruega: OECD-EUROSTAT.

Parada, E.L., Parada, R., Ochoa, J., Olivares, A., \& Verdugo, M.L. (2011). El comportamiento innovador en las empresas manufactureras del estado de Sonora. En A. Olivares y J.A. Coronado (Coord.), Ventajas competitivas empresariales (pp. 75-104). México: Pearson educación.

Pavitt, K. (1984). Sectorial Patters of Technical Change: Towards a Taxonomy and a Theory. Research Policy, 13, 343-375. Recuperado de http://www00.unibg.it/dati/ corsi/22023/61787-08\%20Pavitt\%20(1984).pdf 
Pavón, J., \& Goodman, R. (1981). Proyecto MODELTEC. La planificación del desarrollo tecnológico. Madrid: Centro para el Desarrollo Tecnológico Industrial (CDTI).

Porter, M. (1991). La ventaja competitiva de las naciones. Buenos Aires: Vergara.

Porter, M. (2005). ¿Qué es la competitividad? Apuntes de Globalización y Estragias, 1(1), 2-3. Recuperado de http://www.iese.edu/es/files/5_14558.pdf

Quiroga, D. (2003). Modelo matemático para determinar la competitividad de las pymes. Revista Docencia Universitaria, 4(3). Universidad Industrial de Santander, Colombia.

Schumpeter, J. (1934). The Theory of economic development. Harvard University Press. En L.H. Perego, \& R.S. Miguel (1934), Innovación e Inteligencia estratégica. España: Eumed.net.

Schumpeter, J. (1944). Ensayos sobre el ciclo económico. Ciudad de México: Fondo de cultura económica. 
Factores explicativos de competitividad empresarial

ISBN 978-607-97326-1-5

DOI 10.29410/QTP.16.07

Esta publicación digital se terminó de producir en noviembre de 2016.

Su edición y diseño estuvieron a cargo de:

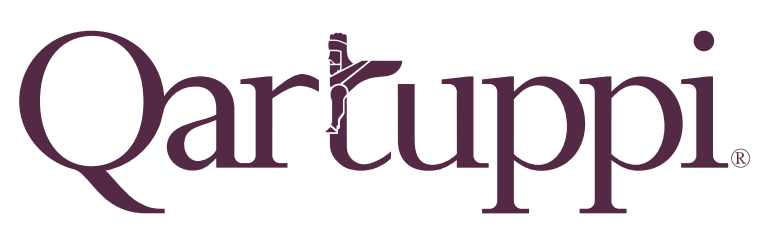

Qartuppi, S. de R.L. de C.V.

http://www.qartuppi.com 
ISBN 978-607-97326-1-5

(c) $\underset{\mathrm{BY}}{\mathrm{NC}}$

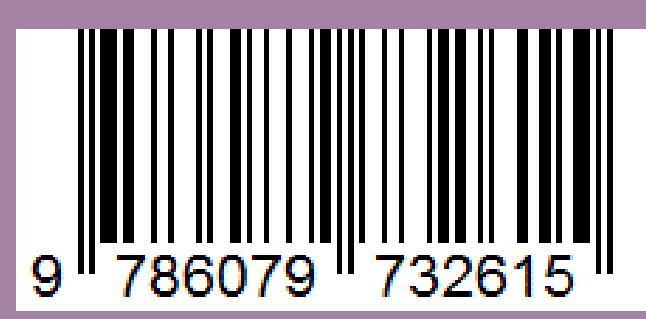

Qartuppi

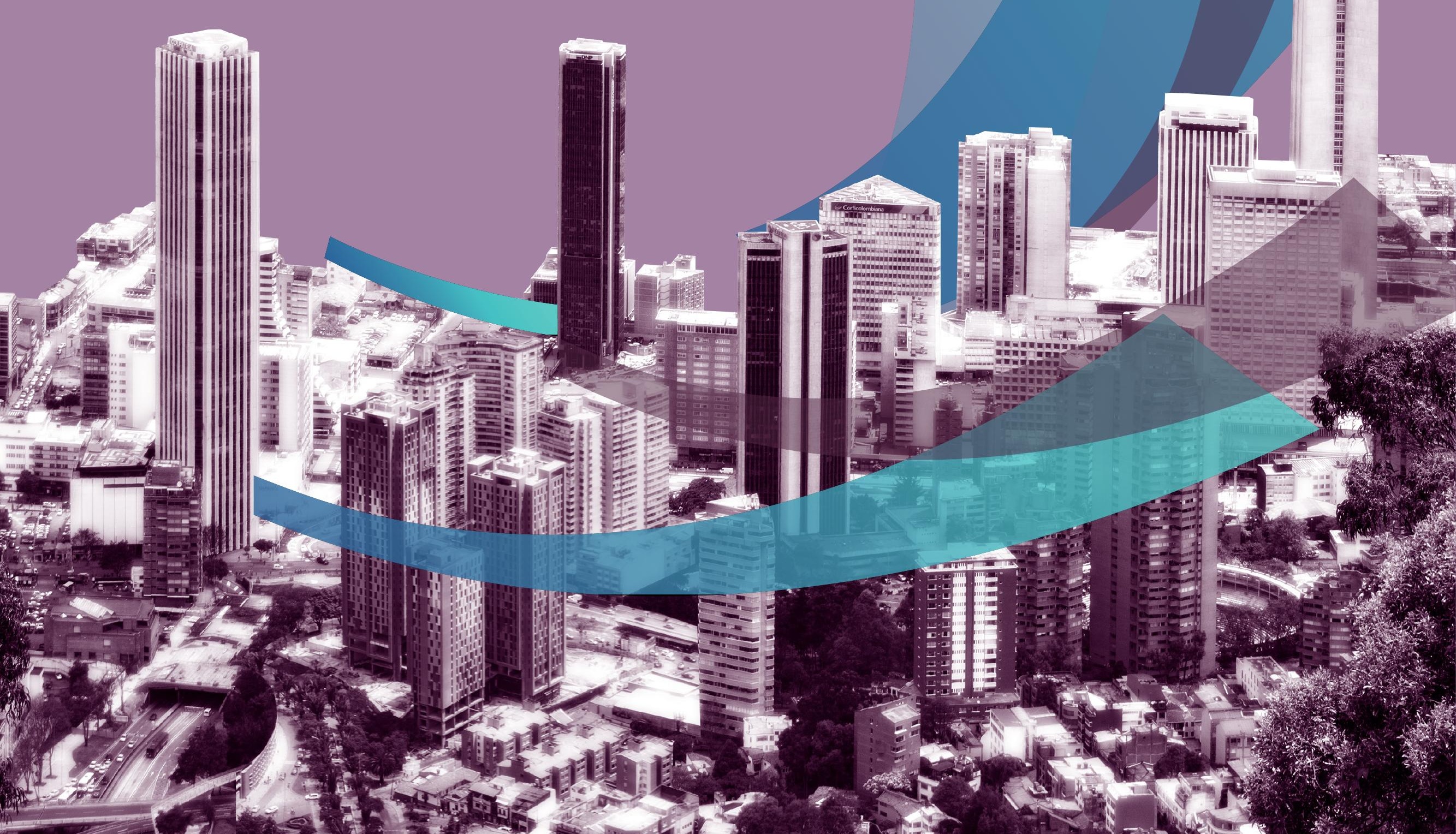

